WENDEL JOHNSON RODRIGUES

\title{
MECANISMO DE FLOTAÇÃO DE PARTÍCULAS GROSSAS EM CÉLULAS MECÂNICAS: INFLUÊNCIA DAS VARIÁVEIS HIDRODINÂMICAS E SUAS IMPLICAÇÕES CINÉTICAS
}


WENDEL JOHNSON RODRIGUES

\section{MECANISMO DE FLOTAÇÃO DE PARTÍCULAS GROSSAS EM CÉLULAS MECÂNICAS: INFLUÊNCIA DAS VARIÁVEIS HIDRODINÂMICAS E SUAS IMPLICAÇÕES CINÉTICAS}

Tese apresentada à Escola Politécnica da Universidade de São Paulo para obtenção do título de Doutor em Engenharia

Área de concentração:

Engenharia Mineral

Orientador:

Prof. Dr. Laurindo de Salles Leal Filho 
Este exemplar foi revisado e alterado em relação à versão original, sob responsabilidade única do autor e com a anuência de seu orientador.

São Paulo, de setembro de 2010.

Assinatura do autor

Assinatura do orientador

FICHA CATALOGRÁFICA

Rodrigues, Wendel Johnson

Mecanismo de flotação de partículas grossas em células mecânicas: influência das variáveis hidrodinâmicas e suas implicações cinéticas / W.J. Rodrigues. - ed.rev. -- São Paulo, 2010. $131 \mathrm{p}$.

Tese (Doutorado) - Escola Politécnica da Universidade de São Paulo. Departamento de Engenharia de Minas e de Petróleo.

1. Hidrodinâmica 2. Turbulência 3. Flotação I. Universidade de São Paulo. Escola Politécnica. Departamento de Engenharia de Minas e de Petróleo II. t. 
Ao meu filho Tiago e minha esposa Ananka 


\section{AGRADECIMENTO}

Ao professor Laurindo de Salles Leal Filho, pela orientação e pelo constante estímulo transmitido durante todo este trabalho.

Aos amigos Ivani Villanova, prof, Arthur Pinto Chaves, prof Eldon Masini, prof. Homero Delboni, Marisa Martins, Antônio Angelini, Luiz Paulo Barbosa, Reinaldo Pini, Maurício Bergerman. Meus pais João Batista Rodrigues e Ana Lúcia Rodrigues e todos que colaboraram de maneira direta e indireta, na execução deste trabalho. 


\section{RESUMO}

A seletividade e eficiência do processo de flotação não estão fundamentadas tão somente nas diferenças das propriedades físico-químicas das superfícies dos minerais, mas também na hidrodinâmica do sistema de concentração. Via de regra, a eficácia da flotação diminui quando o tamanho de partícula ultrapassa $150 \mu \mathrm{m}$. Esta pesquisa visou estudar a influência de variáveis hidrodinâmicas sobre mecanismos de flotação de partículas grossas em células mecânicas e suas implicações cinéticas.

Os ensaios utilizaram células com agitação mecânica e cada situação experimental esteve associada a um conjunto de variáveis hidrodinâmicas: números de hidrodinâmicos adimensionais, características geométricas do impelidor, velocidade mínima de suspensão da polpa, energia dissipada média e energia de preservação do agregado partícula-bolha. Desta forma, a influência dos parâmetros hidrodinâmicos na flotação de apatita e esferas de vidro (diâmetro médio $\cong 248 \mu \mathrm{m}$ ) foi determinada na presença de oleato de sódio e acetato de eteramina em pH 10.

Em condições hidrodinâmicas pouco turbulenta, a recuperação de partículas grossas decresce em função da falta de suspensão de partículas, por outro lado para condições hidrodinâmicas mais severas a recuperação foi quase nula devido à destruição do agregado partícula/bolha. A cinética de flotação da apatita foi estudada em escala de laboratório sob severas condições de turbulência, os resultados indicaram que partículas grossas de apatita têm flotabilidade inferior a finas, corroborando que a flotação dessas partículas grossas não se ajustou ao modelo de primeira ordem. Estes resultados evidenciaram que grossas demandam um ambiente hidrodinâmico apropriado para flotar eficientemente.

Palavras-chaves: Hidrodinâmica. Turbulência. Flotação. 


\begin{abstract}
Coarse particles badly float mostly because the bubble-particle aggregates are not strong enough to prevent the particle detachment from the bubble surface caused by the particle weight and turbulence eddies during the rise of the aggregates in the pulp phase to the froth phase and then to the froth launder. The aim this work was to determine effects and degrees of significance of hydrodynamic variables on coarse particle flotation and their kinetic implications.

The tests were carried out in flotation cells with mechanical stirring system and each experimental condition was related to group of hydrodynamic variables: hydrodynamic dimensionless numbers, impeller geometries, minimum impeller rotational speed, energy dissipation rate and detachment energy. The influence of hydrodynamic parameters on flotation of the apatite and glass spheres (diameter average $\cong 248 \mu \mathrm{m}$ ) was determined in the presence of sodium oleate and etheramine acetate at $\mathrm{pH} 10$.

For more quiescent hydrodynamic conditions, recovery of coarse particles decreased due to a lack in particle suspension, on the other hand, in the most severe hydrodynamic conditions the recovery was almost nil because the bubble-particle aggregates detachment. Flotation kinetics of apatite was studied in laboratory scale under strong hydrodynamic conditions, the results indicated that coarse particles of apatite float at a lower rate than finer particles and the flotation kinetics of coarse particles did not fit to first order model. Those results evidenced that coarse particles demand a suitable hydrodynamic environment to float efficiently.
\end{abstract}

Keywords: Hydrodynamics. Turbulence. Flotation. 


\section{LISTA DE FIGURAS}

Figura 1.1 Desempenho da flotação de cobre no Ok Tedi Concentrator em função da granulometria da partícula

Figura 3.1 Mecanismo de um escoamento com e sem perturbação de uma partícula suspensa

Figura 3.2 Arraste total sobre um corpo imerso

Figura 3.3 Forças que atuam numa partícula em movimento através do fluido

Figura 3.4 $C_{D} R_{e}{ }^{2}$ e $C_{D} / R_{P}$ versus Reynolds da partícula, $R_{P}$

Figura 3.5 Tanque de agitação mecânica, tipo convencional

Figura 3.6 (a) "Rotação sólida" da polpa. (b) Vórtice central na superfície da polpa

Figura 3.7 Exemplos de impelidores para regime turbulento de mistura

Figura 3.8 Curvas de potência para vários tipos de impelidores

Figura 3.9 Gráficos de S versus T/D, usando-se T/C como um parâmetro, para cinco impelidores diferentes

Figura 3.10 Modelos de fluxo de bolhas com turbina de Rushton e aumento de velocidade do impelidor

Figura 3.11 Formação de cavidade de gás atrás das pás

Figura 3.12 Curvas de potência para sistemas gasificados

Figura 3.13 Suspensão de sólidos em sistemas aerados para $\mathrm{D}=\mathrm{T} / 2, \mathrm{C}=\mathrm{T} / 4$ e turbina de Rushton

Figura 3.14 Regiões de segregação, suspensão e arraste de partículas de apatita no interior de uma célula de laboratório Denver

Figura 3.15 Diagrama dos domínios hidrodinâmico

Figura 3.16 Esquema da célula mecânica de flotação

Figura 3.17 Energia dissipada em células industriais de flotação

Figura 3.18 Energia dissipada (P/V) em função do número de fluxo de ar $\left(\mathrm{N}_{\mathrm{Q}}\right)$

Figura 3.19 Zonas que atuam no processo de captura de partículas pela bolha 
Figura 3.20 Eficiência de adesão versus tempo de indução para partículas com diferentes diâmetros

Figura 3.21 Partícula na interface gás - líquido, contato entre as três fases (TPC)

Figura 3.22 Mecanismo de ruptura de uma partícula da bolha num redemoinho turbulento. (a) A bolha rodando em torno de seu centro. (b) Forças agindo na partícula

Figura 3.23 Recuperação de quartzo Em célula de flotação com turbina de Rushton em função do diâmetro de partícula e ângulo de contato

Figura 4.1 Célula de ensaio de microflotação

Figura 4.2 Características geométricas dos impelidores cilindróides utilizados nos ensaios de microflotação

Figura 5.1 A influência das características geométricas do conjunto tanque + impelidor $(D / T)$ e a capacidade do impelidor para manter as partículas em suspensão $(\Omega)$ sobre a recuperação das esferas de vidro $\left(d_{p} \cong 0,248 \mathrm{~mm}\right)$

Figura 5.2 Recuperação das esferas de vidro versus a energia dissipada média e a viscosidade cinemática

Figura 5.3 Recuperação versus número de Reynolds do impelidor

Figura 5.4 Recuperação versus número de Froude do impelidor

Figura 5.5 Recuperação versus energia dissipada média $\left(\varepsilon_{D}\right)$

Figura 5.6 Número de Froude da partícula de esfera de vidro e apatita $\left(d_{p} \cong 248 \mu \mathrm{m}\right)$ versus recuperação

Figura 5.7 Número de Froude da partícula versus recuperação das esferas de vidro dom diferentes diâmetros

Figura 5.8 Recuperação das esferas de vidro $\left(\mathrm{d}_{\mathrm{p}} \cong 248 \mu \mathrm{m}\right)$ versus $\Omega$ para diferentes impelidores, $\mathrm{D} / \mathrm{T}=0,62$

Figura 5.9 Recuperação das esferas de vidro $\left(\mathrm{d}_{\mathrm{P}} \cong 248 \mu \mathrm{m}\right)$ versus número de Froude para diferentes impelidores, $D / T=0,62$

Figura 5.10 Recuperação das esferas de vidro ( $\left.d_{p} \cong 248 \mu \mathrm{m}\right)$ versus número de Potência para diferentes impelidores, $\mathrm{D} / \mathrm{T}=0,62$ 
Figura 5.11 Recuperação das esferas de vidro $\left(d_{p} \cong 248 \mu \mathrm{m}\right)$ versus energia dissipada para diferentes impelidores, $\mathrm{D} / \mathrm{T}=0,62$

Figura 5.12 Diagrama $D / T$ versus $\Omega$. Os números ao lado dos pontos representam as recuperações médias em bancada das esferas de vidro $\left(d_{p} \cong 248 \mu \mathrm{m}\right)$

Figura 5.13 Número de Froude versus recuperação das esferas de vidro em bancada

Figura 5.14 Número de Potência versus recuperação das esferas de vidro em bancada

Figura 5.15 Número de fluxo de ar versus recuperação das esferas de vidro $\left(d_{p} \cong 248 \mu \mathrm{m}\right)$ em bancada

Figura 5.16 Número de Weber versus recuperação das esferas $\left(\mathrm{d}_{\mathrm{p}} \cong 248\right.$ $\mu \mathrm{m})$ em bancada

Figura 5.17 Número de Froude das esferas de vidro $\left(d_{p} \cong 248 \mu \mathrm{m}\right)$ versus recuperação em bancada

Figura 5.18 Energia dissipada pelo impelidor versus recuperação das esferas de vidro utilizando-se turbinas de Rushton

Figura 5.19 Energia dissipada pelos tipos de impelidores versus recuperação das esferas de vidro $\left(d_{\mathrm{p}} \cong 248 \mu \mathrm{m}\right)$

Figura 5.20 Número de potência dos impelidores versus recuperação das esferas de vidro $\left(d_{\mathrm{p}} \cong 248 \mu \mathrm{m}\right)$

Figura $5.21 \Omega$ versus recuperação das esferas de vidro $\left(d_{\mathrm{P}} \cong 248 \mu \mathrm{m}\right)$

Figura $5.22 \quad E_{\text {det }} / E_{\text {kin }}$ versus recuperação das esferas de vidro $\left(d_{P} \cong 248 \mu \mathrm{m}\right)$ utilizando-se três turbinas de Rushton de diferentes diâmetros

Figura 5.23 Número de Bond Modificado versus recuperação das esferas de vidro $\left(\mathrm{d}_{\mathrm{P}} \cong 248 \mu \mathrm{m}\right)$ utilizando-se turbinas de Rushton

Figura 5.24 $N_{Q}$ versus $P / V$ para esferas de vidro $\left(d_{P} \cong 248 \mu \mathrm{m}\right)$ e turbina de Rushton com $\mathrm{D}=37,5 \mathrm{~mm}$

Figura 5.25 $\mathrm{N}_{\mathrm{Q}}$ versus $\mathrm{P} / \mathrm{V}$ para esferas de vidro $\left(\mathrm{d}_{\mathrm{P}} \cong 248 \mu \mathrm{m}\right)$ e turbina de Rushton com $\mathrm{D}=55,5 \mathrm{~mm}$

Figura 5.26 $N_{Q}$ versus $P / V$ para esferas de vidro $\left(d_{p} \cong 248 \mu m\right)$ e turbina de Rushton com $\mathrm{D}=70,5 \mathrm{~mm}$ 
Figura 5.27 $\mathrm{N}_{\mathrm{Q}}$ versus $\mathrm{P} / \mathrm{V}$ para esferas de vidro $\left(\mathrm{d}_{\mathrm{P}} \cong 248 \mu \mathrm{m}\right)$ para impelidor cilindróide com $\mathrm{D}=70,5 \mathrm{~mm}$

Figura 5.28 Velocidade crítica de suspensão da polpa de flotação versus a aeração do sistema

Figura 5.29 Número de Froude versus recuperação das esferas de vidro ( $\mathrm{d}_{\mathrm{p}} \cong 57 ; 248 \mu \mathrm{m}$ ) com turbina de Rushton de diâmetro $37,5 \mathrm{~mm}$

Figura 5.30 Aceleração da máquina $\left(\mathrm{b}_{\mathrm{m}}\right)$ versus diâmetro máximo flotável $\left(d_{\text {pmax }}\right)$ e eficiência de detachment para esferas de vidro $\left(d_{p} \cong 248 \mu \mathrm{m}\right)$

Figura 5.31 Ordem da flotação versus tamanho da partícula de apatita em célula Denver de laboratório

Figura 5.32 Influência do diâmetro da partícula de apatita na constante cinética de flotação em célula Denver de laboratório 


\section{LISTA DE TABELAS}

Tabela 3.1. Resultados de permeabilidade e esfericidade das partículas

Tabela 3.2. Expoentes dos parâmetros sólido-líquido das correlações de velocidade críticas do impelidor e escalas

Tabela 3.3 Números hidrodinâmicos utilizados na flotação

Tabela 3.4 Características de projeto de máquinas de flotação

Tabela 3.5 Números adimensionais em máquinas de flotação

Tabela 3.6 Ângulo de contato para conservar discos de galena de várias granulometrias contra gravidade e força centrífuga

Tabela 4.1 Características geométricas dos impelidores utilizados nos ensaios de microflotação

Tabela 4.2 Características geométricas dos impelidores utilizados nos ensaios de medições de torque

Tabela 4.3 Características geométricas do sistema de flotação em bancada

Tabela 5.1 Parâmetros físico-químicos relevantes ao sistema de flotação

Tabela 5.2 Recuperação versus condições hidrodinâmicas da célula de microflotação

Tabela 5.3 Características físicas da esfera de vidro e apatita e $\mathrm{N}_{z}$.de suas respectivas suspensões

Tabela 5.4 Recuperação versus condições hidrodinâmicas da célula de flotação

Tabela 5.5 Ensaios cinéticos da apatita de Tapira-MG 


\section{LISTA DE SÍMBOLOS}
A Área da seção transversal do corpo
$A_{N g} \quad$ Coeficiente geométrico da equação de Nagata
Ax Impelidor de escoamento axial
a Coeficiente da equação 3.45
a Constante de Laplace
B Largura das chicanas
$b_{m} \quad$ Aceleração do impelidor da célula de flotação
$\mathrm{B}_{\mathrm{Ng}} \quad$ Coeficiente geométrico da equação de Nagata
Bo Número de Bond
Bo' Bond modificado
C Distância do impelidor ao fundo do tanque
Cap Número de capilar
$C_{D} \quad$ Coeficiente de arraste ou fator de atrito
$c_{p} \quad$ Número de partículas por unidade de volume
$c_{b} \quad$ Número de bolhas por unidade de volume
D Diâmetro do impelidor
$\mathrm{d}_{\mathrm{B}} \quad$ Diâmetro de bolha
d $\quad$ Diâmetro de Sauter ou diâmetro média da bolha
$\mathrm{d}_{\mathrm{Bmax}} \quad$ Diâmetro máximo da bolha
$\mathrm{d}_{\mathrm{p}} \quad$ Diâmetro da partícula
$d_{\text {pmax }}$ Diâmetro máximo de uma partícula passível de flotação
$E_{a} \quad$ Eficiência de adesão
$\mathrm{E}_{\mathrm{c}} \quad$ Eficiência de colisão
$E_{\text {Desc }} \quad$ Eficiência de descoleta
$E_{\text {det }} \quad$ Energia de detachment
$E_{k} \quad$ Eficiência de coleta
$E_{s} \quad$ Eficiência de estabilidade do agregado partícula-bolha
F Força
$f \quad$ Fator de correção para os impelidores cilindróides da microflotação
$F_{\text {add }} \quad$ Força adicional de "detachment"
FB Força de empuxo no agregado partícula-bolha 


$\begin{array}{cl}\mathrm{F}_{\mathrm{b}} & \text { Empuxo } \\ \mathrm{F}_{\mathrm{c}} & \text { Força capilar } \\ \mathrm{F}_{\mathrm{D}} & \text { Força de arraste no corpo } \\ \mathrm{F}_{\mathrm{det}} & \text { Forças que colaboram com o rompimento do agregado } \\ \mathrm{F}_{\mathrm{D}-\mathrm{I}} & \text { Força de arraste do impelidor } \\ \mathrm{FG} & \text { Força da gravidade atuante no agregado partícula-bolha } \\ \mathrm{Fr}_{\mathrm{I}} & \text { Número de Froude do impelidor } \\ \mathrm{Fr}_{\mathrm{p}} & \text { Número de Froude da partícula } \\ \mathrm{F}_{\mathrm{X}} & \text { Força externa de aceleração } \\ \mathrm{F}_{\gamma} & \text { Forças que contribuem com a adesão da partícula à bolha } \\ \mathrm{g} & \text { Aceleração da gravidade } \\ \mathrm{H} & \text { Nível da polpa } \\ \mathrm{h}_{\mathrm{crit}(\omega)} & \text { Espessura máxima do filme líquido, onde ainda não ocorre o } \\ & \text { detachment } \\ \mathrm{h}_{\mathrm{eq}(\omega)} & \text { Espessura do filme líquido na posição de equilíbrio da TPC } \\ \mathrm{J}_{\mathrm{g}} & \text { Velocidade superficial do gás } \\ \mathrm{J}_{\mathrm{L}} & \text { Velocidade superficial do líquido } \\ \mathrm{k} & \text { Constante cinética } \\ \mathrm{K}_{0} & \text { Função de Bessel } \\ \mathrm{K}_{1} & \text { Função de Bessel } \\ \mathrm{K}_{1} & \text { Coeficiente da equação de Finch e Dobby } \\ \mathrm{k}_{2} & \text { Coeficiente da equação de Finch e Dobby } \\ \mathrm{L} & \text { Dimensão característica da geometria do sistema } \\ \mathrm{l} & \text { Comprimento do impelidor dos ensaios de microflotação } \\ \mathrm{m} & \text { Massa do corpo } \\ \mathrm{N} & \text { Rotação do impelidor } \\ \mathrm{n} & \text { Ordem da reação } \\ \mathrm{N}_{\mathrm{CD}} & \text { Mínima velocidade para dispersar o gás no sistema líquido-gás } \\ \mathrm{N}_{\mathrm{F}} & \text { Mínima velocidade do impelidor para impedir o afogamento } \\ \mathrm{N}_{\mathrm{Q}} & \text { Número de fluxo de ar } \\ \mathrm{N}_{\mathrm{Q}} & \text { Número de bombeamento do impelidor } \\ \mathrm{N}_{\mathrm{Z}} & \text { Velocidade crítica do impelidor ou velocidade mínima de suspensão } \\ \mathrm{N}_{\mathrm{Zg}} & \text { Velocidade crítica do impelidor ou velocidade mínima de agitação no }\end{array}$


sistema sólido-líquido e gás

P Potência aplicada ao impelidor

p' Coeficiente geométrico da equação de Nagata

Po Número de potência

Pr Pressão

Prd Número de Euler

$\mathrm{Pr}_{\mathrm{HY}} \quad$ Pressão hidrostática da coluna de líquido

$\operatorname{Pr}_{\gamma} \quad$ Pressão capilar da bolha

$Q_{G} \quad$ Vazão de ar ou gás

$Q_{1} \quad$ Vazão bombeamento do impelidor

q $\quad$ Razão entre a vazão de gás que alimenta a células e volume de polpa $\left(\mathrm{Q}_{\mathrm{G}} / \mathrm{V}\right)$

$\mathrm{R} \quad$ Impelidor de escoamento radial

$r \quad$ Raio do vórtice turbulento

$r_{b} \quad$ Raio da bolha

$R_{c} \quad$ Coeficiente geométrico da equação de Nagata

Re Número de Reynolds do sistema

$\mathrm{Re}_{\mathrm{b}} \quad$ Número de Reynolds da bolha

$\mathrm{Re}_{\mathrm{I}} \quad$ Número de Reynolds do impelidor

$\mathrm{Re}_{\mathrm{p}} \quad$ Número de Reynolds da partícula

$r_{F} \quad$ Velocidade da reação ou flotação

$r_{p} \quad$ Raio da partícula

$\mathrm{R}_{\text {pmax }} \quad$ Máximo tamanho flotável de partículas

$R_{\theta} \quad$ Coeficiente geométrico da equação de Nagata

S Constante adimensional relacionado aos parâmetros geométricos do sistema

T Diâmetro do tanque

TPC Ponto de tríplice contato: sólido, líquido e gasoso

$\mathrm{T}_{\mathrm{q}} \quad$ Torque aplicado ao eixo do impelidor

U Velocidade do fluído

$U_{s g} \quad$ Velocidade da fase gasosa em relação à fase líquida ou polpa

$\mathrm{V} \quad$ Volume do tanque ou polpa

$\checkmark \quad$ Velocidade de escoamento 


$\begin{array}{cl}v_{\mathrm{b}} & \text { Velocidade relativa média da bolha } \\ v_{\mathrm{i}} & \text { Velocidade turbulenta relativa da espécie } \\ \mathrm{v}_{\mathrm{p}} & \text { Velocidade relativa média da partícula } \\ \mathrm{v}_{\mathrm{per}} & \text { Velocidade periférica do impelidor } \\ \mathrm{v}_{\mathrm{ps}} & \text { Velocidade terminal da partícula ou velocidade de sedimentação } \\ \mathrm{W} & \text { Largura da pá do impelidor } \\ \mathrm{We}_{\mathrm{B}} & \text { Número de Weber da bolha } \\ \mathrm{We}_{\mathrm{I}} & \text { Número de Weber do impelidor } \\ \mathrm{Y}_{0} & \text { Coordenada do menisco } \\ \mathrm{Z} & \text { Razão entre a energia dissipada na base do tanque e energia média } \\ & \text { dissipada no tanque } \\ \mathrm{Z}_{0} & \text { Altura da coluna de líquido no TPC }\end{array}$

Letras gregas

$\tau \quad$ Tensão de cisalhamento

$\tau^{\circ} \quad$ Tensão de cisalhamento crítica necessária para iniciar a deformação do fluido

$\mu^{*} \quad$ Coeficiente angular da curva $(d \tau /(d v / d y))$ ou viscosidade aparente

$\eta \quad$ Expoente que caracteriza o comportamento do fluido

$\mu \quad$ Viscosidade dinâmica ou absoluta

$v \quad$ Viscosidade cinemática

$\rho \quad$ Densidade do fluido

$\mu_{\mathrm{sl}} \quad$ Viscosidade da suspensão ou polpa

$\mu_{\mathrm{w}} \quad$ Viscosidade da água

$\phi \quad$ Percentagem de sólidos volumétrica

$\vartheta_{\mathrm{W}} \quad$ Arraste de parede

$\beta \quad$ Ângulo

$\rho_{\mathrm{s}} \quad$ Densidade da partícula

$\psi \quad$ Esfericidade da partícula

$\theta_{\mathrm{p}} \quad$ Ângulo de inclinação da pá

$\gamma \quad$ Tensão superficial 


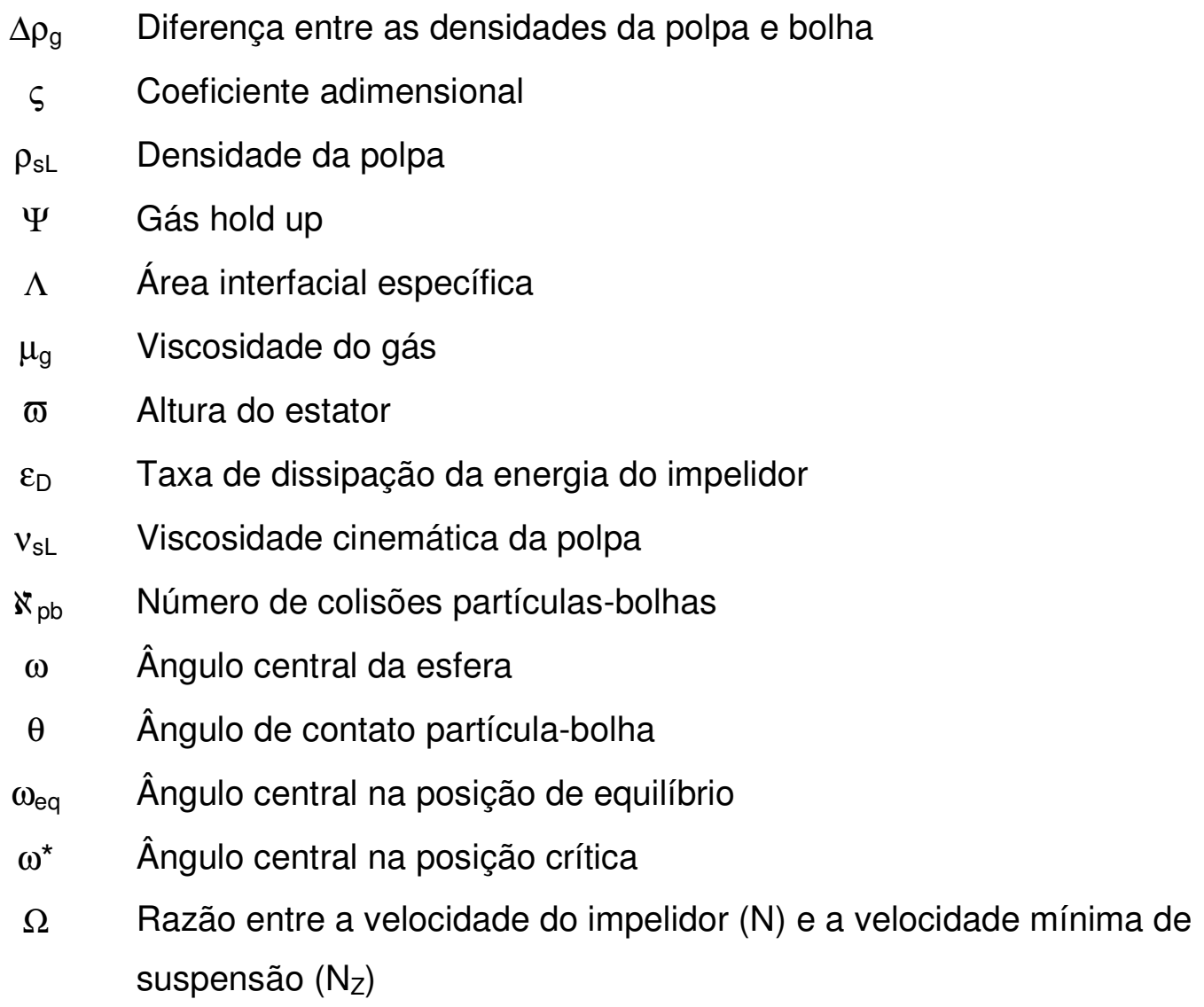




\section{SUMÁRIO}

1. INTRODUÇÃO

2. OBJETIVOS 4

3. REVISÃO BIBLIOGRÁFICA 5

3.1. A viscosidade e caracterização do escoamento de polpa 5

3.2. Movimento de corpos num fluido 11

3.3. Características de agitação nas células mecânicas de flotação 17

3.3.1. Aspectos geométricos e hidrodinâmicos dos vasos agitados $\begin{array}{ll}\text { mecanicamente } & 18\end{array}$

3.3.2. Suspensão de sólidos em líquidos nos vasos mecanicamente agitados 28

3.3.3. Suspensão de sólidos sistemas trifásicos 33

a) Sólido-líquido 34

b) Gás-líquido 34

c) Sólido-líquido e gás $\quad 40$

3.4. Números Hidrodinâmicos das Células Mecânicas de Flotação 44

3.5. Características Geométricas e Mecânicas das Células de Flotação 46

3.6. Processo de Coleta da Partícula 54

3.6.1. Colisão partícula-bolha 56

3.6.2. Adesão partícula-bolha 58

3.6.3. Ruptura do agregado partícula-bolha 59

3.7. Cinética de Flotação 67

4. CARACTERIZAÇÃO DO SISTEMA EXPERIMENTAL 69

4.1. Materiais utilizados nos experimentos 69

4.2. Reagentes e soluções usados nos experimentos 70

4.3. Técnicas e procedimentos experimentais 70

4.3.1. Ensaios de microflotação 73 
5. RESULTADOS E DISCUSSÃO 78

5.1. Fatores físico-químicos e hidrodinâmicos relevantes ao sistema 78

5.2. Ensaios de microflotação 80

5.3. Ensaios de bancada 97

$\begin{array}{ll}\text { 5.4. Cinética de flotação } & 116\end{array}$

6. CONCLUSÃO 119

REFERÊNCIAS BIBLIOGRÁFICAS 122

ANEXO 


\section{INTRODUÇÃO}

O mecanismo fundamental da separação de sólidos por flotação consiste na adesão seletiva de partículas hidrofóbicas a bolhas ascendentes de ar, em meio aquoso, sob condições dinâmicas. Uma vez que o ambiente químico adequado está estabelecido para coleta destas partículas, o desempenho da flotação dependerá das condições hidrodinâmicas da célula.

Apesar de sua óbvia importância, os fenômenos hidrodinâmicos têm recebido pouca atenção de pesquisadores vinculados à Tecnologia Mineral. Via de regra, o principal enfoque está sobre a interação entre espécies químicas (coletores, depressores, ativadores) e sítios ativos da interface mineral/solução. Neste campo, grandes avanços foram observados e muitos mecanismos explicados através de modelos bastante didáticos e úteis, como: "Regra dos Sais Insolúveis" de Taggart (1935); "Teoria das Hemi-micelas" de Gaudin e Fuerstenau (1955) e "Teoria dos Complexos Iono-Moleculares" de Somasundaran (1976 e 1977). Os fenômenos hidrodinâmicos, apesar de já serem estudados por Gaudin nos anos 30 (1932), somente nas últimas décadas têm apresentado algum progresso, principalmente após os trabalhos de Derjaguin e Dukhin (1960), Arbiter (1969), Schulze (1977) e Crawford e Ralston (1988).

Estudos em laboratório e unidades industriais objetivando correlacionar o tamanho de partícula com a recuperação têm revelado que a flotação de partículas muito grossas não é eficiente. Tratamentos teóricos do problema apresentam um importante dilema prático: as mesmas forças que promovem o encontro das partículas com as bolhas (colisão) são capazes de prejudicar a estabilidade do agregado, ou seja, causar o seu rompimento. De um modo geral, o desempenho da flotação também diminui quando o tamanho da partícula ultrapassa $300 \mu \mathrm{m}$ [Crawford e Ralston (1988); Jowett (1980); Schulze (1977); Trahar (1981)].

O ambiente no interior da célula de flotação deve ser propício para bolha capturar a partícula, que foi seletivamente hidrofobizada. Isto reflete no desempenho do processo, tornando-o dependente da ocorrência do sucesso seqüencial de três eventos num determinado período [Arbiter (1969); Crawford e Ralston (1988); Derjaguin e Dukhin (1960); Schulze (1977)]: 
Evento 1. Numa célula de flotação mecânica, as partículas suspensas são conduzidas a colidir com bolhas de ar, promovendo o contato com as mesmas por frações de segundo. Tal evento é controlado pelas condições hidrodinâmicas do meio;

Evento 2. Durante o contato, partículas com variado grau de hidrofobicidade aderem às bolhas de ar, formando agregados estáveis. Esse evento é controlado por parâmetros físico-químicos interfaciais;

Evento 3. Uma vez formado, o agregado partícula - bolha flutuará através de um meio turbulento. Para sobreviver a tal turbulência, a tenacidade da adesão deverá preponderar sobre outras contribuições que lhe fazem oposição, podendo-se citar como exemplo o peso das partículas.

Quando estes três eventos ocorrem com sucesso, na seqüência desejada, presume-se que a cinética de flotação seja discutida adequadamente por um modelo de 1. ${ }^{a}$ ordem $(n=1)$. Todavia, caso um desses eventos falhe, modelos com ordens superiores à unidade $(n>1)$ seriam mais apropriados para descrever a cinética do processo. Além disso, partículas podem se reportar ao produto flutuado por arraste hidrodinâmico, esta situação pode ser explicada por um modelo cinético de ordem zero. [Gaudin (1932); Crawford e Ralston (1988)].

A influência de partículas grossas ou finas na redução do desempenho da flotação tem sido reportada por diversos trabalhos na literatura corrente. Por exemplo, o intervalo ótimo de granulometria na flotação está entre 10 e $100 \mu \mathrm{m}$ na usina de cobre do Ok Tedi Mining Limited (Papua Nova Guiné), observa-se ainda que valores externos a esta faixa propiciam recuperações menores que $40 \%$, conforme apresentado na figura 1.1 [Orwe et.al. (1998)]. 


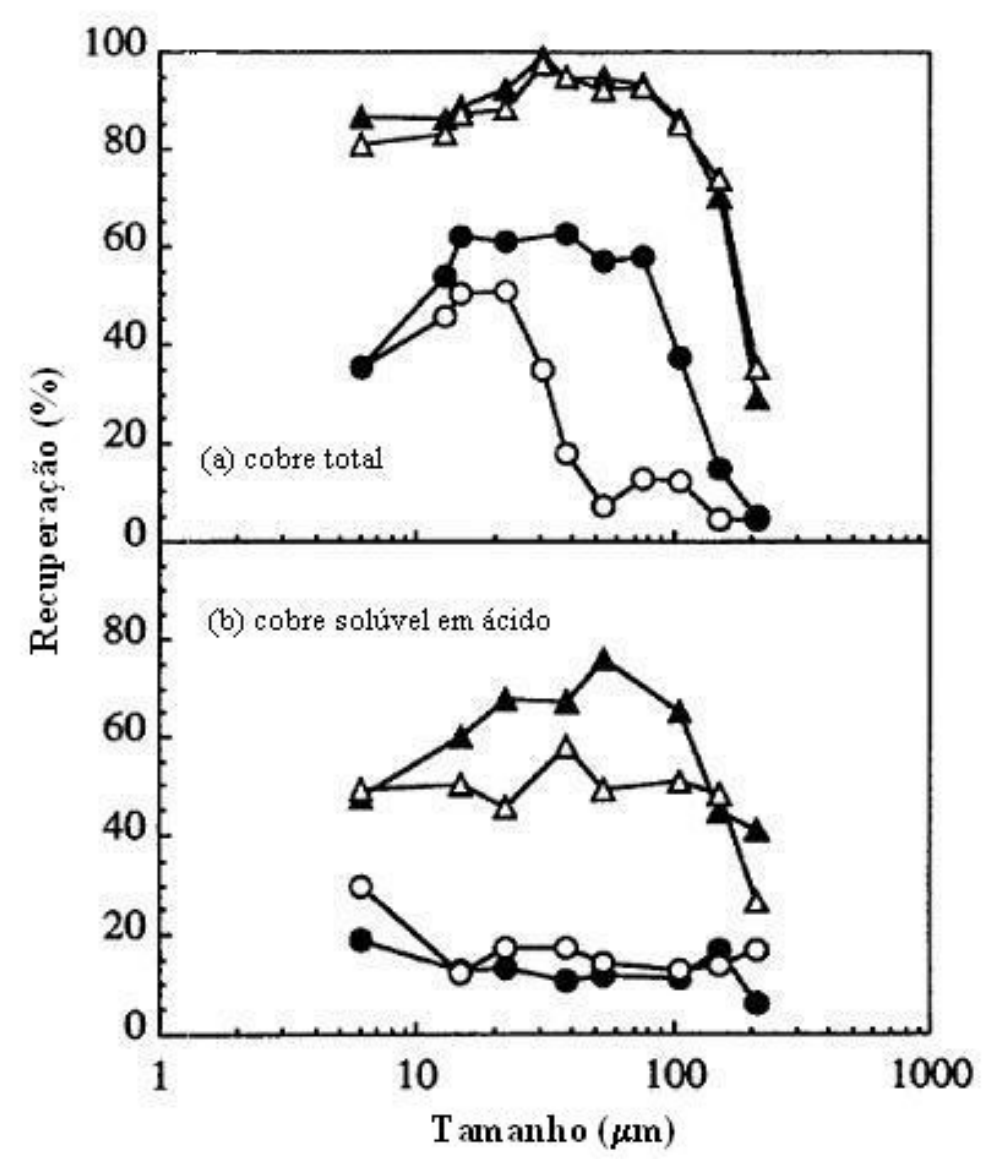

Figura 1.1. (a) Recuperação de cobre total versus granulometria das partículas nos circuitos rougher/scavenger para amostragem 1 sem NaHS: células 1-3 (0) e células 1-15 $(\Delta)$, e amostragem 2 com NaHS: células 1-3 $(\bullet)$ e células 1-15 ( $\mathbf{\Delta})$. (b) Recuperação de cobre solúvel versus granulometria das partículas nos circuitos rougher/scavenger para amostragem 1 sem NaHS: células 1-3 (0) e células 1-15 $(\Delta)$, e amostragem 2 com NaHS: células 1-3 (•) e células 1-15 (\) [Orwe et.al. (1998)].

O estabelecimento de relações de causa-efeito entre parâmetros hidrodinâmicos, eficiência da interação de partículas grossas e bolhas de ar e desempenho do processo pode gerar subsídios técnicos valiosos para se compreender, controlar mecanismos e melhorar a recuperação de partículas grossas. Esta pesquisa contribui neste sentido. 


\section{OBJETIVOS}

Visando a compreensão dos parâmetros hidrodinâmicos do sistema de flotação, esta pesquisa teve por objetivo, definir as condições hidrodinâmicas (números adimensionais, energia dissipada e velocidade crítica de suspensão), baseado em variáveis macro (geometria e dimensões do impelidor) e micro (velocidades e diâmetros de partículas e bolhas), mais favoráveis à flotação de grossos dentro de um sistema mecânico que simula as condições existentes nas células.

Além disso, a pesquisa visa também avaliar a influência dos parâmetros hidrodinâmicos da célula, tais como geometria e velocidade rotacional do impelidor, sobre a cinética da flotação de partículas grossas, estimando a ordem e constante cinética de flotação. 


\section{REVISÃO BIBLIOGRÁFICA}

As polpas minerais das operações de flotação em células mecânicas são constituídas basicamente por [Denver (1995)]:

i. Partículas sólidas, que respondem por aproximadamente $10-20 \%$ do volume útil da célula;

ii. Bolhas de ar, que ocupam aproximadamente $15 \%$ do volume total ("hold-up" do ar em células mecânicas);

iii. Meio aquoso ( $65-80 \%$ do volume), contendo espécies químicas dispersadas.

Com base nessas informações, pode-se ponderar que o estudo do movimento de partículas e bolhas imersas num meio aquoso, assim como a reologia da polpa, é de grande importância para se compreender e atuar sobre os mecanismos que regem o processo de flotação, como: a colisão partícula-bolha, formação do agregado e sua estabilidade num meio turbulento. Este capítulo apresenta o embasamento teórico necessário para se desenvolver tal raciocínio.

\subsection{A viscosidade e caracterização do escoamento de polpa.}

Vários fatores influenciam a maneira que um fluido escoa, particularmente a presença de uma superfície sólida, seja ela uma parede ou partícula. Considere um fluido como um conjunto de lamelas que apresentam espessura infinitesimal (dy), que podem deslizar umas sobre as outras.

De acordo com a figura 3.1a, colocando-se tal fluido entre as placas A e B, mantendo-se fixa a placa $B$ e aplicando-se uma força tangencial $F$ sobre o topo da placa $A$ (cuja área $=A$ ); o fluido escoará na direção e sentido de $F$ com uma velocidade $v$. Após um determinado tempo, cada camada do fluido se atrasará um degrau em relação às adjacentes ( $d v)$. Esta variação de velocidade ocorrerá em função da distância de um ponto de referência e as placas fixas (dy). A razão dv/dy ou gradiente de velocidade é denominada taxa de cisalhamento ou deformação do 
fluido $(d v / d y)$. Por sua vez, a razão F/A é chamada de tensão de cisalhamento $(\tau)$ [Bird et al. (1960); Brown et al. (1950); Foust et al. (1982); Giles (1977); Güven e Pollastro (1992); Perry e Green (1997); Sissom e Pitts (1988); Thomas (1965)].
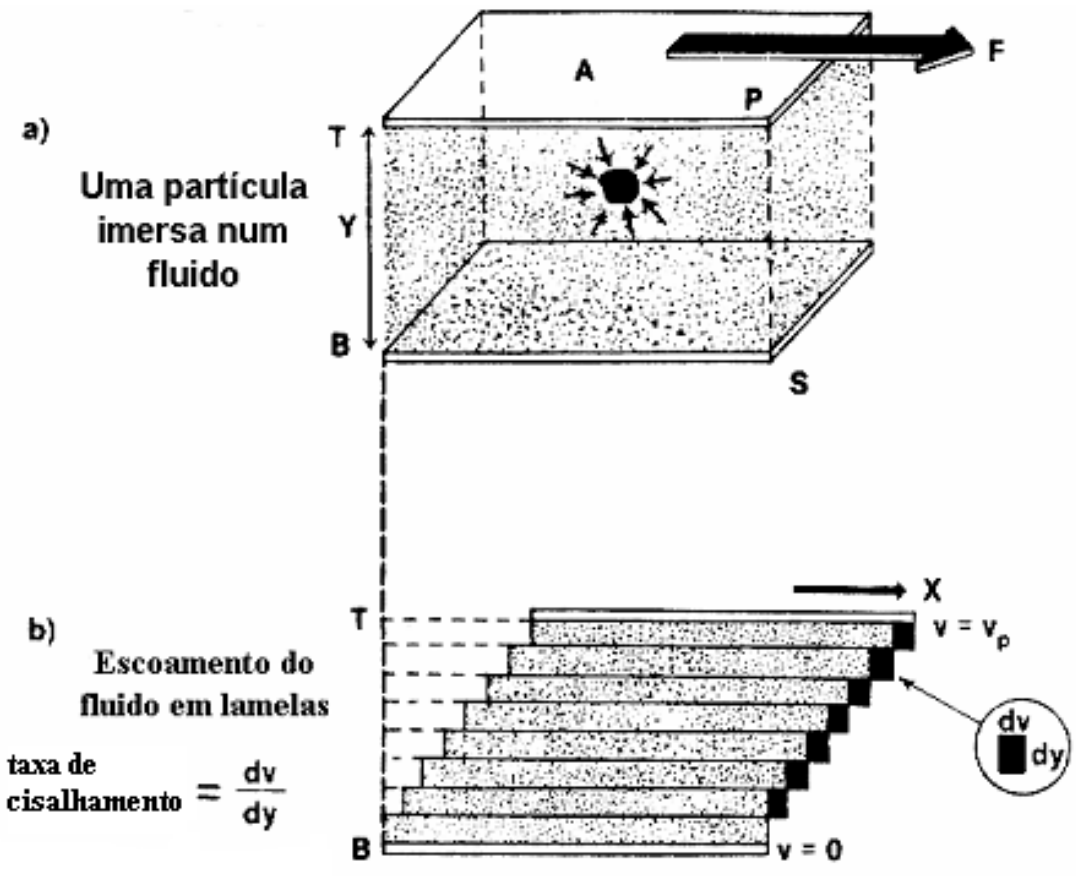

c)

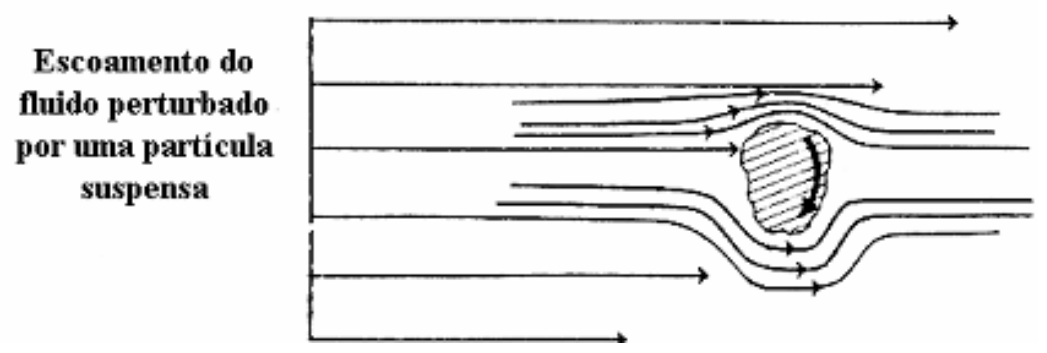

Figura 3.1. Mecanismo de um escoamento com e sem perturbação de uma partícula suspensa [Güven e Pollastro (1992)].

Com base naquilo que foi ilustrado nas figuras 3.1a e 3.1b, a proporcionalidade entre a deformação do fluido (dv/dy) e a tensão de cisalhamento $(\tau)$, a qual foi submetida, pode variar de linear a não-linear. Esse comportamento é caracterizado através de diagramas $\tau$ versus $\mathrm{dv} / \mathrm{dy}$ denominados reogramas ou curvas de fluxo. Uma expressão geral para as curvas de fluxo é representada através da equação 3.1 [Bird et al. (1960); Brown et al. (1950); Foust et al. (1982); Giles (1977); Güven e Pollastro (1992); Perry e Green (1997); Sissom e Pitts (1988)]. 


$$
\tau=\tau^{0}+\mu *\left(\frac{d v}{d y}\right)^{\eta}
$$

Onde:

$\tau^{\circ}=$ Tensão de cisalhamento crítica necessária para iniciar a deformação do fluido;

$\mu^{*}=$ Coeficiente angular da curva $(d \tau /(d v / d y))$ ou viscosidade aparente.

$\eta=$ Expoente que caracteriza o comportamento do fluido.

Para condição mais simples, onde $\tau^{\circ}=0$ e $\eta=1$, o reograma do fluido assume forma linear, conforme descrito pela equação 3.2. Desta forma, o fluido é classificado como newtoniano e o coeficiente angular de seu reograma é denominado como a viscosidade do fluido ( $\mu$ ) [Bird et al. (1960); Brown et al. (1950); Foust et al. (1982); Giles (1977); Güven e Pollastro (1992); Perry e Green (1997); Sissom e Pitts (1988)].

$$
\tau=\mu\left(\frac{d v}{d y}\right)
$$

A viscosidade do fluido, $\mu$, também conhecida como viscosidade dinâmica ou absoluta, pode ser considerada como a maior ou menor resistência do fluido ao escoamento quando submetidos a tensões de cisalhamento. A razão entre a viscosidade absoluta e o peso específico do fluido $(\rho)$ é denominada viscosidade cinemática, v. À temperatura ambiente e pressão atmosférica, a viscosidade de um fluido newtoniano é considerada como sendo uma constante física que caracteriza a substância, como por exemplo: densidade, condutividade térmica, índice de refração, susceptibilidade magnética, constante dielétrica, etc. [Bird et al. (1960); Güven e Pollastro (1992)].

O comportamento newtoniano apresentado por alguns fluidos não é regra, na industria há uma série de substâncias que, submetidas a uma determinada tensão para proporcionar seu escoamento, não possui as características do fluido newtoniano. Estes fluidos apresentam outros possíveis comportamentos, desta forma são chamados de não-newtonianos e são encontrados na literatura corrente Bird et al. (1960); Brown et al. (1950); Foust et al. (1982); Giles (1977); Güven e Pollastro (1992); Knudsen e Katz (1958); Nienow et al.(1985); Perry e Green (1997); Sissom e Pitts (1988); Thomas (1965).

i. Fluido plástico ideal ou Binghan: A peculiaridade deste tipo de fluido é 
a necessidade da superação de uma tensão crítica $\left(\tau^{0}\right)$ para iniciar seu escoamento, porém ele exibe uma relação linear entre taxa e tensão de cisalhamento. Tal fluido é descrito pela equação 3.1 com seu expoente $\eta=1$ e $\mu^{*}$, denominada de viscosidade plástica.

ii. Fluido pseudoplástico: a viscosidade aparente diminui quando a taxa de cisalhamento é aumentada, por exemplo, em polpas de partículas finas, ou até mesmo coloidais, que apresentam tendência de agregarse. Eles não apresentam uma relação linear entre tensão e taxa de cisalhamento, com $\tau^{0}=0, \eta<1$ e $\mu^{*}$ variável na equação 3.1 .

iii. Fluido dilatante: a viscosidade aparente do fluido aumenta, caso a taxa de cisalhamento também aumente. Este comportamento se deve ao efeito da dilatação da polpa, com a água sendo suficiente somente para preencher os vazios há oportunidade para ação de cargas superficiais, que ocasionam a formação de aglomerados, neste caso, $\eta>1$ na equação 3.1 .

Conforme observado na figura 3.1c, sólidos imersos num fluido podem perturbar a direção, sentido e velocidade de seu fluxo. O atrito entre lamelas do fluido e partículas proporciona às últimas terem um movimento de rotação em torno de seu eixo, além de criar regiões de menor pressão em seu entorno. Todos esses fenômenos constituem mecanismos extras de dissipação de energia, fazendo com que, na grande maioria das aplicações industriais, as polpas minerais apresentem comportamento não-newtoniano [Güven e Pollastro (1992)].

Inicialmente, entre todos os parâmetros, a percentagem de sólidos na polpa tem a contribuição mais evidente sobre a reologia da polpa. Os primeiros estudos começaram com Einstein, em 1906 [Einstein apud, Güven (1992)]. Trabalhando inicialmente com esferas rígidas e suspensões extremamente diluídas, esse pesquisador propôs uma relação simples de dependência entre a viscosidade da suspensão $\left(\mu_{\mathrm{sl}}\right)$ e a viscosidade da água $\left(\mu_{\mathrm{w}}\right)$ expressa através da equação 3.3. A variável $\phi$ representa a fração do volume da suspensão ocupada pelas partículas sólidas, sendo que em Tratamento de Minérios, $\phi$ representa a percentagem de sólidos volumétrica [Güven e Pollastro (1992); Kelly e Spottiswood (1982); Roscoe (1952)].

$$
\mu_{s l}=\mu_{w}+2,5 \phi
$$


Outras teorias, envolvendo outras características das partículas presentes na suspensão como morfologia, densidade, distribuição de tamanhos, textura, área específica, hidrofilicidade/hidratação das partículas, grau de dispersão. Cada uma dessas características foi sendo incorporadas à equação fundamental de Einstein na forma de constantes $\left(k_{1}, k_{2}, k_{3}, \ldots, k_{n}\right)$, gerando um polinômio extenso e complexo. Outros pesquisadores preferiram desenvolver relações exponenciais [Giles (1977); Güven e Pollastro (1992)].

A literatura é carente de informações relativas ao comportamento reológico de polpas com granulometria típica das operações unitárias de processamento mineral. No corrente trabalho a viscosidade da polpa $\left(\mu_{\mathrm{sl}}\right)$ foi calculada de acordo com a equação 3.4 [Rodrigues (2001a); Rodrigues et.al. (2001b); Roscoe (1952)].

$$
\mu_{s l}=\mu_{w}(1-\phi)^{-2,5}
$$

A viscosidade de uma polpa de flotação certamente vai variar em função das condições hidrodinâmicas sob as quais as medições foram executadas. Deste modo, uma mesma polpa poderá se comportar como um fluido newtoniano na total ausência de turbulência e como um fluido pseudoplástico em sua presença [Whiten et.al. (1993)].

Quando um fluido é submetido à ação de uma força externa de cisalhamento, suas lamelas de espessura infinitesimal serão conduzidas ao escoamento, podendo deslizar umas sobre as outras. Neste caso, suas linhas de fluxo serão paralelas e a resistência do fluido ao escoamento será devida à fricção entre lamelas adjacentes, assim como entre lamelas e paredes do recipiente, que contém a polpa [Bird et al. (1960); Foust et al. (1982); Güven e Pollastro (1992); Nienow et al.(1985); Perry e Green (1997); Sissom e Pitts (1988); Whiten et.al. (1993)].

O escoamento caracterizado pelo paralelismo entre as lamelas, que se movem em linhas retas e diferentes velocidades, é denominado laminar. O produto da viscosidade pelo gradiente de velocidade, conforme descrito pela equação 3.2., regem o fluxo laminar, ou seja, os efeitos da viscosidade são preponderantes na caracterização deste escoamento [Bird et al. (1960); Foust et al. (1982); Güven e Pollastro (1992); Nienow et al.(1985); Perry e Green (1997); Sissom e Pitts (1988)].

À medida que a polpa escoa com maior velocidade através de dutos de maior diâmetro; ou ainda quando esta é submetida à agitação pela ação de impelidores de maior diâmetro, operando sob rotação mais alta; suas linhas de fluxo perdem o 
paralelismo, tendendo a convergir ou se misturar, como redemoinhos. Nesse caso, o escoamento é chamado de turbulento e os efeitos da inércia são predominantes [Bird et al. (1960); Dickey e Fenic (1976); Foust et al. (1982); Güven e Pollastro (1992); Nienow et al.(1985) ; Perry e Green (1997); Sissom e Pitts (1988)].

Um fluido se deslocando por linhas de fluxo paralelas, ou seja, em escoamento laminar, a troca de energia entre os elementos do fluido é realizada por transferência de quantidade de movimento por mecanismo viscoso. Quando a velocidade do escoamento aumenta, redemoinhos vão se formando paulatinamente, tendendo a crescer e ficar cada vez mais complexos e freqüentes. As linhas de fluxo, conseqüentemente, vão perdendo seu paralelismo e transferem quantidade de movimento pelos redemoinhos, portanto de natureza cinética [Bird et al. (1960); Dickey e Fenic (1976); Foust et al. (1982); Güven e Pollastro (1992); Nienow et al.(1985) ; Perry e Green (1997); Sissom e Pitts (1988)].

A relação entre as quantidades de movimento transferidas por esses dois mecanismos pode ser usada para caracterizar a mudança do fluxo de laminar para turbulento, resultando num número adimensional, denominado Número de Reynolds $(R e)$, que representa a razão entre as forças inerciais $\left(\mathrm{v}^{2} / \mathrm{L}\right)$ e viscosas $\left(\mathrm{vv} / \mathrm{L}^{2}\right)$ que agem sobre um sistema, de acordo, com a equação 3.5 [Bird et al. (1960); Dickey e Fenic (1976); Foust et al. (1982); Güven e Pollastro (1992); Kelly e Spottiswood (1982); Nienow et al.(1985); Perry e Green (1997); Roscoe (1952); Sissom e Pitts (1988)].

$$
\mathrm{Re}=\frac{\text { Forças de Inércia }}{\text { Forças Viscosas }}=\frac{\frac{\mathrm{v}^{2}}{\mathrm{~L}}}{\frac{\mu \mathrm{v}}{\rho \mathrm{L}^{2}}}=\frac{\mathrm{vL} \rho}{\mu}
$$

Sendo:

$$
\begin{aligned}
& v=\text { velocidade do fluido; } \\
& L=\text { dimensão característica da geometria do sistema; } \\
& \mu=\text { viscosidade do fluido; } \\
& \rho=\text { densidade do fluido. }
\end{aligned}
$$

Cada sistema hidrodinâmico, duto, impelidor, bolha, etc. apresenta valores limites de Re, que servem de referência para delimitar o escoamento laminar, turbulento ou a zona de transição:

i. Em dutos, o regime laminar predomina quando $\mathrm{Re}<1000$; no 
intervalo $1000<\operatorname{Re}<3000$ há transição, enquanto que o regime turbulento prepondera em Re>3000 [Bird et al. (1960); Dickey e Fenic (1976); Foust et al. (1982); Güven e Pollastro (1992); Nienow et al.(1985); Perry e Green (1997); Sissom e Pitts (1988)].

ii. Para sistemas agitados (seção 3.4.), condições laminares existem somente para $\mathrm{Re}_{1}<10$; transição ocorre entre $10<\mathrm{Re}_{1}<10000$ e situações turbulentas existem para $R_{-}$-1>10000 [Gaudin (1975); Perry e Green (1997)].

Num âmbito geral, as questões de escoamento em Tratamento de Minério estão dentro de duas grandes categorias: o transporte de polpas em dutos, como é o caso do bombeamento, e o movimento de partículas e/ou bolhas através do fluido, exemplificado pela flotação. Deste modo, as características do escoamento de polpa são fortemente dependentes das propriedades dos sólidos nela contido, como revisado na seção 3.2 [Dickey e Fenic (1976); Kelly e Spottiswood (1982); Roscoe (1952)].

\subsection{Movimento de corpos num fluido.}

Quando partículas e/ou bolhas de ar estão se movendo em relação ao fluido, elas ficam sujeitas a uma determinada força de resistência ao movimento ou de arraste, conforme apresentado na figura 3.2. Tal força é resultante de duas outras componentes [Bird et al. (1960); Dickey e Fenic (1976); Foust et al. (1982); Kelly e Spottiswood (1982); Perry e Green (1997); Sissom e Pitts (1988)].

i. Uma componente gerada pela ação do cisalhamento, chamada arraste de parede ou atrito pelicular;

ii. Outra componente oriunda da pressão do fluido sobre a superfície do corpo, denominada arraste de forma.

iii. O arraste total na superfície de uma partícula é a soma do arraste pelicular e o arraste de forma na direção do escoamento do fluido. 


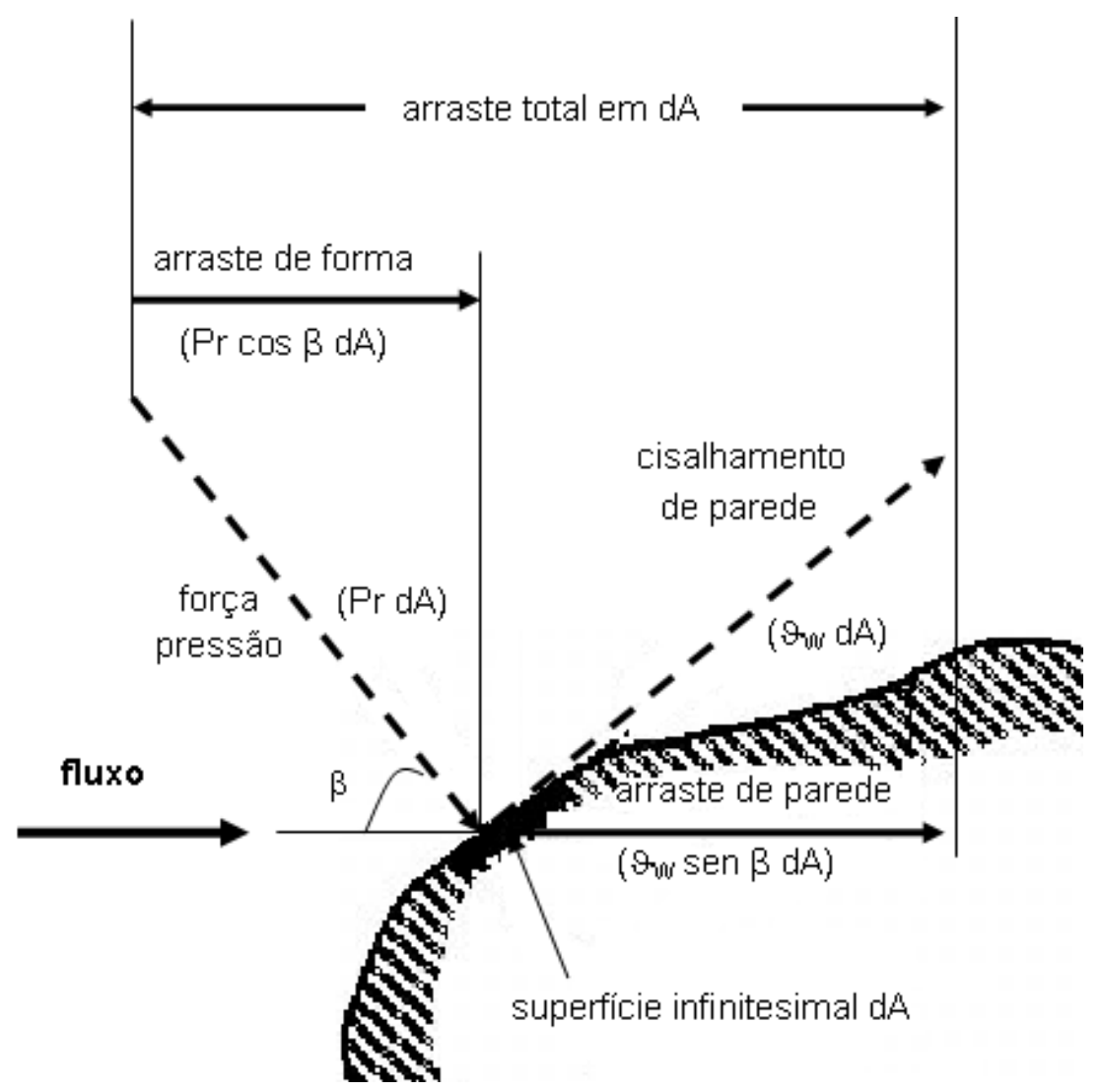

Figura 3.2. Arraste total sobre um corpo imerso [Kelly e Spottiswood (1982)].

Por conseguinte, o mecanismo de transferência de quantidade de movimento ou energia do fluido para partícula apresenta um componente viscoso (fricção pelicular) e outro turbulento (diferença de pressão). A razão entre a quantidade de movimento total transferida à partícula e quantidade do componente turbulento, define-se um número adimensional chamado fator de atrito ou coeficiente de arraste $\left(C_{D}\right)$, expresso pela equação 3.6 que descreve a transferência de quantidade de movimento numa fronteira sólido-líquido [Bird et al. (1960); Dickey e Fenic (1976); Foust et al. (1982); Gaudin (1975); Kelly e Spottiswood (1982); McCabe e Smith (1956); Molerus (1993); Perry e Green (1997); Sissom e Pitts (1988)].

$$
C_{D}=\frac{F_{D}}{\left(\rho v^{2} / 2\right) A}
$$

Onde:

$C_{D}=$ Coeficiente de arraste;

$\mathrm{F}_{\mathrm{D}}=$ força de arraste no corpo;

$\rho=$ densidade do fluido;

$v=$ elocidade na direção do escoamento; 
A = área da seção transversal do corpo.

O estudo do comportamento da partícula ou bolhas se movendo através de fluidos adota como referência básica o movimento livre de corpos de massa constante sob uma aceleração constante, ou seja, a Lei de Newton, conforme a equação 3.7. Assim, um conjunto de forças irá atuar sobre a partícula, sendo que a força externa de aceleração, $F_{x}$ (por exemplo: força peso ou força centrífuga) terá forças opostas como $F_{d}$ (força de arraste) e $F_{b}$ (empuxo), apresentadas na figura 3.3 [Bird et al. (1960); Dickey e Fenic (1976); Foust et al. (1982); Gaudin (1975); Kelly e Spottiswood (1982); McCabe e Smith (1956); Molerus (1993); Perry e Green (1997); Sissom e Pitts (1988)]:

$$
\sum F=m \frac{d v}{d t}
$$

Onde:

$$
\begin{aligned}
& \Sigma F=\text { força resultante que age sobre um corpo } \\
& m=\text { massa do corpo } \\
& d v / d t=\text { aceleração resultante. }
\end{aligned}
$$

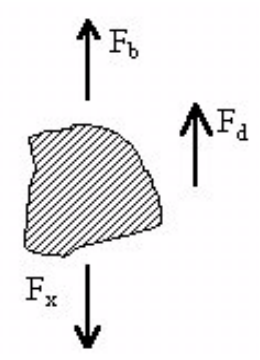

Figura 3.3. Forças que atuam numa partícula em movimento através do fluido [Foust et al. (1982)].

O balanço de forças que atuam no transporte de uma partícula é utilizado para se definir a velocidade de um corpo se movimentando ao longo do fluido, expressa pela equação 3.8 [Bird et al. (1960); Dickey e Fenic (1976); Foust et al. (1982); Kelly e Spottiswood (1982); Perry e Green (1997); Sissom e Pitts (1988)].

$$
F_{x}-F_{d}-F_{b}=m \frac{d v}{d t}
$$

Onde:

$$
\begin{aligned}
& F_{x}=\text { uma força externa, como exemplo, a força centrífuga; } \\
& F_{d}=\text { força de arraste; } \\
& F_{b}=\text { força de empuxo; }
\end{aligned}
$$




$$
\mathrm{m}=\text { massa do corpo }
$$

Caso seja admitido que a partícula acelere a partir do repouso, sua aceleração decrescerá até zerar $(\mathrm{dv} / \mathrm{dt}=0)$, isto é, a resultante das forças que atuam sobre o corpo deverá ser nula e, portanto, sua velocidade constante. Sob tal circunstância, esta velocidade é máxima, sendo denominada velocidade terminal, $v_{p s}$, se a partícula é esférica, a equação 3.9 descreve o fenômeno [Bird et al. (1960); Dickey e Fenic (1976); Foust et al. (1982); Gaudin (1975); Kelly e Spottiswood (1982); Perry e Green (1997); Sissom e Pitts (1988)].

$$
\mathrm{v}_{\mathrm{ps}}=\sqrt{\frac{4}{3} \frac{\mathrm{gd}_{\mathrm{p}}}{\mathrm{C}_{\mathrm{D}}}\left(\frac{\rho_{\mathrm{s}}-\rho}{\rho}\right)}
$$

Onde:

$$
\begin{aligned}
& d_{p}=\text { diâmetro da partícula; } \\
& g=\text { gravidade } \\
& \rho_{s}=\text { densidade da partícula; } \\
& \rho=\text { densidade do fluido; } \\
& C_{D}=\text { coeficiente de arraste. }
\end{aligned}
$$

No fluido sob escoamento laminar, sua viscosidade $(\mu)$ é a única responsável pela força de arraste de uma partícula esférica dentro do fluido, tal proposta é expressa pela Lei de Stokes. Portanto, a velocidade terminal de uma partícula esférica, não - porosa e rígida, num fluido incompressível em escoamento laminar, é definida pela equação 3.10 [Bird et al. (1960); Dickey e Fenic (1976); Foust et al. (1982); Gaudin (1975); Kelly e Spottiswood (1982); McCabe e Smith (1956); Molerus (1993); Perry e Green (1997); Sissom e Pitts (1988)].

$$
\mathrm{v}_{\mathrm{ps}}=\frac{\mathrm{gd}_{\mathrm{p}}^{2}\left(\rho_{\mathrm{s}}-\rho\right)}{18 \mu_{\mathrm{sl}}}
$$

$O$ coeficiente de arraste, em função de $v_{P s}$, para o escoamento laminar depende apenas do número de Reynolds da partícula $\left(R_{-}\right)$, conforme na equação 3.11, cuja expressão é aplicável somente no intervalo $\operatorname{Re}_{\mathrm{P}}<1,9$ [Bird et al. (1960); Dickey e Fenic (1976); Foust et al. (1982); Gaudin (1975); Kelly e Spottiswood (1982); McCabe e Smith (1956); Molerus (1993); Perry e Green (1997); Sissom e Pitts (1988)].

$$
\mathrm{C}_{\mathrm{D}}=\frac{24}{\operatorname{Re}_{\mathrm{p}}}
$$


No regime de transição, $1,9<\mathrm{Re}_{-\mathrm{p}}<500$, a curva do arraste se aproxima da linha reta, conforme a expressão 3.12 [Kelly e Spottiswood (1982)].

$$
\mathrm{C}_{\mathrm{D}}=18,5 \mathrm{Re}_{\mathrm{p}}^{-0,6}
$$

Para $R e_{-p}>500$, intervalo em que é aplicável a Lei de Newton, o escoamento em torno da partícula se apresenta turbulento e o coeficiente de arraste é praticamente independente de $\mathrm{Re}_{\mathrm{P}}$, conforme a equação 3.13 [Dickey e Fenic (1976); Kelly e Spottiswood (1982); McCabe e Smith (1956) Perry e Green (1997)].

$$
C_{D}=0,44
$$

Através de ajustes matemáticos as equações de movimento propiciam métodos para determinação da velocidade terminal para os diferentes tipos de escoamento, como McCabe e Smith (1956). Outra metodologia, empregada por Kelly e Spottiswood (1982) é a utilização de dois adimensionais, conforme as equações 3.14 e 3.15 .

$$
\begin{aligned}
& C_{D} \operatorname{Re}_{\mathrm{p}}^{2}=\frac{4}{3} \frac{\left(\rho_{\mathrm{s}}-\rho\right) \rho g d_{\mathrm{p}}^{3}}{\mu^{2}} \\
& \frac{\mathrm{C}_{\mathrm{D}}}{\operatorname{Re}_{\mathrm{P}}}=\frac{4}{3}\left(\frac{\rho_{\mathrm{s}}-\rho}{\rho^{2}}\right) \frac{\mu \mathrm{g}}{\mathrm{v}_{\mathrm{ps}}^{2}}
\end{aligned}
$$

Uma vez que haja uma única relação entre $R e_{P}$ e $C_{D}$, é possível construir-se o gráfico de $C_{D} R_{P}{ }^{2}$ e $C_{D} / R_{P}$ versus $R e_{P}$, como apresentado na figura 3.4. Por sua vez, constituí um método gráfico para determinação da velocidade terminal da partícula, $v_{P s}$, ou diâmetro das partículas, $d_{P}$, sem conhecimento prévio do regime de escoamento [Kelly e Spottiswood (1982)].

Segundo Dobby e Finch (1990), Ralston (1999a) e Schulze (1984), a velocidade de terminal da esfera é fundamental no processo de flotação. Via de regras, partículas minerais não são esféricas, apresentando formas irregulares que influenciam seu movimento dentro de um fluido [Barnes et.al. (1989)]. 


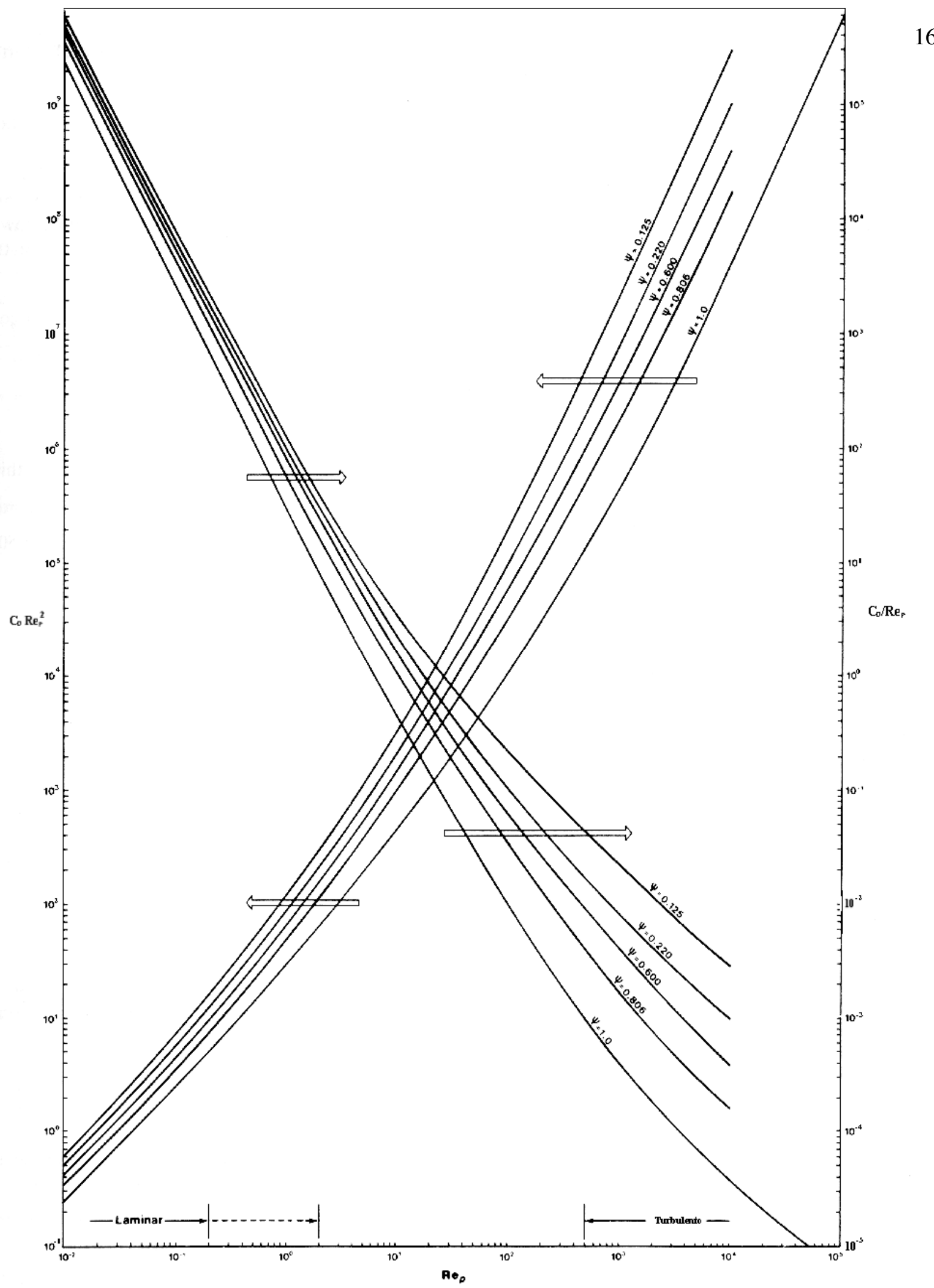

Figura 3.4. $C_{D} R e_{P}{ }^{2}$ e $C_{D} / R e_{P}$ versus Reynolds da partícula, $R e_{P}$ [Kelly e Spottiswood (1982)]. 
Baseado nos estudos de escoamento laminar em meios porosos, Souza Pinto et.al (2009) analisou as esfericidades de apatitas ígneas e sedimentares, deduzidas a partir da equação de Darcy.

Souza Pinto et.al (2009) determinou a permeabilidade do leito fixo via percolação de ar através de um funil preenchido com de partículas de apatita e esferas de vidro, com diâmetros pré-estabelecidos. Uma vez que as características geométricas do leito, bem como, vazão de ar e diferencial de pressão do sistema eram determinadas, a permeabilidade do leito foi deduzida em função da inclinação da reta de $(-\Delta \mathrm{P} / \mathrm{L})$ versus vazão de ar. Os resultados estão sumariados na tabela 3.1.

Tabela 3.1. Resultados de permeabilidade e esfericidade das partículas (Souza Pinto et.al., 2009).

\begin{tabular}{|c|c|c|c|}
\hline \multirow{2}{*}{ Sólido } & $\begin{array}{c}\text { Tamanho de } \\
\text { partícula }(\mu \mathrm{m})\end{array}$ & $\begin{array}{c}\text { Constante de } \\
\text { permeabilidade }(\mathrm{K}) \\
\left(\times 10^{-11} \mathrm{~m}^{2}\right)\end{array}$ & Esfericidade $(\Psi)$ \\
\hline \multirow{3}{*}{ Apatita ígnea } & $-297+210$ & 5,97 & $0,629 \pm 0,004$ \\
\cline { 2 - 4 } & $-210+149$ & 3,33 & $0,623 \pm 0,010$ \\
\cline { 2 - 4 } & $-149+105$ & 1,60 & $0,632 \pm 0,007$ \\
\hline \multirow{3}{*}{ Apatita sedimentar } & $-297+210$ & 5,70 & $0,635 \pm 0,006$ \\
\cline { 2 - 4 } & $-210+149$ & 3,96 & $0,644 \pm 0,002$ \\
\cline { 2 - 4 } & $-149+105$ & 1,82 & $0,643 \pm 0,011$ \\
\hline \multirow{3}{*}{ Esferas de vidro } & $-297+210$ & 8,10 & $0,994 \pm 0,036$ \\
\cline { 2 - 4 } & $-210+149$ & 4,27 & $0,996 \pm 0,010$ \\
\cline { 2 - 4 } & $-149+105$ & 2,03 & $0,987 \pm 0,008$ \\
\hline
\end{tabular}

\subsection{Características de agitação nas células mecânicas de flotação}

Não somente na flotação, mas também, em diversas operações unitárias do Tratamento de Minério, a agitação é de suma importância. Dentre os sistemas que promovem a mistura, aqueles providos de recipientes com impelidores são os mais empregados. 


\subsubsection{Aspectos geométricos e hidrodinâmicos dos vasos agitados mecanicamente.}

Os equipamentos utilizados na agitação consistem normalmente num tanque cilíndrico, um ou mais impelidores (também chamados de rotores), um motor e freqüentemente "baffles" ou chicanas, conforme apresentado na figura 3.5. Em determinadas situações o tanque é provido de serpentinas ou camisas para troca de calor [Brodkey e Hershey (1988); Nagata (1975); Nienow et al. (1985); Oldshue (1983); Tatterson (1991); Uhl e Gray (1966)].

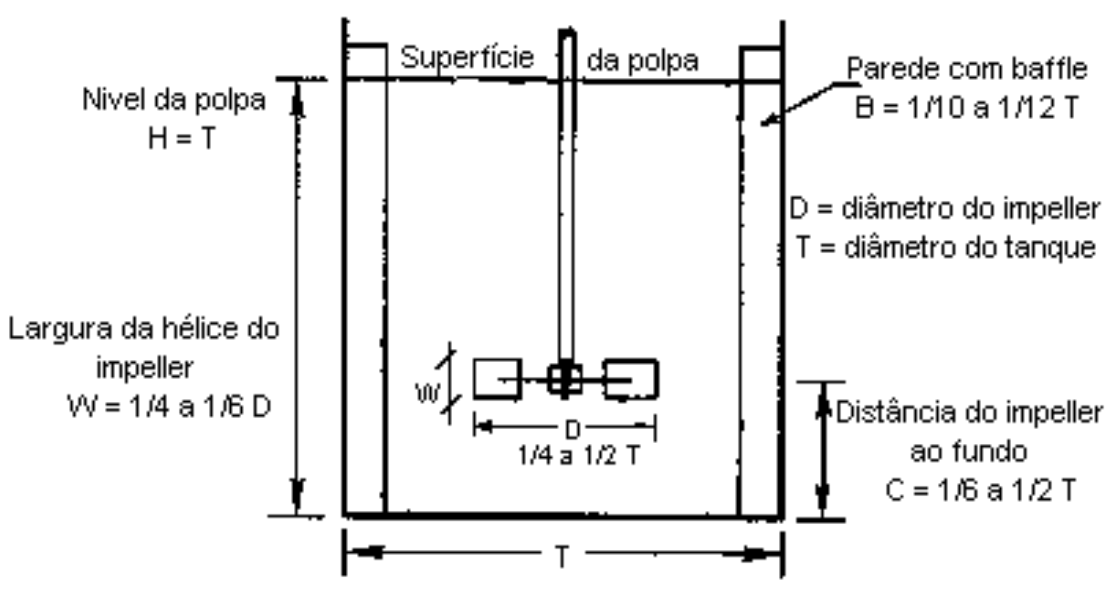

Figura 3.5. Tanque de agitação mecânica, tipo convencional [Tatterson (1991)].

Os impelidores dos sistemas de vasos agitados aplicam energia mecânica ao fluido (líquidos miscíveis, polpa, líquido - gás) para colocá-lo em movimento (bombeamento), superando as resistências hidráulicas do fluxo no interior do recipiente (cisalhamento), no intuito de proporcionar uma mistura eficiente. Portanto, os fundamentos dos fenômenos de transferência de quantidade de movimento, calor e massa contribuem à explicação e otimização da agitação [McCabe e Smith (1956); Nagata (1975); Oldshue (1983); Tatterson (1991); Uhl e Gray (1966)].

A figura 3.5 ilustra um tanque de agitação mecânica, tipo convencional, com as seguintes características [Nagata (1975); Oldshue (1983); Tatterson (1991); Uhl e Gray (1966)]:

- diâmetro do tanque, T;

- impelidor de diâmetro D e largura da pá W;

- distância do fundo do tanque ao impelidor, C ("Impeller Clearance"); 
- nível da polpa $\mathrm{H}$;

- largura das chicanas nas paredes do recipiente, B.

As relações geométricas entre as partes do tanque variam em função da aplicação e do comportamento hidrodinâmico desejado no sistema [Tatterson (1991)].

As chicanas existentes nas paredes do tanque da figura 3.5 são placas ou chapas colocadas para provocar perturbação ou redirecionar o fluxo e sua largura é geralmente expressa em percentagem, normalmente $10 \%$ do diâmetro do tanque. Outras configurações e arranjos de chicanas podem ser empregados, como as colocadas no fundo e na superfície, no entanto raramente elas são aplicadas [Tatterson (1991); Uhl e Gray (1966)].

As chicanas maximizam a transferência de potência para polpa, minimizam o fenômeno da "rotação sólida" da polpa no tanque e inibem a entrada de ar no sistema de mistura, dada a formação de vórtice na superfície, conforme ilustrado na figura 3.6. Tal fenômeno movimenta a polpa como se fosse uma massa sólida, não promovendo uma boa mistura dos seus componentes. A rotação sólida pode causar classificação, estratificação e separação do sistema em fases, prejudicando a mistura [McCabe e Smith (1956); Nagata (1975); Oldshue (1983); Tatterson (1991); Uhl e Gray (1966)].

Segundo o teorema de Bernoulli, o aumento da velocidade da polpa provoca um decréscimo na pressão. Por conseguinte, no caso dos vórtices formados nos tanques agitados mecanicamente, a pressão no seu centro é infinitamente pequena, ou até mesmo negativa, fato que pode ocasionar a sucção de ar [Bird et al. (1960); Brown et al. (1950); Foust et al. (1982); Giles (1977); Nagata (1975); Perry e Green (1997); Sissom e Pitts (1988)]. 
(b)

(a)

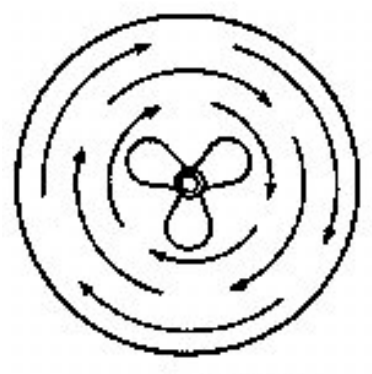

"Rotação sólida" da polpa

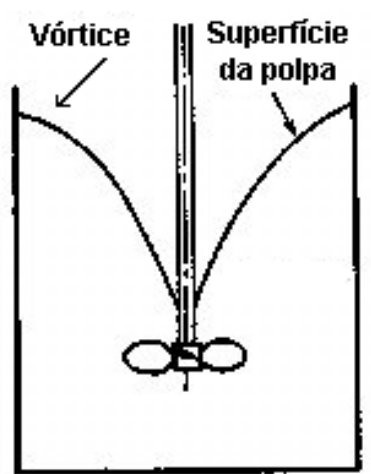

Vórtice central

Figura 3.6. (a) "Rotação sólida" da polpa. (b) Vórtice central na superfície da polpa [McCabe e Smith (1956); Nagata (1975); Oldshue (1983)].

A maioria das operações de agitação é executada com a superfície da polpa livre no tanque, conseqüentemente o modelo de fluxo e a forma da superfície sofrem também interferência do campo gravitacional, sendo o vórtice um produto da ação deste campo. A forma desse vórtice representa o balanço entre as forças de inércia e de gravidade, sendo que a razão entre essas forças resulta num número adimensional, útil para o estudo do sistema de agitação, denominado número de Froude, conforme a equação 3.16 [Bird et al. (1960); Brown et al. (1950); Foust et al. (1982); McCabe e Smith (1956); Nagata (1975); Oldshue (1983); Perry e Green (1997); Rodrigues et.al. (2001); Uhl e Gray (1966)].

$$
\mathrm{Fr}_{\mathrm{I}}=\frac{\mathrm{DN}^{2}}{\mathrm{~g}}
$$

Da mesma forma que no escoamento de polpa em tubos e movimento de partículas em meio fluido, nos sistemas de agitação também se define o número de Reynolds. Neste caso, a velocidade peculiar ao sistema é a velocidade periférica do impelidor, $\pi$ ND. Assim, em função do regime de mistura, os impelidores podem ser classificados como laminar ou turbulento [Tatterson (1991)].

Para que o escoamento laminar seja amplo no sistema de agitação, o diâmetro do impelidor deve se aproximar ao tamanho do tanque, uma vez que a quantidade de movimento transferida para o meio fluido é baixa. Os impelidores mais apropriados para promover o escoamento laminar são do tipo âncora e hélice [Bird et al. (1960); Brodkey e Hershey (1988); Nagata (1975); Oldshue (1983); Tatterson (1991); Uhl e Gray (1966)]. 
No regime de mistura turbulento, uma vez que a transferência de quantidade de movimento é eficiente, impelidores variando de 25 a $50 \%$ do diâmetro de tanque são mais utilizados para promover tal turbulência. Nesse regime, a classificação dos impelidores é refinada em axiais e radiais, conforme a figura 3.7 [McCabe e Smith (1956); Nagata (1975); Nienow et al. (1985); Oldshue (1983); Tatterson (1991); Uhl e Gray (1966)].

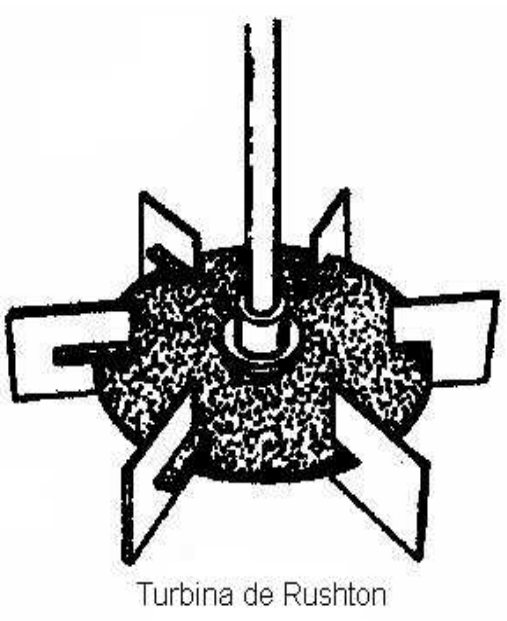

(a) Impelidor de fluxo radial

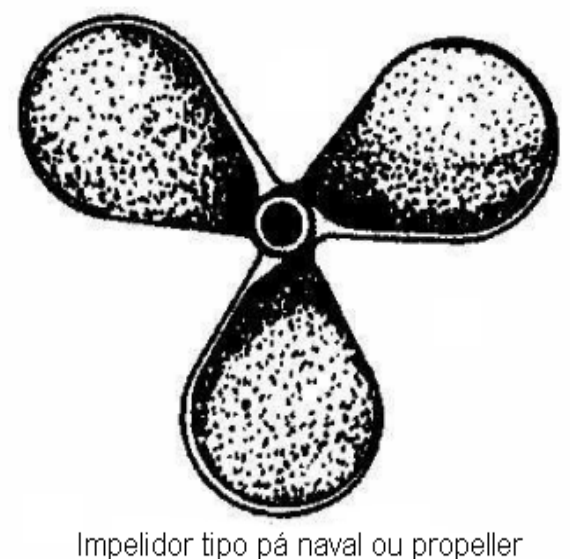

(b) Impelidor de fluxo axial

Figura 3.7. Exemplos de impelidores para regime turbulento de mistura [Oldshue (1983)].

A velocidade do fluxo da polpa, em qualquer ponto do tanque, pode ser decomposta em três componentes, que por sua vez variam de ponto a ponto do escoamento da polpa. Essas componentes interferem diretamente no modelo de escoamento do vaso agitado [McCabe e Smith (1956); Nagata (1975); Oldshue (1983); Tatterson (1991); Uhl e Gray (1966)]:

i. Componente radial: atua numa direção perpendicular ao eixo do impelidor, que descarrega a polpa principalmente de forma radial.

ii. Componente longitudinal ou axial: age em direção paralela ao eixo do impelidor, o qual descarrega predominantemente de maneira axial.

iii. Componente tangencial ou rotacional: atua na direção tangencial à trajetória circular em torno do eixo. Caso o eixo do impelidor esteja numa posição vertical, comum na grande maioria das aplicações da 
agitação, as componentes radiais e tangenciais estão contidas num plano horizontal.

Embora a razão $\mathrm{D} / \mathrm{T}$ e distância do impelidor ao fundo do tanque tenham efeitos significativos no regime de escoamento, o tipo de impelidor para uma determinada aplicação é classificado usualmente por sua geometria. O fluxo predominante no sistema de agitação tem grande importância para o Tratamento de Minério, por sua influência na presença ou não de zonas mortas, na suspensão de partículas, dispersão de bolhas, etc. [Nienow et al. (1985)].

Como foi mencionado anteriormente, impelidores axiais bombeiam o material paralelamente ao eixo, no entanto, eles também produzem escoamentos radiais. Particularmente, em pequenas distâncias entre o fundo e o impelidor e razões $\mathrm{D} / \mathrm{T}$ elevadas (acima de 0,5) o fluxo radial pode preponderar, devido ao domínio das forças centrífugas das pás do impelidor [Oldshue (1983); Tatterson (1991)].

Os impelidores axiais, como do tipo naval e pás inclinadas, são bastante utilizados na mistura e suspensão de sólidos, como no caso das polpas minerais, devido ao seu fluxo longitudinal varrer as partículas sólidas das zonas mortas do fundo do tanque. Nessa aplicação, o impelidor descarrega o material para baixo, segundo a sua rotação e geometria [McCabe e Smith (1956); Nagata (1975); Oldshue (1983); Tatterson (1991); Uhl e Gray (1966)].

Os impelidores radiais mais comuns são as turbinas (Rushton ou pá curvada) e os "paddles" ou pás retas. Eles descarregam o fluxo preferencialmente na direção radial e tangencial, que atinge e elimina zonas de estagnação por todo o tanque. Quando o impelidor está em rotação, sua vizinhança tem alta velocidade, grande turbulência e intenso cisalhamento. Deste modo, o fluido é forçado sobre a pá em alta velocidade [Brodkey e Hershey (1988); McCabe e Smith (1956); Oldshue (1983)].

Quando o fluido transpõe a pá do impelidor tipo turbina, ele tenta se reatar na parte posterior da pá, ocasionando uma pressão negativa e formando um sistema de duplo vórtice, que geram cavidades de gás na região. Por conseqüência da presença desses vórtices, as turbinas são os impelidores mais utilizados em equipamentos que promovem dispersões de gás, como é o caso das células de flotação e fermentadores [Brodkey e Hershey (1988); McCabe e Smith (1956); Nienow et al. (1985); Oldshue (1983)]. 
A quantidade de polpa deslocada pelo movimento do impelidor, num determinado intervalo de tempo, é denominada vazão de descarga ou bombeamento, Q. Sendo que esta capacidade de bombeamento e o cisalhamento do impelidor dependem das características geométricas do sistema de agitação [Nagata (1975); Oldshue (1983); Uhl e Gray (1966)].

As relações entre geometria do impelidor, rotação e outras variáveis do fluido foram estudadas em detalhes para bombas centrífugas. Os princípios básicos que interagem energia desenvolvida, velocidade do fluido, vazões, potência consumida e geometria do equipamento são aplicadas também à rotação do impelidor no sistema de agitação [Oldshue (1983); Uhl e Gray (1966)].

Por conseguinte, como nas bombas centrífugas, o produto entre a vazão de bombeamento e a altura de carga da polpa (funções da velocidade do fluxo) definem a potência transferida pelo impelidor à polpa, conforme descrito na equação 3.17 [Giles (1977); Oldshue (1983); Uhl e Gray (1966)].

$$
P=Q_{I} H \rho
$$

Onde:

$$
\begin{aligned}
& P=\text { potência aplicada pelo impelidor; } \\
& Q_{\mid}=\text {vazão de bombeamento ou descarga promovida pelo impelidor; } \\
& H_{=} \text {nível ou altura de carga da polpa (energia fornecida pelo impelidor } \\
& \quad \text { para movimentá-la); } \\
& \rho=\text { densidade do fluido ou polpa. }
\end{aligned}
$$

Considerando um sistema de agitação, conforme figura 3.5, onde um fluido newtoniano (densidade - $\rho$ e viscosidade - $\mu$ ) é misturado por um impelidor de diâmetro - D e largura - W, girando numa rotação - N, no interior de um tanque com diâmetro - $\mathrm{T}$ e nível do fluido $-\mathrm{H}$, a potência requerida do impelidor - $\mathrm{P}$, sob tais condições, dependerá das seguintes variáveis independentes [Brodkey e Hershey (1988); Nagata (1975); Nienow et al. (1985); Oldshue (1983); Tatterson (1991); Uhl e Gray (1966)].

$$
P=f(\rho, \mu, N, g, D, T, W, H, \text { outras dimensões })
$$

A potência aplicada ao fluido deve superar suas forças de resistência ao movimento. Assim, o torque aplicado ao eixo do impelidor é proporcional ao produto $F_{D-1 .} D$, ou seja, sua força de arraste $\left(F_{D-1}\right)$ e seu diâmetro (D). Podendo assim ser 
relacionado à potência transferida à polpa, conforme a equação 3.19 [Brodkey e Hershey (1988); Nienow et al. (1985)].

$$
T_{q}=\frac{P}{2 \pi N}
$$

Onde:

$$
\begin{aligned}
& \mathrm{P}=\text { potência; } \\
& \mathrm{T}_{\mathrm{q}}=\text { Torque; } \\
& \mathrm{N}=\text { rotação do impelidor. }
\end{aligned}
$$

Uma vez que, a distribuição da pressão sobre a superfície das pás do impelidor reflete no torque atuando sobre o sistema, é possível correlacionar a diferenças de pressão $(\Delta \mathrm{Pr})$ oriunda do escoamento do fluido pela potência consumida pelo impelidor para promover a agitação. Para sistemas dinamicamente similares, as equações 3.20 e 3.21 expressam tal relação [Uhl e Gray (1966)].

$$
\begin{aligned}
& \mathrm{k} \frac{\mathrm{P}}{\mathrm{ND}^{3}}=\Delta \mathrm{Pr} \\
& \frac{\Delta \mathrm{Pr}}{\rho \mathrm{v}^{2}}=\frac{\mathrm{kP} / \mathrm{ND}^{3}}{\rho\left(\mathrm{ND}^{2}\right)}=\frac{\mathrm{kP}}{\rho \mathrm{N}^{3} \mathrm{D}^{5}}
\end{aligned}
$$

Sendo que a constante k não é utilizada neste propósito, podendo ser omitida. O coeficiente de pressão $\left(\Delta \mathrm{Pr} / \rho v^{2}\right)$ é denominado número de potência (Po), conforme a equação 3.22 [Brodkey e Hershey (1988); Nagata (1975); Nienow et al. (1985); Oldshue (1983); Tatterson (1991); Uhl e Gray (1966)].

$$
\mathrm{Po}=\frac{\mathrm{P}}{\rho \mathrm{N}^{3} \mathrm{D}^{5}}
$$

O coeficiente de arraste (equação 3.6) em sistemas de agitação auxilia e intensifica na compreensão do significado físico do número de potência. Para um reator de mistura, o número de Potência é análogo ao coeficiente de arraste, segundo os seguintes argumentos [Oldshue (1983); Uhl e Gray (1966)]:

$$
\begin{aligned}
& v \propto N D \\
& A \propto D^{2} \\
& P \propto N F_{D} D
\end{aligned}
$$

(semelhança geométrica)

Introduzindo estas relações na equação 3.6, tem-se a expressão A [Uhl e Gray (1966)]:

$$
\mathrm{C}_{\mathrm{D}} \alpha \frac{(\mathrm{P} / \mathrm{ND})}{\rho(\mathrm{ND})^{2} \mathrm{D}^{2}}
$$

Expressão A 


$$
\mathrm{C}_{\mathrm{D}} \alpha \frac{\mathrm{P}}{\rho \mathrm{N}^{3} \mathrm{D}^{5}} \quad \text { Expressão } \mathrm{B}
$$

Ou, de forma adimensional [Uhl e Gray (1966)]:

$$
\mathrm{C}_{\mathrm{D}} \alpha \mathrm{Po}
$$

Expressão C

Portanto, o Po é equivalente, ao $C_{D}$, fisicamente a potência é aplicada à polpa através do mecanismo de arraste das pás. Considerando-se a similaridade geométrica e análise dimensional ao sistema de agitação obtém-se a equação 3.23 [McCabe e Smith (1956); Nagata (1975); Oldshue (1983); Rushton et al. (1950a); Uhl e Gray (1966)]:

$$
\mathrm{Po}=f\left(\mathrm{Re}_{1}, \mathrm{Fr}_{\mathrm{l}}\right)
$$

Em tanques que não apresentam chicanas e $\operatorname{Re}_{1}>300$, a forma da superfície, reflexo do modelo do fluxo correspondente, é significativamente afetada pelo campo gravitacional. Assim, o número de Froude tem influência sobre o número de potência. [Brodkey e Hershey (1988); McCabe e Smith (1956); Nagata (1975); Nienow et al. (1985); Oldshue (1983); Rushton et. al. (1950a); Rushton et. al. (1950b); Tatterson (1991); Uhl e Gray (1966)].

Em condições de hidrodinâmicas com $R_{e}$ baixo, as forças viscosas são predominantes, caracterizando o escoamento é laminar. Neste regime de fluxo, o número de Potência (Po) é inversamente proporcional ao número de Reynolds [Uhl e Gray (1966)].

Para sistemas de agitação com número de Reynolds elevado, o escoamento é turbulento, proporcionando assim uma mistura dos componentes da polpa mais rápida, por causa ao movimento de seus vórtices. Nesta região, o número de potência é praticamente constante e independente da viscosidade do meio, portanto, em sistemas com similaridade geométrica, Po é proporcional à densidade da polpa, à rotação ao cubo, ao diâmetro do impelidor a 5. a potência [Uhl e Gray (1966)].

O regime transiente é observado entre o laminar e o completamente turbulento e, com forma variável para sistemas de diferentes geometrias, não tem sido objeto de muito interesse pelos pesquisadores. Entretanto, é possível verificar nesse regime que há diferença de velocidades entre as regiões do tanque, ou seja, a velocidade do fluxo próximo ao impelidor é maior que a um ponto próximo à parede do vaso [Nagata (1975); Oldshue (1983); Schulze (1984); Uhl e Gray (1966)].

A figura 3.8 mostra a relação entre número de potência e número de Reynolds através de curvas experimentais para diferentes impelidores e 
configurações geométricas. Vale ressaltar que a utilização dessas curvas é limitada às aplicações com fluidos Newtonianos e dispersões de concentrações muito baixas [Rushton (1950a); Tatterson (1991); Uhl e Gray (1966)].

Obtendo-se Po, para um determinado valor de $\mathrm{Re}_{\text {, é }}$ possível estimar a potência $(P)$ aplicada pelo impelidor à polpa, conforme a equação 3.22 [Nagata (1975); Rushton et. al. (1950a); Rushton et. al. (1950b); Uhl e Gray (1966)].

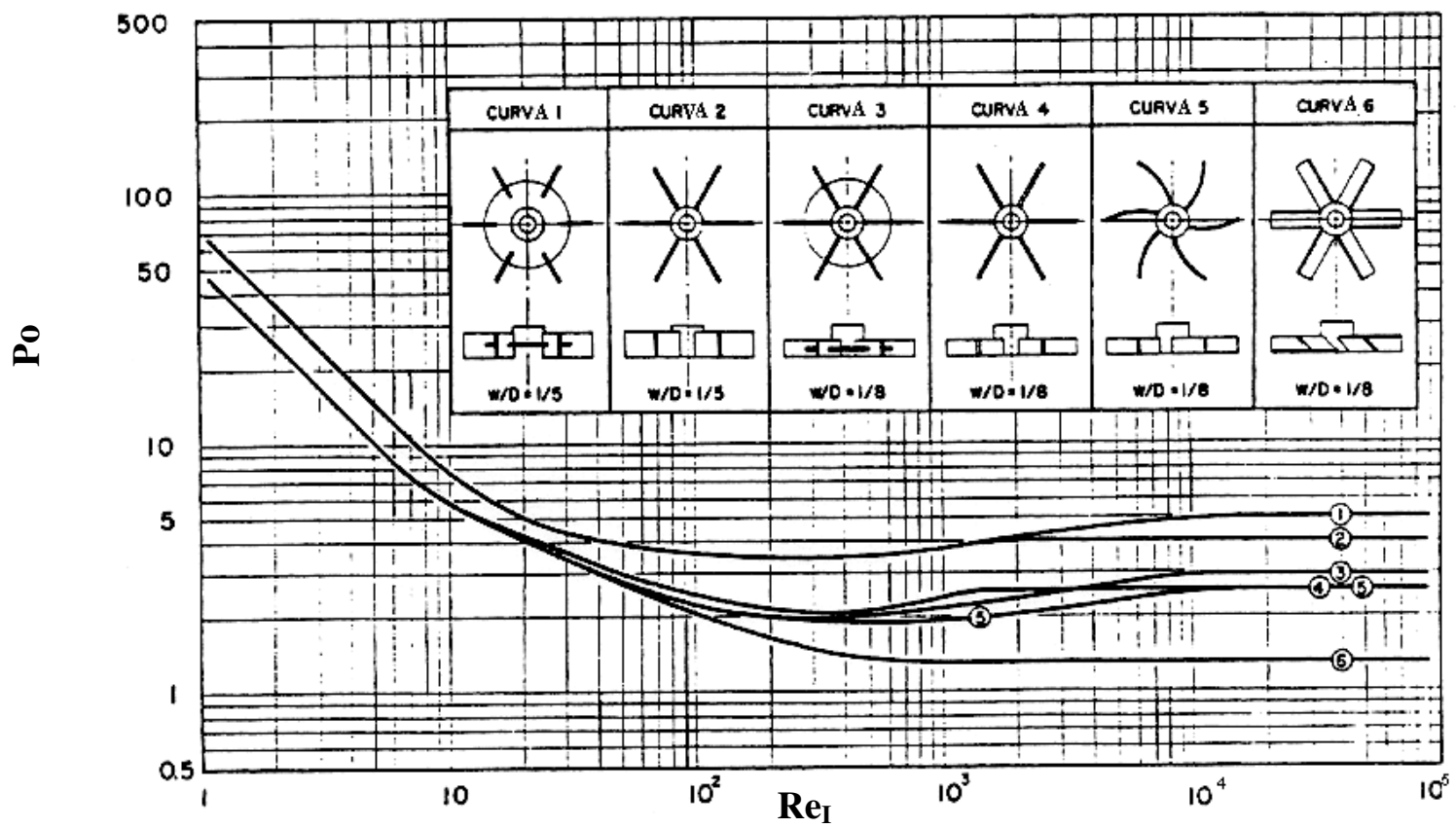

Figura 3.8. Curvas de potência para vários tipos de impelidores [Tatterson (1991); Uhl e Gray (1966)].

A figura 3.8 evidencia três estados de movimento (regimes) para o fluido Newtoniano dentro do vaso agitado [Brown et al. (1950); Dickey e Fenic (1976)]:

i. Turbulento $\left(\operatorname{Re}_{1}>10000\right)$;

ii. Transiente $\left(10<\mathrm{Re}_{\mathrm{l}}<10000\right)$, onde o regime é turbulento próximo ao impelidor e laminar nas partes mais remotas da célula;

iii. Laminar $\left(\operatorname{Re}_{1}<10\right)$, o escoamento é laminar em qualquer região da célula.

Além dos diagramas de Po versus $\mathrm{Re}_{\mathrm{I}}$, outra maneira de determinar a potência consumida pelo escoamento da polpa é através de equações empíricas para avaliação do número de potência. Nesta linha de pesquisa de vasos agitados mecanicamente, a equação empírica 3.24, proposta por Nagata, é a mais empregada [Nagata (1975); Tatterson (1991)]. 


$$
P \mathrm{O}=\frac{A_{N g}}{\operatorname{Re}_{\mathrm{I}}}+B_{N g}\left(\frac{10^{3}+1,2 \mathrm{R} e_{I}^{0,66}}{10^{3}+3,2 \mathrm{R} e_{I}^{0,66}}\right)^{p^{\prime}}\left(\frac{H}{T}\right)^{\left(0,35+\frac{w}{T}\right)}\left(\operatorname{sen} \theta_{p}\right)^{1,2}
$$

Sendo que $A_{N g}, B_{N g}$ e p' são determinados pelas equações 3.25-3.27 [Nagata (1975); Tatterson (1991)]:

$$
\begin{aligned}
& \mathrm{A}_{\mathrm{Ng}}=14+\frac{\mathrm{W}}{\mathrm{T}}\left[670\left(\frac{\mathrm{D}}{\mathrm{T}}-0,6\right)^{2}+185\right] \\
& \log \mathrm{B}_{\mathrm{Ng}}=1,3-4\left(\frac{\mathrm{w}}{\mathrm{T}}-0,5\right)^{2}-1,14\left(\frac{\mathrm{D}}{\mathrm{T}}\right) \\
& \mathrm{p}^{\prime}=1,1+4\left(\frac{\mathrm{w}}{\mathrm{T}}\right)-2,5\left(\frac{\mathrm{D}}{\mathrm{T}}-0,5\right)^{2}-7\left(\frac{\mathrm{w}}{\mathrm{T}}\right)^{4}
\end{aligned}
$$

Para tanques com chicanas e números de Reynolds elevados, quando o número de potência se torna constante (vide figura 3.8 ) diante a variação de Reynolds, tem-se as equações 3.28 [Nagata (1975); Tatterson (1991)].

$$
\begin{aligned}
& \mathrm{Po}=\frac{\mathrm{A}_{\mathrm{Ng}}}{\mathrm{R}_{\mathrm{c}}}+\mathrm{B}_{\mathrm{Ng}}\left(\frac{\mathrm{H}}{\mathrm{T}}\right)^{\left(0,35+\frac{\mathrm{w}}{\mathrm{T}}\right)} \\
& \mathrm{R}_{\mathrm{c}}=\frac{25}{\frac{\mathrm{W}}{\mathrm{T}}}\left(\frac{\mathrm{D}}{\mathrm{T}}-0,4\right)^{0,2}+\left(\frac{\frac{\mathrm{W}}{\mathrm{T}}}{0,11\left(\frac{\mathrm{W}}{\mathrm{T}}\right)-0,0048}\right)
\end{aligned}
$$

Para impelidores de pás inclinadas num ângulo $\theta_{p}, R_{\theta}$ substitui $R_{c}$, conforme a equação 3.29 [Nagata (1975); Tatterson (1991)].

$$
R_{\theta}=10^{4\left(1-\operatorname{sen} \theta_{\mathrm{p}}\right)} R_{\mathrm{c}}
$$

Onde:

$$
\begin{aligned}
& \text { Po = número de potência; } \\
& R e_{I}=\text { número de Reynolds do impelidor; } \\
& \text { w = largura do impelidor; } \\
& H=\text { nível da polpa; } \\
& T=\text { diâmetro do tanque; } \\
& D=\text { diâmetro do impelidor; } \\
& \theta_{p}=\text { ângulo de inclinação da pá do impelidor; }
\end{aligned}
$$

Estabelecidas para bombas centrífugas, as relações entre geometria do 
impelidor, rotação e outras variáveis, são também empregadas para sistemas de agitação mecânica. Assim, a vazão de descarga do impelidor é proporcional ao produto da velocidade pela área perpendicular ao escoamento do fluido $\left(Q_{\downarrow} \alpha N D^{3}\right)$ [Bird et al. (1960); Dickey e Fenic (1976); Foust et al. (1982); Kelly e Spottiswood (1982); Nienow et al. (1985); Oldshue (1983); Perry e Green (1997); Sissom e Pitts (1988)].

Por conseguinte, uma relação adimensional, denominada número de bombeamento (equação 3.30), é característica para cada tipo de impelidor, uma vez que depende do seu número de pás, inclinação e fator de escorregamento das mesmas [Nagata (1975); Nienow et al. (1985); Oldshue (1983); Tatterson (1991); Uhl e Gray (1966)].

$$
N_{Q I}=\frac{Q_{I}}{N D^{3}}
$$

Onde:

$$
\begin{aligned}
& N_{Q I}=\text { número de bombeamento do impelidor; } \\
& Q_{\mid}=\text {vazão de bombeamento do impelidor; } \\
& N \text { = rotação do impelidor; } \\
& D=\text { diâmetro do impelidor }
\end{aligned}
$$

Para um determinado vaso de agitação mecânica, quanto maior a razão entre Po e $\mathrm{N}_{\mathrm{Q}}$ menor será a eficiência de descarga do impelidor, proporcionando maior cisalhamento do fluido. Sistemas que contenham gás e líquidos precisam dispersar as bolhas e utilizam impelidores de grande capacidade de cisalhamento, por sua vez em misturas de sólidos e líquidos, que têm o intuito de promover o contato entre estas fases, o impelidor deve ser capaz de proporcionar o bombeamento da mistura ao longo do tanque, como é o caso dos condicionadores de minério [Nagata (1975)].

\subsubsection{Suspensão de sólidos em líquidos nos vasos mecanicamente agitados}

A suspensão de sólidos é provavelmente a aplicação mais comum na operação de mistura. Este estado de mistura é relevante para muitos processos industriais, tais como: adsorção, cristalização, floculação, lixiviação, fermentação, etc, valendo ainda ressaltar sua grande importância para flotação [Duttar e 
Pangarkar (1995); Nagata (1975); Nienow et al. (1985); Oldshue (1983); Rushton et. al. (1950b); Uhl e Gray (1966); Zwietering (1958)].

Por exemplo, nas células mecânicas de flotação, o ambiente hidrodinâmico deve propiciar o contato entre todas as partículas e bolhas do sistema, ou seja, o minério deve estar em completa suspensão no interior da célula. As configurações geométricas do vaso, o tipo de impelidor, os modelos de fluxo, as velocidades e potência aplicada à polpa interferem na suspensão no tanque.

Além das características geométricas dos sistemas, as propriedades dos sólidos e líquidos influenciam também na uniformidade da suspensão de partículas [Uhl e Gray (1967)]:

i. Densidade da partícula;

ii. Concentração de sólidos;

iii. Densidade da fase líquida;

iv. Tamanho e forma das partículas;

v. Viscosidade da fase líquida;

Nos projetos de agitadores para suspensão de sólidos, como a polpa mineral, dois critérios devem ser considerados [Nagata (1975); Nienow et al. (1985); Oldshue (1983); Uhl e Gray (1966)]:

i. A velocidade mínima do impelidor, para manter os sólidos em suspensão.

ii. A uniformidade da concentração local da polpa, que não se aplica aos sistemas de células mecânicas de flotação.

O estado de suspensão completa da polpa, convencionalmente, é atingido quando todas as partículas estão em movimento e nenhuma delas permanece no fundo do tanque por um período superior a 1-2 segundos. $O$ principal parâmetro que caracteriza esse estado é a velocidade crítica do impelidor ou velocidade mínima de agitação - $\mathbf{N}_{\mathbf{z}}$, que por sua vez, depende da geometria do tanque e do próprio impelidor [Chapman et al. (1983a); Duttar e Pangarkar (1995); Joshi et al. (1982); Kawase et al. (1997); Kushalkar e Pangarkar (1994); Nienow et al. (1985, 1986); Oldshue (1983); Rewatkar e Joshi (1991a); Rewatkar e Joshi (1991b); Roman e Tudose (1996); Uhl e Gray (1967); Zwietering (1958)].

O trabalho de Zwietering (1958) ainda hoje representa a mais completa investigação sobre a velocidade crítica do impelidor $\left(\mathrm{N}_{\mathrm{Z}}\right)$, abrangendo um grande número de tipos de impelidores em tanques com chicanas e de fundo chato, bem 
como, variações das propriedades de polpa (densidade de sólido, viscosidade cinemática e percentagem de sólidos). Zwietering obteve uma equação através da análise dimensional dos dados experimentais para estimar $\mathrm{N}_{Z}$, conforme a expressão 3.31 [Baldi et al. (1978); Chapman et al. (1983a); Duttar e Pangarkar (1995); Joshi et al. (1982); Kawase et al. (1997); Kushalkar e Pangarkar (1994); Nagata (1975); Nienow et al. (1985, 1986); Oldshue (1983); Rewatkar e Joshi (1991a); Rewatkar e Joshi (1991b); Roman e Tudose (1996); Uhl e Gray (1967); Zwietering (1958)].

$$
\mathrm{N}_{\mathrm{Z}}=\frac{\mathrm{S} v^{0,1} \mathrm{~d}_{\mathrm{p}}^{0,2}(g \Delta \rho / \rho)^{0,45} \mathrm{X}^{0,13}}{\mathrm{D}^{0,85}}
$$

Onde:

$\mathrm{N}_{\mathrm{Z}}=$ velocidade crítica do impelidor $\left(\mathrm{s}^{-1}\right)$;

$S=$ constante adimensional relacionado aos parâmetros geométricos do sistema;

$\mathrm{d}_{\mathrm{P}}=$ diâmetro da partícula $(\mathrm{m})$;

$v=$ viscosidade cinemática $\left(\mathrm{m}^{2} / \mathrm{s}\right)$;

$\mathrm{g}=$ aceleração da gravidade $\left(\mathrm{m} / \mathrm{s}^{2}\right)$

$\Delta \rho=$ diferença entre a densidade do sólido e a do líquido $\left(\mathrm{kg} / \mathrm{m}^{3}\right)$;

$\rho=$ densidade do líquido $\left(\mathrm{kg} / \mathrm{m}^{3}\right)$;

$\mathrm{X}=$ concentração de sólidos (massa sólido/massa líquido);

$\mathrm{D}=$ diâmetro do impelidor $(\mathrm{m})$.

A constante adimensional S é determinada em função do tipo de impelidor e das características do sistema e as relações geométricas que interferem diretamente no S são T/C e T/D, como é apresentado na figura 3.9. Sendo observado ainda que em todos os casos $S$ reduz quando o impelidor se aproxima da base, exceto com as turbinas, que $S$ é independente de $C$ para $T / 7 \leq C \leq T / 2$ [Chapman et al. (1983a); Nienow et al. (1985); Zwietering (1958)].

As características hidrodinâmicas locais, como velocidade e nível de turbulência, devem ser suficientes na região para fazer os sólidos deixarem o fundo do vaso. Embora as interpretações dos mecanismos de suspensão existentes na literatura corrente não sejam completamente satisfatórios, Baldi (1978) desenvolveu o enfoque com maior relevância nesta área. Eles postularam que um balanço de energia seria realizado entre os vórtices críticos (admitindo seu tamanho ser da 
ordem da partícula, $d_{p}$ ) e a altura para qual partículas deveriam ser erguidas para entrarem em suspensão (também admitindo ser da ordem de $d_{p}$ ) [Chapman et al. (1983a); Nienow et al. (1985); Zwietering (1958)].

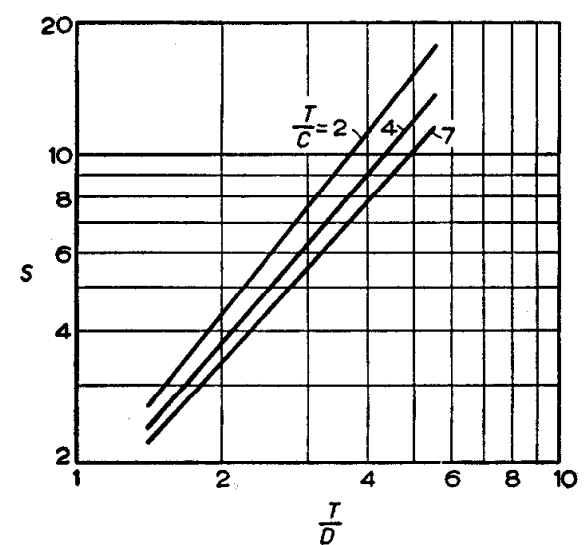

(a) Correlação para suspensão completa com $\mathrm{D} N=2$ e $\mathrm{N}_{\mathrm{P}}=5,9$. Impelidor com 2 pás retas (paddle).

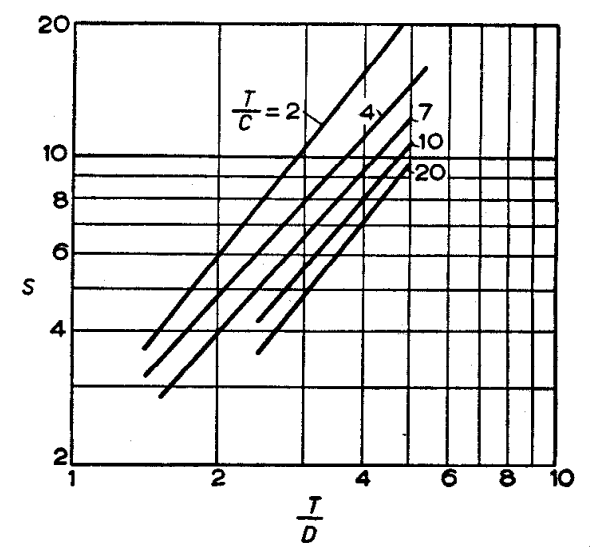

(c) Correlação para suspensão completa com $\mathrm{D} / \mathrm{W}=4$ e $\mathrm{N}_{\mathrm{p}}=2,5$. Impelidor com 2 pás retas (paddle).

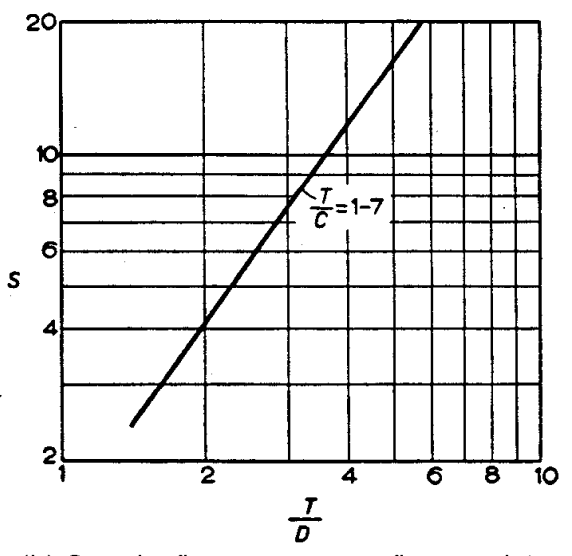

(b) Correlação para suspensão completa usando turbina de Rushton, $N_{P}=6,2$.

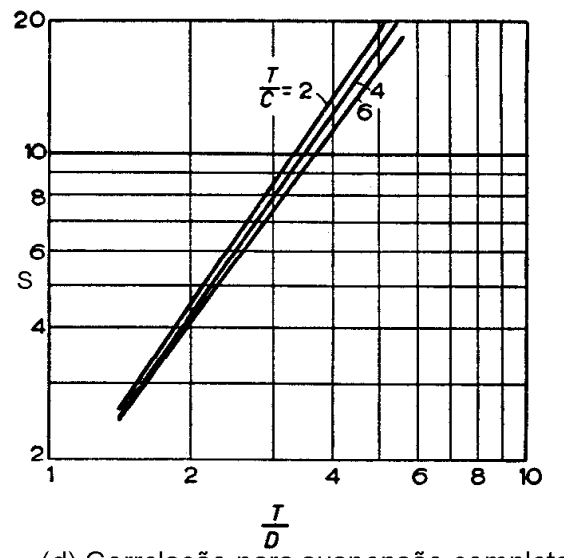

(d) Correlação para suspensão completa usando disco com alheta, $N_{p}=4,6$.

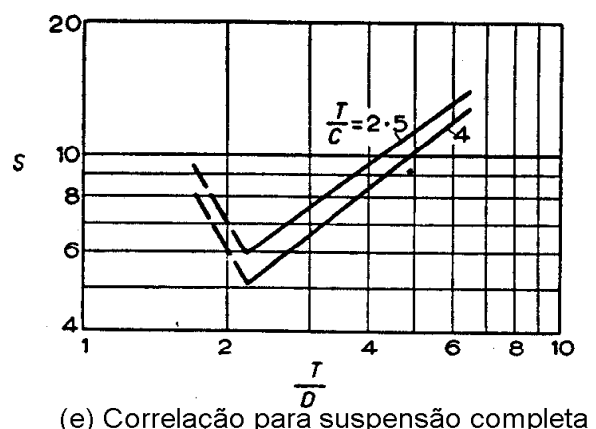

(e) Correlação para suspensão completa usando impelidor tipo pá naval, $N_{p}=0,5$.

Figura 3.9. Gráficos de S versus T/D, usando-se T/C como um parâmetro, para cinco impelidores diferentes [Nienow et al. (1985); Zwietering (1958)].

Este balanço de energia conduz a um grupo adimensional, $Z$, que define a razão entre a energia dissipada na base do tanque $\left(\varepsilon_{T}\right)_{B}$ (responsável pela 
suspensão) e energia média dissipada no tanque $\left(\varepsilon_{\top}\right)$, conforme as expressões 3.32 e 3.33 [Baldi et al. (1978); Chapman et al. (1983a); Nienow et al. (1985)].

$$
\begin{aligned}
& \bar{\varepsilon}_{T}=\frac{4 P_{0} N^{3} D^{5}}{\pi T^{3}} \\
& Z=\left(\frac{g \Delta \rho}{\rho}\right)^{1 / 2} \frac{1}{P^{1 / 3}}\left(\frac{T}{D}\right) \frac{d_{P}{ }^{1 / 6}}{D^{5 / 3}} \frac{1}{N_{Z}}
\end{aligned}
$$

Onde:

$$
\begin{aligned}
& \varepsilon_{T}=\text { energia média dissipada no tanque; } \\
& P_{0}=\text { número de potência; } \\
& N=\text { rotação do impelidor; } \\
& D=\text { diâmetro do impelidor; } \\
& T=\text { diâmetro do tanque; } \\
& g=\text { aceleração da gravidade; } \\
& \Delta \rho=\text { diferença entre a densidade do sólido e a do líquido; } \\
& \rho=\text { densidade do líquido; } \\
& d_{P}=\text { diâmetro da partícula; } \\
& N_{Z}=\text { velocidade crítica do impelidor. }
\end{aligned}
$$

Os expoentes da equação 3.31 possuem excelente concordância com o enfoque teórico de Baldi (1978), expressa pela equação 3.33, e também outros diversos trabalhos apresentados na tabela 3.2. Portanto, é recomendado que a correlação de Zwietering seja utilizada para estudos de suspensão de sólidos em vasos mecanicamente agitados, exceto nas seguintes condições [Baldi et al. (1978); Nienow et al. (1985)]:

- Geometrias especiais estejam envolvidas;

- $\quad$ Correlações baseadas em condições experimentais completamente diferentes das que foram abrangidas por Zwietering. 
Tabela 3.2. Expoentes dos parâmetros sólido-líquido das correlações de velocidade críticas do impelidor e escalas [Nienow et al. (1985)].

\begin{tabular}{|c|c|c|c|c|c|c|c|}
\hline \multirow{2}{*}{ Autor } & \multirow{2}{*}{$\begin{array}{c}\text { Impelidor } \\
(\#)\end{array}$} & \multicolumn{4}{|c|}{ Expoentes } & \multirow{2}{*}{$\begin{array}{c}\text { Diâm. do } \\
\text { tanque } \\
(\mathrm{m})\end{array}$} & \multirow{2}{*}{$\begin{array}{c}\text { Chicanas } \\
\text { S-sim; N- } \\
\text { não }\end{array}$} \\
\hline & & $X$ & $v$ & $\Delta \rho$ & $d_{p}$ & & \\
\hline $\begin{array}{c}\text { Zwietering, } \\
1958\end{array}$ & $R, A_{X}$ & 0,13 & 0,1 & 0,45 & 0,2 & $0,15-0,7$ & S \\
\hline $\begin{array}{c}\text { Nienow, } \\
1968\end{array}$ & $\mathrm{R}$ & 0,12 & - & 0,43 & 0,21 & 0,14 & $S$ \\
\hline $\begin{array}{c}\text { Pavlushen } \\
\text { ko, } 1957\end{array}$ & $A_{x}$ & - & 0,2 & - & 0,4 & 0,3 & $\mathrm{~N}$ \\
\hline $\begin{array}{l}\text { Kneule, } \\
1956\end{array}$ & $45^{0}$ & 0,17 & - & 0,5 & 0,17 & $0,15-0,4$ & $\mathrm{~S}, \mathrm{~N}$ \\
\hline $\begin{array}{c}\text { Narayanan } \\
, 1969\end{array}$ & $\mathrm{R}$ & 0,22 & - & 0,5 & $<0,5$ & 0,11 & S \\
\hline $\begin{array}{l}\text { Baldi, } \\
1978\end{array}$ & $\mathrm{R}$ & 0,13 & $0-0,23^{*}$ & $0,38-0,5^{\star}$ & $0,13-0,17^{*}$ & $0,12-0,23$ & S \\
\hline $\begin{array}{c}\text { Einenkel, } \\
1977\end{array}$ & $A_{x}$ & $0,2^{\bullet}$ & $\begin{array}{l}0,1^{* *} \\
-0,33\end{array}$ & $\begin{array}{l}0,5^{\star *} \\
0,57\end{array}$ & $\begin{array}{c}0,17^{\star *} \\
0,67\end{array}$ & $0,14-0,79$ & $S$ \\
\hline $\begin{array}{c}\text { Herrindge, } \\
1979\end{array}$ & $\mathrm{R}$ & 0,18 & - & 0,42 & 0,3 & $0,15-1$ & S \\
\hline $\begin{array}{c}\text { Rieger, } \\
1978\end{array}$ & $45^{\circ}, \mathrm{R}$ & 0,13 & 0,16 & 0,42 & $-0,1$ & $0,15-0,4$ & $S$ \\
\hline $\begin{array}{c}\text { Chapman, } \\
1983\end{array}$ & $\begin{array}{c}A_{x}, 45^{\circ} \\
R\end{array}$ & 0,12 & - & 0,4 & 0,15 & $0,29-1,8$ & $S$ \\
\hline $\begin{array}{c}\text { Weisman, } \\
1960\end{array}$ & $\mathrm{R}$ & 0,17 & & $\mathrm{v}_{\mathrm{ps}}$ & & $0,14-0,3$ & $\mathrm{~S}, \mathrm{~N}$ \\
\hline $\begin{array}{c}\text { Kolar, } \\
1961\end{array}$ & $45^{0}, A_{x}$ & 0,1 & & $\mathrm{v}_{\mathrm{ps}}$ & & $0,17-0,35$ & $S$ \\
\hline
\end{tabular}

(\#) $\mathrm{R}$ - impelidor de escoamento radial; $A_{x}$ - impelidor de escoamento axial; $45^{\circ}=$ ângulo de inclinação da pá do impelidor em $45^{\circ}$;

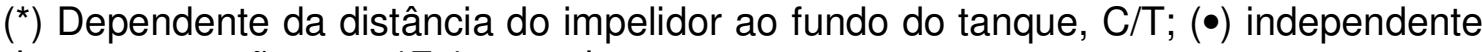
da concentração, se $>17 \%$ em volume;

$\left({ }^{* *}\right)$ Superior para grandes partículas e inferior para pequenas.

\subsubsection{Suspensão de sólidos sistemas trifásicos}

Dispersões de sólido-líquido e gás-líquido foram amplamente pesquisadas, dentre os principais trabalhos podem ser citados Nienow (1985), Nagata (1975) e Uhl (1967). No entanto, a suspensão de sólidos simultaneamente à dispersão de um gás num líquido, ou seja, num sistema trifásico, recebeu menor enfoque, embora 
existam numerosas aplicações destes processos industriais, como hidrogenação, oxidação, fermentação, cristalização e a própria flotação [Chapman et. al. (1983b); Chapman et. al. (1983c); Dutta e Pangarkar (1995); Nienow et. al. (1986)].

Inicialmente deve considerar tais sistemas em dois grupos de interações: as suspensões de sólido em líquido e as dispersões de gás nos líquidos.

a) Sólido-líquido: Amplamente descrita na seção 3.3.2, aumentos na velocidade de impelidor intensificam as interações entre as partículas e os líquidos. Proporcionando desta forma, que toda superfície do sólido esteja disponível para o processo [Zwietering (1958)].

b) Gás-líquido: Uma vez que os contatos das partículas com bolhas de gás no interior da célula são fundamentais para flotação, a dispersão de gás num líquido por agitação mecânica, principalmente por turbina de Rushton, é um aspecto muito relevante para este processo. Sucessivos modelos de escoamento com aumento da rotação e vazão de gás no sistema são apresentados nas figuras $3.10 \mathrm{a}$ a $3.10 \mathrm{c}$ [Chapman et. al. (1983b); Nienow et al. (1985); Uhl (1967); Weiss (1985)].

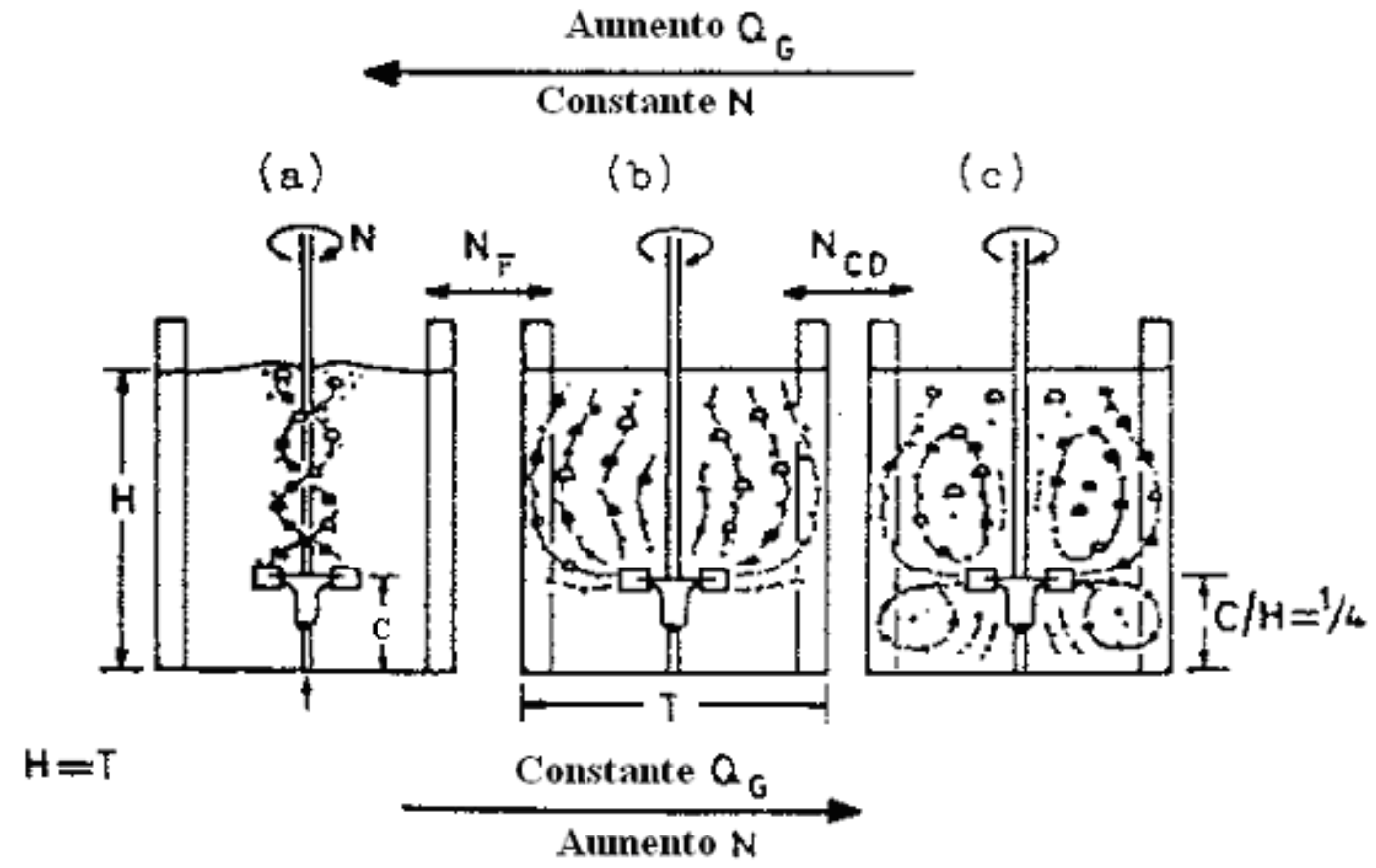

Figura 3.10. Modelos de fluxo de bolhas com turbina de Rushton e aumento de velocidade do impelidor [Chapman et. al. (1983b); Nienow et al. (1985)].

Com relação às figuras 3.10a a 3.10c, ressalta-se [Chapman et. al. (1983b); Nienow et al. (1985)]: 
- $\quad \mathrm{N}=0$ a $\mathrm{N}=\mathrm{N}_{\mathrm{F}}$ (figura 3.10a), o escoamento do sistema está dominado pelo fluxo central e ascendente, uma vez que vazão de gás sobrepõe à capacidade de dispersão do impelidor, isto é, o impelidor está afogado ou flooded, $N_{F}$ - mínima velocidade do impelidor para impedir o afogamento numa vazão de gás.

- $\quad \mathrm{N}_{\mathrm{F}}<\mathrm{N}<\mathrm{N}_{\mathrm{CD}}$ (figura 3.10b) um modelo de escoamento dominado pelo impelidor, fluxo saindo horizontalmente às suas pás. $N_{C D}$ a mínima velocidade para dispersar o gás por todas as partes do tanque.

- $\quad \mathrm{N}>\mathrm{N}_{\mathrm{CD}}$ (figura 3.10c) a dispersão do gás está ocorrendo em todas as partes do líquido, diz-se então que o impelidor está carregado $\left(\mathrm{N}_{\mathrm{CD}}\right)$.

A potência aplicada ao fluido, descrita na seção 3.3.1., decresce com a introdução de gás no sistema. Tal fato é explicado pela formação de cavidades gasosas na parte posterior ao impelidor (em relação ao fluxo), reduzindo assim a densidade em sua volta, de acordo com as figuras 3.11 e 3.12 [Chapman et. al. (1983b); Dutta e Pangarkar (1995); Nagata (1975); Nienow et al. (1985); Oldshue (1983); Tatterson (1991); Uhl e Gray (1966, 1967)].

A dispersão da bolha na polpa de flotação é causada por forças dinâmicas, que devem superar a estática de tensão superficial sobre a polpa. Estas forças podem ser devido ao empuxo ou escoamento induzido [Brodkey e Hershey (1988); Calderbank (1967); Nagata (1975); Nienow et al. (1985); Tatterson (1991); Uhl (1967)].

Os parâmetros mais atuantes sobre a bolha são: tensão de cisalhamento $(\tau)$ e tensão superficial $(\gamma)$, uma vez que o efeito das forças de viscosidade pode ser desprezado para fins práticos. O diâmetro máximo da bolha dispersada $\left(\mathrm{d}_{\mathrm{Bmax}}\right)$ é requerido quando a razão entre as tensões de cisalhamento e superficial tem um determinado valor, tal razão define o número de Weber, conforme a equação 3.34 [Brodkey e Hershey (1988); Calderbank (1967); Chapman et. al. (1983b); Nagata (1975); Nienow et al. (1985); Tatterson (1991); Uhl (1967);].

$$
\mathrm{We}_{\mathrm{B}}=\frac{\tau \mathrm{d}_{\mathrm{B}_{\text {max }}}}{\gamma}
$$



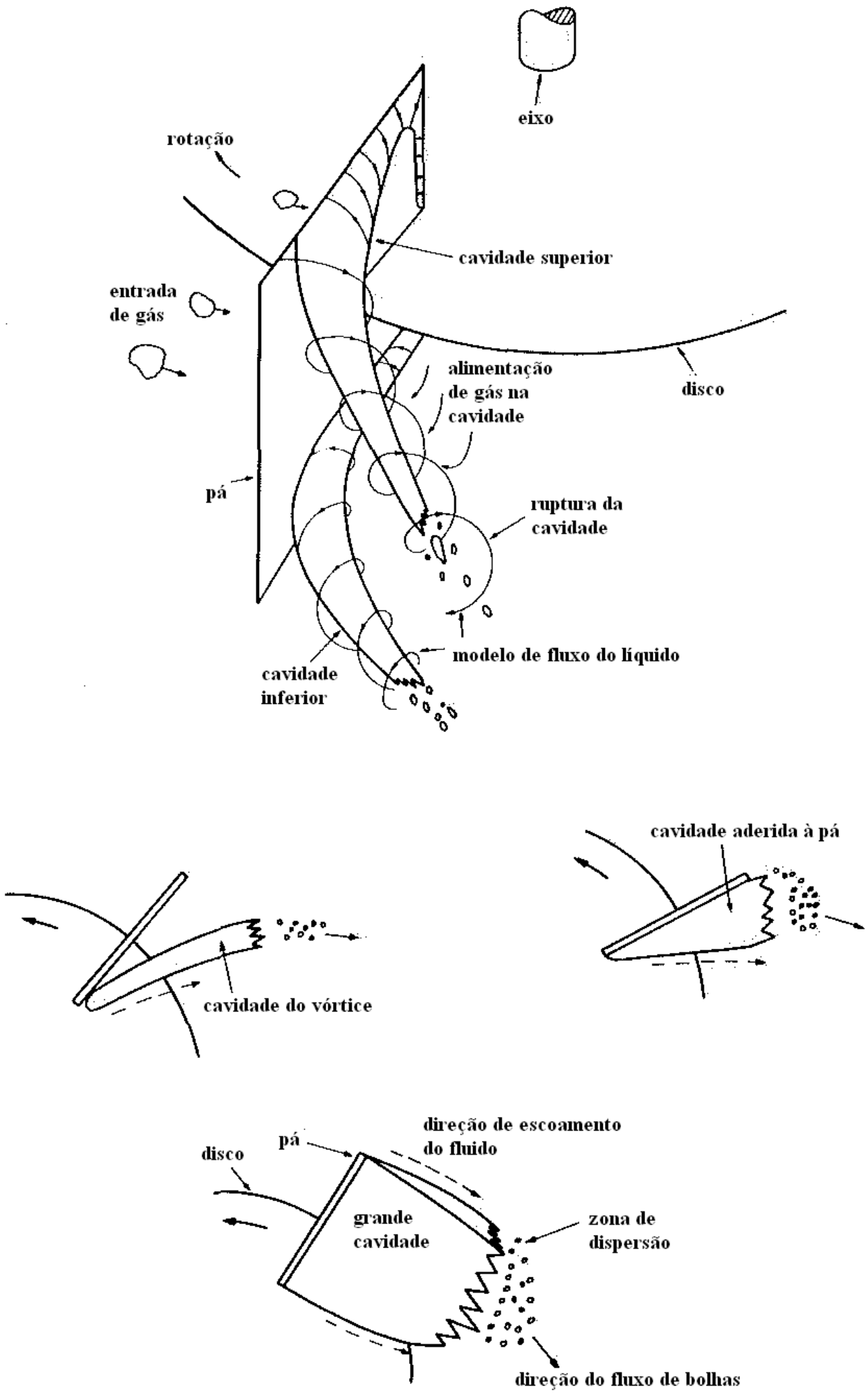

Figura 3.11. Formação de cavidade de gás atrás das pás [Nienow et al. (1985)]. 


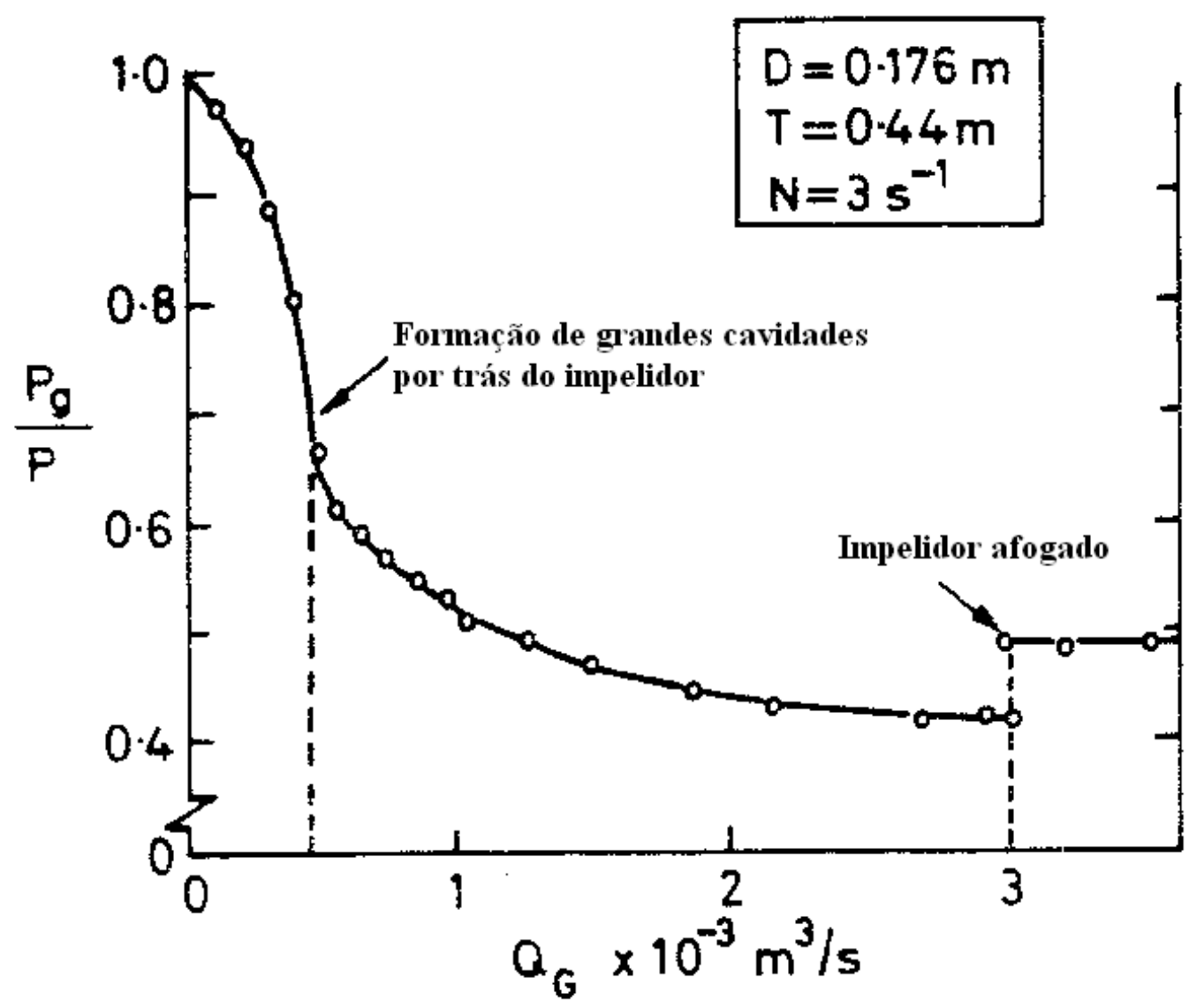

Figura 3.12. Curvas de potência para sistemas gasificados [Chapman et. al. (1983b); Nienow et al. (1985); Tatterson (1991)].

Para bolhas em ascendência ou descendência num líquido, a razão das forças de empuxo $\left(d_{B} \Delta \rho g / 6\right)$ pela tensão superficial deve ser considerada, assim o número de Weber é definido pela equação 3.35 [Calderbank (1967); Nagata (1975); Uhl (1967)].

$$
\mathrm{We}_{\mathrm{B}}=\frac{\mathrm{d}_{\mathrm{B}}^{2} \Delta \rho \mathrm{g}}{6 \gamma}
$$

Sendo $\Delta \rho$ a diferença entre a densidade da polpa e a bolha.

Com relação à dispersão de gases em sistemas de vasos mecanicamente agitados, a tensão de cisalhamento oriunda da turbulência deve ser considerada. Portanto, $\tau$ causada pela turbulência é expresso pela equação 3.36 [Calderbank (1967); Nagata (1975); Uhl (1967)]:

$$
\tau=\varsigma_{1} \rho_{\mathrm{sL}}\left[\left(\frac{\mathrm{P}}{\mathrm{V}}\right)\left(\frac{\mathrm{d}_{\mathrm{B}_{\max }}}{\rho_{\mathrm{sL}}}\right)\right]^{2 / 3}
$$


Sendo:

$$
\begin{aligned}
& \tau=\text { tensão de cisalhamento, } \mathrm{N} / \mathrm{m}^{2} ; \\
& \varsigma_{1}=\text { coeficiente adimensional; } \\
& d_{\mathrm{Bmáx}}=\text { diâmetro máximo da bolha, } \mathrm{m} \\
& \rho_{\mathrm{SL}}=\text { densidade da polpa, } \mathrm{kg} / \mathrm{m}^{3} ; \\
& \mathrm{P} / \mathrm{V}=\text { energia aplicada por unidade de volume no tanque, } \mathrm{W} / \mathrm{m}^{3} \text {. }
\end{aligned}
$$

Segundo Calderbank (1958), tais balanços de força conduzem a estimativa do diâmetro médio da bolha ou diâmetro de Sauter, com ausência de coalescência, para tanques agitados, conforme a equação 3.37 .

$$
\mathrm{d}_{\mathrm{BM}}=\varsigma_{2}\left[\frac{\gamma^{0.6}}{\left(\frac{\mathrm{P}}{\mathrm{V}}\right)^{0,4} \rho_{\mathrm{sL}}^{0.2}}\right]
$$

Onde:

$$
\begin{aligned}
& d_{\mathrm{BM}}=\text { diâmetro médio de Sauter da bolha, } \mathrm{m} ; \\
& \varsigma_{2}=\text { coeficiente adimensional; } \\
& \gamma=\text { tensão superficial, dyn } / \mathrm{cm} ; \\
& \rho_{\mathrm{SL}}=\text { densidade da polpa, } \mathrm{g} / \mathrm{cm}^{3} ; \\
& \mathrm{P} / \mathrm{V}=\text { energia aplicada por unidade de volume no tanque, } \mathrm{erg} / \mathrm{cm}^{3} \text {. }
\end{aligned}
$$

A área interfacial específica $(\Lambda)$ é uma propriedade fase gasosa dispersada na polpa de flotação, que qualifica a qualidade da mistura. Através de $\Lambda$, colocado em função da fração "hold-up" de gás, torna-se possível a determinação de $\mathrm{d}_{\mathrm{BM}}$, equação 3.38 [Calderbank (1967); Nagata (1975); Uhl (1967)].

$$
\mathrm{d}_{\mathrm{BM}}=\frac{6 \Psi}{\Lambda}
$$

Onde:

$$
\begin{aligned}
& \mathrm{d}_{\mathrm{BM}}=\text { diâmetro médio da bolha ou diâmetro de Sauter, } \mathrm{m} ; \\
& \Psi=\text { fração "hold-up" de gás, } \mathrm{m}^{3} ; \\
& \Lambda \text { = área interfacial específica, } \mathrm{m}^{2} ;
\end{aligned}
$$

Usando uma turbina de Rushton em tanque com chicanas e líquidos puros, onde ocorre coalescência. Calderbank (1958) obteve uma expressão (equação 3.39) para o diâmetro de Sauter, (unidades no SI) [Calderbank (1967); Nagata (1975); Nienow et al. (1985); Uhl (1967)]. 


$$
\mathrm{d}_{\mathrm{BM}}=4,15\left[\frac{\gamma^{0,6}}{\left(\frac{\mathrm{P}}{\mathrm{V}}\right)^{0,4} \rho_{\mathrm{sL}}^{0,2}}\right] \Psi^{0,5}\left(\frac{\mu_{\mathrm{g}}}{\mu}\right)^{0,25}+0,0009
$$

Diversos modelos matemáticos foram desenvolvidos, a fim de estimar o diâmetro da bolha. Entre eles, destacam-se os modelos de: Dobby e Finch (1988 e 1990), Drzymala (1994), Ityokumbul et al (1995) e Manqiu Xu e Finch (1988).

A velocidade de uma fase em relação à outra, é chamada de velocidade de deslizamento. Neste caso, a velocidade da fase gasosa em relação à fase líquida (ou polpa), denominada por $\bigcup_{\text {sg }}$ é definida pela equação 3.40 [Dobby et al. (1988); Dobby e Finch (1990); Ityokumbul et. al. (1995); Manqiu Xu e Finch (1988)].

$$
\mathrm{U}_{\mathrm{sg}}=\frac{\mathrm{J}_{\mathrm{g}}}{\Psi} \pm \frac{\mathrm{J}_{\mathrm{L}}}{(1-\Psi)}
$$

Onde:

$\mathrm{U}_{\mathrm{sg}}=$ velocidade da fase gasosa em relação à fase líquida ou polpa, $\mathrm{m} / \mathrm{s}$;

$J_{g}=$ velocidade superficial do gás $(m / s)=Q_{g} / A_{c}$;

Sendo: $Q_{g}=$ vazão do gás $\mathrm{m}^{3} / \mathrm{s}$;

$$
\mathrm{A}_{\mathrm{c}}=\text { área da seção transversal da célula, } \mathrm{m}^{2} \text {; }
$$

$\mathrm{J}_{\mathrm{L}}=$ velocidade superficial do líquido, $\mathrm{m} / \mathrm{s}$;

$\Psi$ = gás "hold-up".

$\mathrm{Na}$ equação 3.40, o sinal +/- refere-se ao fluxo contracorrente ou fluxo concorrente. Convencionalmente aqui será positivo com gás escoando para cima e a polpa para baixo [Dobby e Finch (1990)].

A velocidade de deslizamento é função de diversas variáveis, como o diâmetro da bolha, gravidade, densidade da polpa, etc. Assim, a velocidade de deslizamento para sistema gás/polpa, com bolhas de $d_{B} \leq 2 \mathrm{~mm}\left(\operatorname{Re}_{B} \leq 500\right)$, pode ser expressa pela equação 3.41 [Dobby e Finch (1990)].

$$
\mathrm{U}_{\mathrm{sg}}=\frac{\mathrm{gd}_{\mathrm{B}}^{2}\left(\rho_{\mathrm{sL}}-\rho_{\mathrm{g}}\right) \mathrm{k}_{1}(1-\Psi)}{18 \mu_{\mathrm{sL}}\left(1+0,15 \operatorname{Re}_{\mathrm{b}}^{0,687}\right)}
$$

Onde:

$\mathrm{U}_{\mathrm{sg}}=$ velocidade de uma fase em relação à outra, como a velocidade da fase gasosa em relação à polpa, m/s;

$\mathrm{d}_{\mathrm{B}}=$ diâmetro da bolha, $\mathrm{m}$; 
$\mathrm{g}=$ aceleração da gravidade, $\mathrm{m} / \mathrm{s}^{2}$;

$\rho_{\mathrm{sL}}=$ densidade da polpa, $\mathrm{kg} / \mathrm{m}^{3}$;

$\rho_{\mathrm{g}}=$ densidade da bolha, $\mathrm{kg} / \mathrm{m}^{3}$;

$\mathrm{Re}_{\mathrm{b}}=$ Reynolds do fluxo de bolhas;

$\mu_{\mathrm{sL}}=$ viscosidade da polpa, $\mathrm{kgm}^{-1} \mathrm{~s}^{-1}$.

O número de Reynolds do fluxo de bolhas $\left(R_{b}\right)$ é dado pela equação 3.42 [Dobby et al. (1988); Dobby e Finch (1990); Manqiu Xu e Finch (1988)].

$$
\operatorname{Re}_{\mathrm{b}}=\frac{\mathrm{d}_{\mathrm{b}} \mathrm{U}_{\mathrm{sg}} \rho(1-\Psi)}{\mu}
$$

Os fatores $k_{1}$ e $k_{2}$ são fornecidos pelas equações 3.43 e 3.44 , respectivamente [Dobby et al. (1988); Dobby e Finch (1990); Manqiu Xu e Finch (1988)].

$$
\begin{aligned}
& \mathrm{k}_{1}(1-\Psi)=(1-\Psi)^{1-\mathrm{k}_{2}} \\
& \mathrm{k}_{2}=\left[4,45+18\left(\frac{\mathrm{d}_{\mathrm{B}}}{\mathrm{d}_{\mathrm{c}}}\right)\right] \operatorname{Re}_{\mathrm{b}}^{-0,1} \\
& \mathrm{k}_{2}=4,45 \operatorname{Re}_{\mathrm{b}}^{-0,1}
\end{aligned}
$$

Reportando-se que o número de Reynolds da bolha é obtido da equação 3.10, tomando-se por base as características peculiares do sistema, como o diâmetro da bolha, $d_{P}$, em vez de L. Por sua vez, a velocidade terminal de elevação da bolha $\left(v_{b}\right)$ é calculada usando a equação 3.41 e considerando $\Psi=0$ [Dobby e Finch (1990)].

Se $\Psi$ e Jg são conhecidos, o diâmetro da bolha pode ser estimado. A técnica consiste em substituir um valor de $d_{B}$ na equação 3.41 até $U_{s g}$ dessa equação se igualar à velocidade de deslizamento da equação 3.40 [Dobby e Finch (1990)].

Esta técnica de determinação do diâmetro e velocidade da bolha é geralmente aplicada na flotação em coluna. Se bem que se desprezando $J_{L}$, ela pode ser aplicada para células mecânicas [Dobby e Finch (1990); Manqiu Xu e Finch (1988)].

c) Sólido-líquido e gás: Diversos trabalhos na literatura corrente estudaram as características e correlações da suspensão de sólidos em sistemas trifásicos, como as polpas de flotação. Dentre os estudos, vale ressaltar Bao et al. (2005), Chapman et. al. (1983c), Deglon (2007), Guillard e Trägårdh (2003), Joshi et. al. (1982), Kawase (1997), Khopkar (2005), Kushalkar (1994), Lane (2005), Neale e Pinches 
(1994), Newell e Grano (2006, 2007), Nienow et. al. (1986), Rewatkar e Joshi (1991), Roman e Tudose (1996) e Sun et al. (2006).

Conforme visto anteriormente na seção 3.3.3.b, a introdução de gás em sistemas líquidos e sólido-líquido ocasiona redução da potência aplicada pelo impelidor ao sistema, provocando redução capacidade de circulação da polpa no interior do tanque. Por conseguinte, a velocidade requerida para completa suspensão dos sólidos tenderá a aumentar na presença de gás, mantendo-se as demais condições constantes [Chapman et.al. (1983c); Joshi et al. (1982); Kushalkar et al. (1994), Nienow et al. (1986)].

A introdução de gás no sistema ocasiona o decréscimo na capacidade de bombeamento do impelidor, quando isto ocorre, alguns sólidos são depositados no fundo do tanque, aumentando $\mathrm{N}_{\mathrm{Z}}$, que para sistema trifásico será representado por $\mathrm{N}_{\mathrm{Zg}}$. Desta forma, $\Delta \mathrm{N}_{\mathrm{Z}}\left(=\mathrm{N}_{\mathrm{Zg}}-\mathrm{N}_{\mathrm{Z}}\right)$, é requerido para re-suspender os sólidos, a figura 3.13 apresenta como $\Delta \mathrm{N}_{\mathrm{Z}}$ está relacionado à vazão de gás no tanque [Chapman et.al. (1983c); Joshi et. al. (1982); Kushalkar (1994); Nienow et al. (1986); Rewatkar e Joshi (1991)].

Para desenvolvimento das correlações de $\mathrm{N}_{\mathrm{Zg}}$, dois aspectos devem ser considerados [Chapman et. al. (1983c); Deglon (2007); Oldshue (1983); Zwietering (1958)]:

i. O efeito da vazão de gás (velocidade superficial de gás).

ii. O efeito das outras variáveis, como densidade de sólido e \%sólidos.

De acordo com a figura 3.13, $\mathrm{N}_{\mathrm{Zg}}$ tende a aumentar linearmente com a adição de gás, conduzindo a equação 3.45 [Chapman et. al. (1983c); Deglon (2007); Joshi et. al. (1982); Kushalkar (1994); Nienow et al. (1986); Rewatkar e Joshi (1991)].

$$
N_{\text {ZG }}=N_{Z}+a Q_{V G}
$$

Onde:

$\mathrm{N}_{\mathrm{ZG}}=$ velocidade crítica de suspensão para sistemas aerados;

$\mathrm{N}_{Z}$ = velocidade crítica de suspensão para sistema sólido-líquido;

$a=$ coeficiente linear;

$Q_{\mathrm{GV}}=$ vazão específica de gás $\left(\mathrm{min}^{-1}\right)=J_{\mathrm{G}} / \mathrm{Z}$.

Z = nível da polpa.

Vale ressaltar ainda que " $a$ " é função de outras variáveis, seja geométricas ( $D$, C e T) ou peculiares ao sistema (densidade, percentagem de sólidos, etc) [Chapman 
et. al. (1983c); Deglon (2007); Joshi et. al. (1982); Kushalkar (1994); Nienow et al. (1986); Rewatkar e Joshi (1991)].

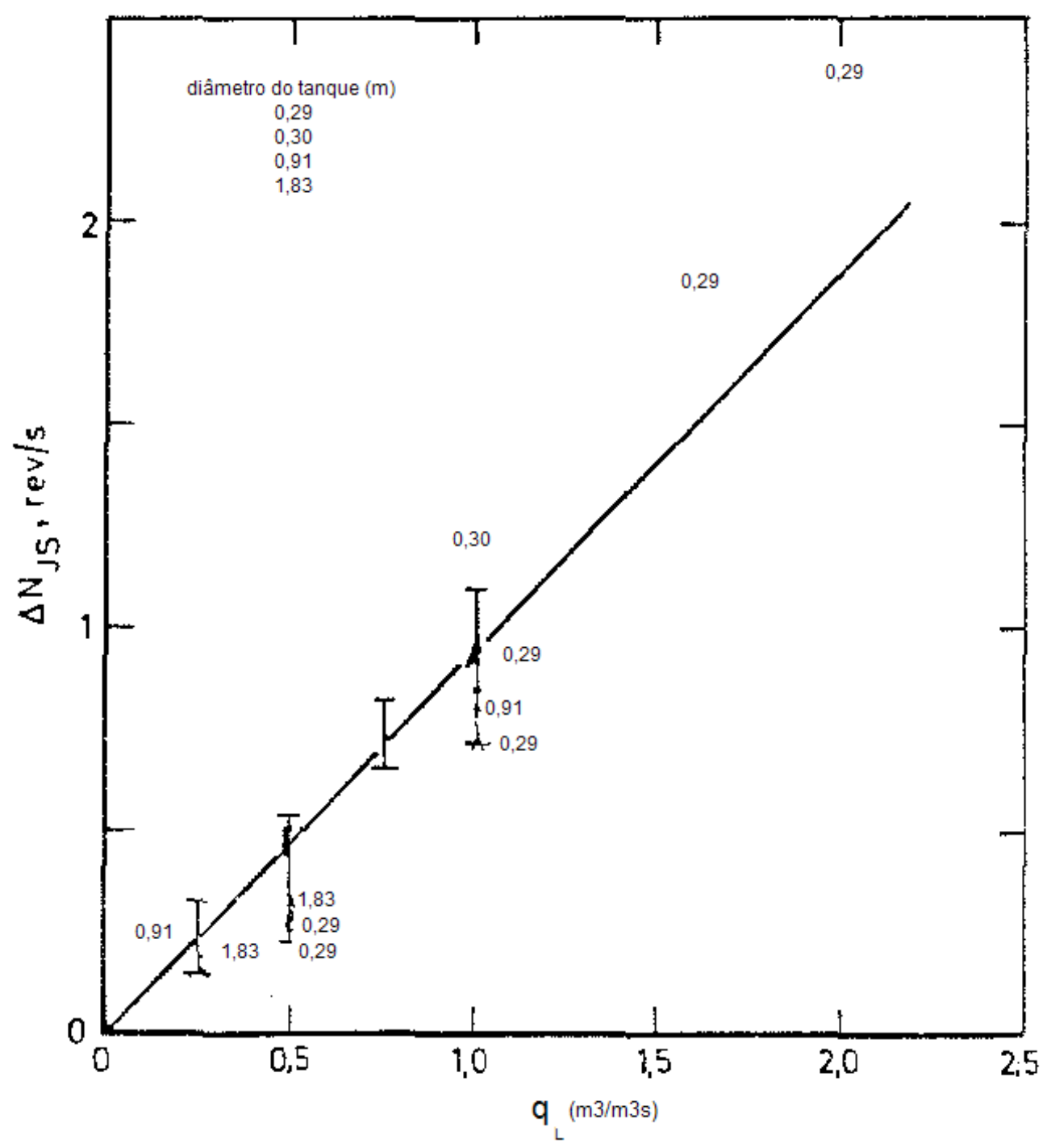

Figura 3.13. Suspensão de sólidos em sistemas aerados para $\mathrm{D}=\mathrm{T} / 2, \mathrm{C}=\mathrm{T} / 4 \mathrm{e}$ turbina de Rushton [Nienow et al. (1986)].

Sumariando, as características da suspensão dos sólidos no interior da célula de flotação dependem principalmente do tamanho das partículas e rotação do impelidor da célula. Lima et.al. (2009) avaliou as contribuições da velocidade terminal das partículas de apatita (com diferentes diâmetros), velocidade do fluido (polpa), mínima velocidade de agitação (critério de Zwitering) e rotação do impelidor numa célula de laboratório Denver, definindo assim, três importantes regiões hidrodinâmicas da polpa de flotação, sob aeração, sistema trifásico - sólido-líquido e gás. 
i. Segregação: rotação do impelidor $60 \%$ da velocidade crítica de suspensão e velocidade de sedimentação $8 \%$ da velocidade do fluido $(U)$, nestas condições as partículas mais grosseiras $\left(d_{p} \cong 254\right.$ $\mu \mathrm{m})$ tendem a permanecer no fundo do tanque, atuando em detrimento à colisão partícula-bolha.

ii. Suspensão: partículas de apatita com diâmetros intermediários entre 180 e $127 \mu \mathrm{m}$, sob as condições hidrodinâmicas $0,60 \leq N / N_{Z} \leq 1$ e $0,06<v_{p s} / U<0,10$, se apresentam distribuídas com significativa uniformidade no interior da célula, possibilitando a colisão entre partículas e bolhas.

iii. Arraste ou "dragging": quando a célula de flotação opera com $\mathrm{N} / \mathrm{N}_{Z} \geq 1$ e $v_{p s} / U \leq 0,03$, as partículas finas $\left(d_{p} \cong 90 \mu \mathrm{m}\right)$ tendem a se concentrar na parte superior do tanque, ficando mais susceptíveis a serem arrastada pelos fluxos ascendentes de líquido para camada de espuma.

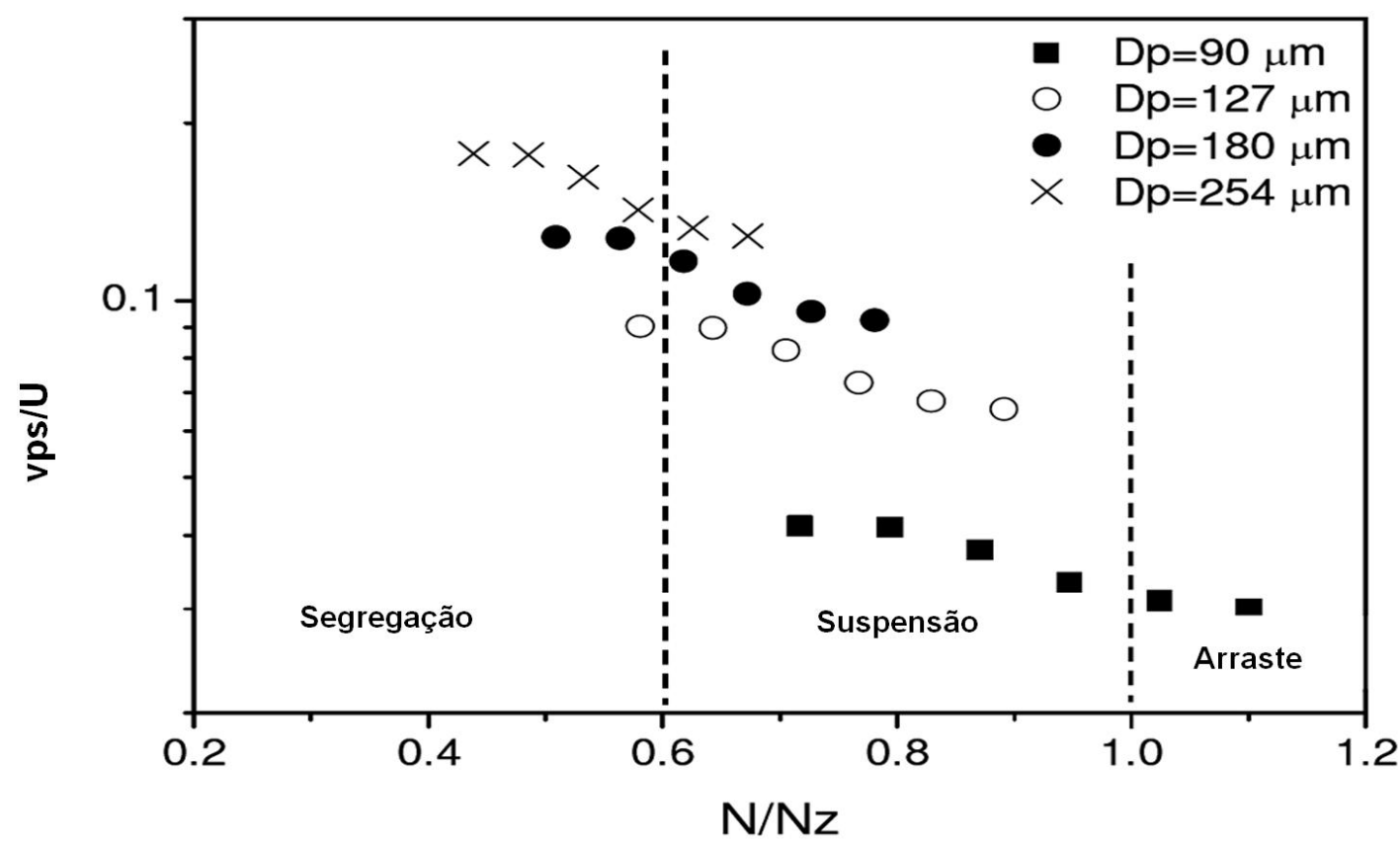

Figura 3.14. Regiões de segregação, suspensão e arraste de partículas de apatita no interior de uma célula de laboratório Denver (Lima et.al., 2009). 


\subsection{Números Hidrodinâmicos das Células Mecânicas de Flotação.}

Os números dinâmicos mais elucidativos para flotação são apresentados na tabela 3.3 [Bird et al. (1960); Brown et al. (1950); Dickey e Fenic (1976); Foust et al. (1982); Giles (1977); Harris (1976); Kelly e Spottiswood (1982); Leja (1982); Perry e Green (1997); Rodrigues et.al. (2001); Schubert e Bischofberger (1978); Schulze (1984); Sissom e Pitts (1988)].

Tabela 3.3. Números hidrodinâmicos utilizados na flotação.

\begin{tabular}{|c|c|c|c|}
\hline NÚMERO & \multicolumn{2}{|c|}{ EQUAÇÃO } & RELAÇÃO ENTRE FORÇAS \\
\hline REYNOLDS & $R e_{I}=D^{2} N \rho_{s L} / \mu_{s l}$ & $(3.46)$ & $\begin{array}{c}\text { Forças de Inércia e as Forças } \\
\text { de Viscosidade. }\end{array}$ \\
\hline FROUDE & $\begin{array}{l}F r_{1}=D^{2} / g \\
F r_{p}=v_{p}^{2} /\left(g d_{p}\right)\end{array}$ & $\begin{array}{l}(3.16) \\
(3.47)\end{array}$ & $\begin{array}{c}\text { Forças de Inércia e as Forças } \\
\text { Gravitacionais. }\end{array}$ \\
\hline POTÊNCIA & $P o=P /\left(N^{3} D^{5} \rho_{s L}\right)$ & $(3.48)$ & $\begin{array}{c}\text { Forças de Arraste do Impelidor } \\
\text { e as Forças de Inércia. }\end{array}$ \\
\hline EULER & $\operatorname{Prd}=\operatorname{Pr} /\left(\mathrm{N}^{2} \mathrm{D}^{2} \rho_{\mathrm{sL}}\right)$ & $(3.49)$ & Pressão e Forças de Inércia. \\
\hline FLUXO DE AR & $N_{Q}=Q_{G} /\left(N D^{3}\right)$ & $(3.50)$ & $\begin{array}{c}\text { Vazão de Ar e Forças de } \\
\text { Inércia. }\end{array}$ \\
\hline WEBER & $W e_{I}=N^{2} D^{3} \rho_{s L} / \gamma$ & $(3.51)$ & $\begin{array}{c}\text { Forças de Inércia e Forças } \\
\text { Capilares. }\end{array}$ \\
\hline BOND & $B o=L^{2} g \rho_{s L} / \gamma$ & (3.52) & $\begin{array}{l}\text { Forças Gravitacionais e Forças } \\
\text { Capilares. }\end{array}$ \\
\hline CAPILAR & Cap $=\mathrm{DN} \mu_{\mathrm{sL}} / \gamma$ & (3.53) & $\begin{array}{c}\text { Forças de Viscosidade e } \\
\text { Forças Capilares. }\end{array}$ \\
\hline
\end{tabular}

Onde:

$D$ = diâmetro do impelidor;

$\mathrm{N}$ = rotação do impelidor;

$\rho_{\mathrm{SL}}=$ densidade da polpa;

$\mu_{\mathrm{sl}}=$ viscosidade da polpa;

$\mathrm{g}$ = aceleração da gravidade;

$\mathrm{P}=$ potência;

$\operatorname{Pr}=$ pressão; 
$Q_{G}=$ vazão de ar ou gás;

$\mathrm{L}=$ dimensão característica da geometria do sistema $(\mathrm{cm})$;

$\gamma=$ tensão superficial.

Para sistemas bifásicos (ar/líquido ou líquido/líquido), é válido o diagrama mostrado na figura 3.15, que por sua vez relaciona o Número de Weber com o Número de Bond, isto é, parâmetros que confrontam os fenômenos interfaciais com grandezas "bulk" [Leja (1982)].

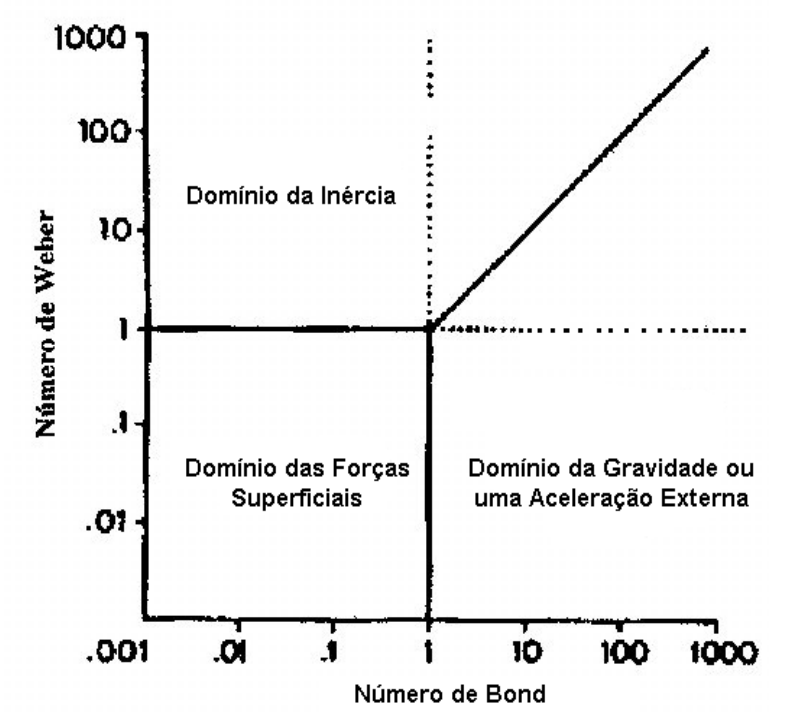

Figura 3.15. Diagrama dos domínios hidrodinâmico [Leja (1982)].

É possível verificar no diagrama que as forças capilares somente serão predominantes para sistemas onde $\mathrm{We}<1$ e $\mathrm{Bo}<1$. Para sistemas envolvendo ar/líqüido (bolhas), sempre que Bo>1, o contorno das bolhas apresentará desvio da esfericidade (característica de sistemas onde predominam as forças de superfície ou capilares), apresentando assim contorno elipsoidal (característico de sistemas onde predominam as forças gravitacionais) [Leja (1982)].

A ausência de deformação nas bolhas permite a flotação de partículas com ângulo de contato mesmo nulo. Tal possibilidade é verificada na prática em sistemas de tratamento de água que utilizam flotação por ar dissolvido. Nesse caso, partículas hidrofílicas flotam perfeitamente [Edzwald (1995)].

Uma vez que o Número de Capilar (Cap) relaciona forças viscosas com tensão interfacial, é evidente que a viscosidade da polpa desempenha um papel relevante nas separações de minerais por flotação. Este fato é amplamente aceito, em virtude de que existe sempre uma faixa ótima de densidade de polpa para se executar a flotação [Leja (1982)]. 
O conhecimento das forças que atuam no sistema de flotação, oriundas da agitação, é de grande valia ao bom entendimento do processo. Uma vez que a hidrodinâmica possui um importante papel na execução deste processo de concentração.

\subsection{Características Geométricas e Mecânicas das Células de Flotação.}

Após o pré - tratamento da superfície das partículas, a máquina de flotação deve proporcionar condições hidrodinâmicas e mecânicas favoráveis para uma separação efetiva de um ou mais minerais. À parte das exigências para entrada de alimentação e saída dos materiais das células ou bancos, e para remoção hidráulica ou mecânica da espuma, os equipamentos devem executar também as seguintes funções [Guimarães (1995); Harris (1976); Poling (1980); Schubert e Bischofberger (1978); Van der Westhuizen e Deglon (2007); Weiss (1985)]:

i. Eficaz suspensão e dispersão das partículas, ambas para impedir a sedimentação e permitir o contato das partículas com as bolhas de ar;

ii. Aeração, formação e dispersão da bolha;

iii. Condições favoráveis para o contato partícula-bolha e adesão;

iv. Fazer com que as partículas coletadas pela bolha caminhem rumo à camada de espuma;

v. Evitar turbulência da polpa próximo da camada de espuma;

vi. Controlar o nível da interface polpa - espuma.

O aparato de flotação é instalado dentro de uma célula e consiste num impelidor (suspenso por um eixo conectado a um sistema de acionamento mecânico, fora e acima da célula) envolvido por uma capa denominada estator, que possui a função de inibir o movimento rotacional da polpa na célula e promover a dispersão do ar, conforme a figura 3.16. Como nas bombas centrífugas, o giro do impelidor faz com que a polpa seja deslocada na direção do topo do tanque, atingindo determinada altura a partir da qual a polpa experimenta um movimento descendente, quando é novamente sugada e direcionada para o topo [Chaves e Leal Filho(1998); Fallenius (1987); Harris (1987), Gorain (2007)]. 


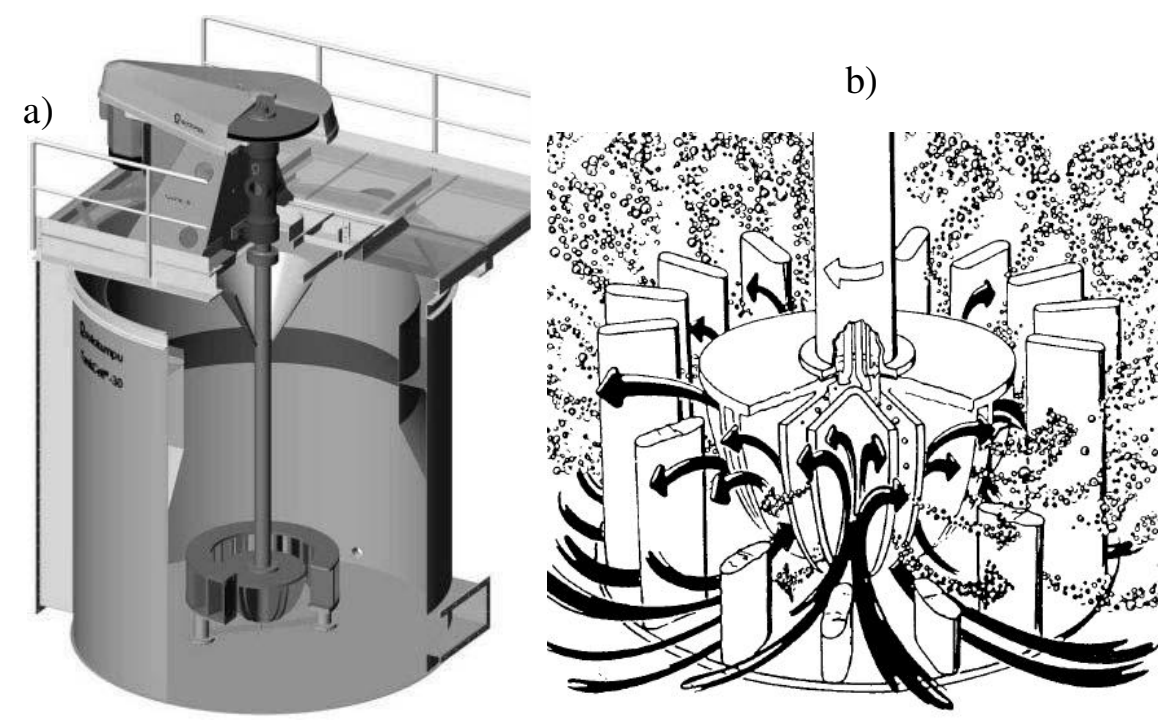

Figura 3.16. Esquema da célula mecânica de flotação [Gorain (2007)].

O movimento rotacional do impelidor gera uma região de pressão negativa dentro do equipamento, isto é suficiente para aspirar o ar necessário a flotação, daí a conveniência de um tubo coaxial com o eixo do impelidor. Todavia, existem modelos cuja aeração é forçada, isto é, ar comprimido é injetado no sistema [Chaves e Leal Filho (1998); Fallenius (1987); Harris (1987)].

As células mecânicas de flotação têm evoluído no sentido de aumentar sua capacidade, o volume máximo da célula de flotação, que era em torno de $2,8 \mathrm{~m}^{3} \mathrm{em}$ 1960, passou para aproximadamente $56 \mathrm{~m}^{3}$ em 1980. Arbiter (1999) refere que nas últimas décadas houve um considerável aumento no volume das células de flotação, devido à necessidade de maiores produções e "lay out". Este aumento é o resultado do maior conhecimento de fatores hidrodinâmicos e como eles auxiliam na eficiência do processo [Arbiter (1999); Nelson e Lelinski (2000)].

No começo dos anos 90, a Outokumpu Mintec desenvolveu o TankCell, cuja célula de flotação considerava fatores como geometria do tanque e impelidor, bem como a capacidade de manuseio e remoção da espuma, além dos subprocessos que ocorrem na polpa (adição de ar e movimento da polpa). Com capacidades superiores até $160 \mathrm{~m}^{3}$, o TankCell é essencialmente uma célula cilíndrica com fundo chato, conforme a figura 3.16a, ele é dotado de um impelidor semi-esférico (figura 3.16b) capaz de fornecer um significativo nível de mistura da polpa e dispersão do ar, cita-se também o fato de seu estator estar montado no fundo do tanque. $O$ TankCell apresenta uma flotação efetiva para todos os tamanhos de partícula, em função de suas configurações geométricas: célula, impelidor e estator, que permitem 
um ambiente hidrodinâmico otimizado, com diminuição da energia dissipada pelo impelidor, todavia, sem perder a capacidade de suspensão dos sólidos (Gorain (2007); Jonaitis (1999)].

Apesar das diferenças de projeto seu comportamento hidrodinâmico apresenta notável similaridade, isto é, as formas variadas de células operam em faixas muito estreitas de parâmetros, conforme apresentados na tabela 3.4. Além disso, os números adimensionais usados na flotação, com seus intervalos de variação, são mostrados na tabela 3.5 [Harris $(1976,1987)$ ].

Tabela 3.4. Características de projeto de máquinas de flotação [Arbiter (1999); Deglon et al. (2000); Fallenius (1987); Harris (1976, 1987); Nelson e Lelinski (2000)].

\begin{tabular}{|c|c|c|}
\hline CARACTERÍSTICAS & DIMENSIONAMENTO & FAIXA DE APLICAÇÃO \\
\hline \multirow{2}{*}{$\begin{array}{l}\text { Geometria do tanque } \\
\mathrm{V}=\mathrm{LWH}_{\mathrm{n}} \text { (nível da } \\
\text { polpa) }\end{array}$} & $\begin{array}{c}\text { Volume versus nível da } \\
\text { polpa }\end{array}$ & $\mathrm{n} \sim 2,6-2,9$ \\
\hline & $\begin{array}{l}\mathrm{H} / \mathrm{L} \text {, diminui com o } \\
\text { tamanho da máquina, }\end{array}$ & $\sim 0,4-1$ \\
\hline \multirow{2}{*}{$\begin{array}{l}\text { Geometria do } \\
\text { impelidor }\end{array}$} & $\begin{array}{c}\text { Altura do } \\
\text { estator/diâmetro do } \\
\text { impelidor }\end{array}$ & $\begin{array}{c}\sim 0,1-1,1: \text { Denver } \sim 0,15 \\
\text { Wemco } 1,1\end{array}$ \\
\hline & $\begin{array}{c}\text { Diâmetros do } \\
\text { impelidor/tanque, D/T }\end{array}$ & $\begin{array}{c}\sim 0,25-0,50 \text { (decresce } \\
\text { ligeiramente em scale-up) }\end{array}$ \\
\hline \multirow{2}{*}{$\begin{array}{c}\text { Aeração e espuma } \\
\text { Área de interface } \\
\text { polpa/espuma, A = TW }\end{array}$} & Ar "hold-up" (por volume) & $\begin{array}{l}\text { Média da célula, } 10-15 \% \\
\text { Na zona do impelidor } \sim 50 \% \\
\text { Na coluna de espuma } \sim 90 \%\end{array}$ \\
\hline & Diâmetro da bolha & $\begin{array}{c}\sim 0,5 \mathrm{~mm} \text {, determinado pela } \\
\text { concentração de surfatantes } \\
\text { na espuma }\end{array}$ \\
\hline \multirow{2}{*}{ Velocidade } & $\begin{array}{l}\text { Velocidade Periférica do } \\
\text { Impelidor }\end{array}$ & $\sim 6$ a $9 \mathrm{~m} / \mathrm{s}$ \\
\hline & $\begin{array}{l}\text { Velocidade superficial do } \\
\qquad \operatorname{ar}(\mathrm{m} / \mathrm{s})\end{array}$ & $\begin{array}{l}\sim 0,7.10^{-2} \text { a } 4.10^{-2} \text { (média } \\
\sim 1,5.10^{-2} \text { a } 3 \cdot 10^{-2} \text { ) }\end{array}$ \\
\hline \multirow{2}{*}{$\begin{array}{l}\text { Produtividade } \\
\text { operacional }\end{array}$} & Capacidade específica & $\begin{array}{c}\sim 25 \text { a } 65 \text { t/dia por } \mathrm{m}^{3} \text { de célula } \\
\text { (sólidos secos) }\end{array}$ \\
\hline & Tamanho de partículas & $10-250 \mu \mathrm{m}$ (média-74 $\mu \mathrm{m})$ \\
\hline Potência & $\begin{array}{c}\text { Potência específica - } \\
\text { decresce com o scale-up }\end{array}$ & $\begin{array}{c}\sim 1,3-5,3 \mathrm{~kW} / \mathrm{m}^{3} \text { de volume } \\
\text { da célula }\end{array}$ \\
\hline
\end{tabular}


Tabela 3.5. Números adimensionais em máquinas de flotação [Arbiter (1999); Deglon et al. (2000); Fallenius (1987); Harris (1976, 1987); Nelson e Lelinski (2000)].

\begin{tabular}{|c|c|}
\hline NÚMERO ADIMENSIONAL & INTERVALOS DE VARIAÇÃO \\
\hline Reynolds & $\sim 10^{5}\left(^{\star}\right)$ a $10^{6}\left(^{\star *}\right)$. \\
\hline Potência & $\sim 0,8$ a 5 depende da geometria impelidor/estator: \\
& $\sim 0,8$ a $1\left(^{+}\right)$ \\
& $\sim 4(++)$ \\
\hline Euler ou Pressão & $\sim 0,5$ a $2,0\left(^{*}\right)$ \\
\hline Froude & $\sim 5\left(^{*}\right)$ \\
& $\sim 0,3$ a $2\left(^{* *}\right)$ \\
\hline Fluxo de Ar & $\sim 1$ a $2.10^{-2}(+)$ \\
& $\sim 4$ a $7.10^{-2}(++)$ \\
\hline
\end{tabular}

$\left(^{*}\right)$ Laboratório

$\left.{ }^{* *}\right)$ Industrial
(+) Denver

$(++)$ Fagergren

Nas células de flotação as bolhas são formadas pelo desprendimento dos vórtices das cavidades de ar atadas ao rastro das extremidades de cada pá do impelidor (região de baixa pressão), tal fato se deve pela turbulência. O fluxo de ar é interrompido pela formação de uma região de alta pressão que por sua vez é seguida por outra de baixa pressão, continuamente; deste modo, a velocidade de rotação do impelidor assume um papel preponderante [Harris $(1976,1987)$; Weiss (1985)].

$\mathrm{Na}$ flotação a velocidade rotacional e, portanto, a intensidade da turbulência, tem forte influência na recuperação e no teor de concentrado de uma única célula ou do banco de células. O processo de funcionamento de uma célula mecânica pode ser considerado como de uma bomba centrífuga, pois, além de bombear a polpa, ele dispersa o ar (sugado ou alimentado, na forma de bolhas finas); conservando os sólidos em suspensão e distribui as bolhas no tanque [Fallenius (1987)].

As máquinas de flotação que operam em escala industrial trabalham em escoamento altamente turbulento $\left(10^{6}<\mathrm{Re}_{1}<7.10^{7}\right)$, obviamente tal estimativa é referente ao Reynolds do impelidor. Para este autor, três efeitos de turbulência são de fundamental importância para o processo [Schubert $(1985,1999)]$ :

i. O fenômeno de transporte turbulento de sólidos em fluxos ascendentes e descendentes dentro da célula. Tal turbulência se 
manifesta em macro escala, sendo chamada de macroturbulência, porque se refere ao movimento do impelidor;

ii. A dispersão turbulenta de ar, partículas e agregados partícula-bolha. Sua causa é a macroturbulência gerada pelo movimento do impelidor, porém, seu efeito é observado em micro escala, isto é, através da quantidade de movimento transferida por mecanismos de micro turbulência às bolhas, partícula e agregados;

iii. A colisão turbulenta partícula - bolha.

A micro-turbulência (relacionada ao movimento de bolhas e partículas) controla os dois últimos efeitos, os quais dependem somente da taxa de dissipação da energia do impelidor $\left(\varepsilon_{\mathrm{d}}\right)$ e da viscosidade cinemática da polpa $\left(v_{\mathrm{sL}}\right)$. A taxa de dissipação de energia pode ser calculada pela equação 3.54 [Schubert (1978, 1985, 1999); Schulze (1984)].

$$
\begin{aligned}
& \varepsilon_{d}=\frac{P}{M} \\
& \varepsilon_{d}=\frac{P}{V}
\end{aligned}
$$

Onde:

$$
\begin{aligned}
& \varepsilon_{d}=\text { taxa de dissipação de energia do impelidor; } \\
& P=\text { potência do impelidor; } \\
& M=\text { massa da água presente na célula; } \\
& V=\text { volume de água. }
\end{aligned}
$$

Schubert $(1978,1985,1999)$ propôs a expressão 3.55 para se calcular a velocidade turbulenta relativa, ou simplesmente velocidade média, de uma espécie (seja partícula ou bolha) ao entrar em contato com a turbulência causada pelo impelidor.

$$
\sqrt{\overline{\mathrm{v}_{\mathrm{i}}{ }^{12}}}=0,33 \frac{\varepsilon_{\mathrm{d}}{ }^{4 / 9} \mathrm{~d}_{\mathrm{i}}{ }^{7 / 9}}{\mathrm{v}_{\mathrm{sL}}^{1 / 3}}\left(\frac{\Delta \rho}{\rho_{\mathrm{sL}}}\right)^{2 / 3}
$$

Onde:

$$
\begin{aligned}
& \sqrt{\overline{\mathrm{v}_{\mathrm{i}}{ }^{\prime 2}}}=\text { velocidade turbulenta relativa da espécie }(\mathrm{m} / \mathrm{s}) ; \\
& \varepsilon_{\mathrm{d}}=\text { taxa de dissipação de energia do impelidor }(\mathrm{W} / \mathrm{kg}) ; \\
& d_{\mathrm{i}}=\text { diâmetro da espécie (partícula ou bolha) }(\mathrm{m}) ; \\
& \Delta \rho=\text { diferença entre a densidade do sólido e da polpa }\left(\mathrm{kg} / \mathrm{m}^{3}\right)
\end{aligned}
$$




$$
\begin{aligned}
& \rho_{\mathrm{SL}}=\text { densidade da polpa }\left(\mathrm{kg} / \mathrm{m}^{3}\right) \\
& v_{\mathrm{SL}}=\text { viscosidade cinemática da polpa }\left(\mathrm{m}^{2} / \mathrm{s}\right) .
\end{aligned}
$$

Para ótima flotação de grossos, a potência consumida deve ser minimizada, desta forma, há a geração de bolhas maiores e a estabilidade dos conjuntos partícula-bolha cresce. Além disso, as forças turbulentas agindo nestes aglomerados são diminuídas, este fato explica a boa recuperação das partículas grossas em rotações não tão altas [Schubert $(1978,1985,1999)]$.

Por sua vez, para sólidos finos e muito finos, o número de colisões requerido é bem maior que das intermediárias e grossas. Deste modo, a potência consumida na flotação de finos e muito finos é superior aquela aplicada nas partículas intermediárias e grossas [Schubert (1978,1985, 1999)].

A figura 3.17 apresenta a energia dissipada pelo impelidor para diferentes células industriais de diversos volumes, evidenciando o crescimento da energia dissipada em células menores, que por sua vez, propiciam um ambiente hidrodinâmico prejudicial à flotação de partículas grossas. Por outro lado, o aumento do volume das células nos últimos anos proporcionou um melhor desempenho da flotação de grossos [Arbiter (1999)].

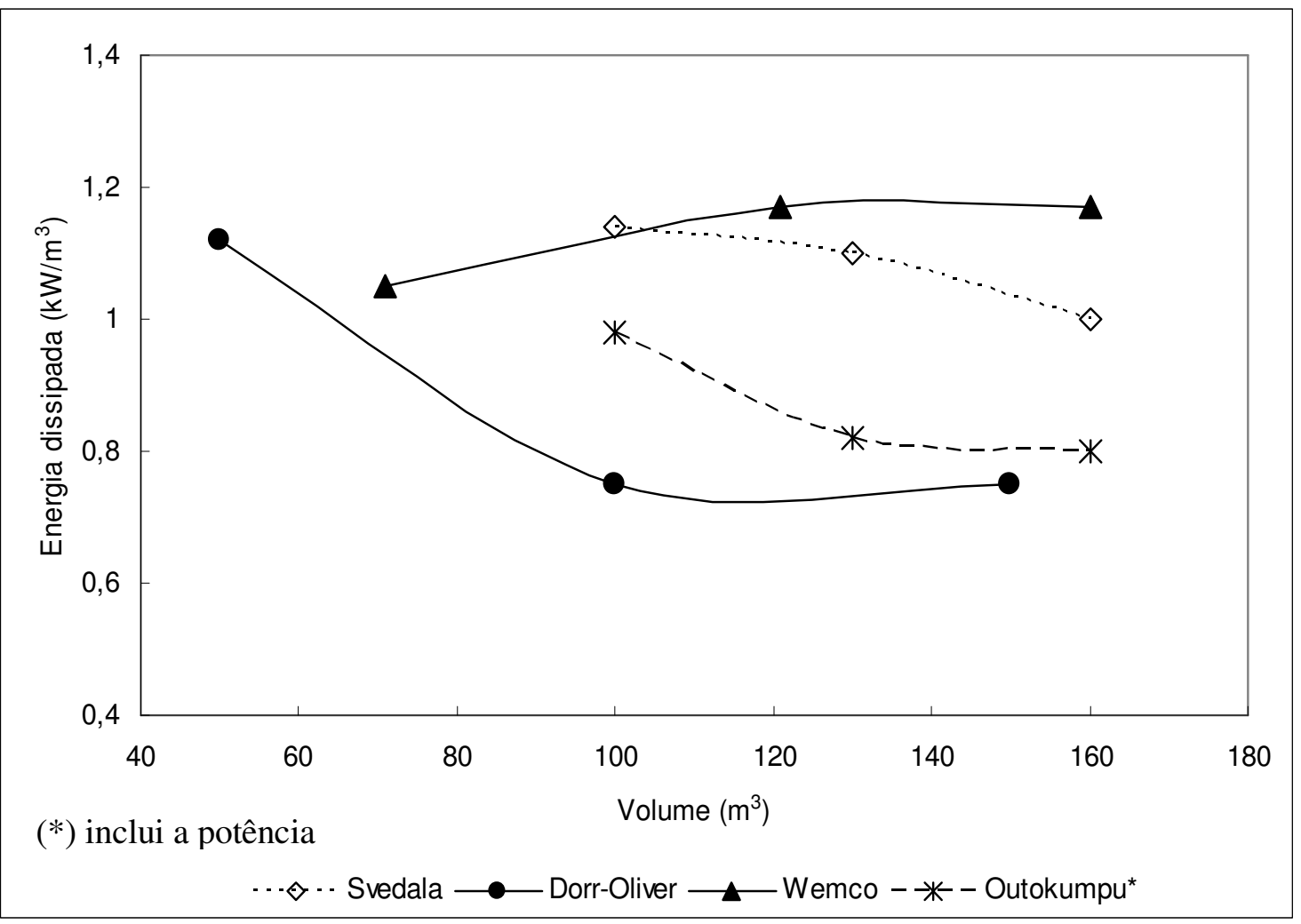

Figura 3.17. Energia dissipada em células industriais de flotação [Arbiter (1999)]. 
Na célula de flotação, os fluxos turbulentos e laminares são subseqüentes e simultâneos. Assim, a turbulência é maior na menor distância do dispositivo gerador de quantidade de movimento, sistema impelidor-estator. Por conseguinte, as considerações podem ser feitas [Schulze (1984)]:

i. Acima de um número de Reynolds crítico, as tensões de cisalhamento, oriundas de fluxo laminar, são desprezíveis, quando comparadas com as do fluxo turbulento, ou seja, as características do escoamento independem do número de Reynolds.

ii. A turbulência é considerada isotrópica, ou seja, ela é a mesma em qualquer direção que for medida.

O estudo do movimento das bolhas dentro da célula de flotação deve também considerar o efeito de tal turbulência. Em vista disto, certamente um dos parâmetros de suma importância é o diâmetro da bolha, que por sua vez tem um profundo efeito na recuperação da flotação. Portanto, a estimativa do diâmetro da bolha, seja por métodos visuais ou matemáticos, é fundamental ao processo.

Conforme mencionado, a suspensão de sólidos é um pré-requisito fundamental para flotação. A literatura técnica corrente, desde a década de 60, enfatiza os mecanismos para colocar os sólidos em suspensão nas células mecânicas de flotação, valendo ressaltar os fatores que alteram a velocidade crítica de suspensão (Ng) [Arbiter (1999); Chaves e Leal Filho (1998); Deglon et al. (2000); Fallenius (1987); Harris (1976, 1987); Nelson e Lelinski (2000); Poling (1980); Schubert (1978, 1985, 1999); Weiss (1985)]:

i. Nas células mecânicas, a influência das características das partículas sobre a velocidade crítica de suspensão é bem mais significativa em comparação aos vasos mecanicamente agitados. Isto pode ser atribuído à proximidade entre estator e o impelidor, que provoca uma diminuição no fluxo de fluído em favorecimento ao aumento da turbulência na região vizinha ao impelidor, provocando maior cisalhamento para geração de bolhas menores. A otimização das condições hidrodinâmicas dos sistemas, velocidade crítica de suspensão e aeração, proporcionam regiões boa flotabilidade, em função da energia dissipada pelo impelidor, conforme a figura 3.18 [Harris (1976, 1987); Mavros (1992); Schubert (1985, 1999); Van der Westhuizen e Deglon (2007)]. 


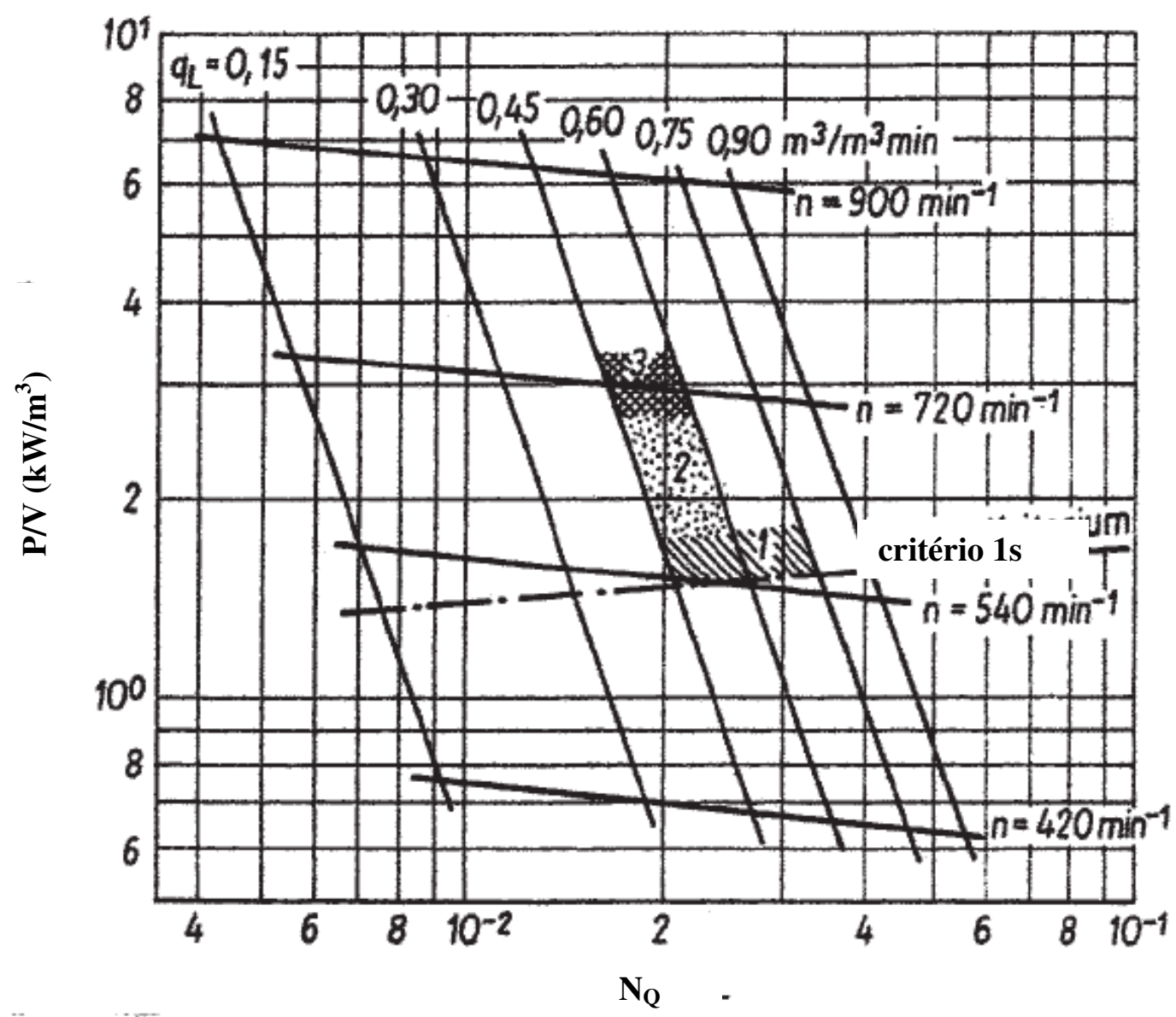

Figura 3.18. Energia dissipada (P/V) em função do número de fluxo de ar $\left(\mathrm{N}_{\mathrm{Q}}\right)$, indicando as condições ótimas de flotação e as velocidades críticas de suspensão [Schubert (1978, 1985, 1999)].

ii. A introdução de gás nas células mecânicas de flotação também causa aumento, de maneira linear, à velocidade crítica de suspensão, em virtude da redução da potência transferida pelo impelidor à polpa [Chapman et al. (1983c); Duttar e Pangarkar (1995); Joshi et al. (1982); Kawase et al. (1997); Kushalkar e Pangarkar (1994); Nienow et al. (1986); Rewatkar e Joshi (1991a); Rewatkar e Joshi (1991b); Roman e Tudose (1996); Van der Westhuizen e Deglon (2007)].

iii. Em termos de scale-up, Schubert $(1978,1985)$ demonstrou que tanto $\mathrm{N}_{\mathrm{Z}}$ como a energia dissipada diminuem em função do aumento de volume do tanque. 


\subsection{Processo de coleta da partícula pela bolha}

Segundo Dobby e Finch (1990), para ocorrer a coleta de uma partícula por uma bolha na flotação, deve haver um dos três processos:

i. Colisão partícula-bolha seguida pela adesão, desde que a superfície do corpo esteja completamente hidrofóbica;

ii. Carreamento da partícula dentro da camada limite e trajetória da bolha;

iii. Precipitação das bolhas de ar em superfícies hidrofóbicas.

Considerando-se, numa célula de flotação, bolhas de gás atravessando uma coluna de água com partículas hidrofóbicas em uma concentração $c_{p}$ (número de partículas por unidade de volume); a eficiência de coleta $\left(E_{k}\right)$ é definida como a fração de partículas capturadas pela bolha (após a colisão e adesão), que conseguiram permanecer aderidas à bolha. Portanto, a expressão abaixo descreve a coleta de partículas [Dobby e Finch (1990)].

taxa de partícula coletada = taxa de partícula coletada por bolha $X$ número de bolhas

A eficiência de colisão $\left(E_{c}\right)$ é a fração de todas as partículas contidas por uma área de influência projetada na bolha, capazes de colidirem com a mesma. Subseqüentemente ao colidir com a bolha, a partícula se deslocará ao longo da superfície da mesma, com um movimento de deslizamento ou de repique. O corpo deslizante mantém o contato com a bolha até ser carreado radialmente, pelas linhas de corrente do escoamento da polpa, para longe da superfície da bolha; exceto quando ocorrer a adesão da partícula [Dobby e Finch (1990)].

A eficiência de adesão é a fração do total das partículas que colidiram com a bolha e obtiveram sucesso na adesão durante o tempo de contato. As forças superficiais de atração comprimem o filme líquido entre a partícula e a bolha, conduzindo-o a uma espessura crítica, na qual ocorre o seu rompimento; havendo então a formação da linha de contato entre estas três fases, sólido, ar e líquido [Dobby e Finch (1990); Fuerstenau (1982); Pike, et. al. (2003); Ralston et. al. (1999a); Ralston et. al. (1999b); Schulze (1984); Yoon (2000)].

Uma baixa recuperação de partículas grossas pode estar associada ao rompimento do agregado partícula-bolha, devido a grande turbulência. Jordan e 
Spears (1989) estudaram os efeitos desta turbulência na flotação de partículas finas; Schulze (1977) analisou o mecanismo de ruptura do agregado com uma visão para determinação do limite superior de flotabilidade das partículas; Jowet (1980) desenvolveu uma estimativa do tamanho crítico para o rompimento do agregado baseado nas velocidades translacionais das zonas de turbulência em células mecânicas de flotação, ele encontrou um tamanho crítico de partícula entre $100 \mu \mathrm{m}$ $\left(\rho_{p}=7,5 \mathrm{~g} / \mathrm{cm}^{3}\right)$ e $200 \mu \mathrm{m}\left(\rho_{p}=4,2 \mathrm{~g} / \mathrm{cm}^{3}\right)$ para um ângulo de contato de $60^{\circ}$, abaixo deste tamanho crítico, o desligamento poderia ser mínimo.

A partícula pode ser arrancada da superfície da bolha somente quando a energia cinética fornecida for igual ou maior que a energia de preservação do agregado. A eficiência de coleta da partícula por uma bolha é definida pela equação 3.56 [Pike et. al. (2003); Ralston et. al. (1999a); Yoon (2000)].

$$
E_{k}=E_{c} \cdot E_{a} \cdot E_{s}
$$

Onde:

$$
\begin{aligned}
& E_{k}=\text { eficiência de coleta; } \\
& E_{c}=\text { eficiência de colisão; } \\
& E_{a}=\text { eficiência de adesão; } \\
& E_{s}=\text { eficiência de estabilidade do agregado partícula-bolha. }
\end{aligned}
$$

Nas células de flotação, o contato partícula-bolha pode ser ilustrado pela figura 3.19, onde é possível observar três camadas de líquido ou zonas que contornam as bolhas [Ralston et. al. (1999a); Schulze (1984)].

Zona 1. é a região de atuação das forças hidrodinâmicas, corresponde à porção mais externa do fluido que circunda a bolha;

Zona 2. há ação de forças difusioforéticas. As forças que agem nessa zona resultam do gradiente de concentração de íons, causado pelo transporte de íons surfactantes originário do movimento na superfície da bolha. Entretanto, a evidência comprovando a presença ou ausência de difusioforese na flotação é equivocada e dispersa;

Zona 3. é a região onde ocorre a interação entre partículas e bolhas. $\mathrm{Na}$ qual, as forças superficiais (interações eletrostáticas, Van Der Waals e interações estruturais) predominam, uma vez que o filme delgado entre a bolha e a partícula está abaixo de 150 nm. A 
grandeza dessas forças pode acelerar, retardar ou mesmo evitar o adelgaçamento do filme líquido entre a partícula e a bolha.

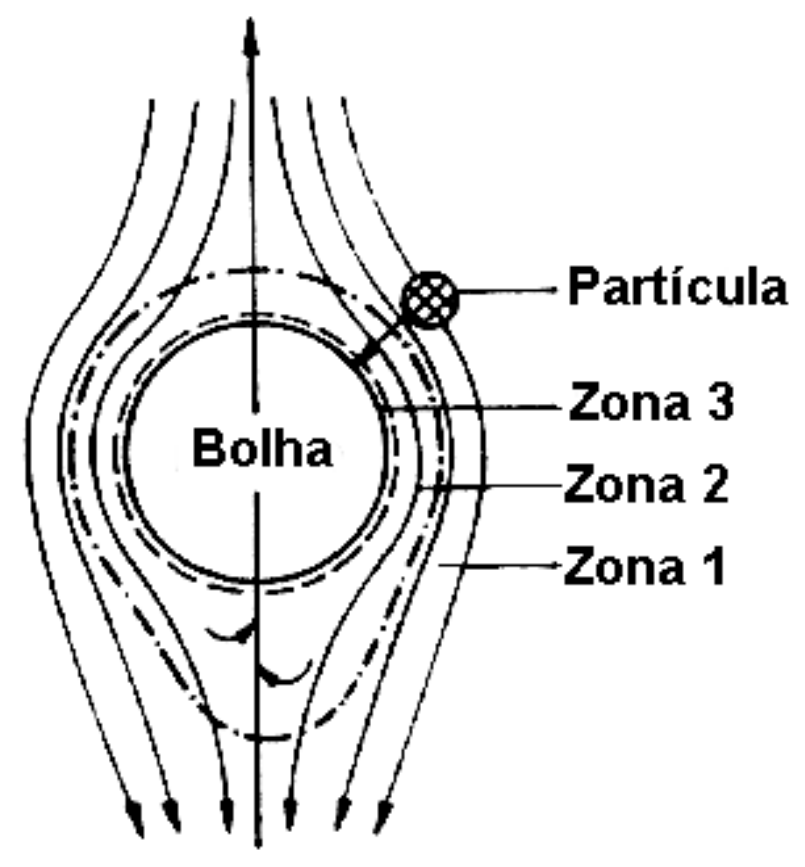

Figura 3.19. Zonas que atuam no processo de captura de partículas pela bolha [Ralston et. al. (1999a)].

\subsubsection{Colisão partícula - bolha.}

A ocorrência de colisões entre partículas hidrofóbicas e bolhas de ar está condicionada à atuação de alguns fatores que podem ser favorecidos pela oferta de bolhas (aeração), partículas hidrofóbicas (porcentagem de sólidos na polpa) e tempo de permanência da polpa na célula de flotação. Baseando-se nos estudos da equação de movimento de uma partícula esférica em relação a uma bolha ascendente na polpa (com mesma forma geométrica e muito maior que a partícula), observa-se que a resistência hidrodinâmica do meio tenderá a arrastar a partícula em torno da bolha, seguindo a direção do escoamento. A inércia da partícula e a gravidade agem de modo combinado, a fim de retirar o sólido das linhas de fluxo da polpa e conduzi-lo à superfície da bolha [Ahmed e Jameson (1989); Dai et. al. 
(2000); Dobby e Finch (1990); Pike et. al. (2003); Ralston et. al. (1999b); Schulze (1984, 1989); Sutherland (1948); Yoon (1989, 2000)].

Schulze (1989) define vários efeitos de colisão que afetam a trajetória da partícula:

i. Aproximação entre as partículas e as bolhas, sem nenhuma mudança de magnitude e direção da velocidade do sólido - colisão ideal.

ii. As partículas seguem as linhas de corrente da bolha sem nenhuma mudança de direção - efeito de intercepção.

iii. Forças inerciais da partícula contribuem mais para o aumento de colisões do que propriamente o efeito de intercepção - efeito inercial;

iv. Forças gravitacionais levam, de certo modo, ao aumento de colisões - efeito gravitacional.

v. A colisão na região turbulenta atrás da bolha.

vi. Colisão causada pelo movimento difuso ou turbulento da partícula efeito da difusão.

vii. Retenção de partículas por uma "nuvem de bolhas", a qual ocorre em interstícios entre as bolhas, menores que os sólidos, é o efeito nuvem.

Segundo Ahmed e Jameson (1989) para que uma bolha colida com a partícula, a última deve ter quantidade de movimento suficiente para resistir à inércia de seguir as linhas de corrente em torno da bolha. Um tubo de colisão de raio $\mathfrak{R}$ pode ser definido, de tal modo que todas as partículas (raio $=r_{P}$ ) em seu interior sejam capturadas, sua relação com o raio da bolha, $r_{b}$ é expressa pela equação 3.57 .

$$
\frac{\Re}{r_{b}}=\left(\frac{3 r_{p}}{r_{b}}\right)^{1 / 2}
$$

Sutherland (1948) define como eficiência de coleta a razão da área do tubo de colisão $\left(\pi \Re^{2}\right)$ pela área projetada da bolha $\left(\pi r_{b}{ }^{2}\right)$, segundo a expressão 3.58 .

$$
\mathrm{E}_{\mathrm{c}_{\text {Suluerand }}}=\frac{\mathfrak{R}^{2}}{\mathrm{r}_{\mathrm{b}}^{2}}=\frac{3 \mathrm{r}_{\mathrm{p}}}{\mathrm{r}_{\mathrm{b}}}
$$

$\mathrm{Na}$ literatura técnica corrente são freqüentes as expressões de $E_{c}$ baseadas 
nos modelos de colisão por interceptação, que podem ser utilizados para condições de flotação relativamente tranqüilas, como é o caso das colunas. No entanto para células mecanicamente agitadas, os modelos turbulentos podem ser mais apropriados. Baseado no modelo de colisão de Abrahamson (1975), Schubert (1979) usou a expressão 3.59 para descrever o número de colisões partículas-bolhas por unidade volumétrica de polpa e tempo.

$$
\aleph_{p b}=5 c_{p} c_{b}\left(\frac{d_{p}+d_{b}}{2}\right)^{2} \sqrt{\overline{v_{p}^{2}}+\overline{v_{b}^{2}}}
$$

Onde:

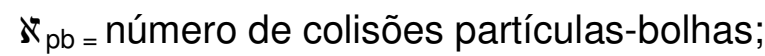

$\mathrm{c}_{p}=$ número de partículas por unidade de volume;

$\mathrm{C}_{\mathrm{b}}=$ número de bolhas por unidade de volume;

$\mathrm{d}_{\mathrm{p}}=$ diâmetro de partícula;

$\mathrm{d}_{\mathrm{b}}=$ diâmetro de bolha;

$\mathrm{v}_{\mathrm{p}}=$ velocidade relativa média da partícula, definida pela equação 3.55;

$\mathrm{v}_{\mathrm{b}}=$ velocidade relativa média da bolha, definida pela equação 3.55;

\subsubsection{Adesão partícula - bolha.}

Assim que uma partícula colide com a bolha, ela começa a deslizar sobre a camada de fluido na região correspondente à zona 3 da figura 3.19 por um tempo finito, denominado de tempo de contato. A magnitude deste tempo de contato é determinada pela velocidade com que o líquido arrasta o sólido ao longo da superfície da bolha. Deste modo, quanto maior for o percurso da partícula, maior será o tempo de contato [Schulze $(1984,1989)]$.

Durante o tempo de contato, o filme de interseção da água deve ser adelgaçado e rompido, se a partícula está sendo aderida à bolha e, eventualmente, coletada na camada de espuma. A adesão partícula-bolha ocorre quando o tempo de contato é maior que o tempo de indução, que por sua vez é definido como o período requerido para o processo de adelgaçamento, rompimento do filme e 
formação da linha de contato entre as três fases (sólido, líquido e gasoso) [Dobby e Finch (1987, 1990); Finch e Smith (1975); Schulze (1984); Yoon e Luttrell (1989)].

Dobby e Finch (1990) relacionaram $E_{A}$ com o diâmetro de partículas que possuem o mesmo tempo de indução, plotando a eficiência de adesão, $E_{A}$, versus o tempo de indução, conforme apresentado na figura 3.20.

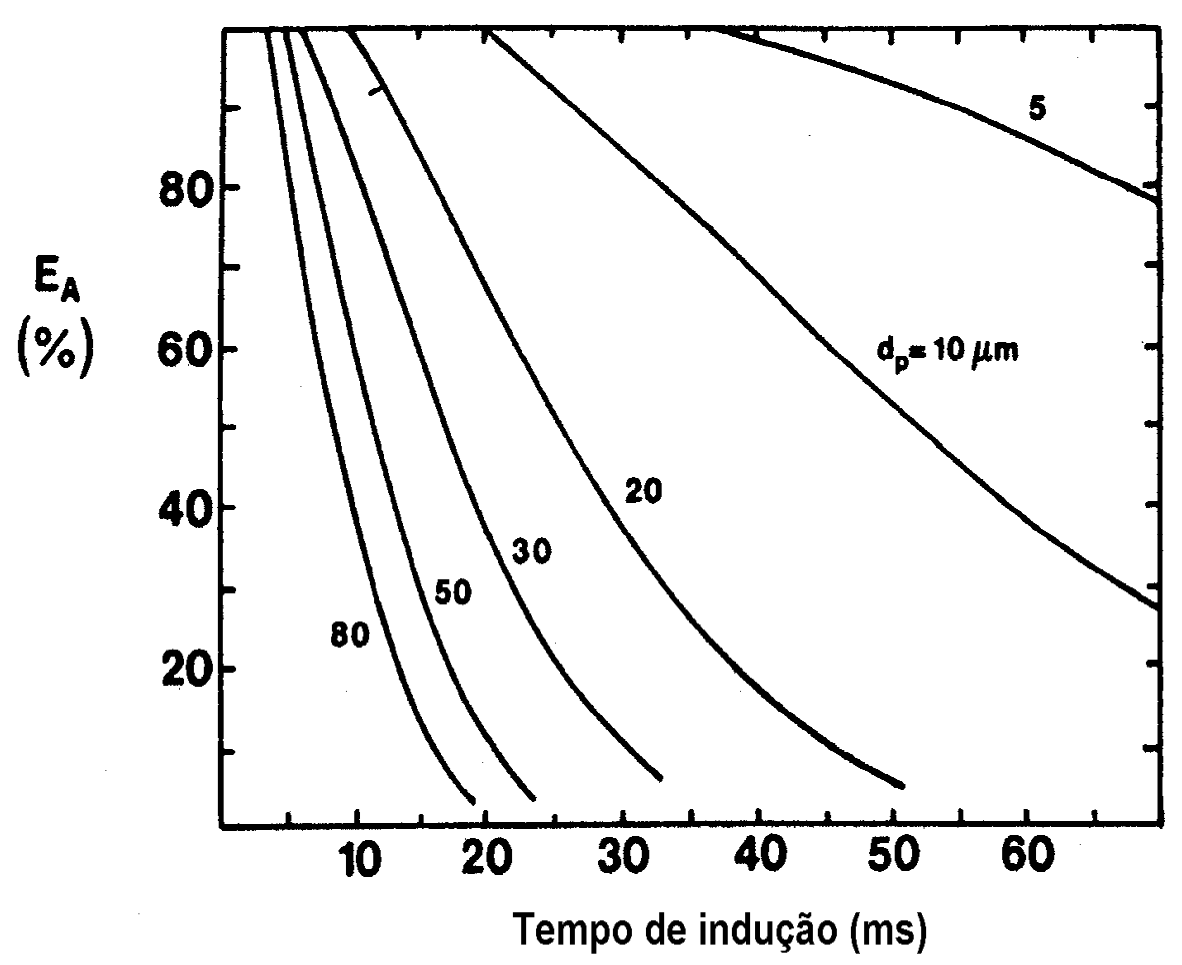

Figura 3.20. Eficiência de adesão versus tempo de indução para partículas com diferentes diâmetros $\left(d_{p}\right)$ [Dobby e Finch (1990)].

A literatura é pródiga em oferecer expressões para o cálculo do tempo de indução e $E_{A}$, todavia elas não estão compreendidas no escopo deste texto [Derjaguin e Dukhin (1960); Dobby e Finch (1990); Ityokumbul et al. (1995); Jordan e Spears (1989); Jowett (1980); Pike et al. (2003); Ralston, et. al. (1999a); Ralston et al. (1999b); Schulze (1984); Yoon (2000)].

\subsubsection{Ruptura do Agregado Partícula - Bolha.}

Conforme descrito na figura 3.21, admitindo-se uma partícula esférica com 
raio $R_{P}$, com superfície homogênea e plana, aderida a uma bolha de raio $R_{b}$ (sendo $R_{b}>>R_{P}$ ), o efeito da pressão capilar, $P_{\sigma}$ é desprezível [Lins e Adamian (1989); Mika e Fuerstenau 1968); Morris (1952); Ralston e Crawford (1988); Ralston et al. (1999a); Schulze (1977, 1982, 1984); Woodburn et al. (1971), Gontijo et.al. (2007)].

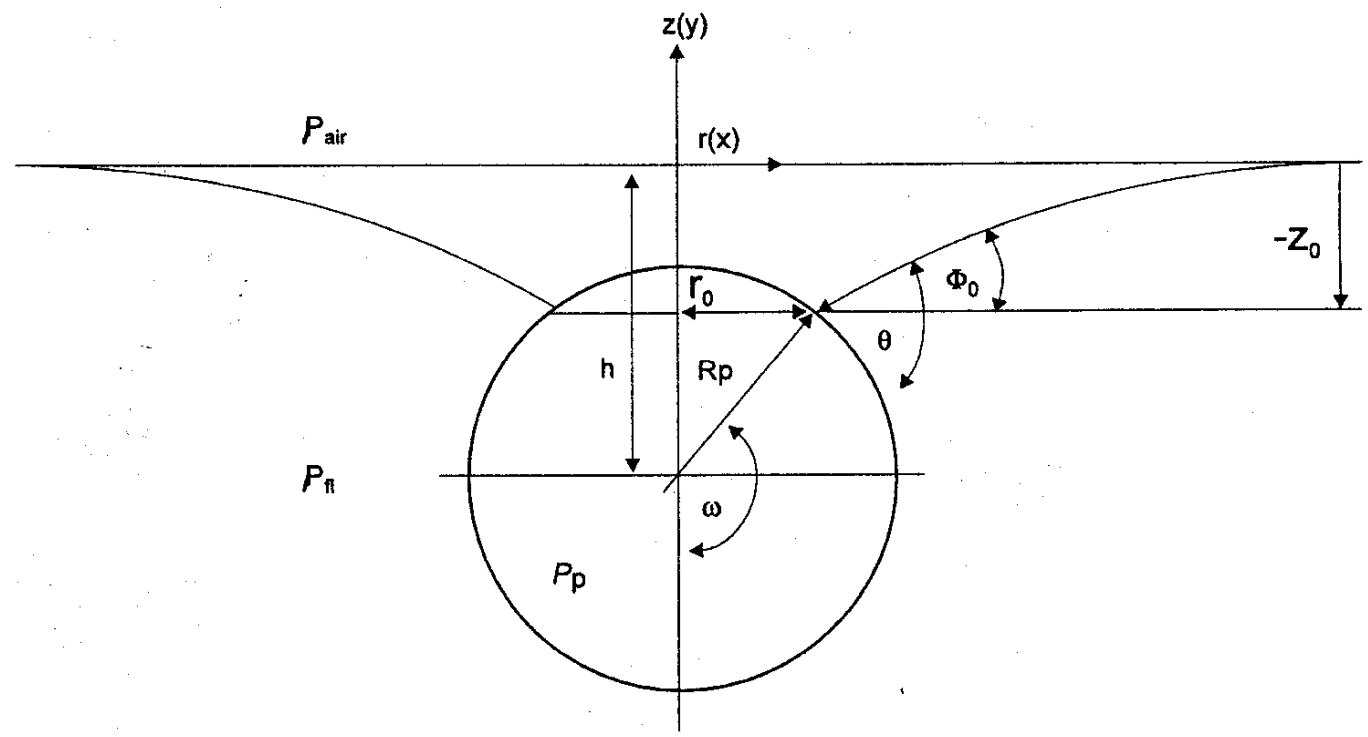

Figura 3.21. Partícula na interface gás - líquido, contato entre as três fases (TPC) [Schulze (1977, 1982, 1984); Ralston e Crawford (1988); Ralston et al. (1999a); Gontijo et.al. (2007)].

Em síntese, as forças que atuam sobre o agregado são as seguintes [Ralston e Crawford (1988); Ralston et al. (1999a); Schulze (1977, 1982, 1984); Woodburn et al. (1971); Gontijo et.al. (2007)]:

i. A força de gravidade:

$$
\mathrm{FG}=\frac{4}{3} \pi \mathrm{r}_{\mathrm{P}}^{3} \rho_{\mathrm{P}} \mathrm{g}
$$

ii. $\quad$ empuxo da parte imersa:

$$
|\mathrm{FB}|=\frac{\pi}{3} \mathrm{r}_{\mathrm{P}}{ }^{3} \rho_{\mathrm{sL}} \mathrm{g}\left[(1-\operatorname{Cos} \omega)^{2}(2+\operatorname{Cos} \omega)\right]
$$

iii. A pressão hidrostática da coluna de líquido (altura $\mathrm{z}_{0}$ ) sobre a área:

$$
\left|\operatorname{Pr}_{\mathrm{HY}}\right|=-\pi \mathrm{r}_{\mathrm{P}}^{2} \rho_{\mathrm{sL}} \mathrm{gz}_{0}\left\{\operatorname{Sen}^{2} \omega\right\}
$$

iv. A força capilar sobre o ponto de tríplice contato (TPC):

$$
|\mathrm{Fc}|=-2 \pi \mathrm{r}_{\mathrm{P}} \gamma\{\operatorname{Sen} \omega\}\{\operatorname{Sen}(\omega+\theta)\}
$$

v. Força adicional de "detaching" considera a aceleração da máquina, $b_{m}$ : 


$$
\mathrm{F}_{\mathrm{add}}=\frac{4}{3} \pi \mathrm{r}_{\mathrm{P}}^{3} \rho_{\mathrm{P}} \mathrm{b}_{\mathrm{m}}
$$

vi. A pressão capilar da bolha sobre a área de contato:

$$
\operatorname{Pr}_{\gamma}=\pi \mathrm{r}_{\mathrm{P}}^{2}\left\{\operatorname{Sen}^{2} \omega\right\}\left[\frac{2 \gamma}{\mathrm{r}_{\mathrm{b}}}-2 \mathrm{r}_{\mathrm{b}} \rho_{\mathrm{sL}} \mathrm{g}\right]
$$

Onde:

$\mathrm{FG}=$ força da gravidade, $\mathrm{N}$;

$\mathrm{r}_{\mathrm{P}}=$ raio da partícula, $\mathrm{m}$;

$\rho_{\mathrm{P}}=$ densidade da partícula, $\mathrm{kg} / \mathrm{m}^{3}$;

$\mathrm{g}=$ aceleração da gravidade, $\mathrm{m} / \mathrm{s}^{2}$;

FB = o empuxo da parte imersa, $\mathrm{N}$;

$\rho_{\mathrm{sL}}=$ densidade do fluído (polpa), $\mathrm{kg} / \mathrm{m}^{3}$;

$\omega=$ ângulo central da esfera, em graus;

$\mathrm{Pr}_{\mathrm{HY}}=$ pressão hidrostática da coluna de líquido, $\mathrm{N}$;

$\mathrm{Z}_{0}=$ altura da coluna de líquido no TPC, $\mathrm{m}$;

FC = força capilar, N;

$\gamma=$ tensão superficial da polpa, $\mathrm{N} / \mathrm{m}$;

$\theta$ = ângulo de contato, em graus;

$\mathrm{F}_{\text {add }}=$ força adicional de "detachment", $\mathrm{N}$;

$\mathrm{b}_{\mathrm{m}}=$ aceleração do impelidor da célula de flotação, $\mathrm{m} / \mathrm{s}^{2}$;

$\operatorname{Pr}_{\gamma}=$ pressão capilar da bolha, $\mathrm{N}$;

$r_{b}=$ raio da bolha, $m$.

A estabilidade do agregado partícula - bolha dependerá da força de adesão entre eles e sua relação com as forças externas existentes no ambiente. $O$ balanço de força para partícula na interface líquido - gás no equilíbrio é representada pela equação 3.66 [Schulze (1977, 1982, 1984); Gontijo et.al. (2007)].

$$
\Sigma F=0
$$

É importante ressaltar que para determinação do $\Sigma F$, tem-se para $\theta \leq 90^{\circ}$ e $\omega \geq 90^{\circ}$ a seguinte definição de sinais [Schulze $\left.(1977,1982,1984)\right]$ :

$\begin{array}{lc}\text { FC }>0 ; & F G<0 ; \\ F B>0 ; & \operatorname{Pr}_{\gamma}<0 ; \\ \operatorname{Pr}_{H Y}>0 ; & F_{\text {add }}<0 ; \\ h>0 ; & Z_{0}<0\end{array}$


A energia de detachment $\left(E_{\text {det }}\right)$ corresponde ao trabalho realizado para mover a partícula de sua posição de equilíbrio, caracterizado pela distância $h_{e q}(\omega)$, que é função do ângulo central, $\omega$, para algum ponto crítico, $h_{\text {crit }}(\omega)$, onde o detachment ocorre e a partícula será deslocada para fase líquida. A resultante das forças que atuam sobre a TPC é relacionada a $E_{\text {det }}$ pela expressão 3.67 [Ralston e Crawford (1988); Ralston et al. (1999a); Schulze (1977, 1982, 1984); Gontijo et.al. (2007)].

$$
E_{\mathrm{det}}=\int_{h e q(\omega)}^{h c r i t(\omega)} \Sigma F d h(\omega)
$$

Onde:

$$
\mathrm{E}_{\text {det }}=\text { energia de detachment, J; }
$$

$\mathrm{h}_{\text {crit( }(\omega)}=$ espessura máxima do filme líquido, onde ainda não ocorre 0 detachment, m;

$h_{\text {eq( } \omega)}=$ espessura do filme líquido na posição de equilíbrio da TPC, m;

$\Sigma \mathrm{F}=$ somatório das forças que atuam sobre a partícula, $\mathrm{N}$;

$\omega=$ ângulo central, em graus.

A equação 3.67 foi resolvida por integração numérica, através da regra de Simpson. Os limites de integração foram determinados pelas equações 3.68-3.69 [Schulze $(1977,1982,1984)]$.

$$
\begin{aligned}
& \mathrm{h}_{(\omega \mathrm{eq})}=-\left(\frac{\mathrm{y}_{0}+\mathrm{ar}_{\mathrm{P}} \cos \omega_{\mathrm{eq}}}{\mathrm{a}}\right) \\
& \mathrm{h}_{\left(\omega^{*}\right)}=-\left(\frac{\mathrm{y}_{0}+\mathrm{ar}_{\mathrm{P}} \cos \omega^{*}}{\mathrm{a}}\right) \\
& \omega_{\mathrm{eq}}=180-0,95 \theta \\
& \omega^{*}=180-0,5 \theta
\end{aligned}
$$

Onde:

$$
\begin{aligned}
& a=\text { constante de Laplace }=\left(\rho_{\mathrm{s} L \mathrm{~g} / \gamma}\right)^{0,5} \\
& \mathrm{y}_{0}=\text { coordenada do menisco, } \mathrm{m} ; \\
& \omega_{\mathrm{eq}}=\text { ângulo central na posição de equilíbrio; } \\
& \omega^{*}=\text { ângulo central na posição crítica. }
\end{aligned}
$$

A coordenada y do menisco líquido na esfera, que está aderido à bolha, é determinada pela integração da equação de Laplace. Em virtude de tal resolução ser 
demasiadamente trabalhosa e difícil, optou-se pela solução de Huh e Scriven (1969), segundo a equação 3.72 .

$$
\mathrm{y}=-\frac{\mathrm{K}_{0}\left(\mathrm{x}_{*}\right)}{\mathrm{K}_{1}\left(\mathrm{x}_{*}\right)} \tan \Phi_{*}
$$

Sendo que $\mathrm{K}_{0}$ e $\mathrm{K}_{1}$ são funções de Bessel. A coordenada correspondente $\mathrm{x}$ é obtida pela equação 3.73 [Huh e Scriven (1969); Schulze (1984)].

$$
x=a R_{P} \operatorname{sen} \omega
$$

$\Phi$ é definido pela equação 3.74 [Schulze (1984); Huh e Scriven (1969); Gontijo et.al. (2007)]:

$$
\Phi=\omega+\theta+\pi
$$

$x_{0}$ e $\Phi$ são funções de $\omega$.

A razão entre as forças de detachment e adesão caracteriza a estabilidade do agregado. Esta proporção é um parâmetro adimensional, Bo', denominado número de Bond modificado, conforme a equação 3.75 [Nguÿen (2003); Schulze (1977, 1982, 1984)].

$$
\mathrm{Bo}^{\prime}=\frac{\mathrm{F}_{\mathrm{det}}}{\mathrm{F}_{\gamma}}
$$

Onde:

$F_{\text {det }}=$ forças que colaboram com o rompimento do agregado;

$\mathrm{F}_{\gamma}=$ forças que contribuem com a adesão da partícula à bolha.

O Bond modificado crítico seria o número no qual os agregados são destruídos. É possível assumir a seguinte aproximação [Nguÿen (2003); Schulze (1984)]:

- $\quad B o^{\prime}<1$, as partículas flotaram $\left(\mathrm{R}_{\mathrm{P}}<\mathrm{R}_{\mathrm{Pmax}}\right)$;

- $\quad B^{\prime}=1$, ocorre o máximo tamanho de partícula flotável;

- $\quad$ Bo'> 1, as partículas não flotaram.

A determinação do máximo tamanho flotável de partículas foi realizada de acordo com a equação 3.76 [Lins e Adamian (1989); Mika e Fuerstenau 1968); Morris (1952); Nguÿen (2003); Ralston e Crawford (1988); Ralston et al. (1999a); Schulze (1977, 1982, 1984); Woodburn et al. (1971)].

$$
\mathrm{r}_{\mathrm{P}}^{2}+\mathrm{r}_{\mathrm{P}} \frac{3 \operatorname{Sen}^{2} \omega^{*}\left(\gamma^{\prime}-\rho_{\mathrm{sL}} \mathrm{gz}_{0}\right)}{4\left(\Delta \rho \mathrm{g}+\rho_{\mathrm{P}} \mathrm{b}_{\mathrm{m}}\right)}+\frac{3 \gamma \operatorname{sen} \omega * \operatorname{sen}\left(\omega^{*}+\theta\right)}{2\left(\Delta \rho \mathrm{g}+\rho_{\mathrm{P}} \mathrm{b}_{\mathrm{m}}\right)}=0
$$

Sendo [Schulze (1984)]: 


$$
\gamma^{\prime}=\left(\frac{2 \gamma}{r_{b}}-2 r_{b} \rho_{s L} g\right)
$$

Para $r_{b} \geq 0,05 \mathrm{~cm}$, o termo $\operatorname{Pr}_{\gamma}<(F B+F c)$ e pode ser negligenciado. Resultando na equação 3.78 [Schulze (1984)].

$$
\mathrm{R}_{\mathrm{P} \max } \approx \sqrt{-\frac{3}{2} \frac{\gamma \operatorname{sen} \omega * \operatorname{sen}\left(\omega^{*}+\theta\right)}{\Delta \rho g+\rho_{\mathrm{P}} \mathrm{b}_{\mathrm{m}}}}
$$

$\mathrm{R}_{\mathrm{Pmax}}$ pode ser determinado através de aproximação sucessiva, sendo $z_{0}$ estimado pela equação 3.79 [Schulze (1984); Gontijo et.al. (2007)]:

$$
\left|\mathrm{z}_{0}\right|=\mathrm{r}_{\mathrm{p}} \operatorname{sen} \omega \cdot \operatorname{sen} \Phi\left\{\operatorname{Ln}\left[\frac{4}{\sqrt{\frac{\rho_{\mathrm{sl}} \mathrm{gr}_{\mathrm{p}}^{2} \operatorname{sen}^{2} \omega}{\gamma}(1+\cos \Phi)}}\right]-0,58\right\}
$$

Considerando a turbulência isotrópica, a aceleração do vórtice, $b_{m}$, depende da estrutura e intensidade do campo turbulento e finalmente da energia dissipada no volume do aparato, conforme a equação 3.80 [Schulze $(1982,1984)]$.

$$
\mathrm{b}_{\mathrm{m}} \cong \frac{1,9 \varepsilon_{\mathrm{D}}{ }^{2 / 3}}{\mathrm{r}^{1 / 3}} \cong \frac{1,9 \varepsilon_{\mathrm{D}}{ }^{2 / 3}}{\mathrm{~d}_{\mathrm{b}}{ }^{1 / 3}}
$$

Onde:

$$
\begin{aligned}
& \varepsilon_{D}=\text { energia dissipada }(\mathrm{W} / \mathrm{kg}) ; \\
& r=\text { raio do vórtice turbulento, } \mathrm{m} ; \\
& d_{b}=\text { diâmetro da bolha, } \mathrm{m} .
\end{aligned}
$$

O raio do vórtice pode ser substituído pelo diâmetro do agregado partículabolha, $d_{b}$. $r$ é dependente da micro-escala de Kolmogoroff, $I_{D}$, em função disso, ele pode ser representado pela equação 3.81 [Schulze $(1982,1984)$ ].

$$
r \cong 3\left(v^{3} / \varepsilon_{D}\right)^{1 / 4}
$$

Para garantir a estabilidade do agregado de partícula-bolha num sistema estático, as forças características associadas com o peso da partícula devem ser balanceadas pela força restauradora de tensão superficial. $O$ balanço entre elas determina o máximo tamanho flotável de partícula. As chances de preservação do agregado crescem com a hidrofobicidade da superfície, o aumento do tamanho da bolha e diminuição do tamanho da partícula [Ahmed e Jameson (1989); Morris (1952)]. 
Por outro lado, Jowett (1980) considera a força de ruptura em termos da força centrífuga, um fator " $g$ ", desenvolvido pela rotação dos redemoinhos de turbulência no sistema. $\mathrm{O}$ argumento mais comum sugere que a força de ruptura crescerá com a diminuição do diâmetro da bolha e o aumento do tamanho da partícula.

Uma vez que o contato estável entre as três fases está formado, a partícula somente pode ser arrastada para fora por algum fator externo, neste caso a energia do campo turbulento. Deste modo, o agregado partícula-bolha capturado em um redemoinho turbulento girará com uma freqüência apropriada ao tamanho do mesmo e se, a energia cinética da partícula for maior que o trabalho de ruptura, o conjunto partícula-bolha romperá, como ilustrado na figura 3.22 [Schulze $(1977,1982,1984)$ ].

\section{Pressão do líquido}

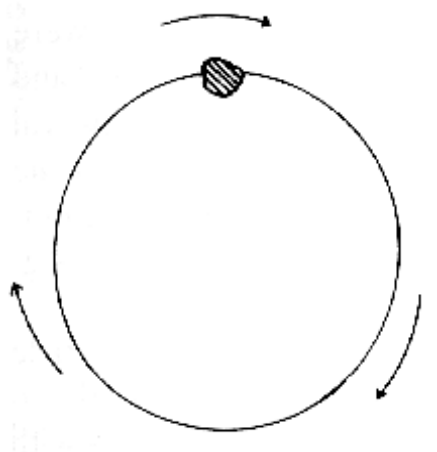

a

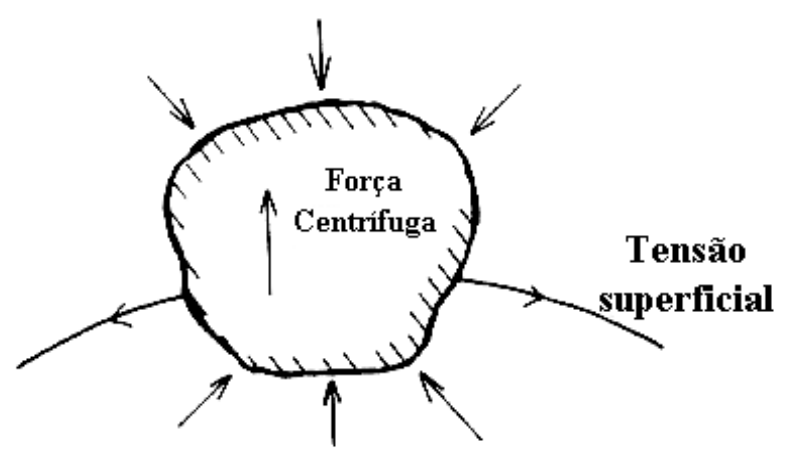

Pressão do gás

b

Figura 3.22. Mecanismo de ruptura de uma partícula da bolha num redemoinho turbulento. (a) A bolha rodando em torno de seu eixo. (b) Forças agindo na partícula [Schulze (1977)]

Lins e Adamian (1989) estudaram a influência das variáveis aeração e velocidade de agitação na flotação de partículas de ouro em diversas granulometrias. Os resultados mostraram a importância do ajuste adequado nos níveis dessas variáveis à recuperação de partículas mais grosseiras.

Segundo Gaudin (1975), para agregados de galena e bolha permanecerem estáveis na polpa sob agitação, o ângulo de contato deve ser muito maior que aquele considerado mínimo necessário para flotação em condições estáticas, conforme ilustrado na tabela 3.6. 
Tabela 3.6. Ângulo de contato para conservar discos de galena de várias granulometrias contra gravidade e força centrífuga 100 vezes maior que a gravidade [Gaudin (1975)].

\begin{tabular}{|c|c|c|}
\hline Diâmetro $(\mu \mathrm{m})$ & $\begin{array}{c}\text { Mínimo ângulo requerido } \\
\text { contra a gravidade. }\end{array}$ & $\begin{array}{c}\text { Mínimo ângulo requerido contra } \\
100 \text { vezes a gravidade. }\end{array}$ \\
\hline 2290 & $90^{\circ}$ & Impossível \\
\hline 500 & $3^{\circ} 8^{\prime}$ & Impossível \\
\hline 200 & $0^{\circ} 30^{\prime}$ & $61^{\circ}$ \\
\hline 100 & $0^{\circ} 7^{\prime} 30^{\prime \prime}$ & $12^{\circ} 40^{\prime}$ \\
\hline 50 & $0^{\circ} 1^{\prime} 52^{\prime \prime}$ & $3^{\circ} 8^{\prime}$ \\
\hline 20 & $0^{\circ} 0^{\prime} 18^{\prime \prime}$ & $0^{\circ} 30^{\prime}$ \\
\hline 10 & $0^{\circ} 0^{\prime} 4^{\prime \prime}$ & $0^{\circ} 7^{\prime} 30^{\prime \prime}$ \\
\hline
\end{tabular}

i. Flotação de todas as partículas de galena menores que $212 \mu \mathrm{m}$, um ângulo de contato menor que $1^{\circ}$ foi suficiente para suportar a gravidade;

ii. Galenas menores que $104 \mu \mathrm{m}$, um ângulo de contato menor que $13^{\circ}$ foi suficiente para suportar uma força centrífuga 100 vezes maior que a gravidade na célula de flotação;

iii. Para partículas de galena maiores que $212 \mu \mathrm{m}$, não foi possível a flotação ser independente do ângulo de contato entre a bolha e a partícula.

Gontijo et.al. (2007), utilizando partículas de quartzo previamente hidrofobizadas através de metilação (trimetil, cloro silano-TMCS), corroborou que maiores ângulos de contato são requeridos para flotar partículas maiores, conforme figura 3.23. Todavia, neste estudo ficou evidenciada que as três variáveis têm forte influência na flotação de partículas grossas: nível de turbulência (aceleração externa), carregamento de bolhas, uma vez que interfere na energia cinética do agregado, e o diâmetro das bolhas.

Segundo Woodburn et al. (1971), a eficiência de descoleta ( $\left.E_{\text {Desc }}\right)$ é calculada pela expressão 3.82 .

$$
E_{\text {Desc }}=\left(d_{p} / d_{\text {Pmáx }}\right)^{1,5}
$$

Onde:

$$
\mathrm{d}_{\mathrm{P}}=\text { diâmetro da partícula que está aderida à bolha; }
$$


$\mathrm{d}_{\text {Pmáx }}=$ diâmetro máximo de uma partícula passível de flotação.

Portanto a eficiência de estabilidade do agregado partícula/bolha $\left(E_{S}\right)$ pode ser calculada em função da eficiência de descoleta $\left(E_{\text {Desc }}\right)$, conforme a equação 3.83 [Ralston et. al. (1999a)].

$$
E_{S}=1-E_{\text {Desc }}
$$

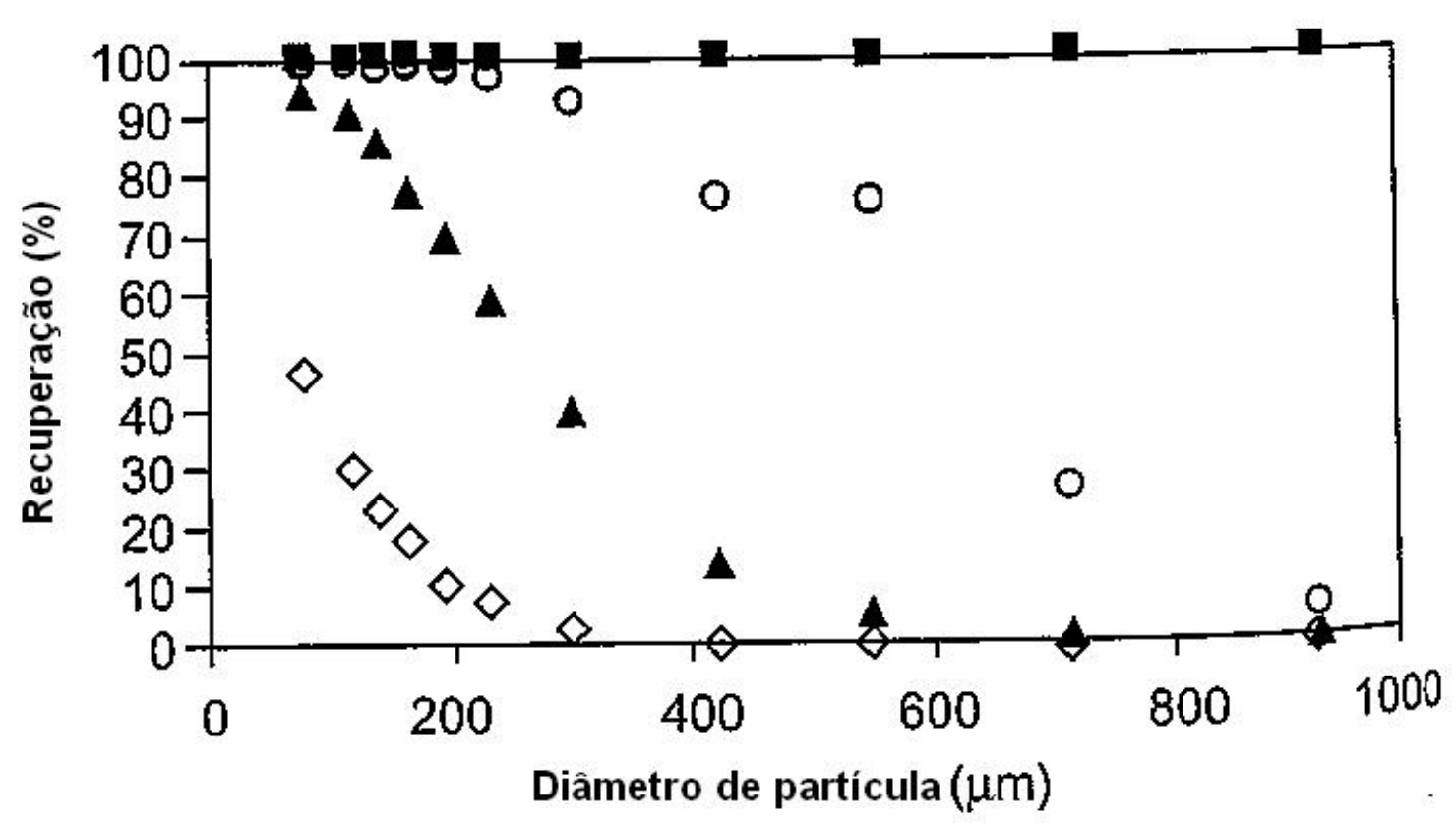

Figura 3.23. Recuperação de quartzo (8 min. de flotação) em célula de flotação com turbina de Rushton em função do diâmetro de partícula e ângulo de contato $\left[(\diamond) 40^{\circ}\right.$; (A) $57^{0} ;$ (O) $\left.75^{0} ;(\boldsymbol{\square}) 83^{0}\right], \rho_{p}=2650 \mathrm{~kg} / \mathrm{m}^{3} ; \mathrm{d}_{\mathrm{p} 50}=353 \pm 8 \mu \mathrm{m}$; espumante $(\mathrm{DF} 250)=20$ $\mathrm{mg} / \mathrm{L} ; \mathrm{d}_{b}=0,7 \pm 0,3 \mathrm{~mm}$; rotação do impelidor=650 $\pm 4 \mathrm{rpm}$, energia dissipada=6,46 $\mathrm{m}^{2} / \mathrm{s}^{3}$; Re=26063; vazão de gás=4,5 L/min [Gontijo et.al. (2007)].

\subsection{Cinética de Flotação}

O desempenho do processo de flotação é função das eficiências dos eventos consecutivos de colisão, adesão e preservação do agregado, que interferem diretamente nos mecanismos de interações entre as partículas e bolhas no interior da polpa [Alexander e Morrison (1998); Arbiter (1969); Derjaguin e Dukhin (1960); 
Dobby e Finch (1990); Ralston et. al. (1999a); Ralston e Crawford (1988); ; Rodrigues et al. (2001); Schulze (1977, 1984)].

O sucesso destes três eventos propiciará a coleta da partícula pela bolha, refletindo assim, o aspecto cinético na flotação. Por outro lado, se um dos eventos falhar, o desempenho do processo será retardado e a partícula não flotará.

Se o ar fornecido é constante, a tendência para alguma alteração na concentração de bolha é pequena. Em tal situação, a equação da velocidade é expressa pela equação 3.84, na qual k é a constante cinética [Dobby e Finch (1990); Harris (1987); Ralston e Crawford (1988); Rodrigues et al. (2001)].

$$
-r_{F}=\frac{-d c_{P}}{d t}=k \cdot c_{P}^{n}
$$

Onde:

$$
\begin{aligned}
& r_{F}=\text { velocidade da flotação; } \\
& \mathrm{C}_{\mathrm{p}}=\text { concentração das partículas; } \\
& \mathrm{t}=\text { tempo de flotação; } \\
& \mathrm{k}=\text { constante cinética de flotação; } \\
& \mathrm{n}=\text { ordem cinética da flotação. }
\end{aligned}
$$

Diversos trabalhos caminham na vertente do desenvolvimento de modelos matemáticos para o melhor entendimento dos fenômenos cinéticos. No presente trabalho a ordem e constante cinética de flotação serão estimadas pelos métodos amplamente aplicáveis na literatura técnica corrente como Connors (1990), Fogler (1999), Leal Filho et al. (2006), Levenspiel (1974) e Vatcha (1987).

No presente estudo, os parâmetros cinéticos, como ordem de reação e constante cinética, foram estimados por três metodologias distintas:

1. Tentativa e erro [Fogler (1999); Levenspiel (1974)].

2. Razão dos tempos [Vatcha (1987)].

3. Tempos fracionários [Connors (1990)]. 


\section{CARACTERIZAÇÃO DO SISTEMA EXPERIMENTAL}

\subsection{Materiais utilizados nos experimentos.}

Esferas de vidro (densidade $=2480 \mathrm{~kg} / \mathrm{m}^{3}$ ), com diâmetros médios $\left(d_{p}\right): 496$, 248 e $57 \mu \mathrm{m}$ foram usadas nos experimentos. Sendo que os dois primeiros diâmetros de partícula são considerados grossos para concentração por flotação, enquanto que esferas de $57 \mu \mathrm{m}$ se reportam à qualidade de finas.

As esferas de vidro foram submetidas aos seguintes procedimentos:

i. Lavagem exaustiva com solução sulfocrômica P.A e água destilada, nesta ordem, com objetivo de efetuar completa limpeza da superfície;

ii. Peneiramento a úmido nas malhas 0,$84 ; 0,59,0,42,0,297,0,210$, 0,149,0,105,0,075,0,044 e 0,037 mm. Tomaram-se as seguintes frações: -0,59+0,42 mm, -0,297+0,212 mm e -0,075+0,044 mm.

iii. Filtragem a vácuo e posterior secagem em estufa $\left(80{ }^{\circ} \mathrm{C}\right)$ das frações requeridas;

iv. Separação Magnética em separador isodinâmico Frantz, para retirada de materiais magnéticos;

v. Homogeneização das frações $-0,59+0,42 \mathrm{~mm},-0,297+0,212 \mathrm{~mm}$ e $-0,075+0,044 \mathrm{~mm}$, de onde foram extraídas alíquotas de $1,0 \mathrm{~g}$, as quais foram utilizadas nos ensaios de microflotação.

vi. Homogeneização das frações -0,297+0,212 mm e -0,075+0,044 $\mathrm{mm}$, de onde foram extraídas alíquotas de $400,0 \mathrm{~g}$, as quais foram utilizadas nos ensaios de flotação em bancada.

Além das esferas de vidro, cristais de apatita ígnea (densidade $=3200 \mathrm{~kg} / \mathrm{m}^{3}$ ) de Monteiro-PB foram utilizados nos experimentos de microflotação. Por sua vez, a apatita foi submetida às seguintes etapas de preparação:

i. Secada e moída até $100 \%$ menor que 0,297 mm;

ii. Devidamente peneirada, a massa da fração $-0,297+0,212 \mathrm{~mm}$ foi purificada por líquido denso; 
iii. Posteriormente, separação magnética em separador isodinâmico Frantz, para retirada de materiais magnéticos;

iv. A amostra purificada foi exaustivamente lavada em etanol e água deionizada.

\subsection{Reagentes e soluções usados nos experimentos.}

Como coletor nos ensaios de flotação das esferas de vidro foi utilizado o acetato de eteramina (Flotigan EDA, produzido pela Clariant S.A.). Tal coletor foi utilizado na concentração de $1 \%$ p/v.

No que se refere à flotação de apatita, o coletor utilizado foi oleato de sódio em grau analítico. A concentração da solução coletora foi da ordem de $1 \% \mathrm{p} / \mathrm{v}$.

Com o objetivo de ajustar o pH da polpa de flotação foram utilizados soluções de hidróxido de sódio P.A e ácido clorídrico P.A, ambos a $10 \%$ p/v, as quais eram preparadas da seguinte forma:

i. $\quad 10 \mathrm{~g}$ de substância, NaOH P.A. ou HCl P.A. (produzidos pela Merck), colocados em béquer de $100 \mathrm{~mL}$;

ii. Água destilada era adicionada até a total diluição do $\mathrm{NaOH}$ ou $\mathrm{HCl}$;

As soluções eram transferidas para um balão de $100 \mathrm{~mL}$, completando-se o volume com água deionizada.

\subsection{Técnicas e procedimentos experimentais.}

As soluções de substâncias coletoras, como a eteramina, adsorvem na interface líquido-gás, tal fato provoca imprecisões nas medidas de tensão superficial da solução pelo método do desprendimento do anel (Du Noüy Ring). Em função disso, neste trabalho a tensão superficial foi determinada pelo método da placa de Wilhelmy, devido a sua importância para caracterização hidrodinâmica do sistema [Lando e Oakley (1967); Padday (1969)].

As medidas de tensão superficial realizada no tensiômetro Krüss (modelo 
K12e) seguiram o procedimento:

i. A cuba de vidro, na qual se coloca a amostra, foi previamente lavada com acetona P.A. e secada a $100{ }^{\circ} \mathrm{C}$, durante 1 hora. Lavou-se a cuba novamente com hexano P.A. repetindo o procedimento de secagem;

ii. A placa de Wilhelmy foi flambada a cada medida no bico de busen, até atingir uma coloração vermelha, a fim de evitar contaminações;

iii. $\quad 45 \mathrm{~mL}$ da solução de eteramina (na concentração desejada) foram adicionados na cuba de vidro, posteriormente a cuba (com a amostra) e a placa foram colocadas em seus devidos lugares dentro do tensiômetro;

iv. Com auxílio de um programa de computador (adjunto ao tensiômetro Krüss modelo $\mathrm{K} 12 \mathrm{e}$ ) as medidas de tensão superficial foram realizadas.

O programa do tensiômetro $\mathrm{K} 12 \mathrm{e}$ fornece um gráfico de tensão superficial versus tempo (vide anexo).

As medidas de ângulo de contato $(\theta)$ das esferas de vidro foram realizadas através da técnica de taxa de penetração de líquido, que constitui na determinação da altura de penetração do líquido em capilares de um leito compacto de partículas contidas num tubo de vidro ("garrafa") em função do tempo. O fundo do tubo é lacrado com uma placa porosa de 1 a $2 \mathrm{~mm}$ de espessura para reter as partículas.

A determinação do ângulo de contato $(\theta)$ foi realizada no tensiômetro Krüss modelo $\mathrm{K} 12 \mathrm{e}$, obedecendo ao seguinte procedimento:

i. A garrafa foi previamente lavada com acetona P.A. e secada a 100 ${ }^{0} \mathrm{C}$ por 1 hora. Posteriormente, lavada novamente com hexano P.A. e também secada a $100{ }^{\circ} \mathrm{C}$ por $1 \mathrm{~h}$;

ii. Pesou-se $0,5000 \mathrm{~g}$ de esferas de vidro hidrofóbicas, oriundas de produtos flotados de ensaios de microflotação, a fim de determinar uma constante que englobe as características físicas do material e do leito;

iii. Considerando-se que as partículas hidrofóbicas fossem totalmente "molhadas" por hexano ( $\operatorname{Cos} \theta=0)$, o programa do tensiômetro K12e determinava a constante do leito; 
iv. Pesou-se $0,500 \mathrm{~g}$ de esferas de vidro $(-297+212 \mu \mathrm{m} \mathrm{e}-75+44 \mu \mathrm{m})$ condicionadas com solução de éter - amina (75 mg/L) em pH = 10 . Posteriormente a amostra foi colocada na "garrafa" e determinou-se o ângulo de contato, com auxílio do programa do tensiômetro K12e, que utiliza o método de Washburn [Subrahmanyam et al. (1996, 1999)].

Impelidores com configurações geométricas distintas foram aplicadas nos ensaios de microflotação, conforme descritos na tabela 4.1.

Tabela 4.1. Características geométricas dos impelidores utilizados nos ensaios de microflotação.

\begin{tabular}{|c|c|c|c|c|c|}
\hline Geometria & $\mathbf{D}(\mathbf{m m})$ & $\mathbf{D} / \mathbf{T}$ & $\mathbf{T} / \mathbf{C}$ & $\mathbf{D} / \mathbf{W}$ & $\mathbf{S}$ \\
\hline Cilindróide-1 & 8,3 & 0,26 & 10,7 & 1,04 & 1,9 \\
\hline Paddle & 20 & 0,62 & 10,7 & 4 & 1,7 \\
\hline Turbina de Rushton & 20 & 0,62 & 10,7 & 5 & 1,7 \\
\hline
\end{tabular}

No caso dos ensaios de bancada (seção 4.5), a potência aplicada à polpa pode ser determinada em função das medidas de torque no eixo do impelidor. Tais ensaios foram realizados com o transdutor de torque (Fast Technology Mod.-TM-HRRD-2,5) e seguiram o procedimento:

i. $\quad 400 \mathrm{~g}$ de esferas de vidro $(-297+212 \mu \mathrm{m})$ foram colocadas numa cuba de 1,5 L de capacidade;

ii. Adicionou-se 1,2 $\mathrm{L}$ de água destilada, isto perfaz uma percentagem volumétrica de aproximadamente $12 \%$;

iii. Duas chicanas (dimensão $=10 \%$ do diâmetro do tanque) foram colocadas na célula, objetivando-se evitar formação de vórtices;

iv. O impelidor foi posto na célula, de maneira que a distância entre 0 fundo do tanque e o impelidor fosse $10 \%$ do nível da polpa.

v. O agitador usado foi fabricado pela Fisaton (Mod.713D). Além disso, o transdutor de torque foi ajustado para um filtro de 2.5 , no intuito de amenizar os efeitos das vibrações do eixo nas medidas;

vi. Os ensaios de medições de torque foram realizados impelidores, que apresentam suas características na tabela 4.2: 
Tabela 4.2. Características geométricas dos impelidores utilizados nos ensaios de medições de torque.

\begin{tabular}{|c|c|c|c|c|c|}
\hline Geometria & $\mathbf{D}(\mathbf{m m})$ & $\mathbf{D} / \mathbf{T}$ & $\mathbf{T} / \mathbf{C}$ & $\mathbf{D} / \mathbf{W}$ & $\mathbf{S}$ \\
\hline Cilindróide & 70,5 & 0,26 & 10 & 7,8 & 5,3 \\
\hline Turbina de Rushton & 37,5 & 0,34 & 10 & 4 & 9,5 \\
\hline Turbina de Rushton & 55,5 & 0,50 & 10 & 4 & 6,7 \\
\hline Turbina de Rushton & 70,5 & 0,64 & 10 & 4 & 4,2 \\
\hline
\end{tabular}

vii. As medidas de torque foram feitas variando-se a rotação (6 a 53 rps) e a aeração (0 a $10 \mathrm{~L} / \mathrm{min}$ ) para cada impelidor, mantendo-se o nível da polpa constante.

\subsubsection{Ensaios de microflotação}

Os ensaios de flotação foram executados numa célula de microflotação (diâmetro = 32,2 mm; altura = 94,2 mm), cuja forma e geometria assemelham-se ao tradicional tubo de Hallimond modificado, conforme apresentado na figura 4.1.

A suspensão da polpa foi realizada por um sistema de agitação mecânica com controle da velocidade rotacional e as características dos impelidores de formato cilindróide estão descritas na figura 4.2.

O material flotado foi manualmente coletado da célula por uma espécie de pá.

A velocidade rotacional variou dentro de um amplo intervalo: 0,07 a 49,33 $\mathrm{s}^{-1}$. A velocidade crítica do impelidor para completa suspensão $\left(\mathrm{N}_{\mathrm{Z}}\right)$ foi determinada pela observação visual. $\mathrm{N}_{Z}$ possibilitou estimar o parâmetro geométrico (S), que caracteriza o impelidor cilindróide usado nos ensaios de flotação. Os valores calculados de $S$ são referenciados na figura 4.2. 


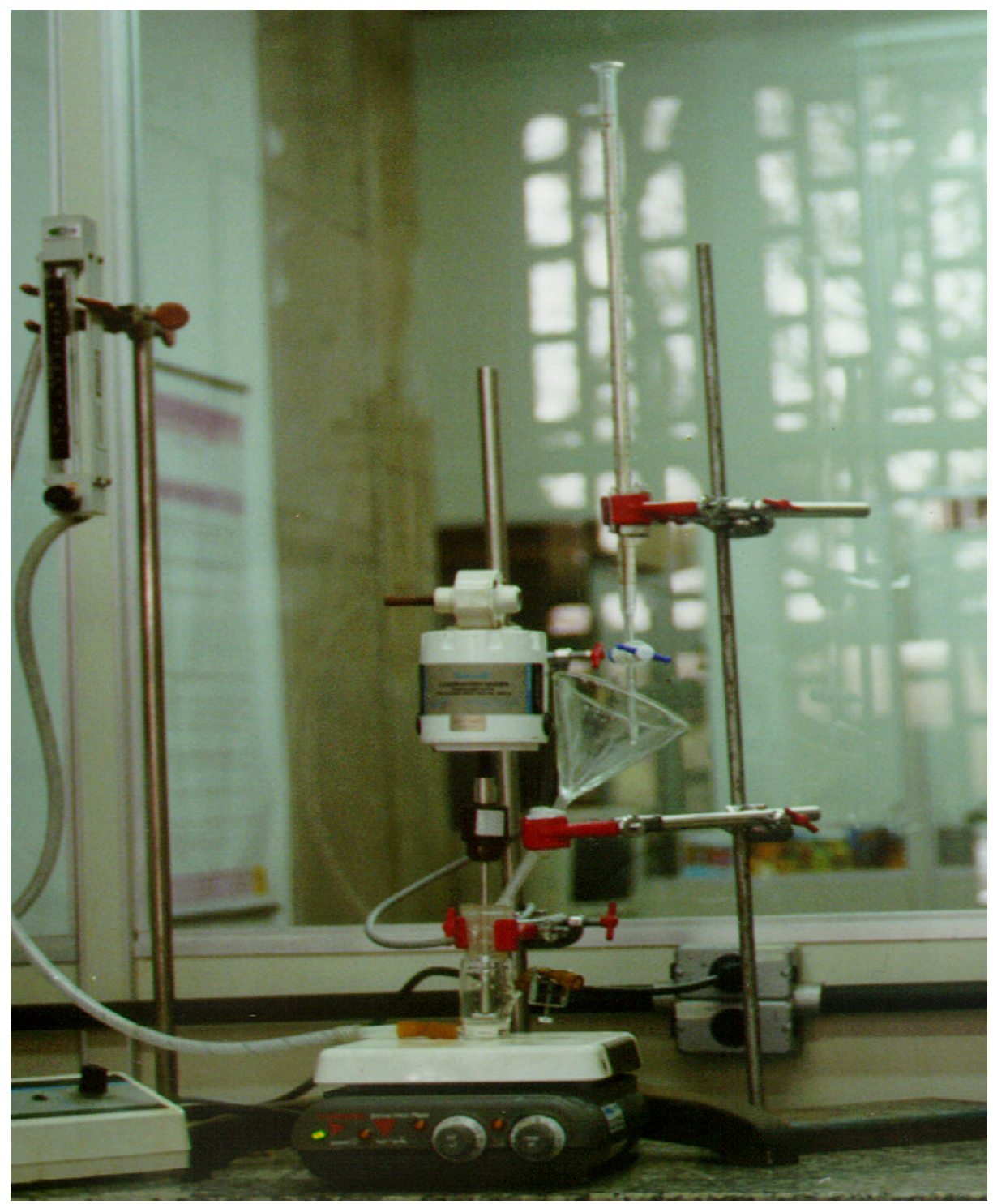

Figura 4.1. Célula de ensaio de microflotação.

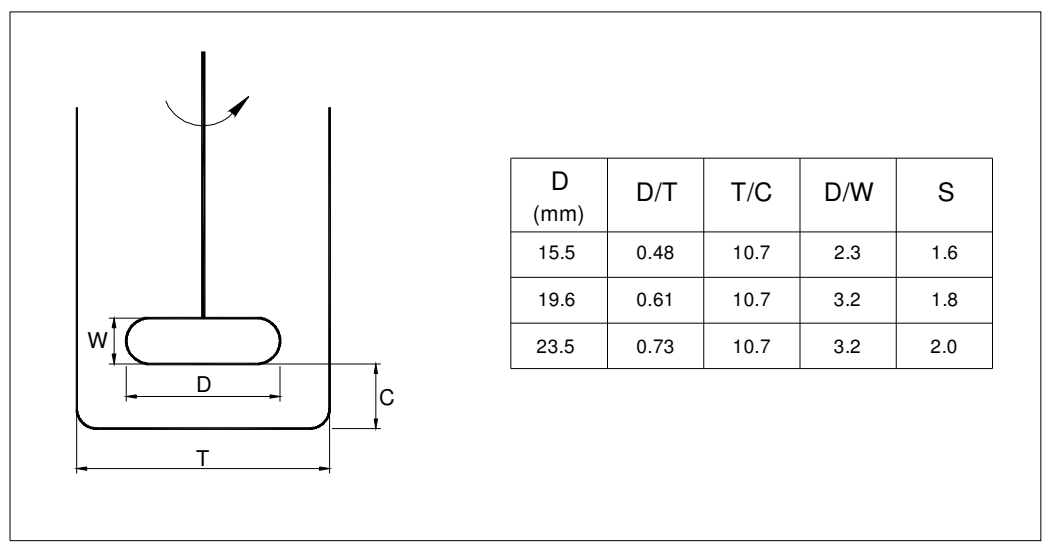

Figura 4.2. Características geométricas dos impelidores cilindróides utilizados nos ensaios de microflotação. 
Gás nitrogênio $\left(\mathrm{N}_{2}\right)$ foi injetado na célula de microflotação, através de uma placa sinterizada (raio médio do poro $=0,2549 \mathrm{~mm}$ ).

Resumindo, os ensaios obedeceram aos seguintes procedimentos:

i. $\quad 1 \mathrm{~g}$ de esferas de vidro $(-595+420 \mu \mathrm{m}$ ou $-297+212 \mu \mathrm{m})$, quartzo $(-297+212 \mu \mathrm{m})$ ou apatita $(-297+212 \mu \mathrm{m})$ eram colocados na célula;

ii. Na flotação das esferas de vidro, adição de $60 \mathrm{~mL}$ de solução de acetato de eteramina (água ou sacarose a 30\% como solventes) com concentração 75 mg/L e pH=10;

iii. Para apatitas, adicionou-se $60 \mathrm{~mL}$ da solução aquosa de oleato (1\%) na concentração de 100 mg/L e pH 10,5.

iv. Condicionava - se a polpa com a solução de coletor, durante 1 minuto;

v. Injetava-se o gás $\left(\mathrm{N}_{2}\right)$ no sistema, numa vazão de $9,0.10^{-4} \mathrm{dm}^{3} / \mathrm{s}$.

vi. Executava-se a flotação dentro do intervalo de tempo requerido, 60 segundos;

vii. As massas flutuadas e afundadas foram filtradas à vácuo, secadas em estufa $\left(80^{\circ} \mathrm{C}\right)$ e pesadas.

Para variar a viscosidade da polpa, uma solução aquosa de sacarose $(30 \%$ w/w, a $25^{\circ} \mathrm{C}$ ) foi usada no lugar de água pura.

A recuperação foi calculada em base percentual pela divisão da massa do produto flotado pela massa de alimentação.

\subsubsection{Ensaios de Flotação em Bancada.}

Todos os ensaios de flotação foram executados numa cuba de geometria retangular (largura $=$ comprimento $=111 \mathrm{~mm}$ ), com capacidade de 1,5 L. A agitação foi realizada por um sistema de agitação mecânica, com controle da velocidade rotacional. O material flotado foi manualmente retirado da célula por uma pá.

Os impelidores utilizados nos ensaios de flotação eram turbinas de Rushton, que apresentam suas características geométricas na tabela 4.3. 
Tabela 4.3. Características geométricas do sistema de flotação em bancada.

\begin{tabular}{|c|c|c|c|c|}
\hline \multirow{2}{*}{$\mathrm{D}(\mathrm{mm})$} & \multirow{2}{*}{$\mathrm{D} / \mathrm{T}$} & \multirow{2}{*}{$\mathrm{D} / \mathrm{W}$} & \multicolumn{2}{|c|}{$\mathrm{N}_{\mathrm{Z}}(\mathrm{rpm})$} \\
\cline { 4 - 5 } & & & Para $\mathrm{d}_{\mathrm{p}}=248 \mu \mathrm{m}$ & Para $\mathrm{d}_{\mathrm{p}}=57 \mu \mathrm{m}$ \\
\hline 37,5 & 0,33 & 4 & 1560 & 1050 \\
\hline 55,5 & 0,5 & 4 & 750 & 460 \\
\hline 70,5 & 0,64 & 4 & 510 & 228 \\
\hline
\end{tabular}

Todos os ensaios obedeceram ao seguinte procedimento básico:

i. $\quad 400 \mathrm{~g}$ de esferas de vidro $(-297+212 \mu \mathrm{m}$ e $-75+44 \mu \mathrm{m})$ eram colocados em cuba de 1,5 L;

ii. Adicionavam-se $1,2 \mathrm{~L}$ de solução de éter-amina $75 \mathrm{mg} / \mathrm{L}$ (para esferas de $-297+212 \mu \mathrm{m})$ ou $250 \mathrm{mg} / \mathrm{L}(-75+44 \mu \mathrm{m})$. Tal solução tinha seu $\mathrm{pH}$ previamente corrigido para 10;

iii. Condicionava-se a polpa por 1 minuto;

iv. Injetava-se nitrogênio, numa vazão de $1,67.10^{-2} \mathrm{dm}^{3} / \mathrm{s}$;

v. Após o condicionamento com o coletor, executava-se a flotação por 2'40". Além disso, flotava-se até a total exaustão;

vi. O produto flotado e também afundado eram secados e pesados.

O gás $\left(\mathrm{N}_{2}\right)$ foi introduzido no sistema durante o tempo de flotação necessário. A recuperação foi calculada em base percentual pela divisão da massa do produto flotado pela alimentação.

\subsubsection{Cinética de flotação.}

Os ensaios cinéticos foram executados em célula Denver, escala de laboratório, ( $\mathrm{D}=0,07 \mathrm{~m}$ e $\mathrm{N}=18,3 \mathrm{rps}$ ) utilizando fosfato de Tapira-MG, oriundo da Fosfértil S.A. A composição mineralógica do minério foi a seguinte:

- Apatita $=18 \%$;

- Micas $=13 \%$;

- Diopsídio = 12\%;
- Carbonatos $=7 \%$;

- Quartzo = 20\%;

- Óxidos de $\mathrm{Fe}$ e $\mathrm{Ti}=13 \%$

As condições dos ensaios de flotação foram:

i. Porcentagem de sólidos ( $\mathrm{v} / \mathrm{v})$ da ordem de $12 \%$; 
ii. Dosagem de amido $=500 \mathrm{~g} / \mathrm{t}$;

iii. Dosagem de coletor $=350 \mathrm{~g} / \mathrm{t}$, este coletor era composto de $80 \%$ de óleo de arroz e $20 \%$ de KE- $883^{\circledR}$, fabricado pela Cognis;

iv. $\quad \mathrm{pH}$ de flotação foi 9,3;

v. A espuma foi coletada de modo acumulativo nos intervalos de tempo $(\Delta \mathrm{t})$ de 5, 15, 35 e $80 \mathrm{seg}$;

vi. Os produtos da flotação eram secados, pesados e enviados à análise química;

vii. A recuperação foi calculada em função da quantidade de $\mathrm{P}_{2} \mathrm{O}_{5}$ contido no flotado e na alimentação do ensaio. 


\section{RESULTADOS E DISCUSSÃO}

Este capítulo foi estruturado de maneira que sejam definidas as condições hidrodinâmicas mais favoráveis para flotação de grossos ( $\left.d_{\mathrm{P}} \sim 248 \mu \mathrm{m}\right)$, baseado em dados de ensaios de microflotação e bancada, visando a compreensão das interações das forças que atuam no sistema e sua contribuição para flotação.

\subsection{Fatores físico-químicos e hidrodinâmicos relevantes ao sistema}

Os parâmetros físico-químicos como ângulo de contato e tensão superficial possuem um papel fundamental na caracterização hidrodinâmica do sistema de flotação. Tais parâmetros utilizados na flotação das esferas de vidro e apatita são apresentados na tabela 5.1.

Tabela 5.1. Parâmetros físico-químicos relevantes ao sistema de flotação.

\begin{tabular}{|c|c|c|c|c|c|}
\hline Material & Coletor & $\begin{array}{c}\text { Concentraçãoflotação } \\
(\mathrm{mg} / \mathrm{L})\end{array}$ & $\mathrm{pH}_{\text {flotação }}$ & $\gamma(\mathrm{N} / \mathrm{m})^{*}$ & $\theta$ \\
\hline $\begin{array}{c}\text { Esferas de } \\
\text { vidro }\end{array}$ & Eteramina & 75 & 10 & $36.10^{-3}$ & $89^{0}$ \\
\hline Apatita & Oleato & 100 & 10,5 & $32.10^{-3}$ & $87^{0}$ \\
\hline
\end{tabular}

$\left({ }^{*}\right)$ Tensão superficial medida em $23^{\circ} \mathrm{C}$.

A viscosidade da polpa foi estimada pela equação 3.4, proposta por Roscoe em 1952. Em polpas aquosas, as viscosidades variaram de $9,4.10^{-4}$ a $1,1.10^{-3}$ $\mathrm{N} . \mathrm{s} / \mathrm{m}^{2}$, enquanto para polpas com sacarose $(30 \%)$ valores de aproximadamente $2,7.10^{-3} \mathrm{~N} . \mathrm{s} / \mathrm{m}^{2}$ para viscosidade. Com eteramina, a tensão superficial não variou tanto para suspensões aquosas como em polpa com sacarose (30\%).

Nos ensaios de microflotação, a potência medida no eixo do impelidor era menor que a sensibilidade do transdutor de torque, assim o número de potência foi calculado através das equações empíricas de Nagata (1975).Todavia, para solucionar o problema da geometria real do impelidor (cilindróide) usado nos ensaios de flotação, houve necessidade de fazer correções baseadas na analogia existente entre Po e o coeficiente de arraste $\left(C_{D}\right)$ de corpos imersos (cilindros versus placas retangulares), que têm similaridade geométrica e a mesma razão 
comprimento/largura (I/W) para placas retangulares ou comprimento/diâmetro (I/D) para cilindros.

Segundo Knudsen (1958) e Sisson (1988), o valor de $C_{D}$ para corpos cilindros $(3<\mathrm{I} / \mathrm{W}<5)$ está em torno de 0,69 e placas retangulares $(1<\mathrm{I} / \mathrm{W}<5) \mathrm{C}_{\mathrm{D}} \sim 1,18$. Estimase um fator de correção $f$ exemplificado pela expressão 5.1 para $d / b=3,2(D / W=3,2$ na figura 4.2).

$$
f \cong \frac{\mathrm{C}_{\mathrm{D}}(\text { cilindro de } \mathrm{d} / \mathrm{b}=3,2)}{\mathrm{C}_{\mathrm{D}}(\text { placa retangular de } \mathrm{d} / \mathrm{b}=3,2)} \cong \frac{0,69}{1,18} \cong 0,58
$$

Assim, a magnitude de Po relacionada ao impelidor tipo cilindróide pode ser calculada pela equação 5.2 .

$$
\mathrm{Po}=\mathrm{Po}_{(\text {cilindro })} \cong f \mathrm{Po}_{(\text {paddle })}
$$

Uma vez que o torque pode ser determinado no eixo do impelidor através do transdutor, a potência dissipada pode ser determinada através da equação 3.19.

O parâmetro $S$ foi obtido em função da velocidade crítica para completa suspensão $\left(\mathrm{N}_{\mathrm{Z}}\right)$ de cada impelidor (determinada pela observação visual). Nos impelidores cilindróides utilizados nos ensaios de microflotação S variou de 1,6 a 2 .

Nos ensaios de flotação em bancada, os valores de $S$ variaram principalmente em função do diâmetro e configuração geométrica do impelidor. Para um impelidor tipo turbina de Rushton, com diâmetro de $70,5 \mathrm{~mm}$, S encontrado foi da ordem de 4,2, enquanto que o impelidor cilindróide, com mesmo diâmetro, apresentou $S$ de 9,2. Por conseguinte, a constante adimensional relacionado aos parâmetros geométricos do sistema, $\mathrm{S}$, possibilita contemplar essas diferenças de geometria do impelidor na mínima velocidade de suspensão da célula de flotação.

Uma vez que o gás hold-up, avaliado visualmente, na célula de microflotação foi aproximadamente $3 \%$, estimou-se o diâmetro da bolha em 0,374 mm neste sistema, conforme método descrito por Manqiu e Finch (1988). De acordo com Finch e Dobby (1980), d $d_{B}$ estimado tem um desvio padrão de $\pm 15 \%$ do valor real.

A descrição dos parâmetros hidrodinâmicos na célula de flotação foi explicitada por parâmetros para os sistemas macro e micro. Considerando um enfoque macro, considera-se o diâmetro do impelidor (D), a velocidade rotacional $(\mathrm{N})$, o diâmetro do tanque $(\mathrm{T})$. Por sua vez, reportando-se ao micro, estão os diâmetros de partícula e bolha, bem como, velocidades turbulentas de partículas e bolhas. 


\subsection{Ensaios de Microflotação.}

$\mathrm{Na}$ célula de flotação, para que partículas sejam capturadas por bolhas ascendentes, é necessário que elas estejam em suspensão. Deste modo, para completa suspensão de partículas num líquido, a velocidade rotacional do impelidor $(\mathrm{N})$ tem de ser maior ou igual que a velocidade crítica $\left(\mathrm{N}_{\mathrm{Z}}\right)$. Assim, a razão $\mathrm{N} / \mathrm{N}_{\mathrm{Z}}-\Omega$, poderia ser considerada como um parâmetro prático para avaliar a capacidade do impelidor manter as partículas em suspensão dentro da célula de flotação e macro turbulência disponível no sistema para transportar o agregado partícula-bolha.

Deste modo, quando $\Omega \geq 1$, o impelidor produz macro turbulência suficiente para suspender as partículas e permitir um grande número de colisões com as bolhas. Por sua vez, quando $\Omega<1$, partículas tenderão a sedimentar, diminuindo a quantidade de encontro com as bolhas.

Vale ressaltar que a velocidade crítica não teve alteração significativa e perceptível em função da introdução de $N_{2(g)}$ na célula de microflotação. Provavelmente explicado em função do baixo valor de hold-up no sistema, que estava na ordem de $3 \%$.

As características geométricas do impelidor (formas e dimensões) e tanque interferem diretamente no rendimento da flotação, uma vez que ditam, juntamente com a velocidade, as condições de turbulência no sistema. A influência da suspensão de partículas $(\Omega)$ e relação entre os diâmetros do impelidor e do tanque $(D / T)$ na recuperação das esferas de vidro $\left(d_{p}=0,248 \mathrm{~mm}\right)$ é apresentada num diagrama tridimensional, figura 5.1. 


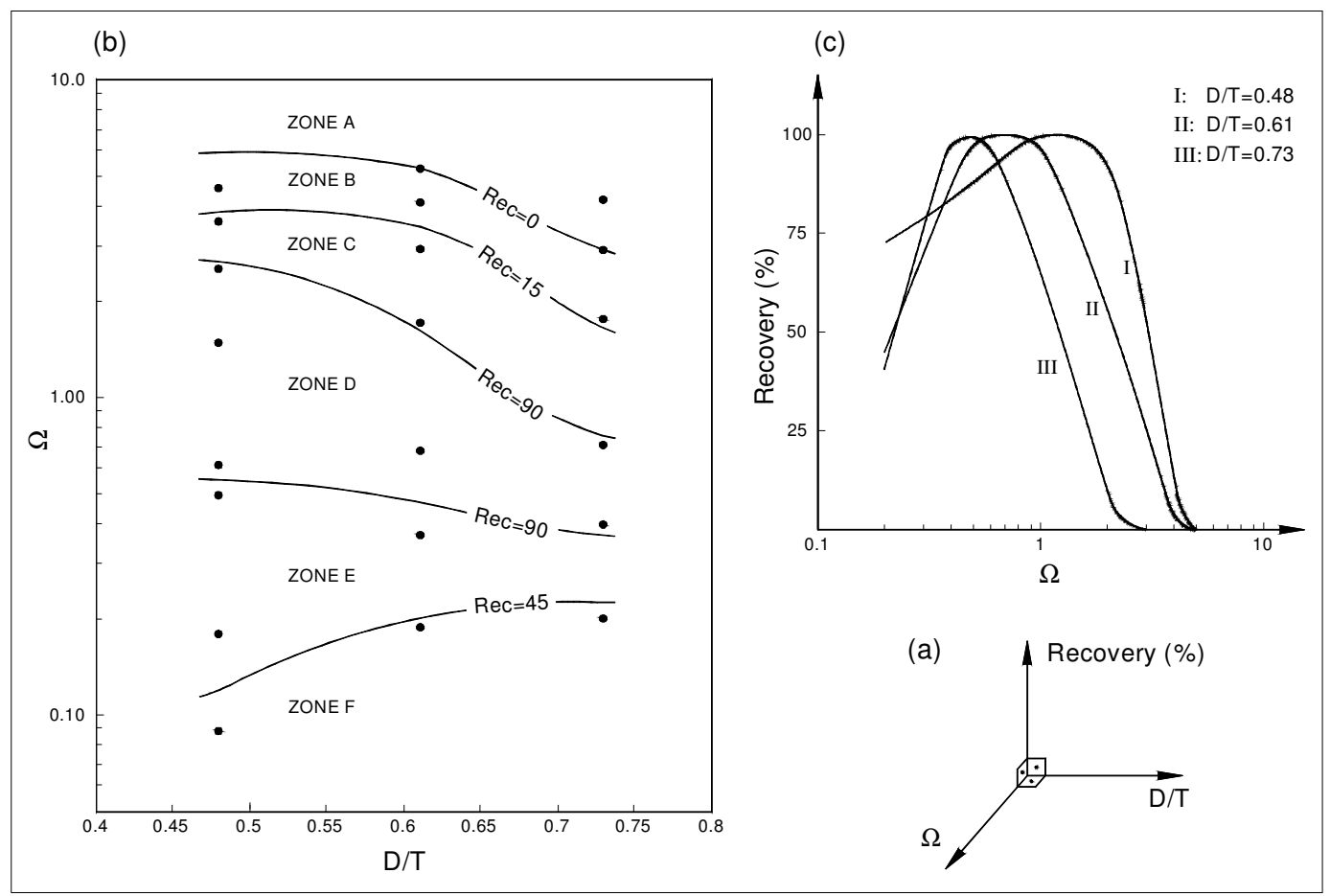

Figura 5.1. A influência das características geométricas do conjunto tanque + impelidor (D/T) e a capacidade do impelidor para manter as partículas em suspensão $(\Omega)$ sobre a recuperação das esferas de vidro $\left(d_{p} \cong 0,248 \mathrm{~mm}\right)$.

A figura 5.1 compreende os parâmetros tanto geométricos como dinâmicos do sistema, bem como o desempenho da flotação.

i. Características geométricas do conjunto tanque + impelidor (D/T no eixo $\mathrm{X})$;

ii. A disponibilidade de macro turbulência para manter as partículas em suspensão ( $\Omega$ no eixo $Y$ );

iii. Recuperação da flotação (R no eixo Z).

É possível observar que na figura 5.1 (b), ao longo do plano $X Y$, curvas nas quais todos os pontos (D/T, $\Omega$ ) exibem a mesma recuperação. Elas foram denominadas curvas de iso - recuperação ( $\operatorname{Rec}=0$; $\operatorname{Rec}=15 ; \operatorname{Rec}=45$ e $\operatorname{Rec}=90$ ) e foram utilizadas para delimitar os domínios hidrodinâmicos (Zonas de A a F). Os resultados são resumidos na tabela 5.2 . 
Tabela 5.2. Recuperação versus condições hidrodinâmicas da célula de microflotação.

\begin{tabular}{|c|c|c|c|}
\hline \multirow{2}{*}{$\begin{array}{c}\text { Domínios } \\
\text { hidrodinâmicos }\end{array}$} & \multirow{2}{*}{$\begin{array}{c}\text { Comportamento da } \\
\text { recuperação }\end{array}$} & \multicolumn{2}{|c|}{ Números adimensionais } \\
\hline & & $\mathrm{D} / \mathrm{T}=0,48$ & $\mathrm{D} / \mathrm{T}=0,73$ \\
\hline $\begin{array}{l}\text { Zonas A+B } \\
\text { - Grande turbulência; } \\
\text { - Forças inerciais } \\
\text { predominando sobre } \\
\text { a gravidade; } \\
\text { - Menores valores de } \\
\text { Po; } \\
\text { - Bolhas + solução } \\
\text { se comportando } \\
\text { como se fossem } \\
\text { uma única fase. }\end{array}$ & $\begin{array}{l}\text { - Muito baixa } \\
\text { - 0\%<Rec }<15 \%\end{array}$ & $\begin{array}{l}\operatorname{Re}_{1}>10300 \\
\mathrm{Fr}_{1}>2,95 \\
\mathrm{Po}<1,18 \\
\operatorname{Re}_{\mathrm{p}}>18,44 \\
\operatorname{Re}_{b}>29,91 \\
\mathrm{Fr}_{\mathrm{p}}>1,94 \\
\mathrm{We} \mathrm{e}_{\mathrm{B}}>0,064\end{array}$ & $\begin{array}{l}\operatorname{Re}_{1}>15400 \\
\mathrm{Fr}_{1}>1,86 \\
\mathrm{Po}<0,71 \\
\operatorname{Re}_{\mathrm{p}}>11,78 \\
\operatorname{Re}_{b}>19,11 \\
\mathrm{Fr}_{\mathrm{p}}>0,77 \\
\mathrm{We} \mathrm{e}_{\mathrm{B}}>0,026\end{array}$ \\
\hline $\begin{array}{l}\text { Zona C } \\
\text { - Transição entre B e } \\
\text { D }\end{array}$ & $\begin{array}{l}\text { - Muito sensível às } \\
\text { condições } \\
\text { hidrodinâmicas } \\
\text { - } 15 \%<\operatorname{Rec}<90 \%\end{array}$ & $\begin{array}{l}7700<\mathrm{Re}_{1}<10300 \\
1,66<\mathrm{Fr}_{1}<2,95 \\
1,18<\mathrm{Po}_{0}<1,32 \\
11,91<\mathrm{Re}_{\mathrm{p}}<18,44 \\
19,34<\mathrm{Re}_{\mathrm{b}}<29,91 \\
0,83<\mathrm{Fr}_{\mathrm{p}}<1,94 \\
0,027<\mathrm{We}_{\mathrm{B}}<0,064\end{array}$ & $\begin{array}{l}8800<\operatorname{Re}<15400 \\
0,61<\mathrm{Fr}_{1}<1,86 \\
0,71<\mathrm{Po}_{0}<0,92 \\
3,96<\mathrm{Re}_{\mathrm{p}}<11,78 \\
6,42<\mathrm{Re}_{\mathrm{b}}<11,78 \\
0,09<\mathrm{Fr}_{\mathrm{p}}<0,77 \\
0,0029<\mathrm{We}_{\mathrm{B}}<0,026 \\
\end{array}$ \\
\hline $\begin{array}{l}\text { Zona D } \\
\text { - O escoamento é } \\
\text { menos turbulento } \\
\text { que as zonas } \\
\text { A+B+C; } \\
\text { - A gravidade } \\
\text { começa a dominar } \\
\text { sobre a inércia; } \\
\text { - As bolhas estão } \\
\text { completamente } \\
\text { dispersas na célula. }\end{array}$ & $\begin{array}{l}\text { - Máxima recuperação } \\
\text { - Rec>90\% }\end{array}$ & $\begin{array}{l}1300<\mathrm{Re}_{\mathrm{l}}<7700 \\
0,05<\mathrm{Fr}_{1}<1,66 \\
1,32<\mathrm{Po}_{0}<2,01 \\
1,61<\mathrm{Re}_{\mathrm{p}}<11,91 \\
2,61<\mathrm{Re}_{\mathrm{b}}<19,34 \\
0,05<\mathrm{Fr}_{\mathrm{p}}<0,83 \\
49.10^{-5}<\mathrm{We}_{\mathrm{B}}<0,027\end{array}$ & $\begin{array}{l}3600<\operatorname{Re}_{1}<8800 \\
0,10<\mathrm{Fr}_{1}<0,61 \\
0,92<\mathrm{Po}_{\mathrm{P}}<1,06 \\
1,94<\mathrm{Re}_{\mathrm{p}}<3,96 \\
3,15<\mathrm{Re}_{b}<6,42 \\
0,02<\mathrm{Fr}_{\mathrm{p}}<0,09 \\
71.10^{-5}<\mathrm{We}_{\mathrm{B}}<0,0029\end{array}$ \\
\hline $\begin{array}{l}\text { Zonas E+F } \\
\text { - Baixa suspensão } \\
\text { de partículas; } \\
\text { - Menor turbulência; } \\
\text { - Baixa dispersão de } \\
\text { bolhas na célula; } \\
\text { - Alto Po. }\end{array}$ & $\begin{array}{l}\text { - Pequeno aumento } \\
\text { ou decréscimo em } \\
\text { função das condições } \\
\text { hidrodinâmicas } \\
\text { - Rec<90\% }\end{array}$ & $\begin{array}{l}\operatorname{Re}_{1}<1300 \\
\mathrm{Fr}_{1}<0,05 \\
\mathrm{Po}>2,01 \\
\operatorname{Re}_{\mathrm{p}}<1,61 \\
\operatorname{Re}_{b}<2,61 \\
\mathrm{Fr}_{\mathrm{p}}<0,05 \\
\mathrm{We}_{\mathrm{B}}<49.10^{-5}\end{array}$ & $\begin{array}{l}\operatorname{Re}_{1}<3600 \\
\mathrm{Fr}_{1}<0,1 \\
\mathrm{Po}>1,06 \\
\operatorname{Re}_{\mathrm{p}}<1,94 \\
\operatorname{Re}_{b}<3,15 \\
\mathrm{Fr}_{\mathrm{p}}<0,02 \\
\mathrm{We}_{\mathrm{B}}<71.10^{-5}\end{array}$ \\
\hline
\end{tabular}

Segundo os resultados apresentados na figura 5.1 (b) e tabela 5.2, é importante ressaltar:

i. Na zona $\mathrm{A}+\mathrm{B}$, a velocidade do impelidor $(\mathrm{N})$ é de 3 a 4 vezes maior que a velocidade crítica para completa suspensão das partículas $\left(\mathrm{N}_{\mathrm{Z}}\right)$, assim bolhas e a solução se comportam como se fossem uma única fase. A recuperação é muito baixa ou, em alguns casos, nula.

ii. Na zona $\mathrm{C}, \mathrm{N}$ é de 2 a 3 vezes maior que $\mathrm{N}_{\mathrm{Z}}$, e a recuperação varia 
de $15 \%$ a $90 \%$, dependendo das condições hidrodinâmicas que caracterizam o experimento. As partículas estão completamente suspensas (disponíveis para colidir com as bolhas); bolhas mostram movimento relativo em relação ao fluido (observação visual) e estão totalmente dispersas na célula. Por sua vez, o desempenho da flotação está dependente do nível de turbulência disponível no sistema para destruir o agregado partícula-bolha.

iii. Na zona $D, \Omega$ varia de 0,6 a 2, onde a flotação atinge seu melhor desempenho (Recuperação>90\%). Esta zona proporciona a melhor condição hidrodinâmica para partículas flotarem: turbulência suficiente para manter as partículas em suspensão e dispersão das bolhas, preservando o agregado partícula - bolha. Embora o impelidor opere com valores de $\mathrm{N}$ pouco menores que $\mathrm{N}_{Z}(0,6<\Omega<1)$, o desempenho da flotação não é afetado. Certamente, a existência de um fluxo ascendente de ar forneceu um auxílio adicional para suspender as partículas. Isto deve ser levado em consideração quando se usa o enfoque de Zwietering.

iv. Na zona $E+F, N$ é notavelmente menor que o valor crítico $(\Omega<0,5)$ e partículas tenderão a sedimentar. As bolhas não estão completamente dispersas na célula. Por conseguinte, a recuperação decresce com a diminuição de $\mathrm{N}$.

No sistema experimental utilizado nessa pesquisa, para $\mathrm{D} / \mathrm{T}=0,48$, trabalhouse em condição de equilíbrio entre cisalhamento de polpa e bombeamento, enquanto que para $\mathrm{D} / \mathrm{T}=0,61$ e $\mathrm{D} / \mathrm{T}=0,73$, operou-se sob o domínio de condições cisalhantes. Através da figura 5.1 (c) se pode verificar que:

i. Para $\Omega>1,5$, a relação $\mathrm{D} / \mathrm{T}=0,48$ apresentou maior recuperação que $\mathrm{D} / \mathrm{T}=0,63$ e $\mathrm{D} / \mathrm{T}=0,75$. Isto indica que condições equilibradas de bombeamento e cisalhamento criam condições turbulentas mais propícias no sistema para maior preservação do agregado partículabolha.

ii. $\operatorname{Em} \Omega>0,2$, a condição $\mathrm{D} / \mathrm{T}=0,48$, privilegiando o bombeamento da polpa em prejuízo ao seu cisalhamento, propiciou melhores condições de suspensão e, conseqüentemente, colisão partícula - 
bolha.

Como observado na tabela 5.2, a turbulência é continuamente abrandada da zona $A+B$ (maior turbulência) para zona $E+F$ (menor turbulência). No entanto, admitindo-se Reynolds ( $\mathrm{Re}_{\mathrm{l}}, \mathrm{Re}_{\mathrm{p}}, \mathrm{Re}_{\mathrm{b}}$ ) como parâmetro usado para caracterizar o regime, diferentes classificações foram encontradas, como por exemplo, na zona $\mathrm{A}+\mathrm{B}$ :

i. Se $\mathrm{Re}_{\text {I }}$ fosse usado como um parâmetro de referência, o regime de escoamento seria classificado como turbulento;

ii. O escoamento seria semi-turbulento, caso $R e_{p}$ ou $R e_{b}$ fossem adotados como referência.

A mesma observação poderia ser feita para o número de Froude: as forças inerciais são continuamente diminuídas da zona $A+B$ (valores maiores) para zona $\mathrm{E}+\mathrm{F}$ (valores inferiores). Todavia, se $\mathrm{Fr}_{\text {ı }}$ é usado como parâmetro de referência, a inércia poderia ser considerada como predominante na zona C. Porém, caso $\mathrm{Fr}_{\mathrm{p}}$ seja utilizado como referencial, prevaleceria a gravidade.

Embora esses números sejam utilizados para delimitar as condições hidrodinâmicas que promovem a maior recuperação, quando se faz considerações teóricas baseadas somente nesses números adimensionais, deve-se tomar muito cuidado no que diz respeito ao sistema adotado como referência.

Quando as bolhas estão dispersas num meio turbulento, elas estão sujeitas às tensões de cisalhamento oriundas dos movimentos dos vórtices turbulentos e o efeito estabilizador provém da pressão capilar na bolha. É possível verificar na tabela 5.2 que o número de Weber da bolha decresce da zona $A+B$ (maior turbulenta) para zona $E+F$ (menor turbulência) e $W e_{B}<<1$ em todos os casos.

Ao contrário da suspensão das partículas, que é amplamente controlada pela macro turbulência, a dispersão do gás na polpa, a colisão partícula-bolha e a estabilidade desse agregado no meio turbulento são controlados pela micro turbulência, a qual é gerada pelo cisalhamento da polpa. Uma vez que a estrutura e intensidade da micro turbulência dependem somente da energia dissipada $\left(\varepsilon_{\mathrm{D}}\right)$ e da viscosidade cinemática da polpa $(v)$, foi importante estudar a influência de ambas variáveis sobre a flotação das esferas de vidro grossas. Os resultados são apresentados na figura 5.2 . 


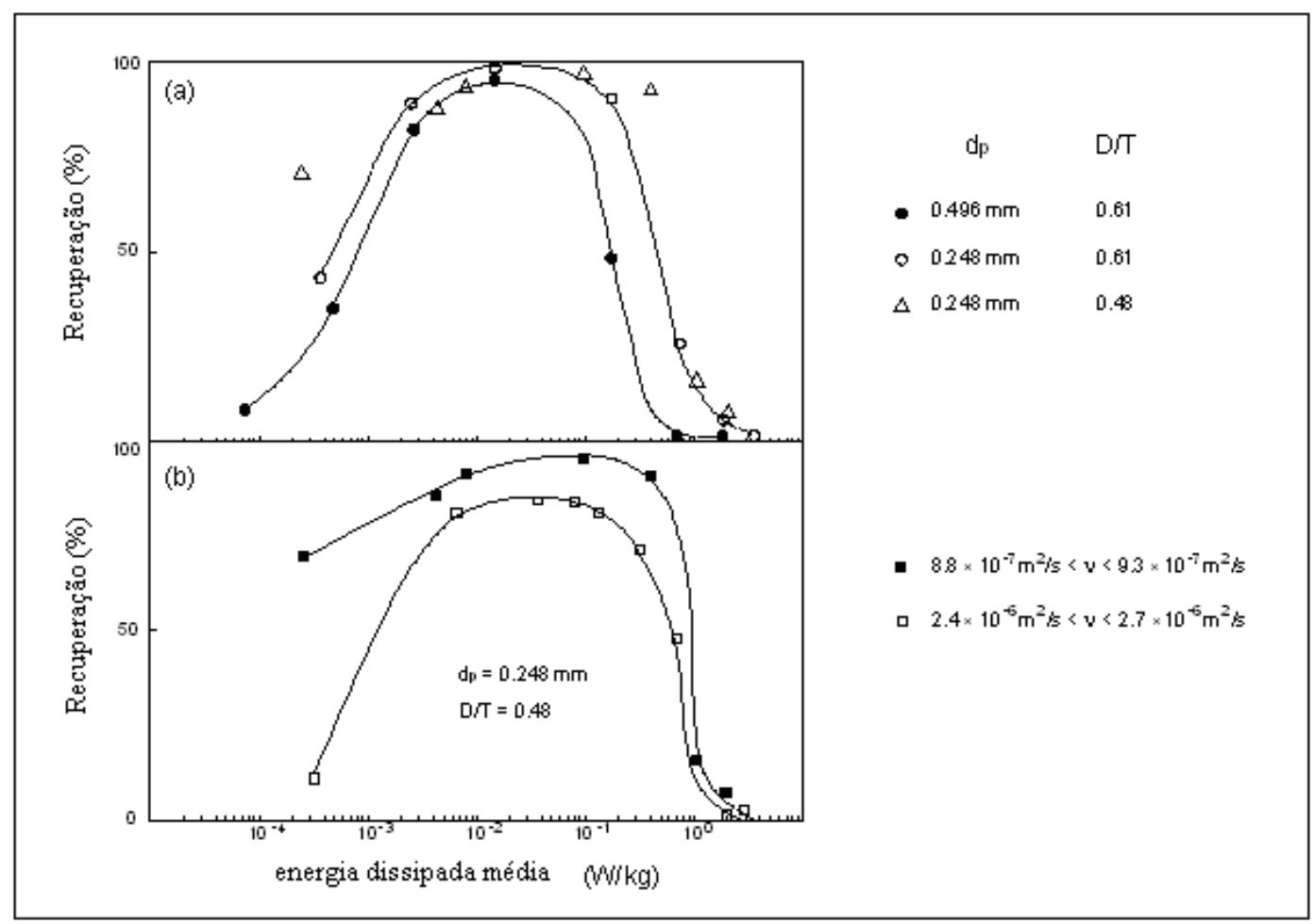

Figura 5.2. Recuperação das esferas de vidro versus a energia dissipada média e a viscosidade cinemática.

É possível observar na figura 5.2 que a recuperação atinge seu máximo quando a energia dissipada média está no intervalo $3.10^{-3}<\varepsilon_{D}<2.10^{-1} \mathrm{~W} / \mathrm{kg}$ para esferas com $d_{p}=0,248 \mathrm{~mm}$ e $3.10^{-3}<\varepsilon_{D}<1.10^{-1} \mathrm{~W} / \mathrm{kg}$ para partículas de diâmetro igual a 0,496 mm. No que diz respeito à figura 5.2 (a) é importante ressaltar que:

i. Os valores de $\varepsilon_{D}$ que promovem a máxima recuperação são aproximadamente os mesmos para ambas, $d_{p}=0,248 \mathrm{~mm}$ e $d_{p}=$ $0,496 \mathrm{~mm}$. Além disso, o diâmetro da bolha é maior que $d_{p}=0,248$ $\mathrm{mm}$ e menor que $d_{p}=0,496 \mathrm{~mm}$;

ii. Quando $\varepsilon_{D}<3.10^{-3} \mathrm{~W} / \mathrm{kg}$, há uma fraca dispersão das bolhas e suspensão das partículas no sistema, como aquelas que ocorrem ao longo da zona $E+F$ (tabela 5.2 e figura 5.1).

iii. Quando $\varepsilon_{D}>2.10^{-1} \mathrm{~W} / \mathrm{kg}$, a micro turbulência disponível no sistema é alta o suficiente para destruir o agregado partícula-bolha e comprometer a recuperação da flotação das esferas de vidro.

Nos sistemas reais de flotação, partículas grossas são flotadas juntamente com finas em polpas que contêm considerável quantidade de sólidos $(10 \%<\phi<30 \%)$. 
Para simular tal situação, experimentos com esferas de vidro $\left(d_{p}=0,248 \mathrm{~mm}\right.$ e 0,496 $\mathrm{mm}$ ) foram executados com solução aquosa de sacarose a $30 \%$, mantendo-se $\theta$ entre $88^{\circ}$ e $89^{\circ}$.

Os resultados são apresentados na figura 5.2 (b), na qual é possível verificar como a recuperação das esferas de vidro foi afetada pela viscosidade cinemática do sistema. Pequenas variações na viscosidade cinemática ocorreram devido à oscilação de temperatura $\left(8,8 \cdot 10^{-7}<v<9,3 \cdot 10^{-7} \mathrm{~m}^{2} / \mathrm{s}\right.$ e $\left.2,6 \cdot 10^{-6}<\mathrm{v}<2,7.10^{-6} \mathrm{~m}^{2} / \mathrm{s}\right)$.

Conforme os resultados apresentados na figura 5.2 (b), são relevantes os seguintes comentários:

i. Para $\varepsilon_{\mathrm{d}}>1 \mathrm{~W} / \mathrm{kg}$, a flotação das esferas de vidro não foi afetada pela viscosidade cinemática (v). Para ambos os casos (alto ou baixo v), a recuperação foi muito baixa ou nula. Tal fato corrobora que sob severa turbulência e inércia (como na zona $A+B$ ), a influência da viscosidade cinemática é subjugada pelas forças inerciais, o que caracteriza um regime turbulento.

ii. No intervalo $0,1<\varepsilon_{d}<1 \mathrm{~W} / \mathrm{kg}$, um sistema menos turbulento, $v$ tem a maior influência na recuperação. Uma vez que, esse intervalo de energia dissipada está colocado no domínio da zona C (figura 5.1 e tabela 5.2), na qual a recuperação é muito sensível às condições hidrodinâmicas, mesmo pequenas alterações na magnitude da viscosidade cinemática, podem ser prejudiciais à flotação (principalmente em $0,6<\varepsilon_{d}<0,8 \mathrm{~W} / \mathrm{kg}$ ).

iii. No intervalo $7.10^{-3}<\varepsilon_{d}<1.10^{-1} \mathrm{~W} / \mathrm{kg}$, maior $v$ é realmente prejudicial à flotação. No entanto nesse intervalo, em ambos os casos (baixa e alta viscosidade), a diferença de recuperação $(\Delta \mathrm{Rec})$ permanece constante, em torno de 9\%. Esta diferença de recuperação, não pode ser explicada somente pelas condições hidrodinâmicas que caracterizam a zona D. Há na literatura especializada algumas evidências experimentais de que a viscosidade interfere diretamente no tempo de indução, logo, na eficiência de adesão partícula bolha.

iv. A condição $\varepsilon_{d}<7.10^{-3} \mathrm{~W} / \mathrm{kg}$ ajusta-se aos domínios hidrodinâmicos caracterizados pela zona $E+F$, na qual a turbulência não é suficiente 
para promover a colisão partícula - bolha. Uma vez que há fraca dispersão de bolhas e suspensão de partículas.

No entendimento do comportamento hidrodinâmico na célula de flotação, a densidade do sólido tem uma significante contribuição, uma vez que interfere diretamente nos eventos de colisão e estabilidade do agregado. No intuito de observar o efeito desta característica física dos minerais sobre o desempenho da flotação, gráficos dos parâmetros hidrodinâmicos versus recuperação para esferas de vidro e apatita ígnea, ambas com $d_{P} \cong 248 \mu \mathrm{m}$ são apresentado na figura 5.3 a 5.5 .

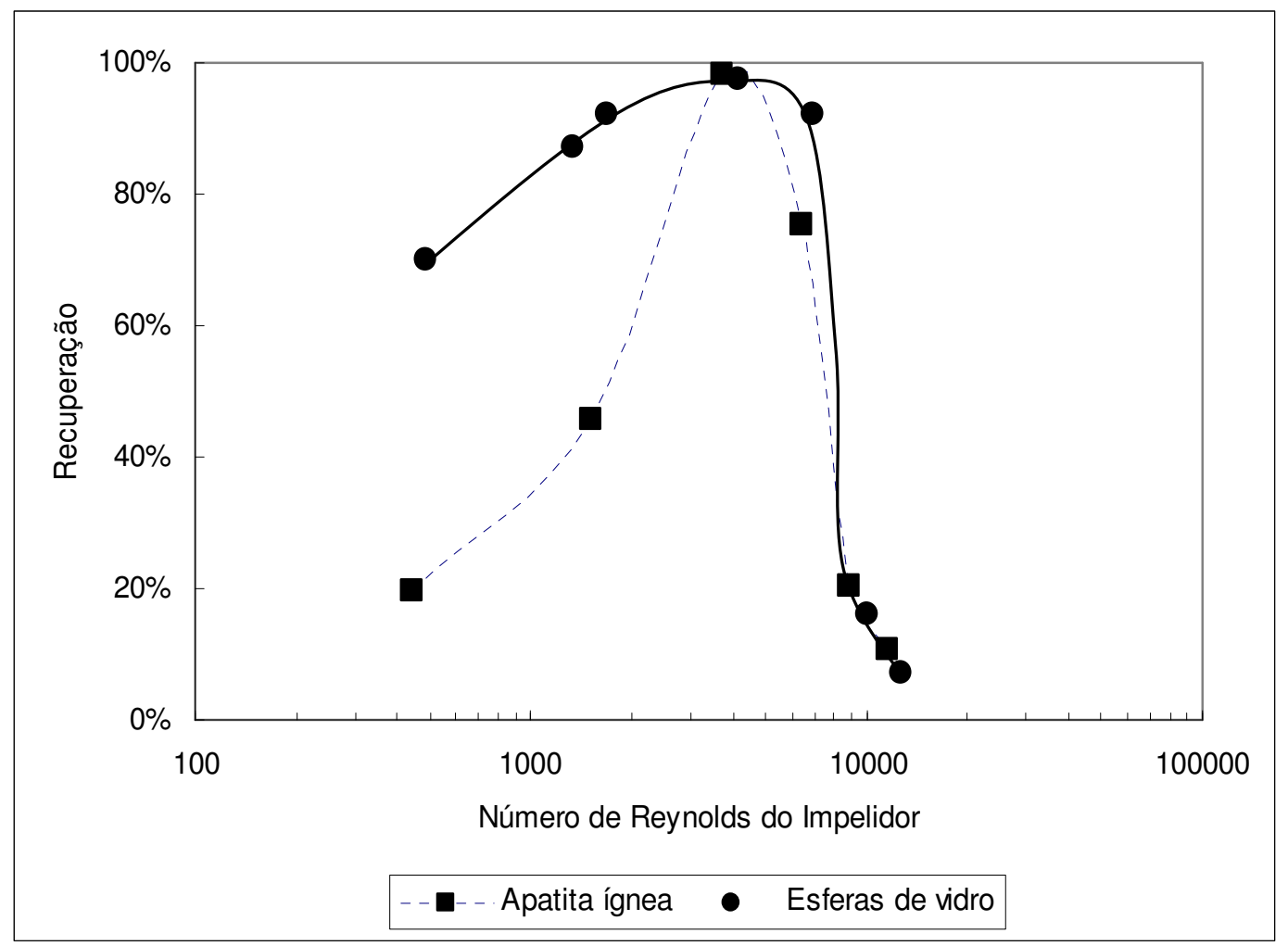

Figura 5.3. Recuperação versus número de Reynolds do impelidor. 


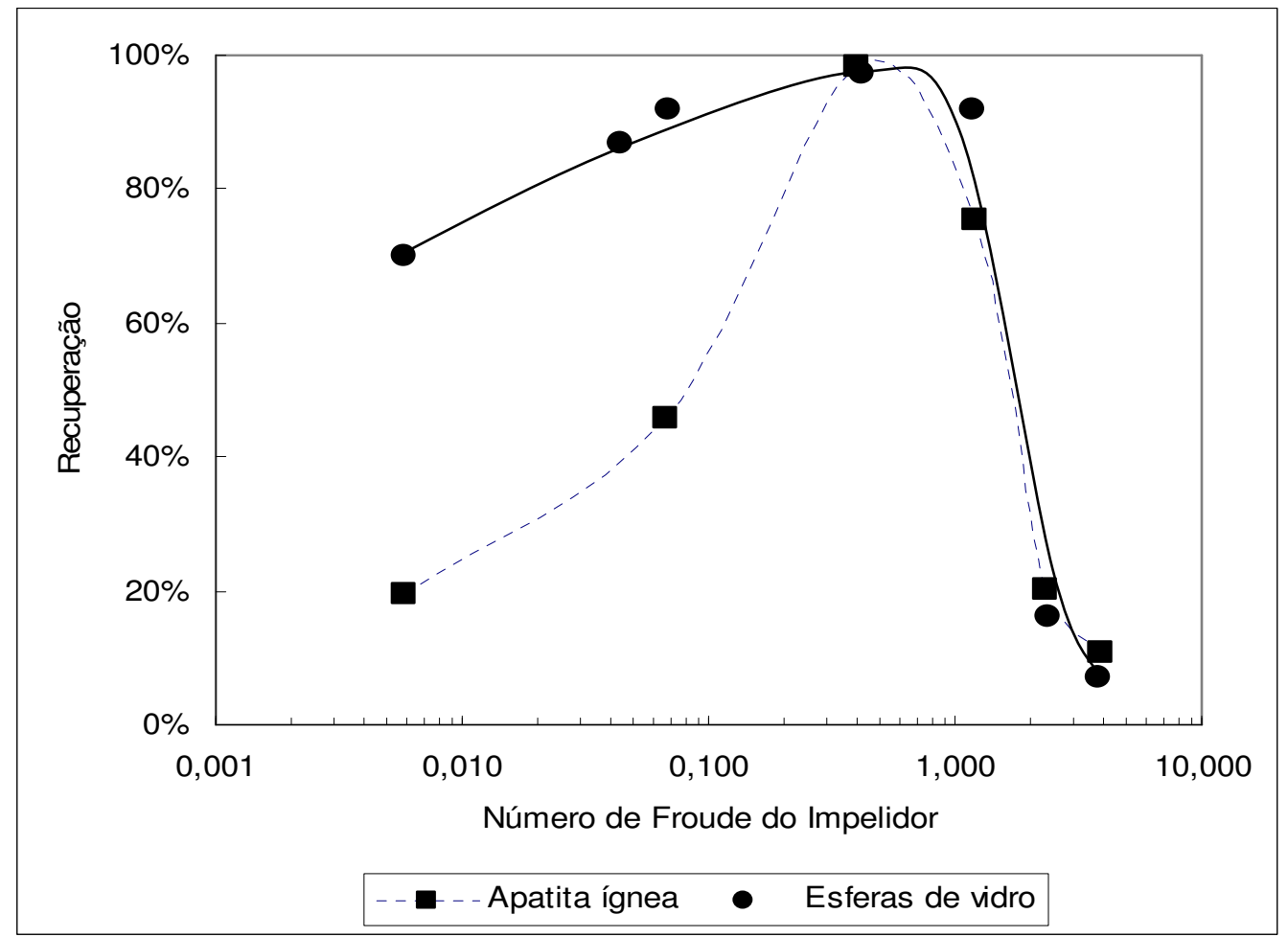

Figura 5.4. Recuperação versus número de Froude do impelidor.

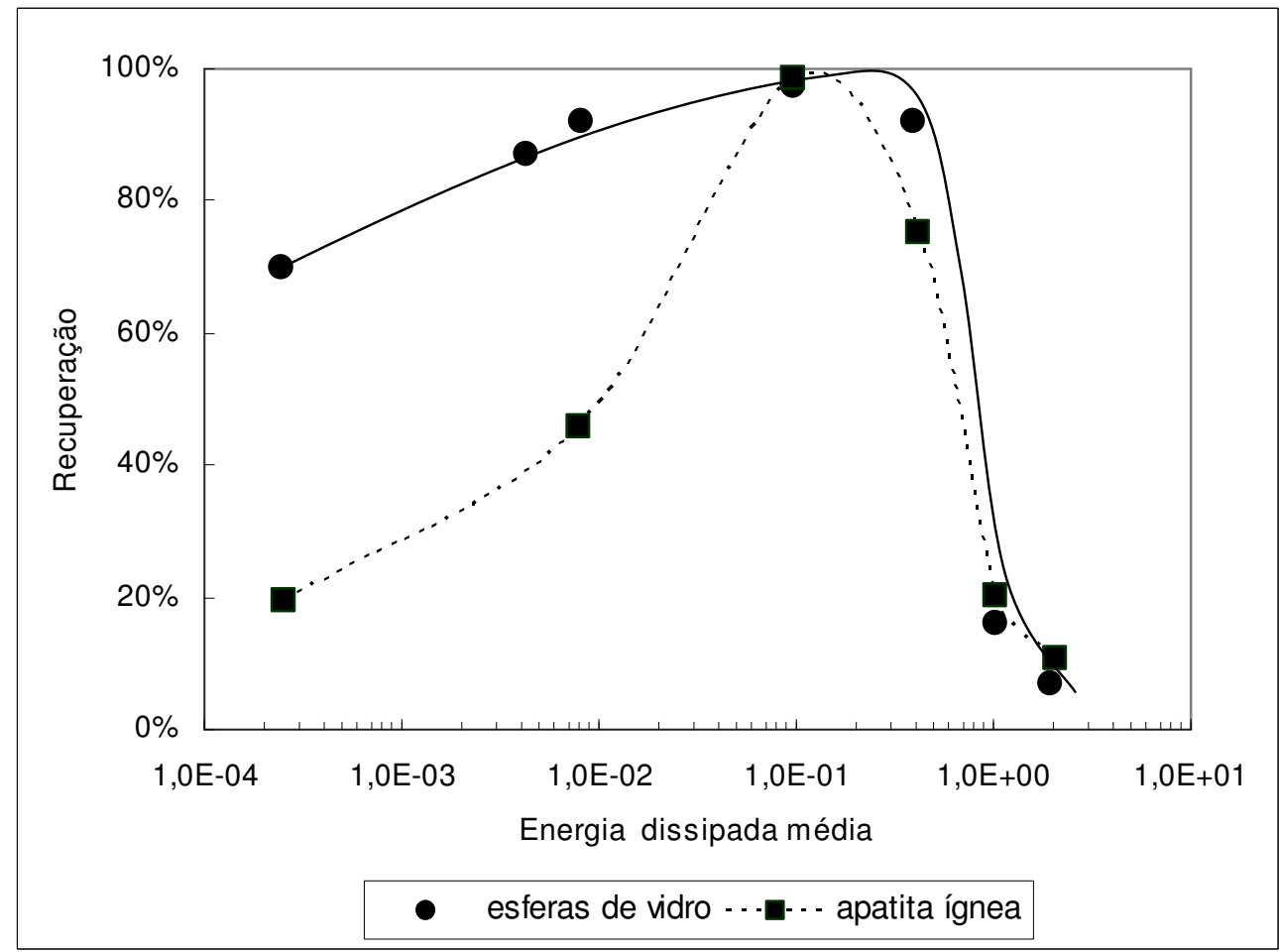

Figura 5.5. Recuperação versus energia dissipada média $\left(\varepsilon_{D}\right)$.

As figuras 5.3 a 5.5 indicam que recuperações superiores a $90 \%$ são obtidas em ambiente hidrodinâmico propício para flotação: 
- $0,3<\mathrm{Fr}_{1}<0,8$

- $4000<\mathrm{Re}_{1}<6000$;

- $0,08<\varepsilon_{D}<0,20$;

Por outro lado, o decréscimo nas colisões entre partículas e bolhas é evidenciado para condições menos turbulentas na célula de flotação, para $\mathrm{Fr}_{1}<0,3$; $R e_{1}<4000$ e $\varepsilon_{D}<0,08$, em função da suspensão incompleta dos sólidos na polpa. No entanto, em ambientes mais severos à flotação, ou seja, com aumento da turbulência, $\mathrm{Fr}_{1}>0,8 ; \operatorname{Re}_{1}>6000$ e $\varepsilon_{D}>0,20$ a sobrevivência do agregado partículabolha é comprometida.

Sumariando as figuras 5.3-5.5, vale ressaltar:

i. Em condições hidrodinâmicas pouco turbulenta a densidade da partícula possui maior influência, comprometendo a suspensão da polpa. Corroborado pelo critério de 1 segundo de Zwietering para um impelidor cilindróide (diâmetro $=15,5.10^{-2} \mathrm{~m}$ ), a apatita apresenta mínima velocidade de suspensão superior à esfera de vidro, interferindo desta forma no desempenho da flotação, conforme os valores apresentados na tabela 5.3, em virtude da redução de capacidade de transporte do impelidor nas proximidades de suas pás, em virtude da geração de cisalhamento.

Tabela 5.3. Características físicas da esfera de vidro e apatita e

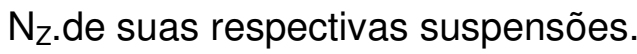

\begin{tabular}{|c|c|c|}
\hline Parâmetros & $\begin{array}{c}\text { Esferas de } \\
\text { vidro }\end{array}$ & $\begin{array}{c}\text { Apatita } \\
\text { ígnea }\end{array}$ \\
\hline Diâmetro da partícula, $\mathrm{d}_{\mathrm{p}},(\mathrm{mm})$ & 0,248 & 0,248 \\
\hline $\begin{array}{c}\text { Densidade da partícula, } \rho_{\mathrm{p}} \\
\left(\mathrm{kg} / \mathrm{m}^{3}\right)\end{array}$ & 2480 & 3200 \\
\hline $\mathrm{N}_{\mathrm{Z},(\mathrm{rps})}$ & 10,8 & 16 \\
\hline
\end{tabular}

ii. Ressalta-se ainda na tabela 5.3, que não houve alteração significativa na velocidade crítica em relação à introdução de gás nitrogênio no sistema de microflotação.

iii. Uma vez que a quantidade de movimento transmitida pelo impelidor às partículas na célula é suficiente para promover o maior número de colisões possível com as bolhas, a flotação atinge seu melhor 
desempenho.

iv. $\quad$ excesso de energia dissipada pelo impelidor atua em detrimento à estabilidade do agregado partícula-bolha.

A compreensão do efeito das forças de inércia e gravidade sobre a flotação foi possibilitada pelo uso de número de Froude da partícula $\left(\mathrm{Fr}_{\mathrm{p}}\right)$ como parâmetro hidrodinâmico de referência. Gráficos do número de Froude da partícula versus recuperação são apresentados na figura 5.6 e 5.7.

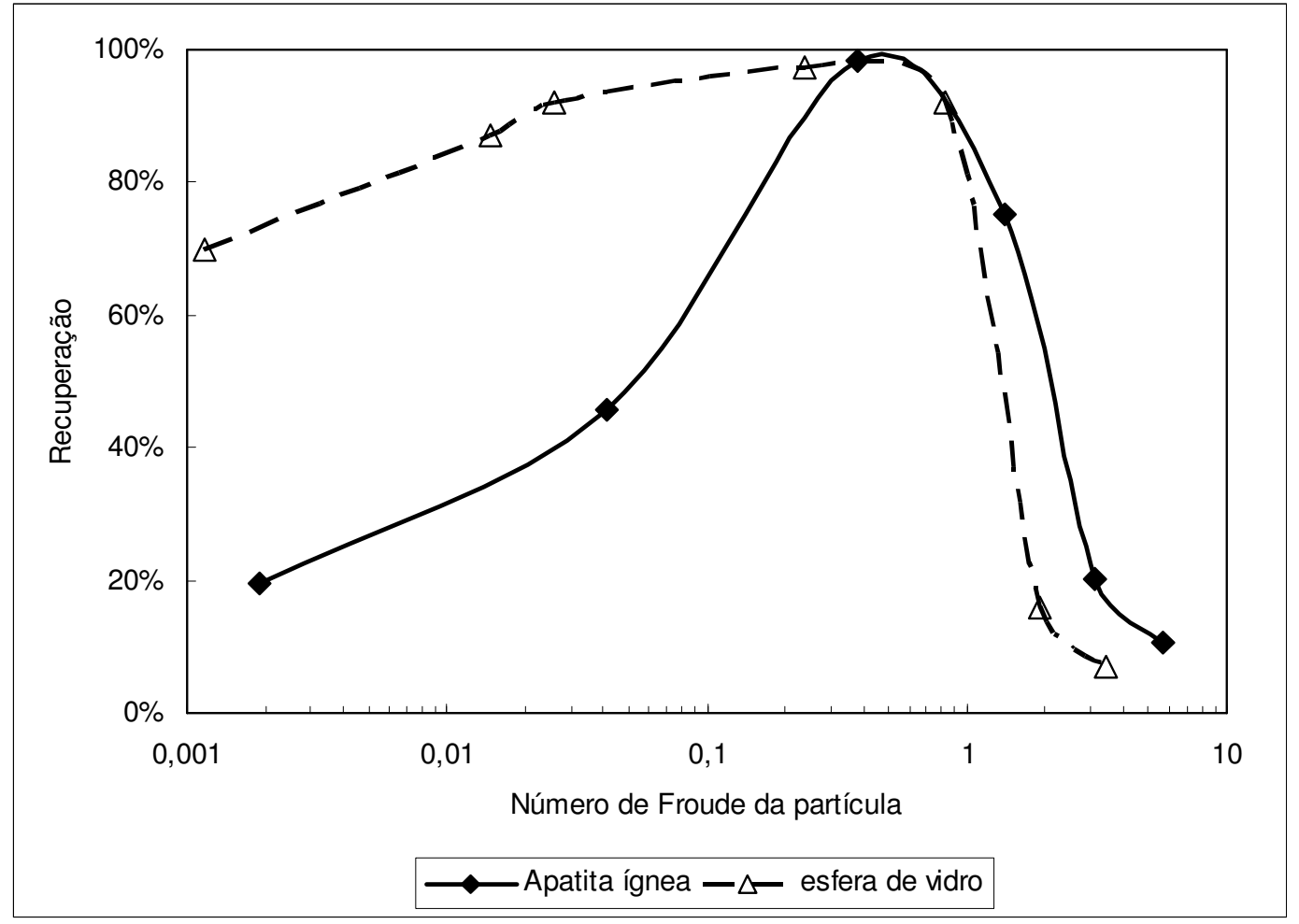

Figura 5.6. Número de Froude da partícula de esfera de vidro e apatita $\left(d_{P} \cong 248 \mu \mathrm{m}\right)$ versus recuperação. 


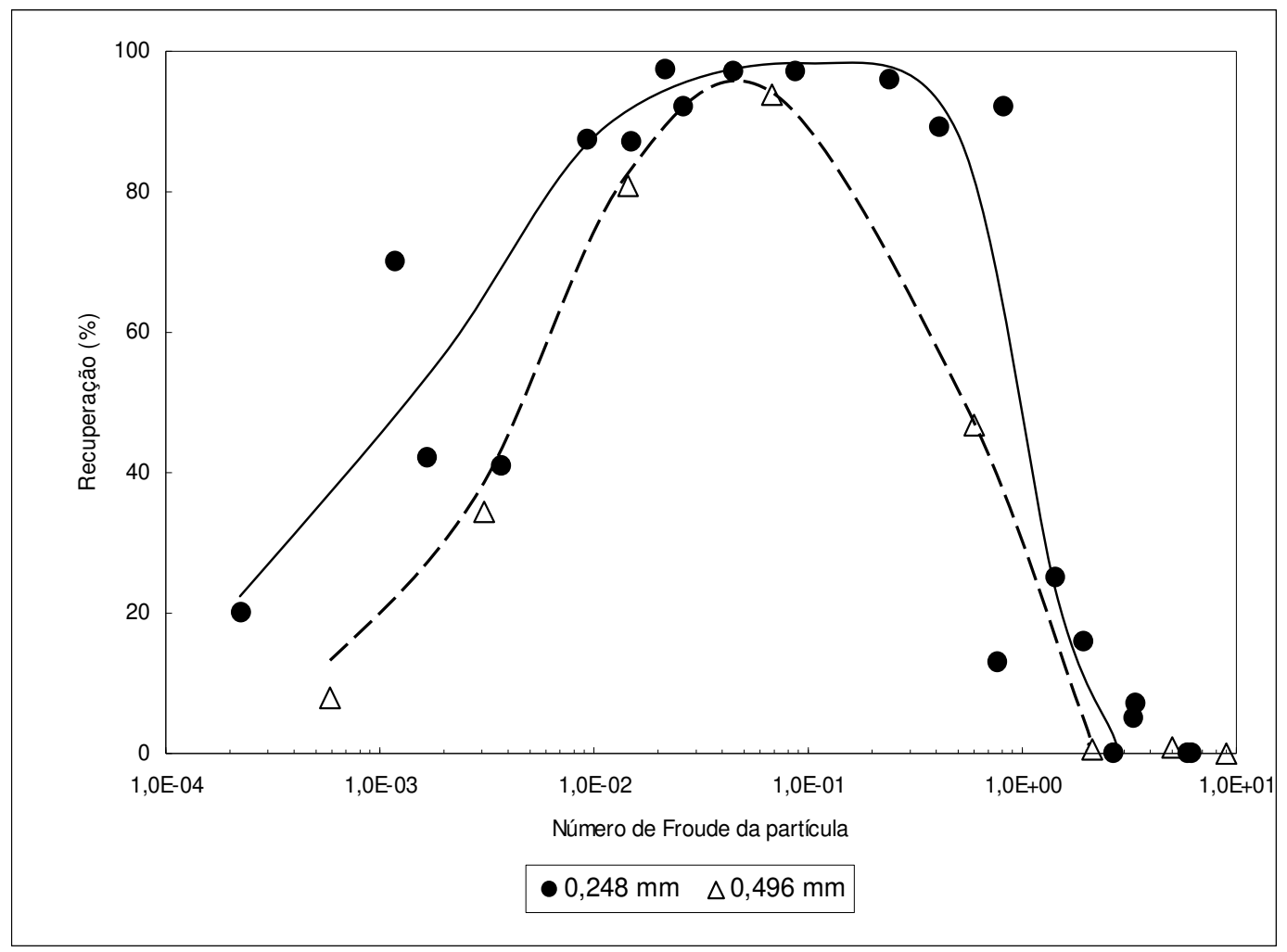

Figura 5.7. Número de Froude da partícula versus recuperação das esferas de vidro com diferentes diâmetros.

Com relação às figuras 5.6. e 5.7, observa-se:

i. $\quad E m \operatorname{Fr}_{p}>1,0$, a recuperação tanto das esferas de vidro $\left(d_{p} \cong 0,496 m m\right.$ e $0,248 \mathrm{~mm}$ ) como da apatita é baixa $(<20 \%)$ ou nula. As forças inerciais atuantes sobre as partículas fazem com que estas se incorporem ao fluido, isto é, não exibam movimento relativo. Isto significa que as partículas seguiram as linhas de fluxo do fluido em vez de colidirem e aderirem às bolhas. Isto tudo age em detrimento ao desempenho da flotação;

ii. Na figura 5.6, no intervalo $0,3<\mathrm{Fr}_{\mathrm{p}}<1$ é encontrado o melhor desempenho da flotação tanto para esferas de vidro como apatita ígnea, ambas com $d_{p} \cong 0,248 \mathrm{~mm}$, com recuperação $>90 \%$. No que se refere à figura 5.7 o melhor desempenho da flotação é observado na faixa $1.10^{-2}<\mathrm{Fr}_{\mathrm{p}}<8,3.10^{-2}$ para esferas de vidro $\mathrm{d}_{\mathrm{p}} \cong 0,248 \mathrm{~mm}$ e $d_{p} \cong 0,496 \mathrm{~mm}$. Nessas regiões a inércia é suficiente para promover a colisão da partícula - bolha e preservar o agregado, de modo que este alcance à camada de espuma; 
iii. $\quad E m F_{p}<1.10^{-2}$, onde há uma diminuição na recuperação, é possível observar que o amplo domínio da gravidade sobre a inércia é prejudicial à flotação. Isto se deve à baixa eficiência de colisão entre partículas e bolhas.

Ensaios de microflotação com diferentes formas de impelidores (Rushton, paddle e cilindróide) foram realizados no intuito de se avaliar a influência da forma do impelidor sobre a flotação das esferas de vidro ( $d_{p} \cong 0,248 \mathrm{~mm}$ ). Para uma mesma relação $\mathrm{D} / \mathrm{T}$ foi possível observar o comportamento hidrodinâmico da flotação, com auxílio dos parâmetros adimensionais e energia, conforme as figuras 5.8 a 5.11.

Com relação às figuras 5.8, 5.9 e 5.11, observa-se que a recuperação com relação ao tipo de impelidor não apresentou variações significativas para todos os parâmetros avaliados. No entanto, reportando-se à figura 5.10 , as seguintes notações devem ser feitas:

i. A máxima recuperação (100\%) para o impelidor cilindróide é obtida próxima a $\mathrm{Po}=1$, para turbina de Rushton com $\mathrm{Po}=1,3$ e Paddle para $P o=1,6$. Isto se explica pelo fato dos impelidores cilindróides apresentarem menor resistência ao fluxo da polpa, conseqüentemente suporta mais a turbulência no sistema.

ii. À medida que o Po diminui foi possível observar grande declínio na recuperação, devido ao aumento do nível de turbulência no sistema.

iii. As baixas recuperações para os maiores Po de cada impelidor podem ser justificadas pelos baixos níveis de agitação, ou seja, pouquíssimo contato entre as partículas e as bolhas.

Com a necessidade de observar a influência da percentagem de sólidos e parâmetros em maior escala, como diâmetro do impelidor, foram realizados os ensaios em escala de bancada. Estes resultados estão apresentados no tópico posterior. 

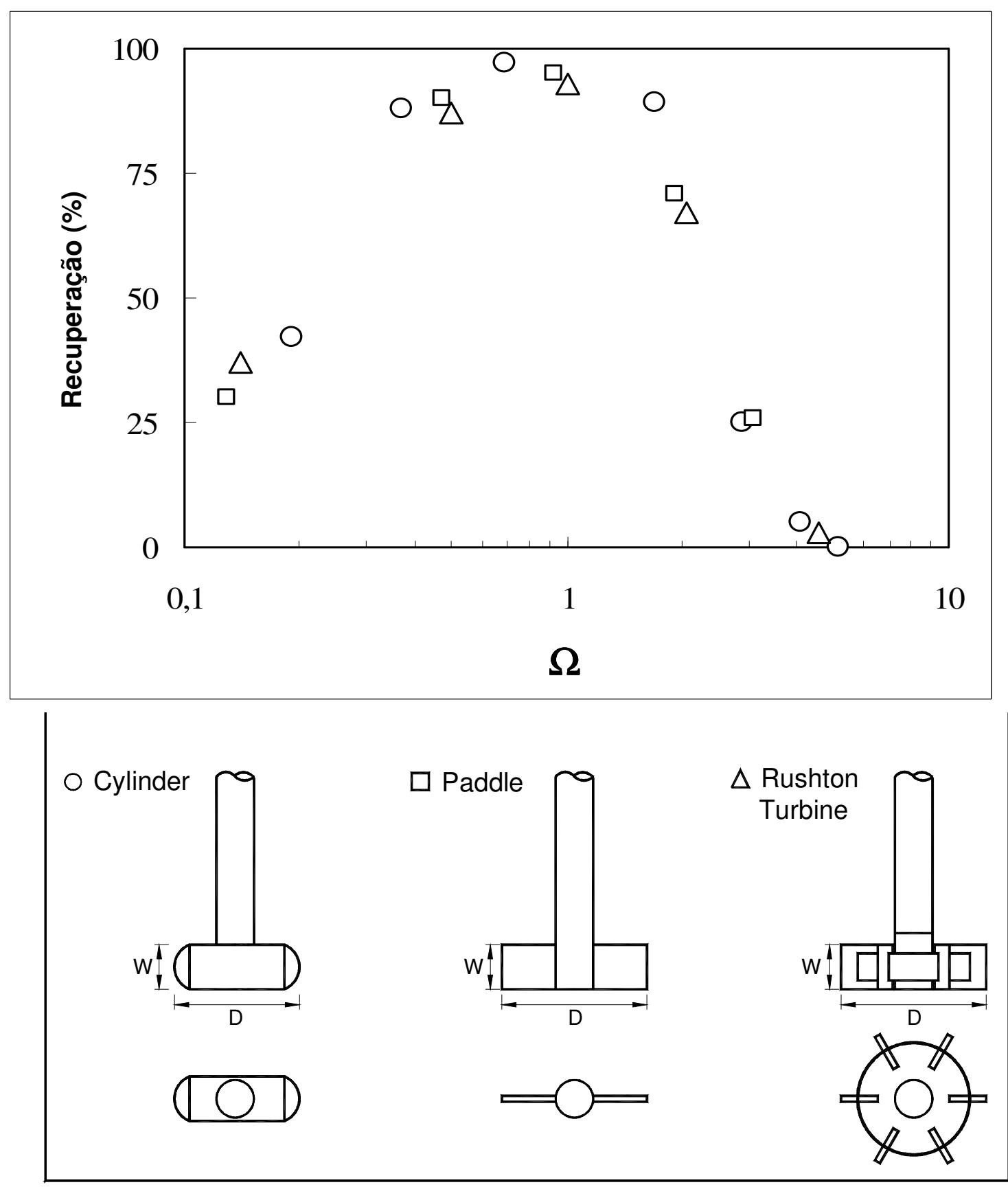

Figura 5.8. Recuperação das esferas de vidro $\left(d_{p} \cong 248 \mu \mathrm{m}\right)$ versus $\Omega$ para diferentes impelidores, $\mathrm{D} / \mathrm{T}=0,62$. 


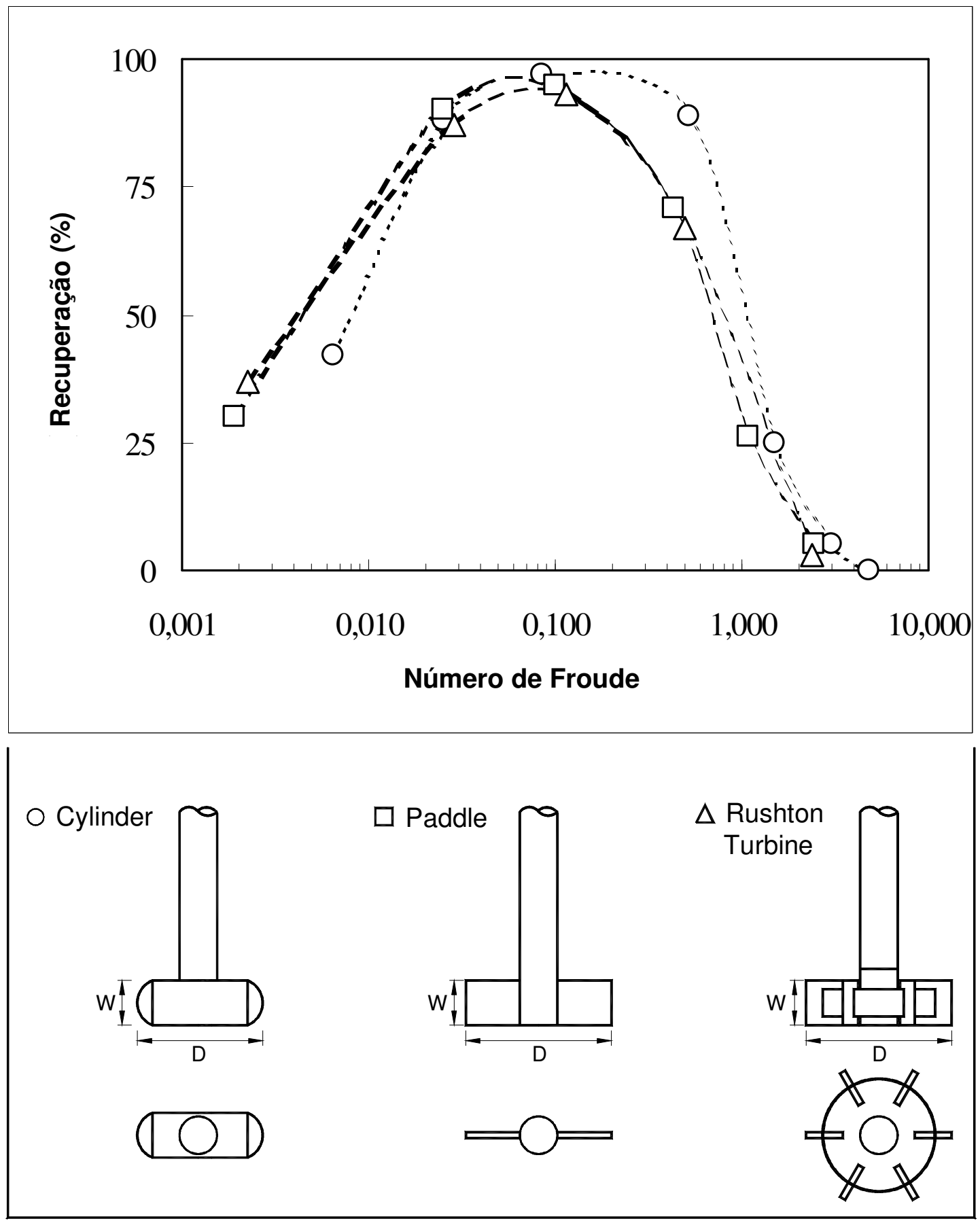

Figura 5.9. Recuperação das esferas de vidro $\left(d_{p} \cong 248 \mu \mathrm{m}\right)$ versus número de Froude para diferentes impelidores, $\mathrm{D} / \mathrm{T}=0,62$. 


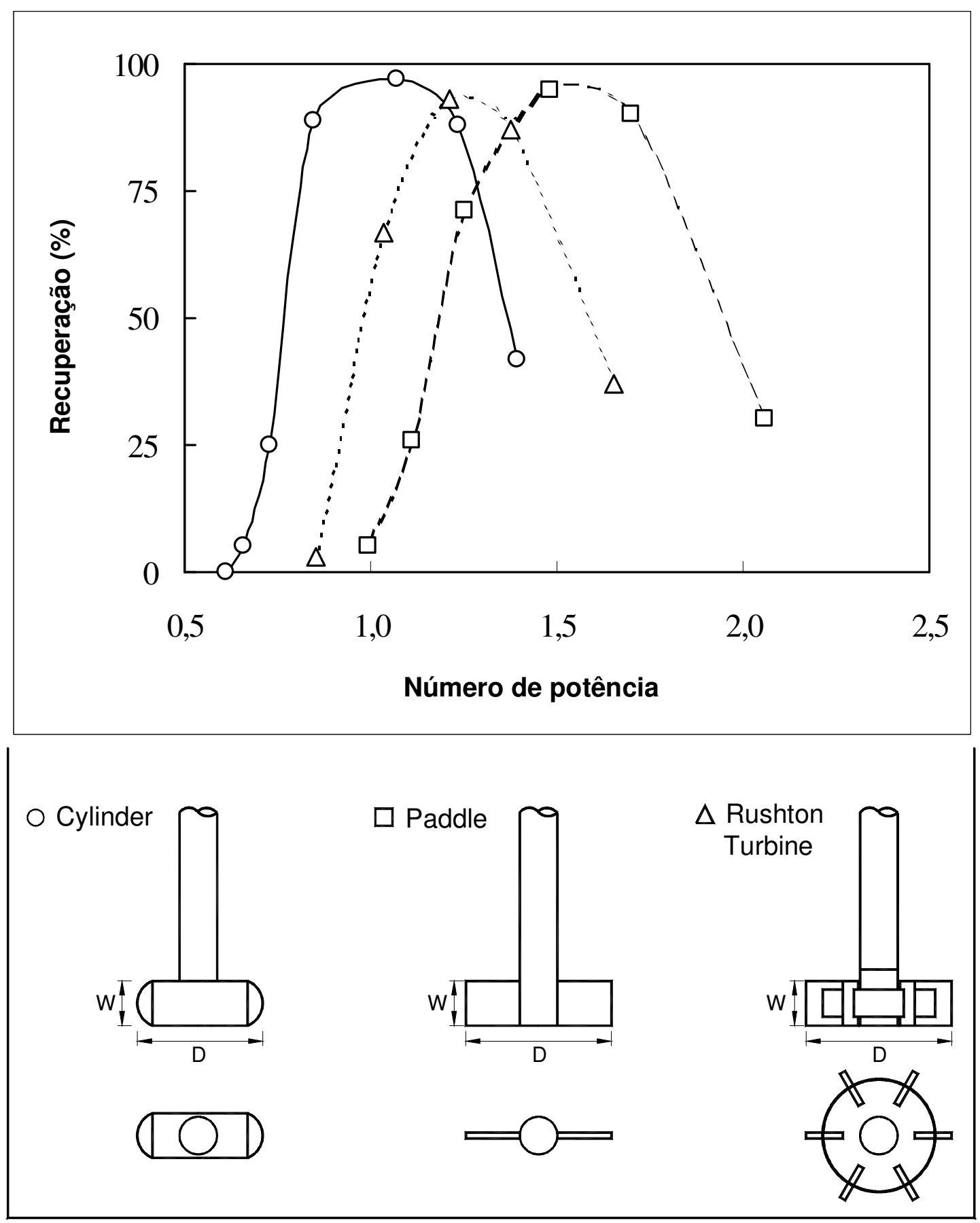

Figura 5.10. Recuperação das esferas de vidro $\left(d_{p} \cong 248 \mu \mathrm{m}\right)$ versus número de Potência para diferentes impelidores, $\mathrm{D} / \mathrm{T}=0,62$. 


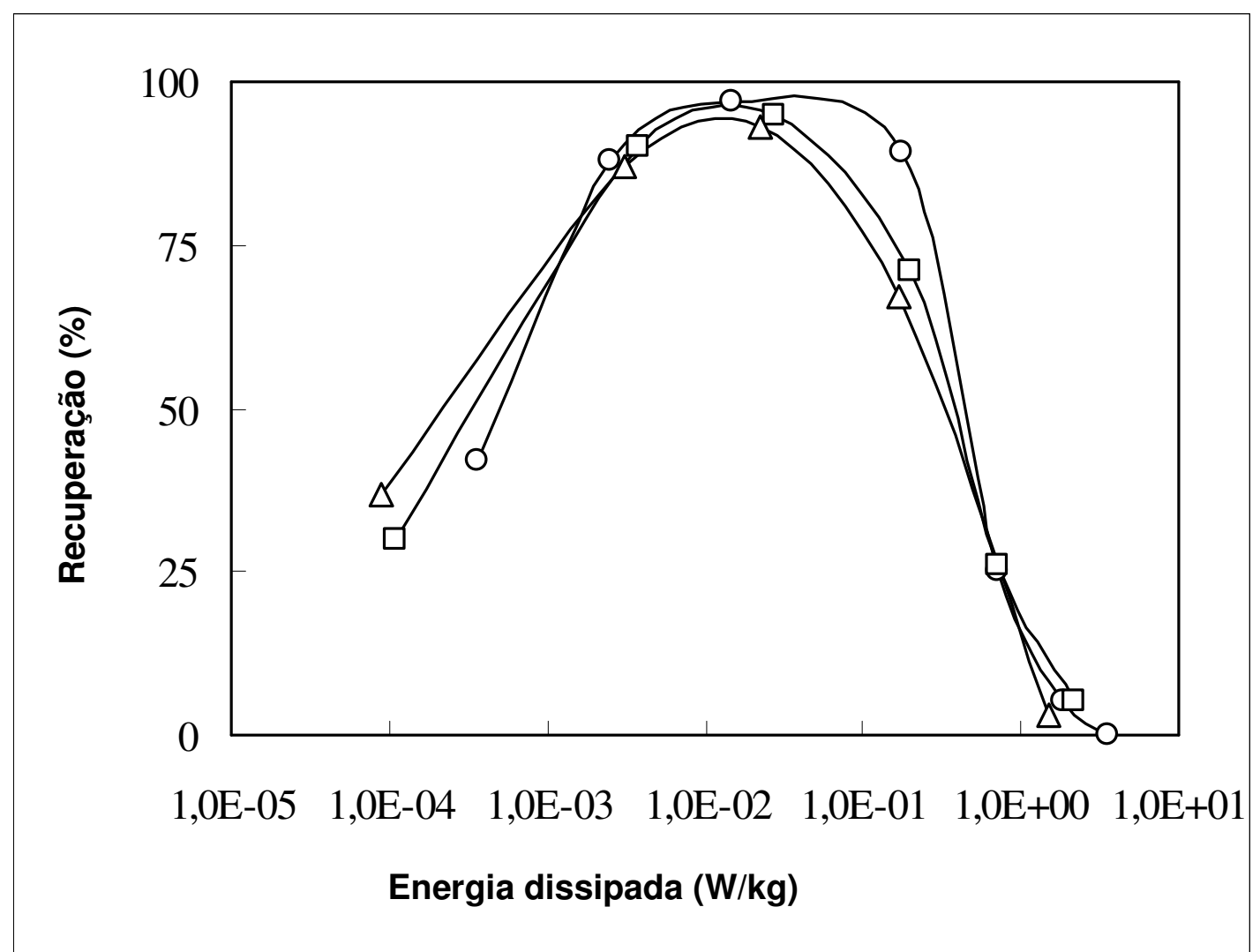

Cylinder
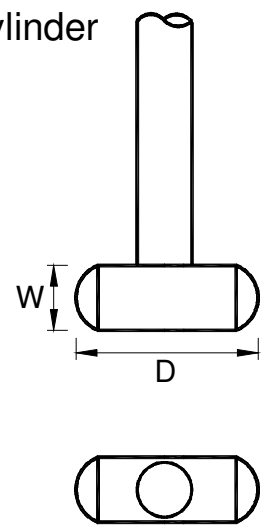

Paddle
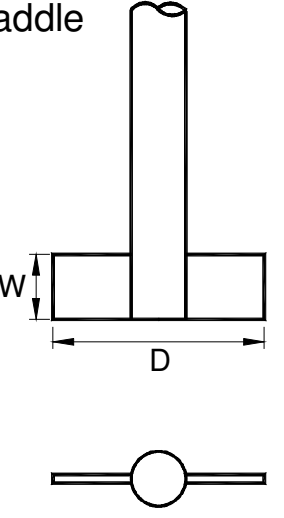

$\triangle$ Rushton

Turbine

W
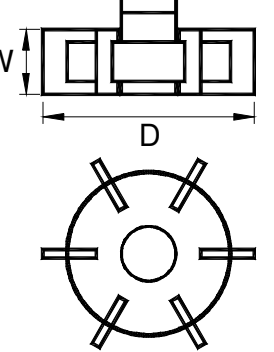

Figura 5.11. Recuperação das esferas de vidro $\left(d_{p} \cong 248 \mu \mathrm{m}\right)$ versus energia dissipada para diferentes impelidores, $\mathrm{D} / \mathrm{T}=0,62$. 


\subsection{Ensaios de Bancada.}

Ensaios de flotação, com maior percentagem de sólidos e volume polpa, possibilitam uma melhor visualização do comportamento hidrodinâmico do processo. Esta fase da pesquisa teve o intuito inicial de realizar o scale-up dos ensaios de microflotação.

Nos ensaios de flotação de bancada foram utilizados turbinas de Rushton, impelidores mais semelhantes aos utilizados em circuitos industriais. Um diagrama $\mathrm{D} / \mathrm{T}$ versus $\Omega$, com observações nas recuperações médias em cada ponto, foi construído a fim de estudar a influência de parâmetros geométricos (D/T) e de suspensão da polpa $(\Omega)$ no desempenho da flotação, conforme a figura 5.12 e a tabela 5.4 .

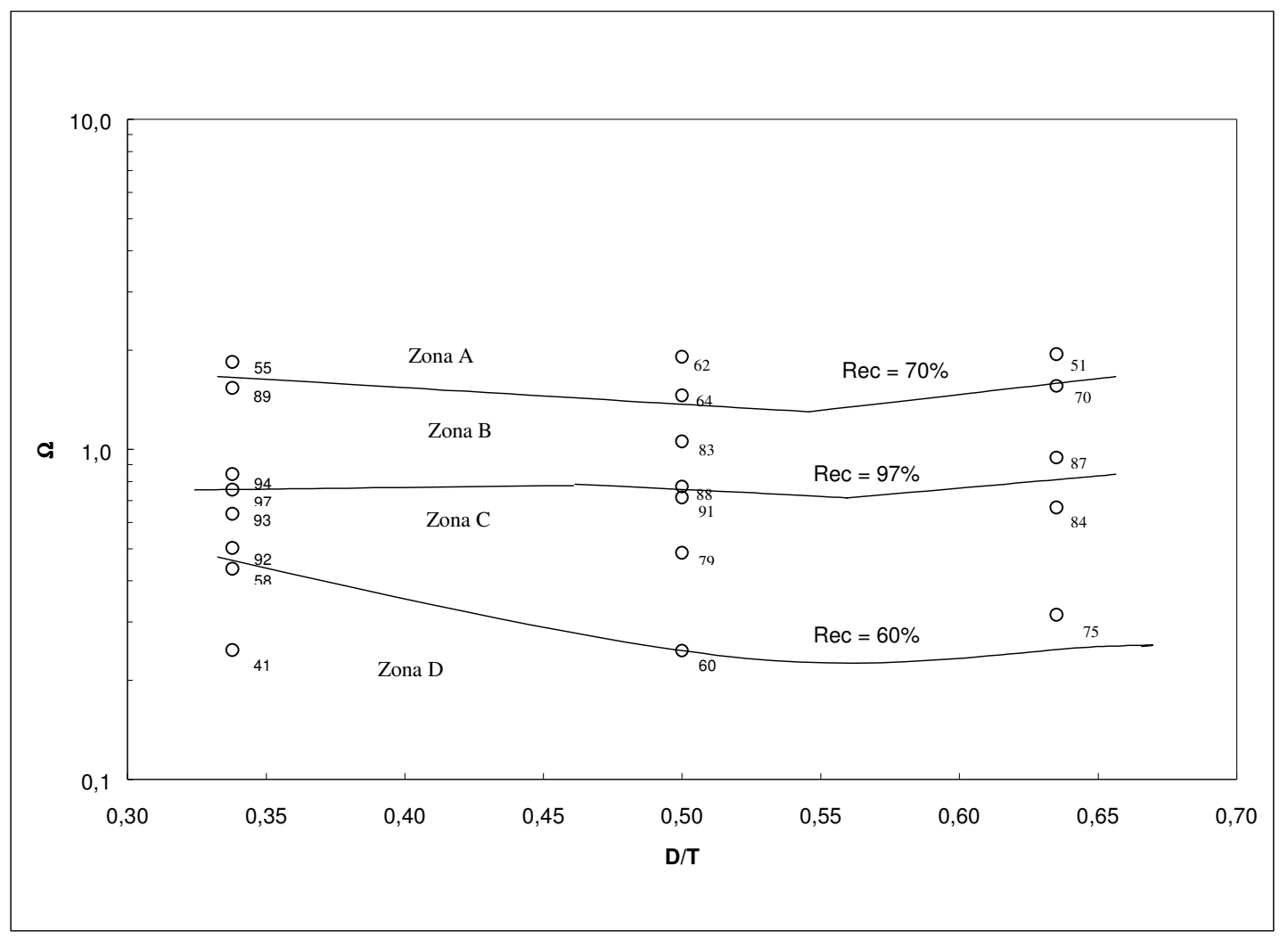

Figura 5.12. Diagrama $\mathrm{D} / \mathrm{T}$ versus $\Omega$. Os números ao lado dos pontos representam as recuperações médias das esferas de vidro ( $\left.\mathrm{d}_{\mathrm{P}} \cong 248 \mu \mathrm{m}\right)$. 
Tabela 5.4. Recuperação versus condições hidrodinâmicas da célula de flotação.

\begin{tabular}{|c|c|}
\hline Domínios hidrodinâmicos & Comportamento da recuperação \\
\hline $\begin{array}{l}\text { Zonas A+B } \\
\text { - Intensa turbulência; } \\
\text { - As partículas e bolhas não } \\
\text { apresentam grande movimento } \\
\text { relativo, ou seja, estão incorporadas } \\
\text { ao escoamento da polpa; } \\
\text { - Bolhas + solução se comportando } \\
\text { como uma única fase. }\end{array}$ & $\begin{array}{l}\text { - Média } \\
\text { - Rec }<70 \%\end{array}$ \\
\hline $\begin{array}{l}\text { Zona B } \\
\text { - Transição entre A e C }\end{array}$ & $\begin{array}{l}\text { - Muito sensível às condições } \\
\text { hidrodinâmica } \\
\text { - } 70 \%<\text { Rec }<97 \%\end{array}$ \\
\hline $\begin{array}{l}\text { Zona C } \\
\text { - O escoamento é menos turbulento } \\
\text { que as zonas A e B; } \\
\text { - As partículas e bolhas apresentam } \\
\text { significativo movimento relativo; } \\
\text { - As bolhas estão completamente } \\
\text { dispersas na célula. }\end{array}$ & $\begin{array}{l}\text { - Máxima recuperação } \\
\text { - Rec>95\% }\end{array}$ \\
\hline $\begin{array}{l}\text { Zonas D } \\
\text { - Baixa suspensão de partículas; } \\
\text { - Menor turbulência; } \\
\text { - Baixa dispersão de bolhas na } \\
\text { célula; } \\
\text { - Alto Po. }\end{array}$ & $\begin{array}{l}\text { - Pequeno aumento ou decréscimo em } \\
\text { função das condições hidrodinâmicas } \\
\text { - Rec } \leq 60 \%\end{array}$ \\
\hline
\end{tabular}

No que diz respeito ao comportamento da flotação das esferas de vidro $\left(d_{p} \cong 248 \mu \mathrm{m}\right)$, observa-se:

i. O comportamento da flotação nos ensaios de bancada foi bastante semelhante ao de microflotação, uma vez que as maiores 
recuperações (Recuperação > 85\%) para todas as relações $\mathrm{D} / \mathrm{T}$ ficaram próximas a $\Omega=1$.

ii. Para $\Omega=1$, o aumento da relação $\mathrm{D} / \mathrm{T}$ age em detrimento a recuperação. Provavelmente, devido à intensificação das forças de cisalhamento que agem sobre o agregado, em função do crescimento de $\mathrm{D} / \mathrm{T}$.

iii. $\operatorname{Em} \Omega<0,5$, a rotação do impelidor não é suficiente para promover a boa suspensão das partículas, resultando em recuperações um pouco inferiores. No entanto, observa-se que com aumento de $\mathrm{D} / \mathrm{T}$, melhora-se a recuperação, em baixas rotações, impelidores com diâmetros maiores melhoram a capacidade de mistura do sistema e também movimentam uma maior quantidade de massa.

iv. Para $\Omega>1,4$, as recuperações começaram a diminuir para todos $D / T$. Devido ao aumento de rotação do impelidor, a eficiência de preservação do agregado é prejudicada, pelo crescimento da energia cinética das esferas.

Para um $\Omega$ constante e igual a um, observa-se que o aumento de D/T provoca diminuição na recuperação. Uma vez que a condição de completa suspensão foi satisfeita, o crescimento de D/T diminui a preservação do agregado, em conseqüência da intensificação das forças de cisalhamento sobre o sistema, geradas pelos impelidores. Gráficos de parâmetros hidrodinâmicos versus recuperação foram construídos no intuito de observar a sua influência na flotação. Conforme as figuras 5.13 a 5.17 . 


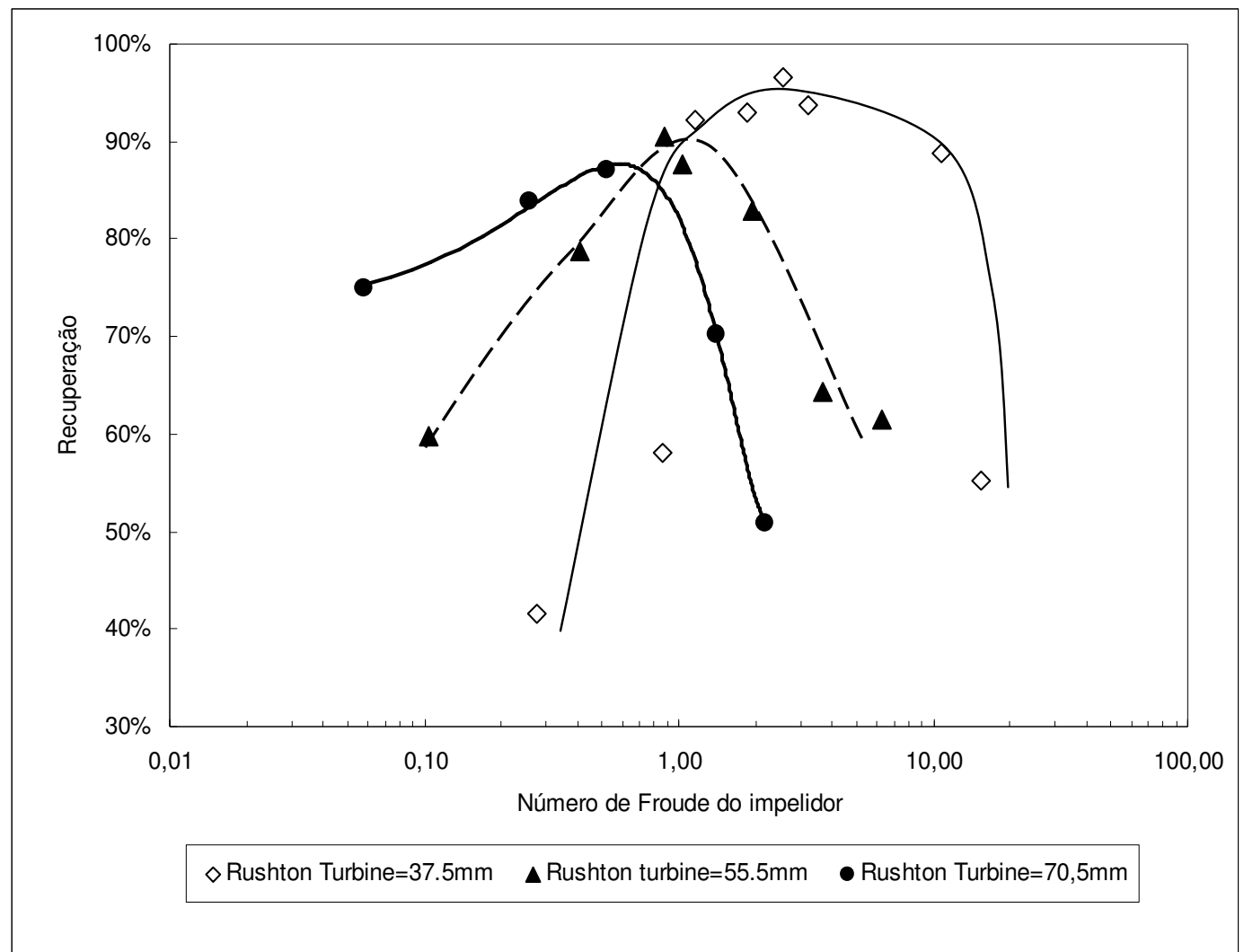

Figura 5.13. Número de Froude versus recuperação das esferas ( $\left.d_{p} \cong 248 \mu \mathrm{m}\right)$.

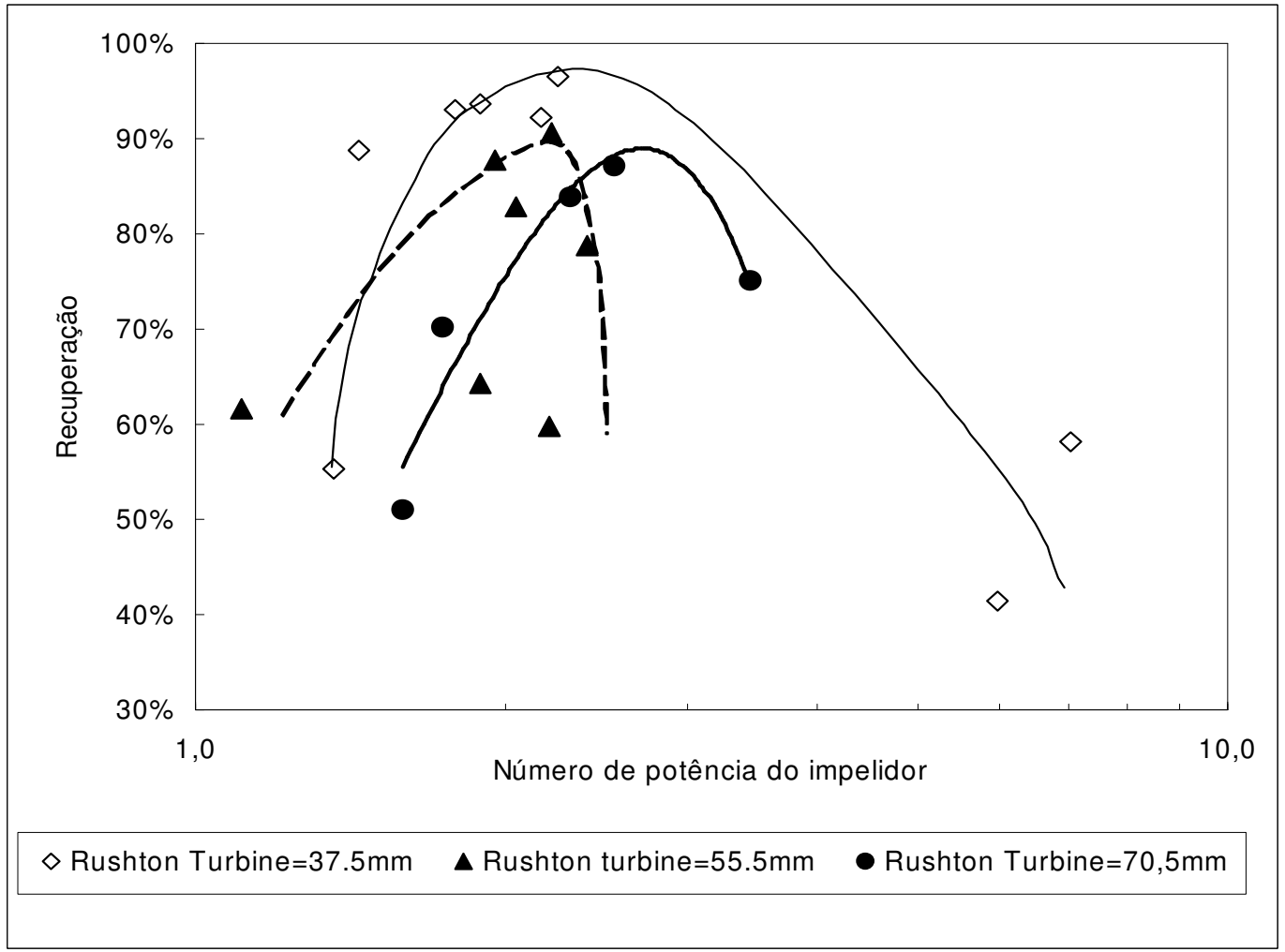

Figura 5.14. Número de Potência versus recuperação das esferas ( $\left.d_{P} \cong 248 \mu \mathrm{m}\right)$. 


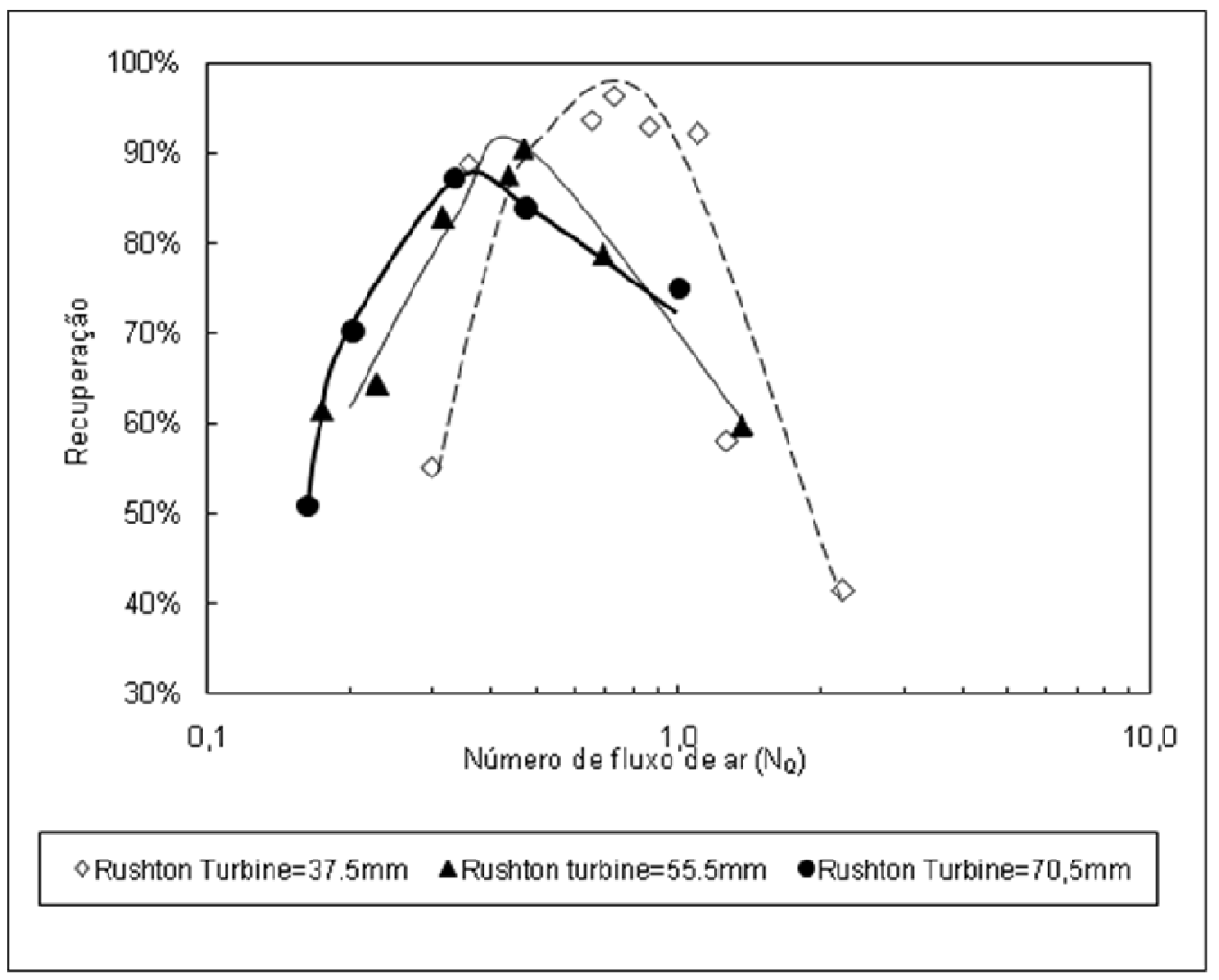

Figura 5.15. Número de fluxo de ar versus recuperação das esferas ( $\left.d_{p} \cong 248 \mu \mathrm{m}\right)$.

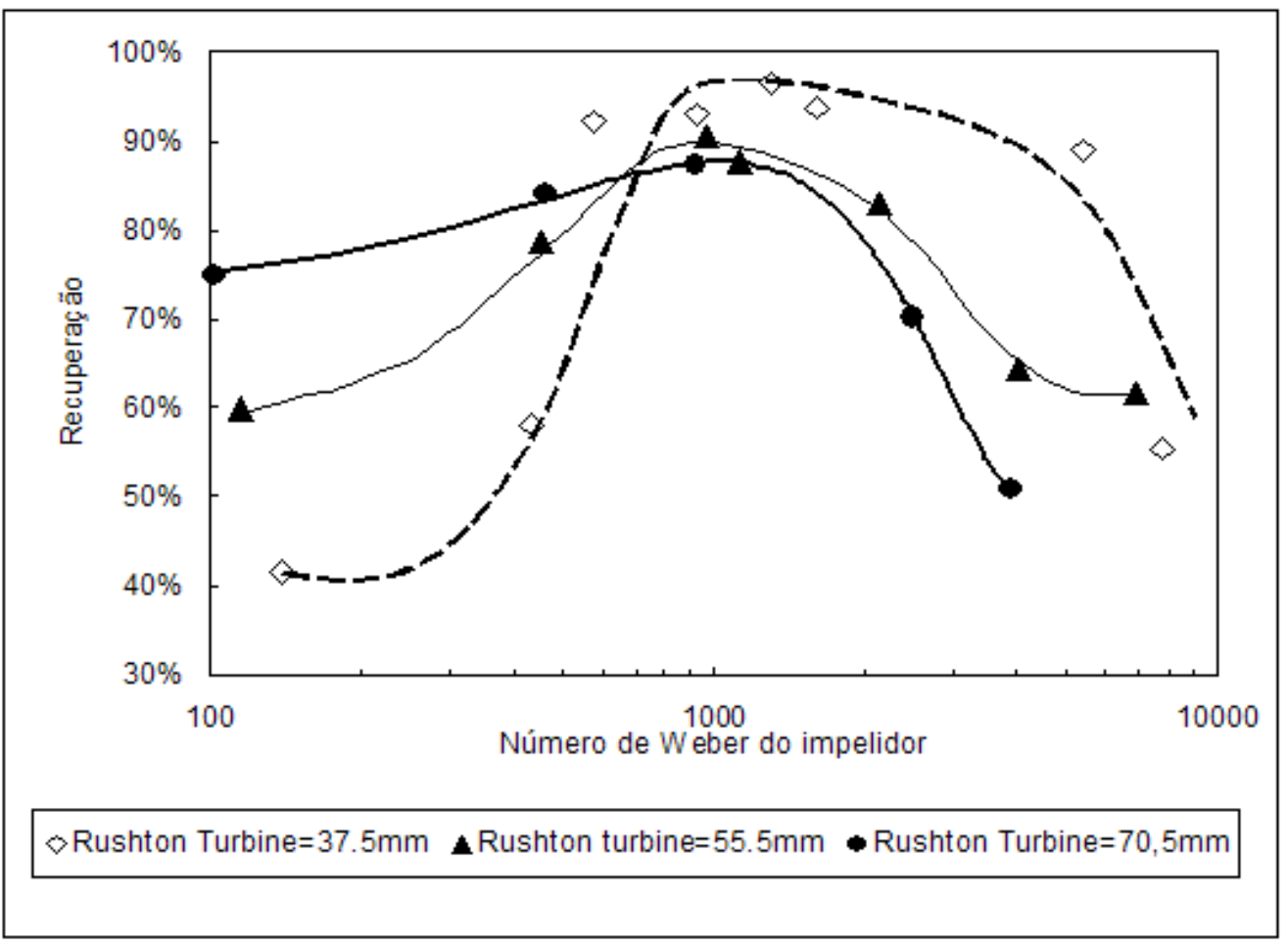

Figura 5.16. Número de Weber versus recuperação das esferas ( $\left.d_{P} \cong 248 \mu \mathrm{m}\right)$. 


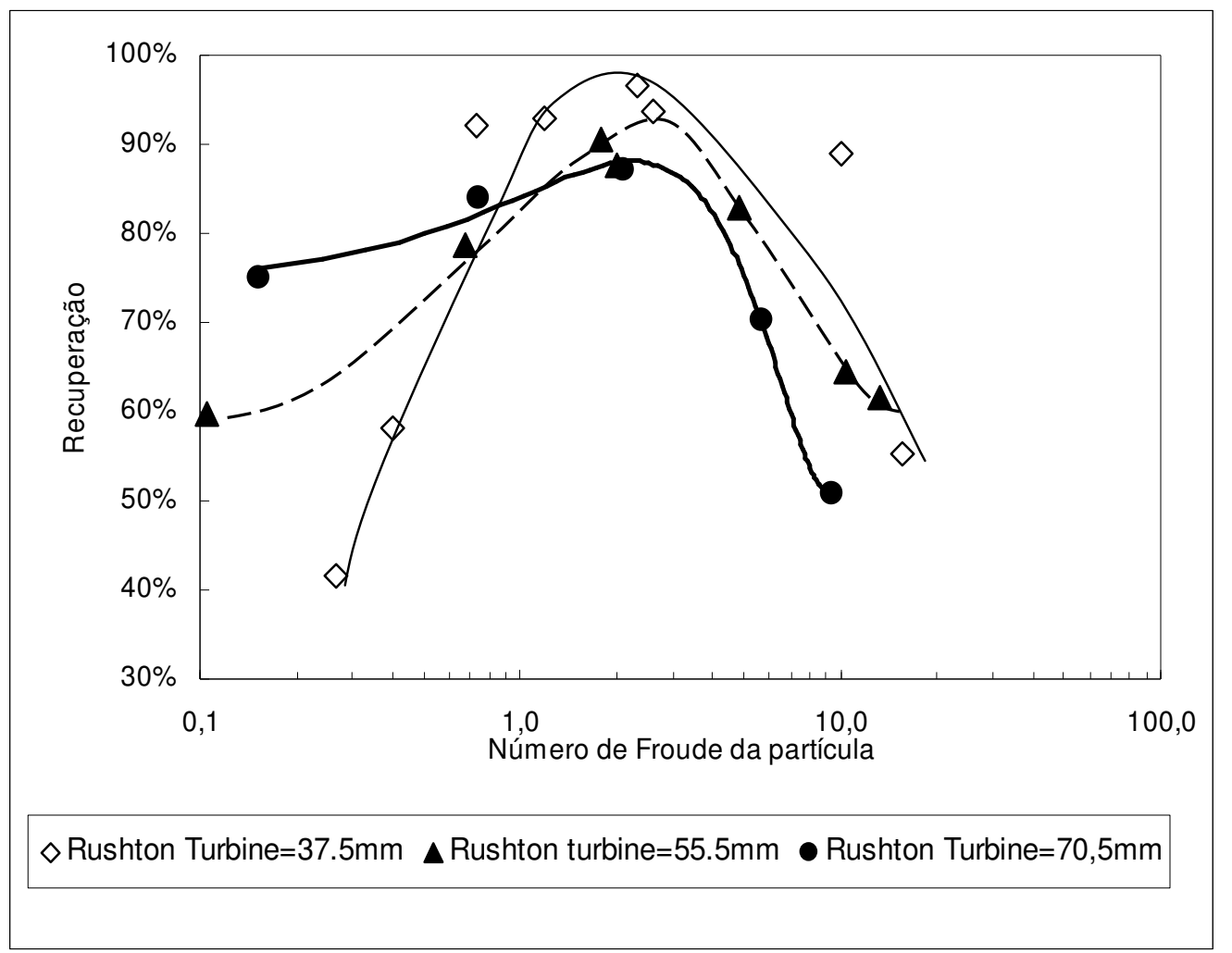

Figura 5.17. Número de Froude das esferas $\left(\mathrm{d}_{\mathrm{P}} \cong 248 \mu \mathrm{m}\right)$ versus recuperação.

Com relação às figuras 5.13 a 5.16, foram feitas as seguintes observações:

i. Os aumentos no número de Froude e Weber indicaram uma diminuição na recuperação das esferas de vidro $\left(d_{p} \cong 248 \mu \mathrm{m}\right)$. Desta forma, fica evidenciado que o crescimento das forças de inércia no sistema prejudica o desempenho da flotação;

ii. Quando os números de potência e fluxo de gás diminuem, há uma queda no desempenho da flotação. Ratificando assim que o aumento das forças de inércia age em detrimento ao rendimento do processo.

iii. Com relação aos impelidores de diâmetros de distintos, a turbina de Rushton ( $D=37,5 \mathrm{~mm})$ atinge a máxima recuperação em número de Froude e Weber maior que os impelidores de diâmetros superiores. Tal fato se explica, devido aos impelidores menores necessitarem de elevadas velocidades, conservando-se a aeração do sistema, conseqüentemente maior inércia, para manterem as partículas em suspensão, ou seja, promoverem a colisão partícula - bolha.

iv. Os impelidores com diâmetros maiores possuem maior sensibilidade 
ao aumento do número de Froude e Weber em comparação com a turbina de Rushton=37,5 mm, ou seja, há diminuição na recuperação das esferas $\left(d_{P} \cong 248 \mu \mathrm{m}\right)$ em função do aumento da inércia no sistema. Os gráficos de número de potência e fluxo de gás não ratificam esta idéia, devido à carência de pontos experimentais em alta rotação.

v. $\quad$ Em número de Froude $<0,3$, Weber $<200$, Po $>2$ e $\mathrm{N}_{\mathrm{Q}}>1$ há diminuição na recuperação das esferas $\left(d_{p} \cong 248 \mu \mathrm{m}\right)$ justificado pelas baixas taxas de colisão entre partículas e bolhas. Grande parte da polpa está sedimentada.

No âmbito da microturbulência no sistema ficou evidenciado que o aumento da forças de inércia das partículas é prejudicial à recuperação das esferas, com $d_{P} \cong 248 \mu \mathrm{m}$ ), conforme apresentado na figura 5.17. O crescimento da velocidade de turbulência das partículas faz com que estas incorporem ao fluido, prejudicando a estabilidade do agregado.

Ainda com relação à figura 5.17, observou-se que para um mesmo número de Froude para esferas $\left(\mathrm{d}_{\mathrm{P}} \cong 248 \mu \mathrm{m}\right)$ obtido com 3 diâmetros diferentes de turbinas de Rushton havia variação na recuperação. A transferência de energia do impelidor para as esferas de vidro pode ser compreendida pelo o gráfico de energia dissipada versus recuperação, conforme a figura 5.18.

É possível verificar nesta figura que:

i. As melhores recuperações (Rec>87\%) são obtidas no intervalo $1<\varepsilon_{D}<2,52$. É possível neste intervalo que o sistema consiga maximizar a energia transferida pelo impelidor, colocando a polpa em boas condições de suspensão e não permitindo que a turbulência atinja o nível de destruição do agregado.

ii. $\quad E m \varepsilon_{D}<0,30$ há uma diminuição na recuperação das esferas de vidro $\left(d_{P} \cong 248 \mu \mathrm{m}\right)$. Isto se deve a péssima qualidade da suspensão, uma vez que existem zonas mortas e considerável quantidade de material sedimentado, prejudicando deste modo a colisão partícula - bolha.

iii. Para $\varepsilon_{D}>10$, observa-se que o turbina de Rushton com diâmetro igual a 70,5 mm apresenta pior desempenho frente a turbina com diâmetro de $55,5 \mathrm{~mm}$, que por sua vez origina uma recuperação 
menor que o impelidor de $37,5 \mathrm{~mm}$. É provável que quanto maior o diâmetro da turbina menor seja o tamanho de bolha, tal fato prejudica a estabilidade do agregado, além disso, turbinas maiores geram maiores forças de cisalhamento no sistema o que também age em deletério à eficiência de preservação do agregado.

iv. A questão da força de cisalhamento também pode ser discutida para baixas $\varepsilon_{D}$, nesta situação é possível observar que impelidores maiores apresentam melhor desempenho na flotação das esferas $\left(d_{\mathrm{p}} \cong 248 \mu \mathrm{m}\right)$. Quanto maior o impelidor maior será o deslocamento de massa, por conseguinte haverá o aumento no número de colisão partícula - bolha, isto é verificado para $\varepsilon_{D}<0,3$.

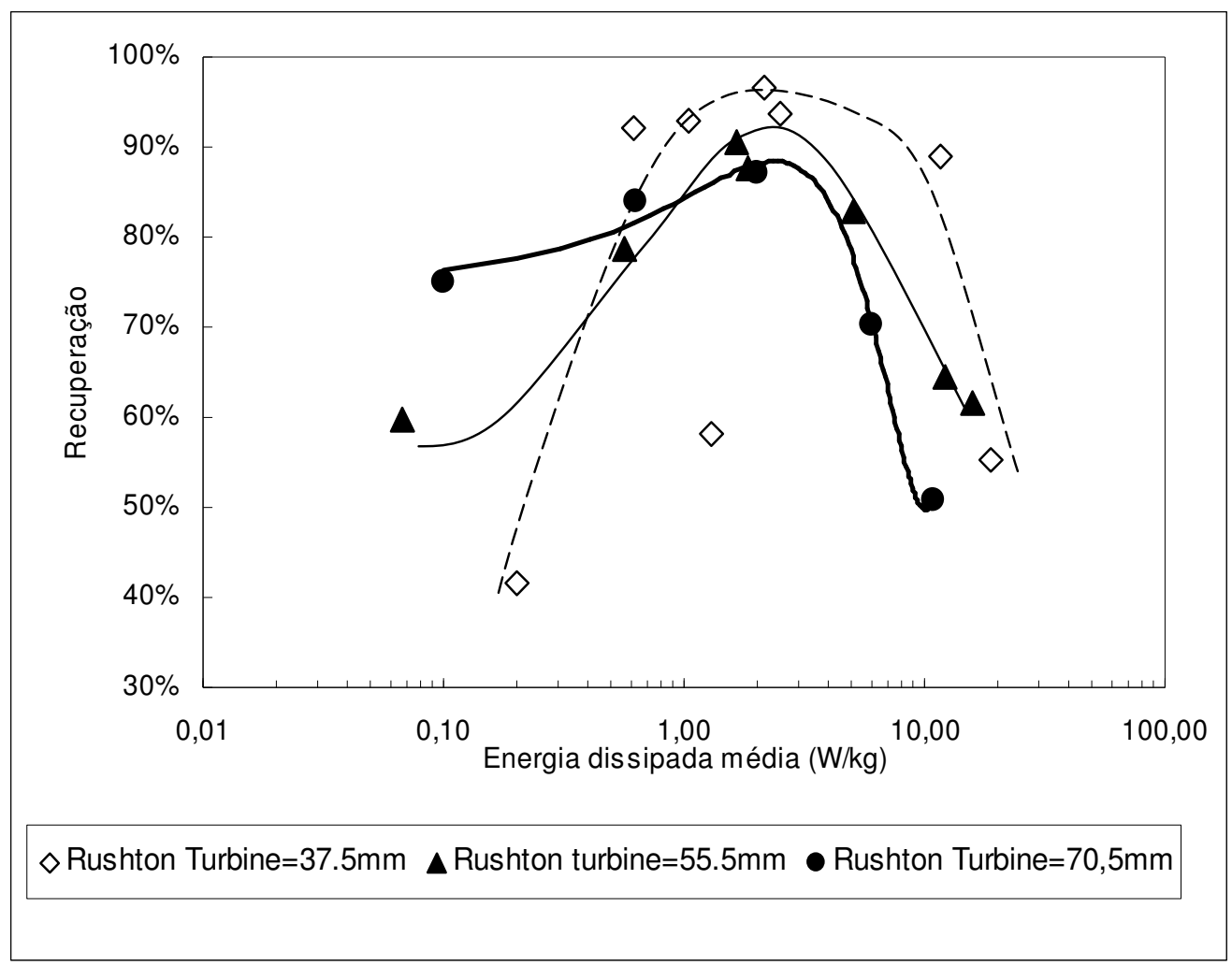

Figura 5.18. Energia dissipada pelo impelidor versus recuperação das esferas de vidro $\left(\mathrm{d}_{\mathrm{P}} \cong 248 \mu \mathrm{m}\right)$ utilizando-se turbinas de Rushton.

A geometria do impelidor interfere diretamente nas condições hidrodinâmicas da flotação. Comparando-se a energia dissipada e o número de potência do impelidor cilindróide e a turbina de Rushton, ambos com diâmetro igual a 70,5 mm, foi possível observar significativas diferenças, conforme as figuras 5.19 e 5.20. 


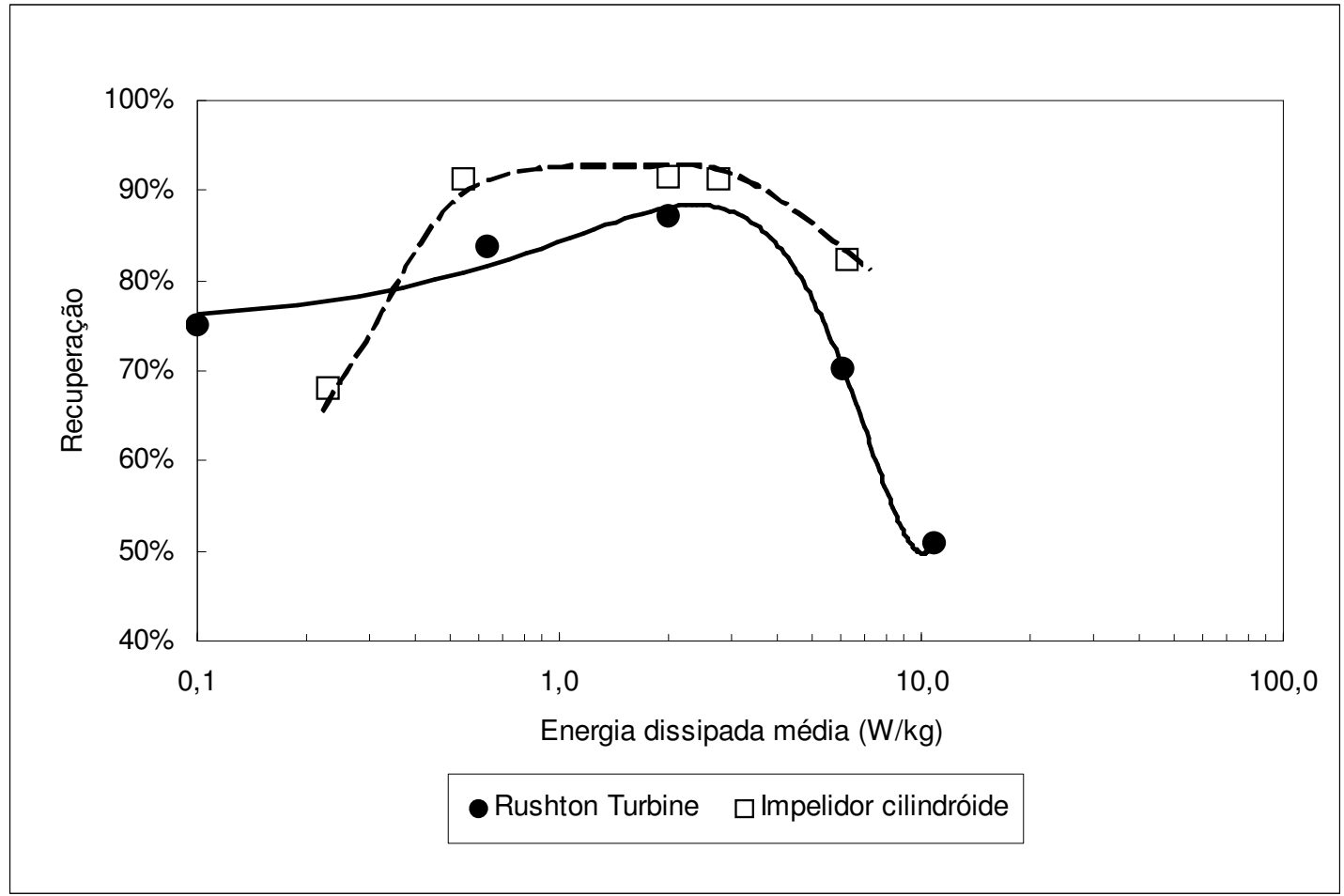

Figura 5.19. Energia dissipada pelos tipos de impelidores versus recuperação das esferas de vidro $\left(d_{P} \cong 248 \mu \mathrm{m}\right)$.

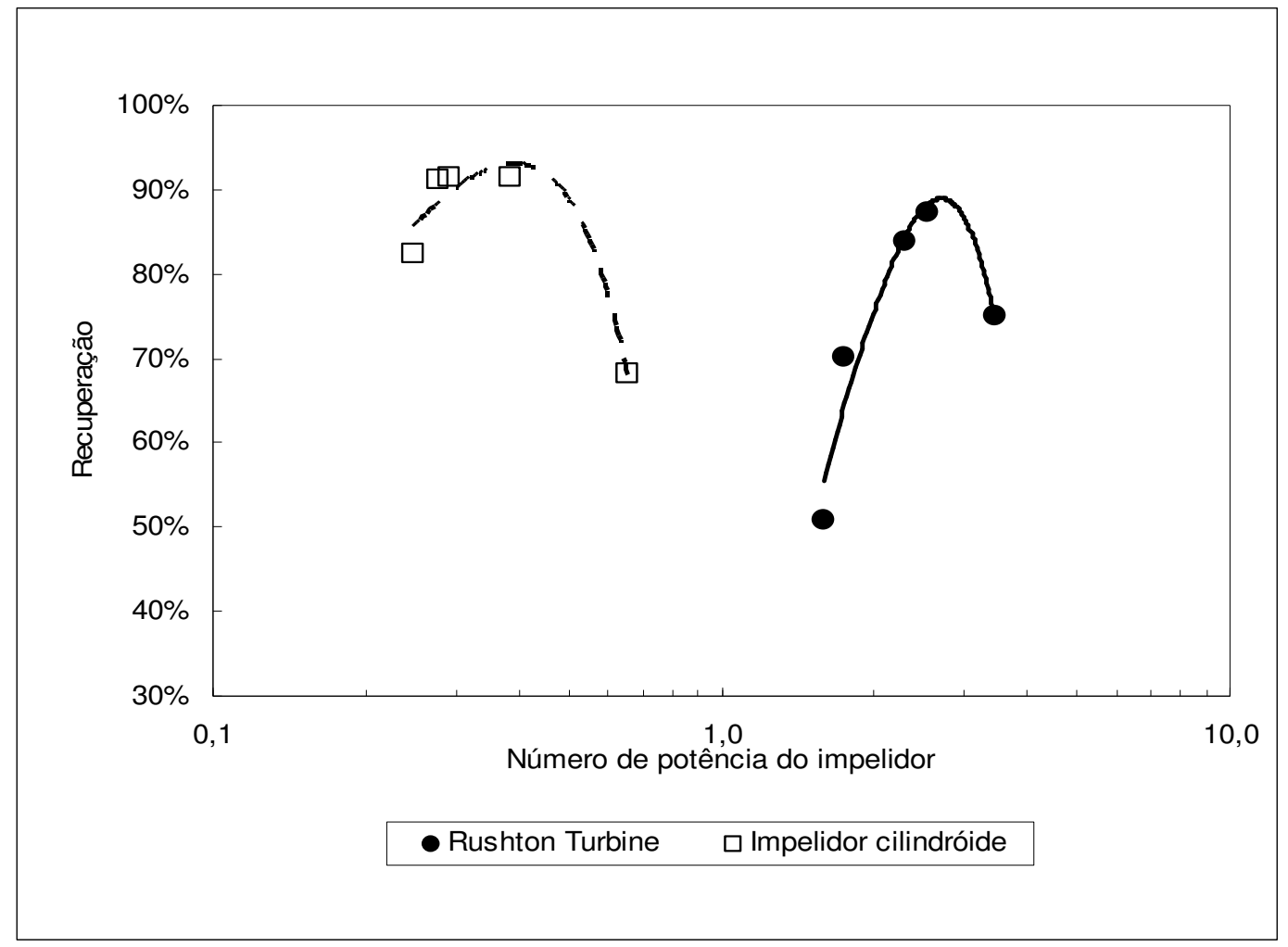

Figura 5.20. Número de potência dos impelidores versus recuperação das esferas de $\operatorname{vidro}\left(d_{\mathrm{P}} \cong 248 \mu \mathrm{m}\right)$. 
Na figura 5.19, a máxima recuperação se encontra no intervalo $0,54<\varepsilon_{D}<2,76$, no entanto é possível verificar um melhor desempenho do impelidor cilindróide em termos de recuperação. $O$ cilindróide promove, predominantemente, o bombeamento da polpa, enquanto que a turbina de Rushton o cisalhamento, isto faz com que o agregado não sofra tanto cisalhamento com o impelidor cilindróide, aumentando deste modo a preservação do agregado.

Ainda com relação à figura 5.19 , verifica-se que quanto maior energia dissipada pelo impelidor menor é a recuperação, provavelmente pelo aumento do nível de turbulência no sistema. Além disso, a turbina de Rushton se mostra mais sensível ao excesso turbulência, é possível que esteja havendo cisalhamento das bolhas, por conseguinte diminuição de seu diâmetro, prejudicando assim a preservação do agregado.

Conforme a figura 5.20, observa-se que o impelidor cilindróide apresenta número de potência bem menor, em relação à turbina de Rushton, comprovando-se assim sua boa capacidade de bombeamento da polpa. No entanto, a recuperação diminui, para ambos impelidores, em função do decréscimo do número de potência, devido o aumento do nível de turbulência no sistema.

Com relação às condições da suspensão da polpa plotou-se $\Omega$ versus recuperação das esferas de vidro ( $\left.\mathrm{d}_{\mathrm{P}} \cong 248 \mu \mathrm{m}\right)$, que é apresentada na figura 5.21.

Observou-se na figura 5.21 que as máximas recuperações se encontram no intervalo $0,67<\Omega<1,0$. Tal fato ratifica os experimentos de microflotação (vide figura 5.1), é claro que a completa suspensão da polpa possibilita o maior número de colisão possível entre as partículas e as bolhas, otimizando o desempenho da flotação.

Referente à figura 5.21 , em baixos valores de $\Omega$, menores que 0,5 , a flotação possui fraco desempenho, possivelmente pela grande quantidade de material sedimentado, indicando baixa eficiência de colisão. Por outro lado, para $\Omega>1,06$ a recuperação diminui em função do aumento do nível de turbulência no sistema. A partir deste ponto, esferas e bolhas perdem seu movimento relativo, incorporando totalmente ao fluxo, prejudicando assim a preservação do agregado. 


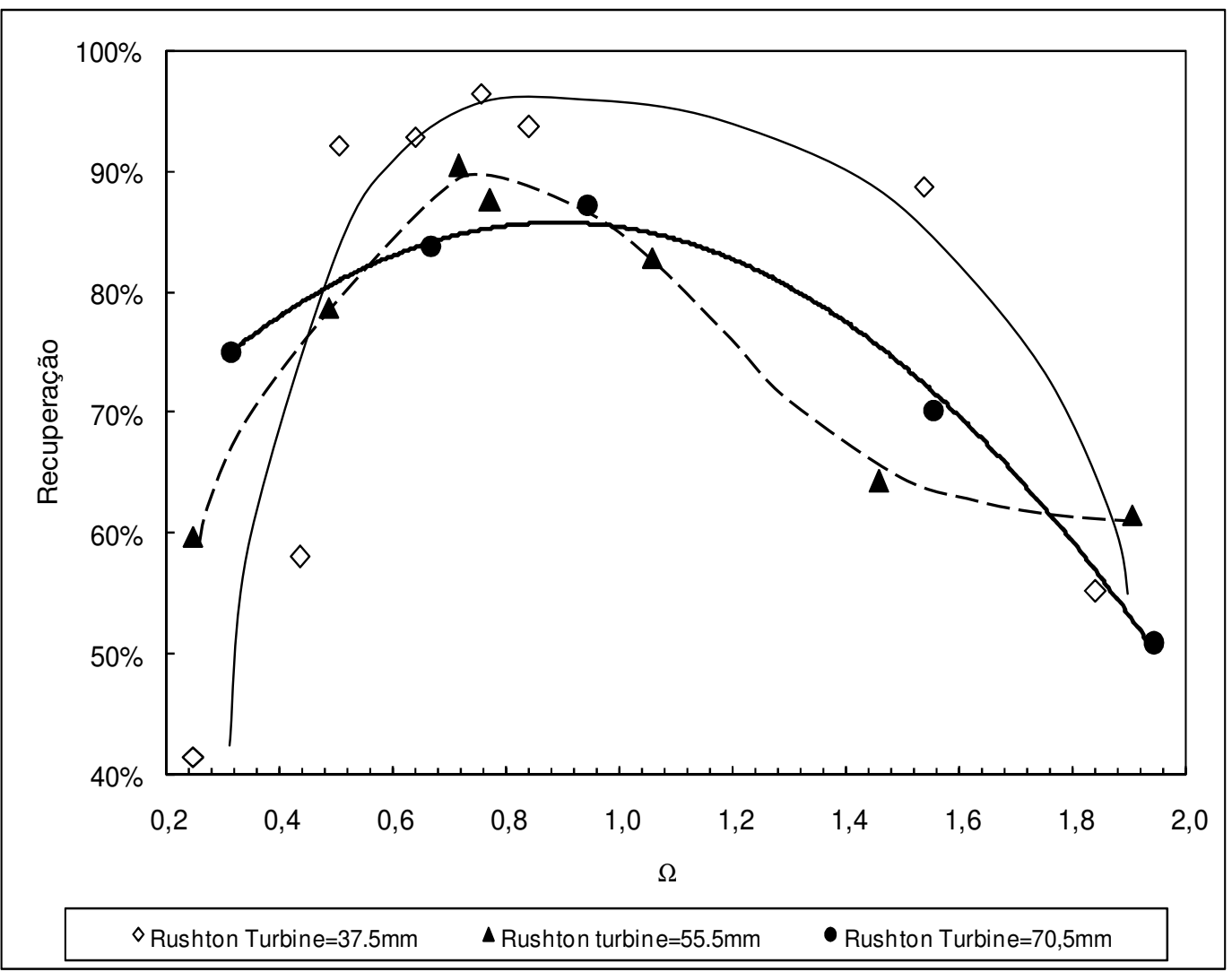

Figura 5.21. $\Omega$ versus recuperação das esferas de vidro ( $\left.d_{P} \cong 248 \mu \mathrm{m}\right)$.

Admitindo-se que o diâmetro médio de bolha fosse aproximadamente $1 \mathrm{~mm}$, baseado em Harris (1976) estimou-se a distribuição de forças sobre o agregado. Isto possibilitou o cálculo da energia de "detachment" no sistema. A relação entre as energias de "detachment" e cinética da esfera $\left(E_{\text {det }} / E_{k i n}\right)$ permite visualizar o nível de turbulência no sistema que provocará o rompimento do agregado, uma vez que a partícula terá energia cinética suficiente para se desprender do agregado.

Plotou-se a relação entre energias de detachment e cinética versus recuperação das esferas, conforme a figura 5.22, sobre a qual foram feitas as seguintes observações: 


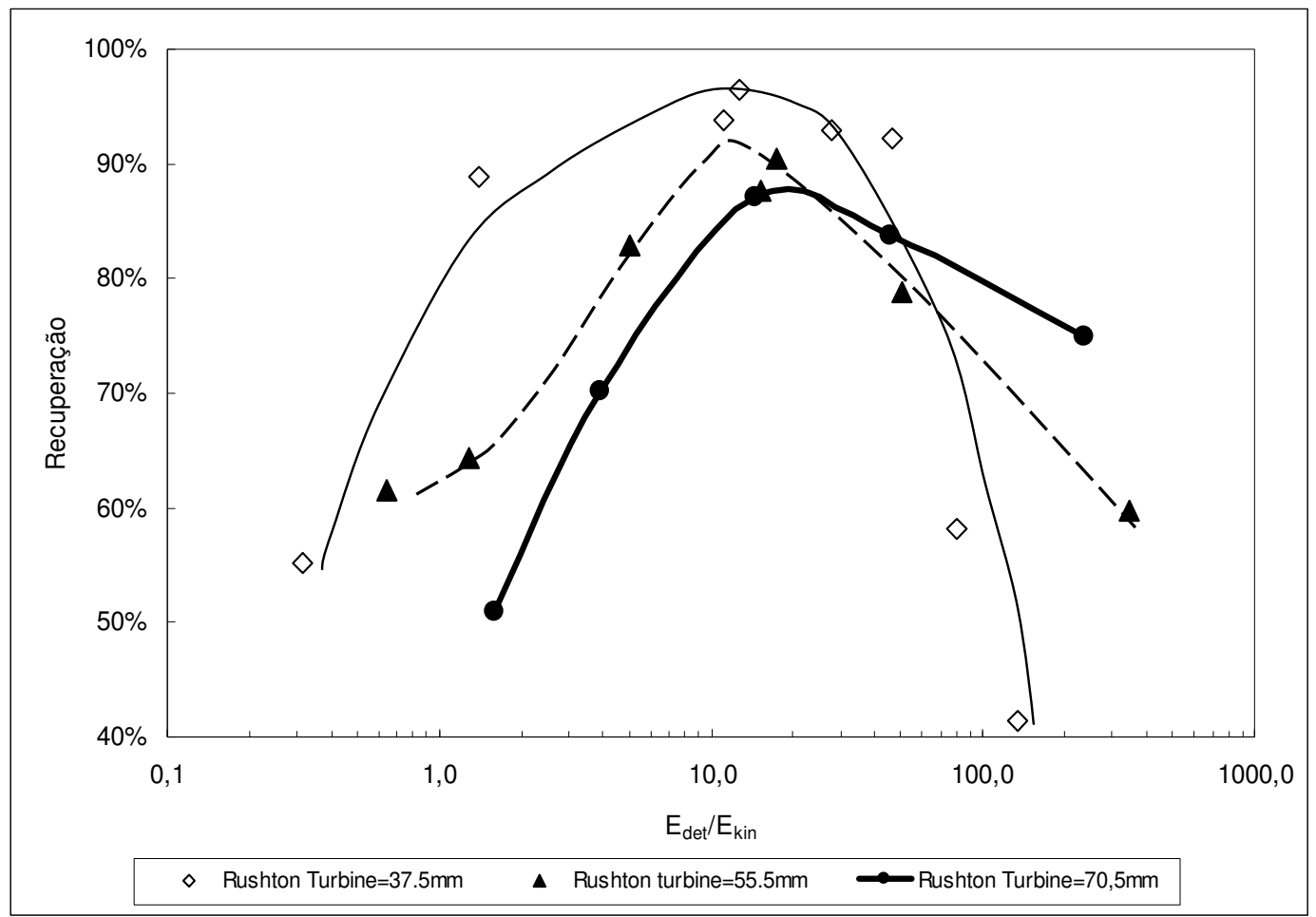

Figura 5.22. $E_{\text {det }} / E_{\text {kin }}$ versus recuperação das esferas de vidro ( $\left.d_{p} \cong 248 \mu \mathrm{m}\right)$ utilizando-se três turbinas de Rushton de diferentes diâmetros.

i. A máxima recuperação se encontra no intervalo $11,15<E_{\text {det }} / E_{\text {kin }}<46,74$. Neste intervalo, as forças que preservação a esfera aderida à bolha predominam sobre as forças de detachment, como a gravidade e o vetor gerado pela aceleração dos vórtices, de tal forma que a energia cinética das partículas não é suficiente para o rompimento do agregado.

ii. À medida que a relação $E_{\text {det }} / E_{k i n}$ decresce, a recuperação tende a diminuir, principalmente para os impelidores de maiores diâmetros. Tal fato é atribuído ao aumento das forças de detachment geradas pela aceleração dos vórtices turbulentos na polpa, tal aceleração ainda provoca o aumento da energia cinética da partícula até destruir o agregado.

iii. Além disso, o aumento de $E_{\text {det }} / E_{\text {kin }}$ faz com que as esferas não tenham energia cinética suficiente para serem mantidas em suspensão na polpa, por conseguinte diminuindo a recuperação da flotação, devido ao baixo número de colisões entre partículas e bolhas. 
iv. Os impelidores maiores geram grande quantidade de cisalhamento no sistema, ou seja, o aumento do diâmetro do impelidor decresce a energia de detachment, uma vez que não só intensificam as acelerações dos vórtices como também devem diminuir o diâmetro das bolhas.

Outra alternativa para verificar o balanço das forças que atuam sobre o agregado partícula-bolha é através do número de Bond modificado, o qual relaciona as forças de destruição do agregado (detachment) pelas que mantêm a partícula aderida à bolha. Os resultados da influência do número de Bond modificado são apresentados na figura 5.23.

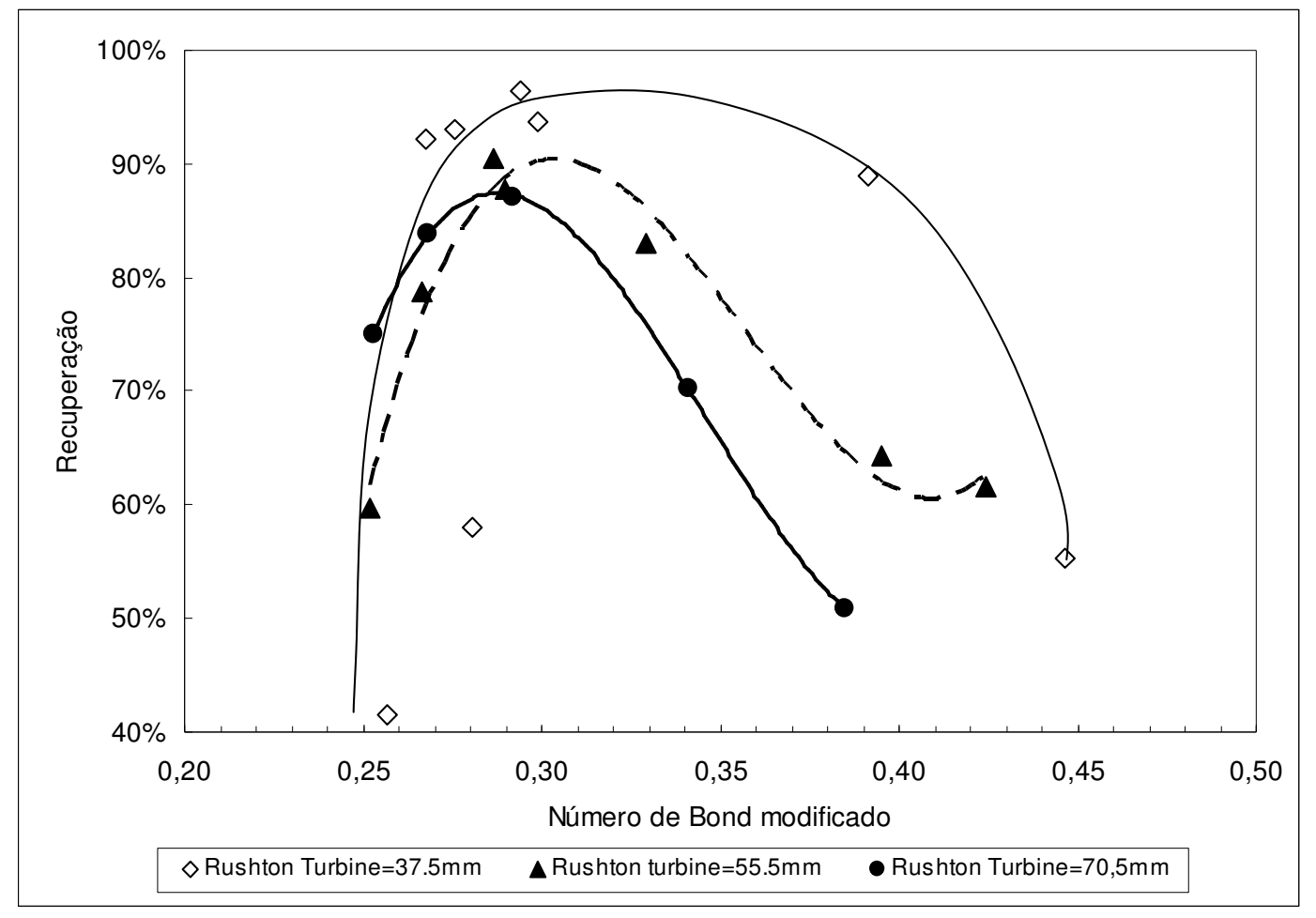

Figura 5.23. Número de Bond Modificado versus recuperação das esferas de vidro $\left(d_{\mathrm{P}} \cong 248 \mu \mathrm{m}\right)$ utilizando-se turbinas de Rushton.

É possível verificar na figura 5.23 que quando o número de Bond modificado se aproxima da unidade a recuperação diminui, isto é causado pelo aumento da turbulência no sistema, por conseguinte, o aumento das acelerações nos vórtices. No entanto, o desempenho da flotação tende a diminuir com o decréscimo no número de Bond modificado provavelmente pela baixa qualidade de suspensão da polpa, ou seja, há sedimentação na célula de flotação provocando assim um número de colisão entre partículas e bolhas insuficiente. 
Outra variável bastante importante na caracterização hidrodinâmica da flotação, além das características geométricas do impelidor e da rotação, é a aeração. Uma vez que a densidade da polpa modifica em função da quantidade de ar nos sistema, construiu-se um diagrama de $\mathrm{P} / \mathrm{V}$ versus número de fluxo de ar $\left(\mathrm{N}_{\mathrm{Q}}\right)$ para todos os impelidores utilizados nos ensaios de flotação, conforme as figura 5.24 a 5.27 .

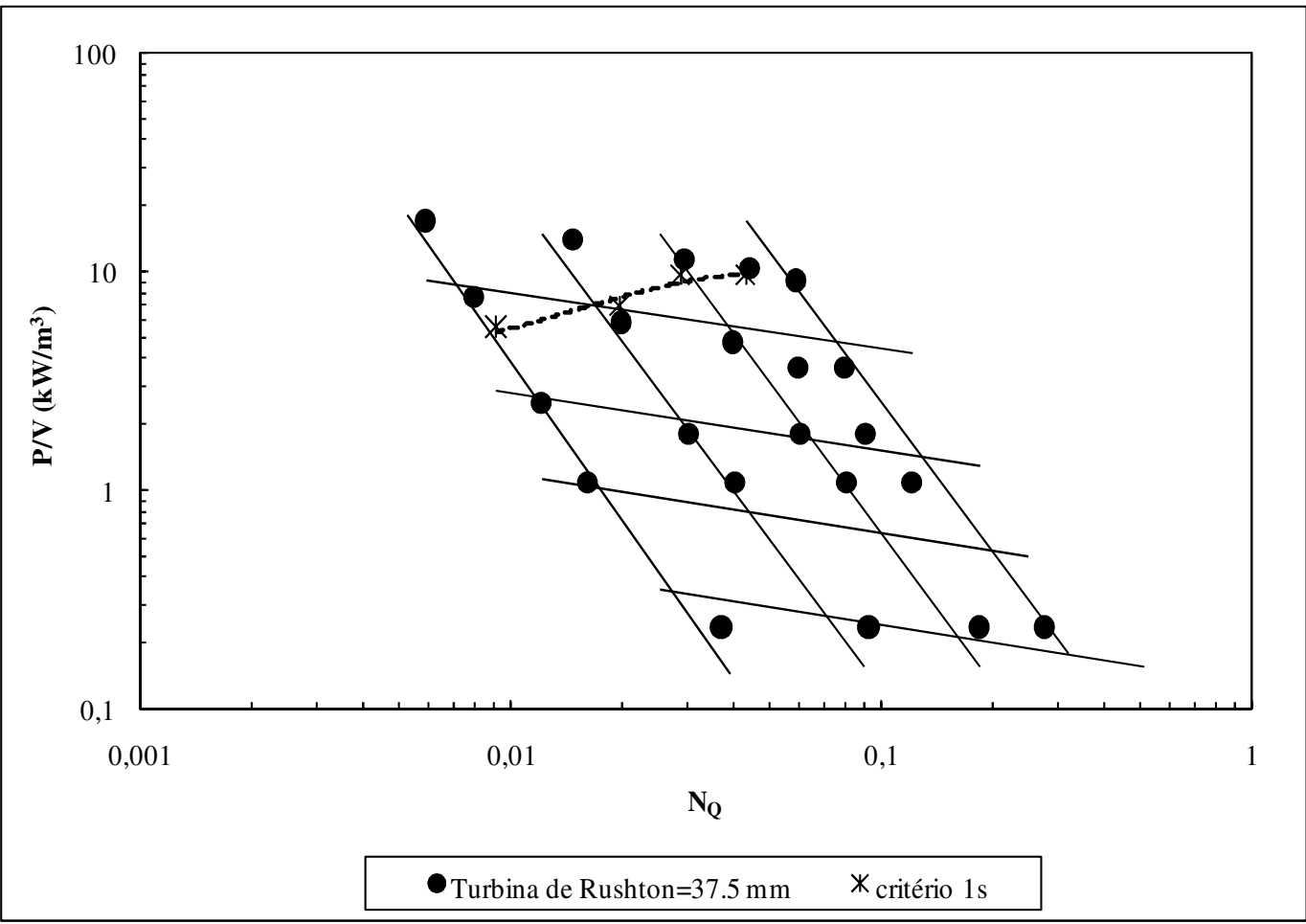

Figura 5.24. $\mathrm{N}_{\mathrm{Q}}$ versus $\mathrm{P} / \mathrm{V}$ para esferas de vidro $\left(\mathrm{d}_{\mathrm{P}} \cong 248 \mu \mathrm{m}\right)$ e turbina de Rushton com $\mathrm{D}=37,5 \mathrm{~mm}$. 


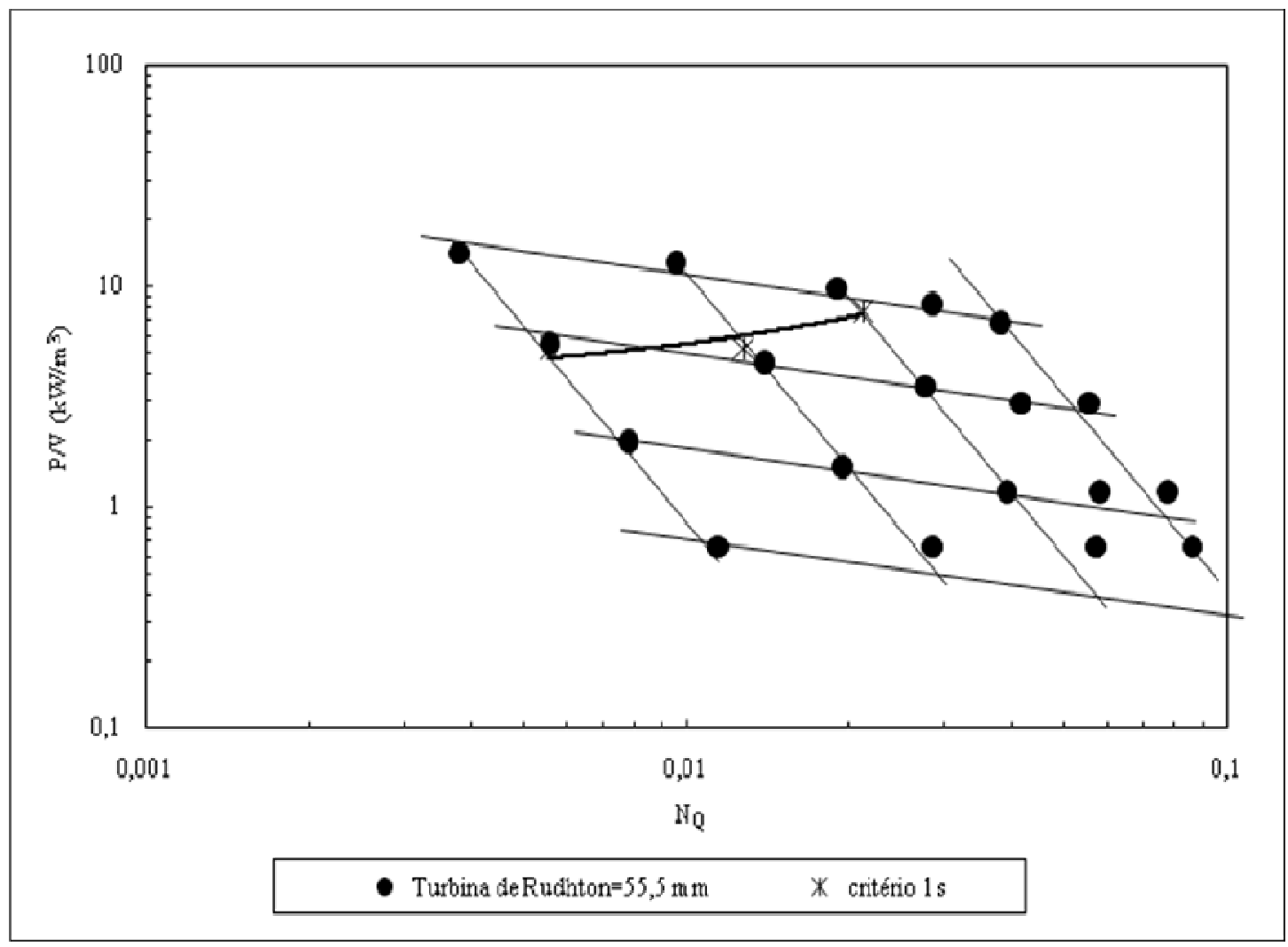

Figura 5.25. $\mathrm{N}_{\mathrm{Q}}$ versus $\mathrm{P} / \mathrm{V}$ para esferas de vidro $\left(\mathrm{d}_{\mathrm{P}} \cong 248 \mu \mathrm{m}\right)$ e turbina de Rushton com $\mathrm{D}=55,5 \mathrm{~mm}$. 


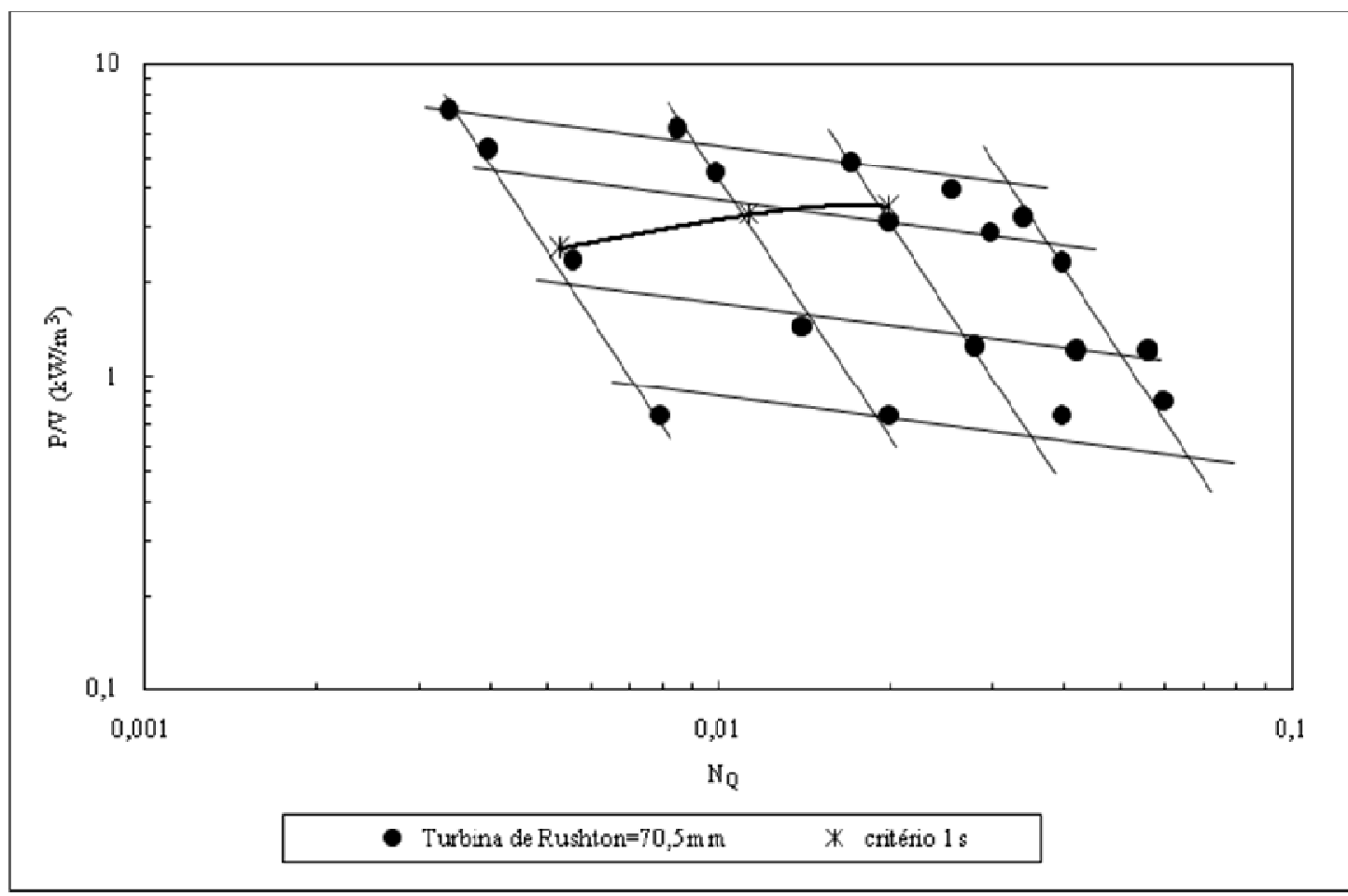

Figura 5.26. $N_{Q}$ versus $P / V$ para esferas de vidro $\left(d_{p} \cong 248 \mu m\right)$ e turbina de Rushton com $\mathrm{D}=70,5 \mathrm{~mm}$.

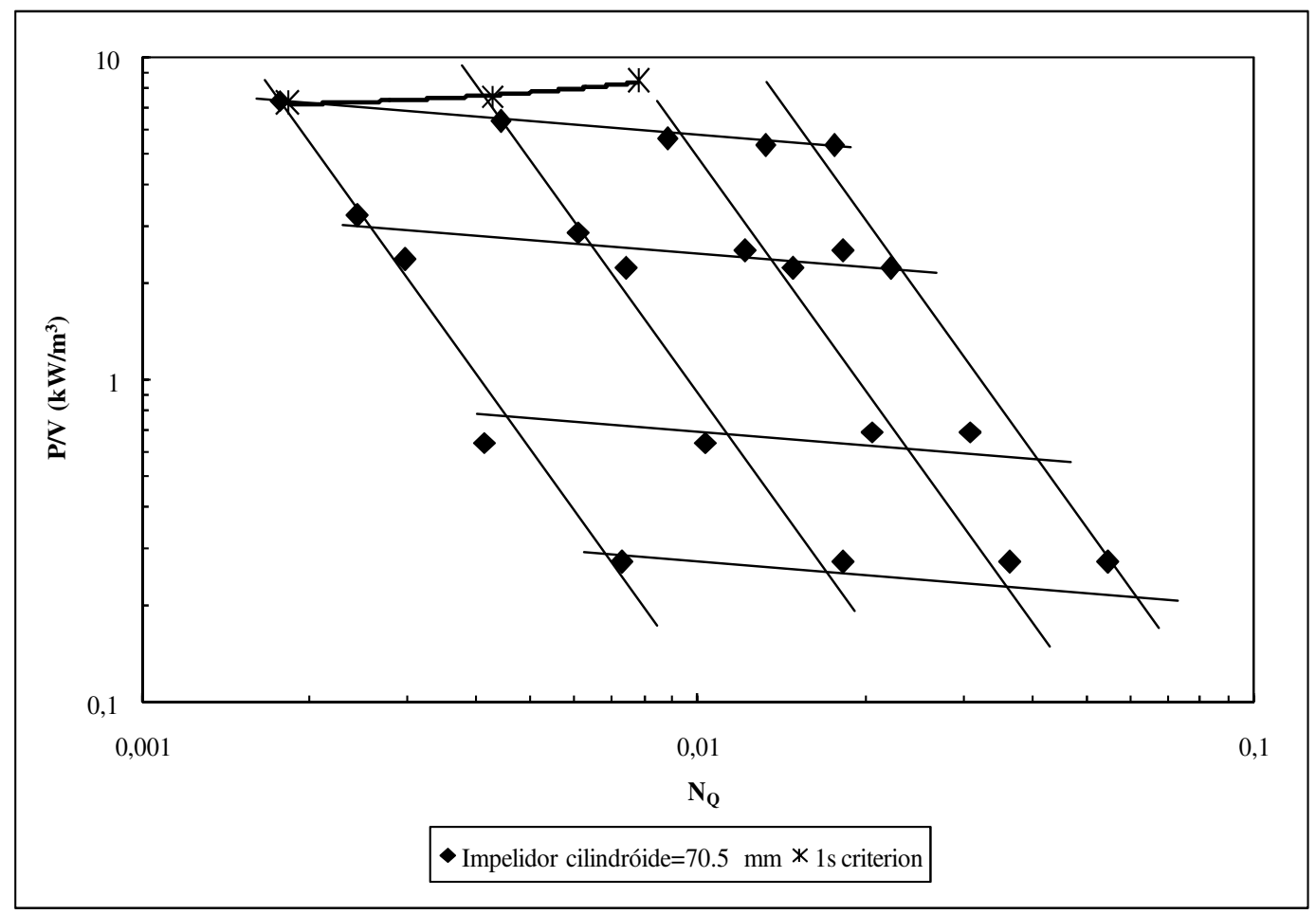

Figura 5.27. $\mathrm{N}_{\mathrm{Q}}$ versus $\mathrm{P} / \mathrm{V}$ para esferas de vidro $\left(\mathrm{d}_{\mathrm{P}} \cong 248 \mu \mathrm{m}\right)$ para impelidor cilindróide com $\mathrm{D}=70,5 \mathrm{~mm}$. 
Com relação às figuras 5.24 a 5.27 são possíveis as seguintes observações:

i. A potência aplicada à polpa $(P / V)$ diminui com o aumento de $N_{Q}$, praticamente de forma linear, em função do aumento da massa gasosa no sistema, a polpa também tem seu volume acrescido, isto gera baixa eficiência de colisão, devido aumentar a quantidade de sólidos sedimentada.

ii. A velocidade mínima de suspensão aumenta com o crescimento de $\mathrm{N}_{\mathrm{Q}}$, isto se deve ao fato do sistema necessitar maior agitação para manter as partículas em suspensão, uma vez que a potência aplicada pelo impelidor (P/V) está diminuindo.

iii. É muito provável que a região de bom desempenho da flotação esteja próximo à mínima velocidade de suspensão. No entanto, deve-se sempre levar em consideração também turbulência gerada pela forte aeração.

$\mathrm{Na}$ escala de bancada foi possível observar a influência da aeração sobre a $\mathrm{N}_{z}$ de suspensão do sistema, ao aumentarmos a vazão de nitrogênio no sistema há um crescimento significativo na mínima velocidade de suspensão da polpa. Tal observação é mostrada na figura 5.28.

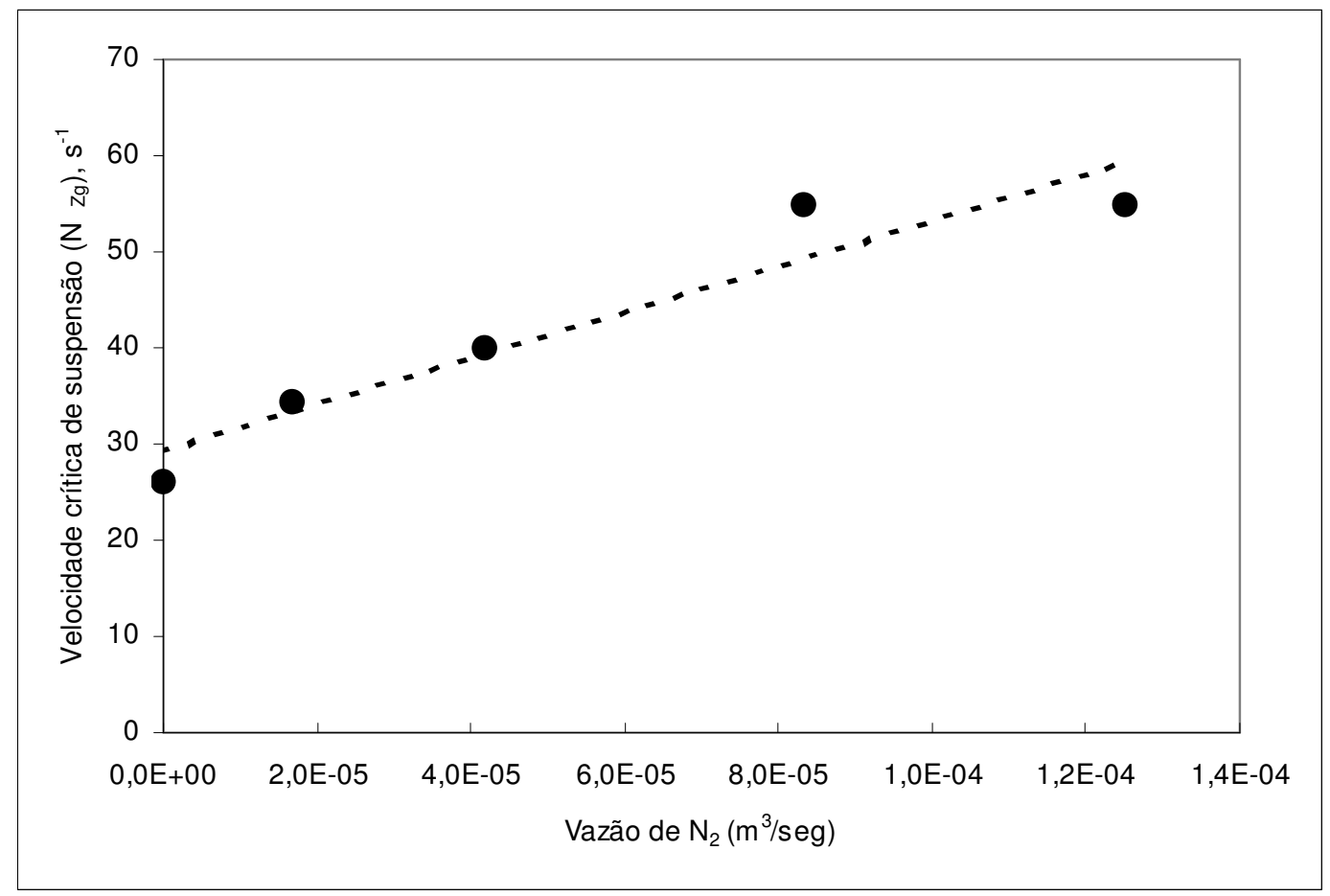

Figura 5.28. Velocidade crítica de suspensão da polpa de flotação versus a aeração 
do sistema.

A figura 5.28 corrobora com a literatura corrente, que aumento em $\mathrm{N}_{\mathrm{z}} \mathrm{em}$ função do aumento de vazão de gás ocorre devido à geração de cavidades gasosas na região posterior à pá do impelidor. Por conseguinte, há diminuição na capacidade de transporte de energia pelo impelidor à polpa para colocar os sólidos em suspensão em favorecimento ao aumento do cisalhamento no fluido.

Os ensaios de flotação com esferas de vidro finas $\left(d_{P} \cong 57 \mu \mathrm{m}\right)$ foram realizados a fim de comparar o seu desempenho com as outras esferas $\left(d_{p} \cong 248\right.$ $\mu \mathrm{m})$, nestes testes se utilizou a turbina de Rushton, com diâmetro de $37,5 \mathrm{~mm}$. Seus resultados são apresentados na figura 5.29.

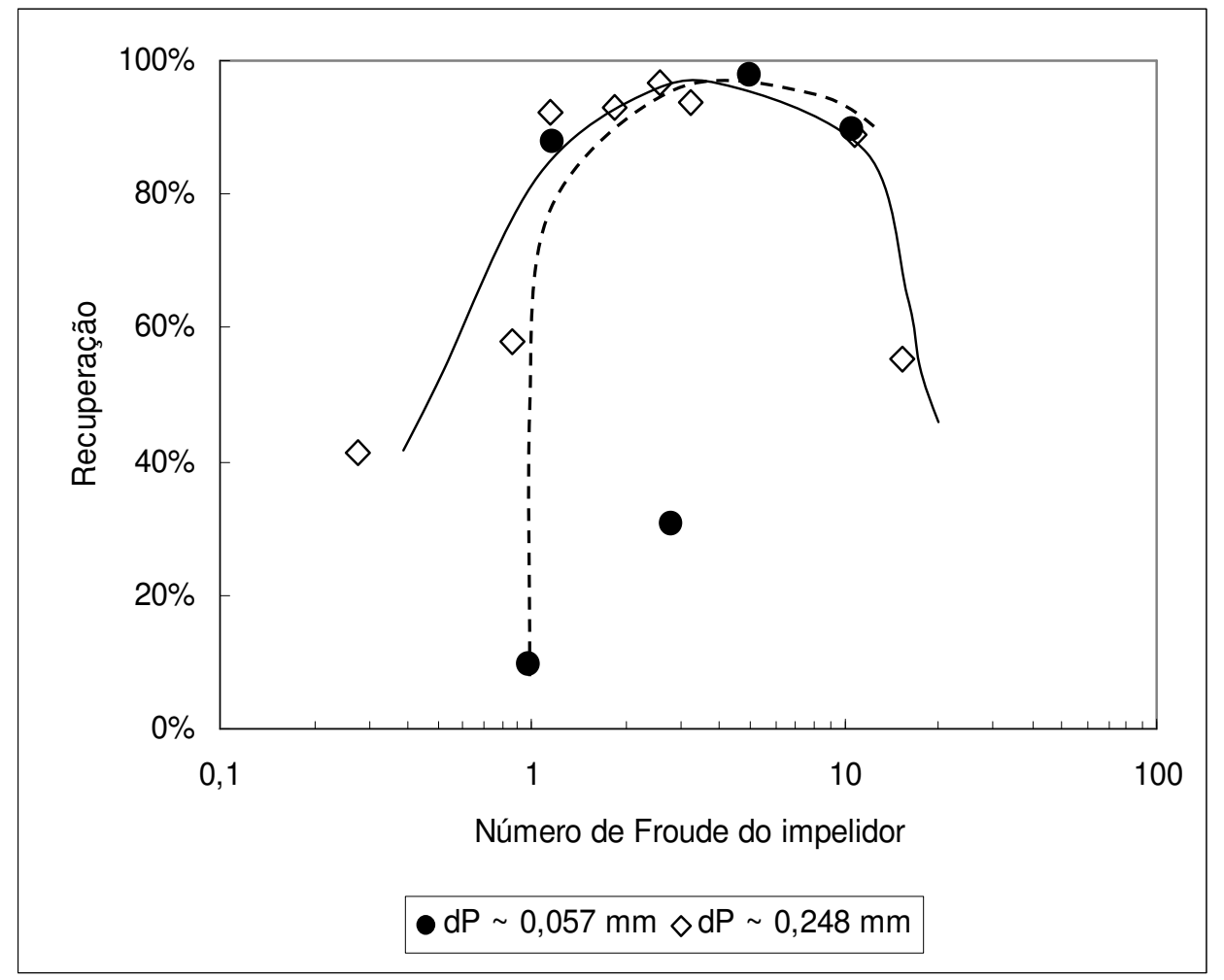

Figura 5.29. Número de Froude versus recuperação das esferas de vidro $\left(d_{p} \cong 57\right.$ e $248 \mu \mathrm{m})$ com turbina de Rushton de diâmetro $37,5 \mathrm{~mm}$.

$\mathrm{Na}$ figura 5.29 foi possível observar que as esferas com menor diâmetro $\left(d_{p} \cong 57 \mu m\right)$ são mais resistentes ao aumento das forças inércia no sistema. Por outro lado, as esferas $\left(d_{P} \cong 248 \mu \mathrm{m}\right)$ apresentam maior recuperação em número de Froude superior a unidade, tal fato confirma que as partículas menores apresentam problema de eficiência de colisão em níveis de turbulência baixos no sistema.

Vale reportar que as esferas de vidro $\left(d_{p} \cong 57 \mu m\right)$ já vieram hidrofóbicas do 
fabricante (COPERLAB), impossibilitando ensaios de medição de torque, conseqüentemente, melhor caracterização hidrodinâmica.

Admitindo-se ainda que o diâmetro de bolha seja $1 \mathrm{~mm}$, valor mais freqüente das células mecânicas [Harris (1976, 1987)], foi possível simular o diâmetro máximo flotável e a eficiência de "detachment" ou de preservação do agregado. Os dados são apresentados na figura 5.30 .

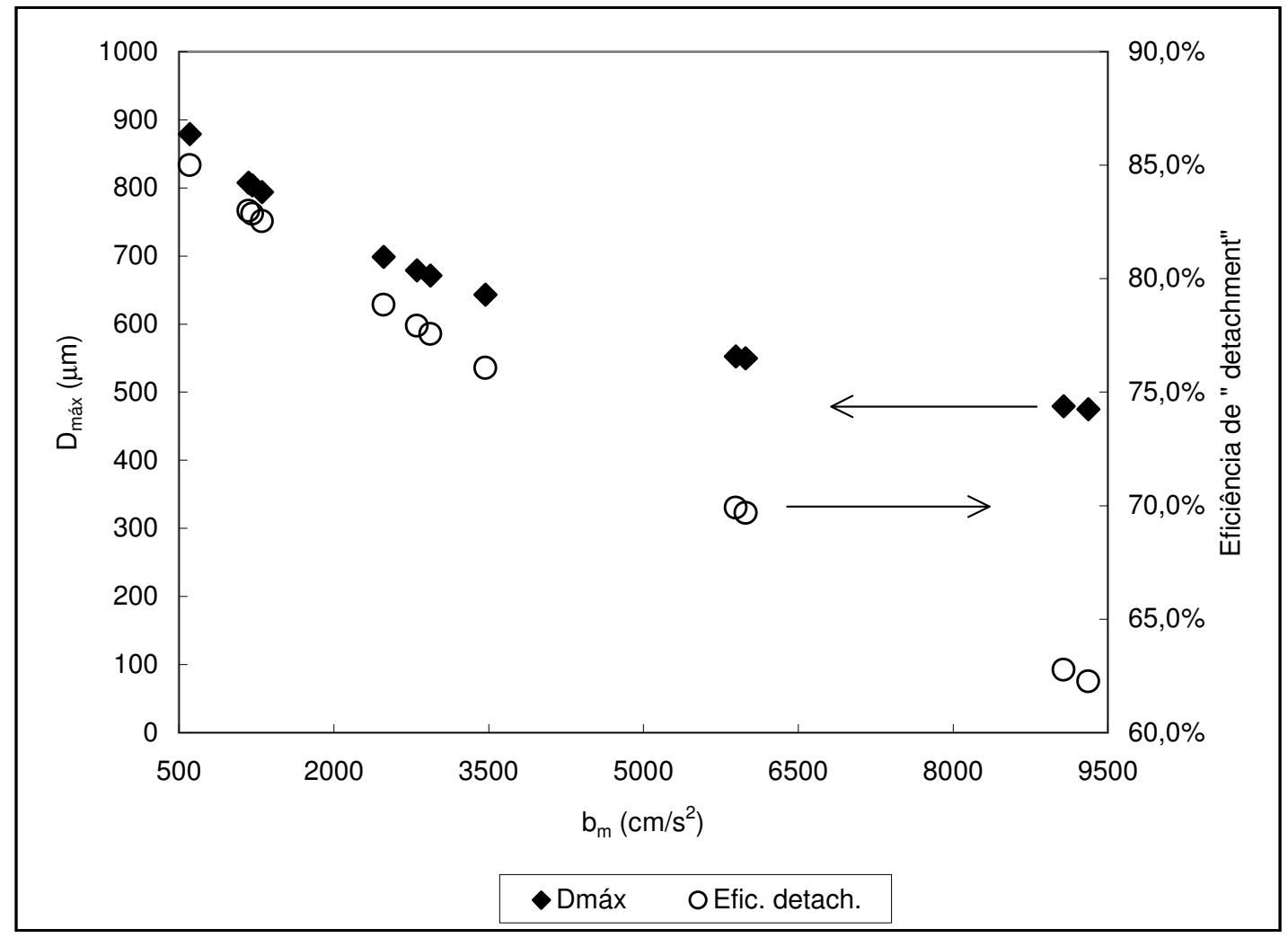

Figura 5.30. Aceleração da máquina $\left(b_{m}\right)$ versus diâmetro máximo flotável $\left(d_{p m a x}\right)$ e eficiência de detachment para esferas de vidro $\left(d_{p} \cong 248 \mu \mathrm{m}\right)$.

Conforme a figura 5.30, observou-se que o aumento da aceleração da máquina diminui o diâmetro máximo flotável, desta forma, prejudicando a eficiência de detachment. Uma vez que, o crescimento do nível de turbulência na célula indicado por $b_{m}$ gera a elevação das tensões de cisalhamento no sistema, há também a elevação da energia cinética das partículas, tendendo assim, diminuir seu diâmetro máximo flotável, no intuito de conservar a estabilidade do agregado partícula-bolha.

Referente aos resultados dos ensaios em escala de bancada com recuperações superiores a 40\%, verificou-se a ocorrência de aeração na célula, mesmo durante o condicionamento dos reagentes. Embora não houvesse injeção de 
ar, à medida que a rotação era aumentada no interior da célula micro-bolhas apareciam. Deste modo, o hold up poderia variar, prejudicando a análise do comportamento hidrodinâmico da flotação, o quê impossibilitou o prosseguimento destes ensaios.

\subsection{Cinética de Flotação.}

Uma vez que as condições hidrodinâmicas presentes na célula de flotação influenciam os eventos de colisão e preservação do agregado, elas também interferem na análise cinética da flotação. Sob condições muito turbulentas, que caracterizam a célula Denver de laboratório, $\mathrm{Fr}_{\text {I }}$ igual a 2,6 e $\mathrm{Re}_{\text {। }}$ da ordem de $1,18.10^{5}$, o comportamento cinético do minério de fosfato da mina de Tapira foi estudado. Os ensaios de flotação tiveram um hold-up aproximado de $10 \%$.

Os resultados dos ensaios cinéticos são apresentados nas figuras 5.31 e 5.32 e tabela 5.5 .

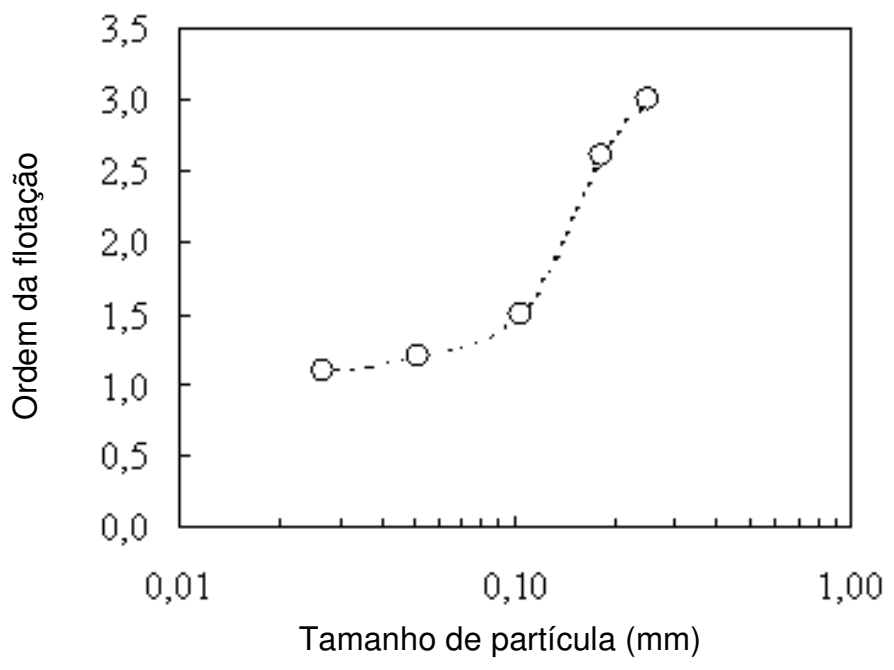

Figura 5.31. Ordem da flotação versus tamanho da partícula de apatita em célula Denver de laboratório $\left(\mathrm{Fr}_{1}=2,6 ; \mathrm{Re}_{\mid}=1,18 \times 10^{5}\right)$. 


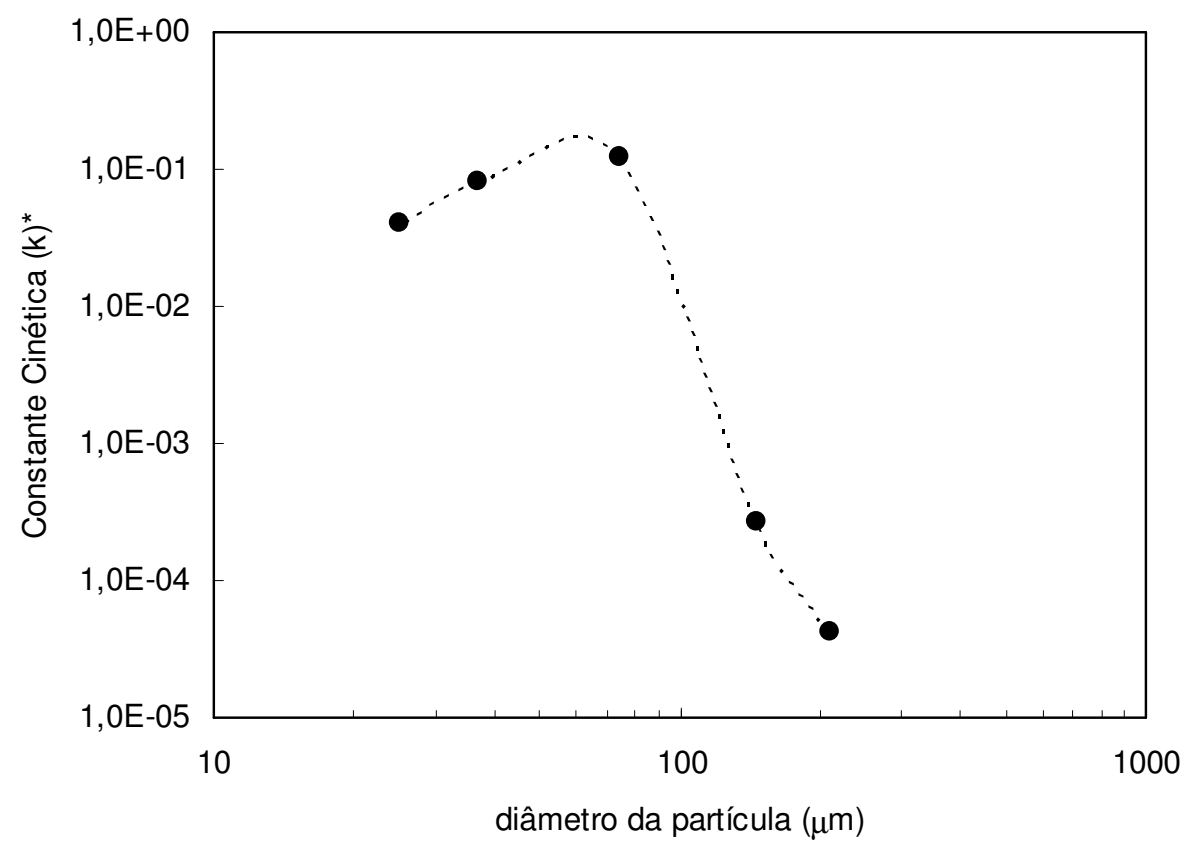

Figura 5.32. Influência do diâmetro da partícula de apatita na constante cinética de flotação em célula Denver de laboratório $\left(\mathrm{Fr}_{\mathrm{I}}=2,6 ; \mathrm{Re}_{\mathrm{l}}=1,18 \times 10^{5}\right)$.

Tabela 5.5. Ensaios cinéticos da apatita de Tapira-MG.

\begin{tabular}{|c|c|c|c|c|c|}
\hline Método & $d_{p}(\mu \mathrm{m})$ & 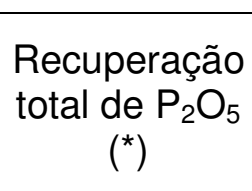 & $\begin{array}{l}\text { Ordem } \\
\text { (n) }\end{array}$ & $\begin{array}{l}\text { Constante } \\
\text { cinética }(\mathrm{k})\end{array}$ & $\begin{array}{c}\text { Coeficiente } \\
\text { de } \\
\text { correlação } \\
\left(r^{2}\right)\end{array}$ \\
\hline 1 & \multirow{3}{*}{+210} & \multirow{3}{*}{60,4} & $10,0\left(^{* \star}\right)$ & $1,1 \times 10^{-13} \mathrm{~g}^{-9} \mathrm{~s}^{-1}$ & 0,9964 \\
\hline 2 & & & 3,0 & $2,2 \times 10^{-5} \mathrm{~g}^{-2} \mathrm{~s}^{-1}$ & 0,8691 \\
\hline 3 & & & 3,1 & $8,2 \times 10^{-5} \mathrm{~g}^{-2} \mathrm{~s}^{-1}$ & 1,000 \\
\hline 1 & \multirow{3}{*}{$-210+147$} & \multirow{3}{*}{84,2} & 3,0 & $2,3 \times 10^{-4} \mathrm{~g}^{-2} \mathrm{~s}^{-1}$ & 0,9999 \\
\hline 2 & & & 2,6 & $5,3 \times 10^{-4} \mathrm{~g}^{-1,6} \mathrm{~s}^{-1}$ & 0,9960 \\
\hline 3 & & & 2,2 & $1,5 \times 10^{-4} \mathrm{~g}^{-1,2} \mathrm{~s}^{-1}$ & 0,9998 \\
\hline 1 & \multirow{3}{*}{$-147+74$} & \multirow{3}{*}{99,9} & 1,1 & $8,3 \times 10^{-2} \mathrm{~g}^{-0,1} \mathrm{~s}^{-1}$ & 0,9996 \\
\hline 2 & & & 1,6 & $1,3 \times 10^{-1} \mathrm{~g}^{-0,6} \mathrm{~s}^{-1}$ & 0,9310 \\
\hline 3 & & & 1,9 & $1,7 \times 10^{-1} \mathrm{~g}^{-0,9} \mathrm{~s}^{-1}$ & 0,9992 \\
\hline 1 & \multirow{3}{*}{$-74+37$} & \multirow{3}{*}{99,9} & 1,2 & $9,7 \times 10^{-2} \mathrm{~g}^{-0,2} \mathrm{~s}^{-1}$ & 0,9967 \\
\hline 2 & & & 0,8 & $8,8 \times 10^{-2} g^{0,2} s^{-1}$ & 0,8955 \\
\hline 3 & & & 1,9 & $6,0 \times 10^{-2} \mathrm{~g}^{-0,9} \mathrm{~s}^{-1}$ & 0,9947 \\
\hline 1 & \multirow[b]{3}{*}{-37} & \multirow[b]{3}{*}{87,3} & 1,0 & $4,5 \times 10^{-2} \mathrm{~s}^{-1}$ & 0,9997 \\
\hline 2 & & & 1,2 & $3,7 \times 10^{-2} \mathrm{~g}^{-0,2} \mathrm{~s}^{-1}$ & 0,9972 \\
\hline 3 & & & $\begin{array}{c}\text { Não } \\
\text { válido } \\
\text { para } n=1\end{array}$ & - & - \\
\hline
\end{tabular}

$\left(^{*}\right)$ Após a exaustão total da espuma mineralizada (80 segundos).

$\left.{ }^{* *}\right)$ Valor ignorado no cálculo da média geométrica.

- Método 1 - Tentativa e erro. 
- Método 2 - Razão dos tempos.

- Método 3 - Tempos fracionários.

Com relação à tabela 5.5 e figuras 5.31. e 5.32, é possível verificar na condição hidrodinâmica que se realizaram os ensaios:

i. Partículas grosseiras tendem apresentar cinética mais lenta no processo, como pode ser evidenciado pelo crescimento de sua ordem.

ii. Por sua vez, as partículas de diâmetros inferiores possuem melhor desempenho cinético de flotação, ratificado em função de suas constantes cinéticas maiores.

iii. A constante cinética apresenta tendência de queda em função do aumento do diâmetro da apatita, visto o severo ambiente hidrodinâmico.

iv. Os três métodos usados para definir a ordem da flotação (n) exibiram coerência, embora as magnitudes de seus produtos fossem diferentes. Quando o diâmetro médio das partículas estudadas decresceu de $248 \mu \mathrm{m}$ para $27 \mu \mathrm{m}$ a ordem da flotação tende a 1 .

Em virtude da destruição do agregado partícula-bolha, a flotação de grossos é extremamente prejudicada pelo excesso de turbulência no sistema. Desta forma, é conveniente assumir, nestas condições hidrodinâmicas, que o desempenho da flotação dos grossos seja inferior aos finos, conforme ratificado pelos problemas na flotação das partículas superiores a $0,210 \mathrm{~mm}$, que apresentaram cinética mais lenta, demandando mais tempo para flotar. 


\section{CONCLUSÃO}

Esferas de vidro grossas $\left(d_{p} \cong 248 \mu m\right)$ e muito hidrofóbicas $\left(\theta \cong 89^{\circ}\right)$, suspensas em meio aquoso $(\gamma=32 \mathrm{mN} / \mathrm{m})$ por agitação criada pela rotação de um impelidor, apresentarão ótima recuperação quando as variáveis hidrodinâmicas que controlam o ambiente físico da flotação propiciarem a ocorrência de colisão entre esferas e bolhas. Após sucesso dos eventos de colisão e adesão (formação do agregado partícula-bolha), a turbulência criada pela ação do impelidor não poderá ser suficientemente alta para destruir o agregado partícula-bolha recém-formado. Portanto, para se obter uma máxima recuperação na flotação de partículas grossas, é preciso identificar e medir os parâmetros hidrodinâmicos que governam tais eventos. Dentro do universo deste sistema experimental, é possível concluir:

i. É de fundamental importância para flotação que a célula seja capaz de manter as partículas em suspensão, tanto para microflotação quanto para escala de bancada. A melhor resposta do processo é encontrada para $\Omega \cong 1$, indicando que a mínima velocidade de suspensão, utilizada por Zwietering (1958), é um parâmetro que deve ser levado em consideração na caracterização hidrodinâmica dos sistemas de flotação, não só como fator de dimensionamento, mas também com instrumento de controle de rendimento do processo.

ii. No que diz respeito à relação $D / T$, é explicitado que seu aumento atua em detrimento a flotação, uma vez que o agregado estará submetido ao crescimento das tensões de cisalhamento no sistema. $O$ efeito desta relação é contra atacada pela regulagem da rotação do sistema, $\mathrm{D} / \mathrm{T}<0,5$ oferecem melhores condições de flotação num intervalo de rotação mais amplo $0,6<\Omega<1,8$, uma vez que a geometria da turbina de Rushton, bem como de todos os impelidores industriais, já favorece o cisalhamento das bolhas, é preferível operar com uma relação $D / T$ inferior a 0,5 , preponderando os fluxos de bombeamento no sistema, com o intuito de manter a maior 
quantidade possível de esferas de vidro em suspensão.

iii. O aumento da rotação intensifica a dispersão de bolhas, fato que contribui para uma boa recuperação das esferas. No entanto, impelidores de fluxo radial, como as turbinas de Rushton, podem cisalhar as bolhas, possivelmente diminuindo seu diâmetro, deste modo prejudicando a flotação de grossos com a elevação das forças de cisalhamento no sistema, ocasionada pelo aumento de rotação.

iv. Parâmetros adimensionais como o número de Froude e o Weber do equipamento podem caracterizar a hidrodinâmica do sistema de flotação, todavia, as características geométricas da célula devem ser consideradas, principalmente com relação à $\mathrm{D} / \mathrm{T}$. Uma vez que a diminuição do impelidor deve ser acompanhada pelo aumento da sua velocidade periférica, a fim de manter as partículas em suspensão.

v. A microturbulência presente no sistema pode ser responsável pela destruição do agregado partícula-bolha, pela dispersão das bolhas na polpa e também pela colisão partícula-bolha. Em nossos experimentos, a máxima recuperação das esferas de vidro com $\mathrm{d}_{\mathrm{p}}=0,248 \mathrm{~mm}$ foi observada quando a dissipação de energia ficou na faixa de $1<\varepsilon_{D}<2,52 \mathrm{~kW} / \mathrm{kg}$, evidenciam que:

- Para baixa energia dissipada $\left(\varepsilon_{D}<0,3 \mathrm{~W} / \mathrm{kg}\right)$, a microturbulência presente no sistema não é suficiente para promover adequada colisão partícula-bolha ou ainda suficiente dispersão do fluxo de bolhas ao longo da célula (observação visual);

- Para $\varepsilon_{\mathrm{D}}$ muito elevada $\left(\varepsilon_{\mathrm{D}}>10 \mathrm{~W} / \mathrm{kg}\right)$, a turbulência é excessiva, criando condições mais propícias para a quebra do agregado partícula - bolha;

- A magnitude da energia dissipada pelo impelidor pode constituir um parâmetro valioso para controlar a microturbulência presente nas células de flotação.

vi. $\quad$ aumento da densidade do sólido, no caso apatita versus esferas de vidro, acarretará no aumento da velocidade crítica de suspensão.

vii. Outro parâmetro que também deve ser sempre levado em 
consideração é a geometria do impelidor, tal fator contribui diretamente na dispersão dos componentes da polpa de flotação.

viii. A aeração atua em detrimento há capacidade de transporte do impelidor, aumentando, quase que linearmente, a velocidade crítica de suspensão. O aumento de aeração diminui a potência aplicada pelo impelidor à polpa.

ix. O aumento da turbulência no sistema reduz a eficiência de detachment, em função do diâmetro de partículas, admitindo um diâmetro de bolha da ordem de 0,001 m. Partículas grosseiras tendem a requerer um ambiente menos turbulento possível, ou seja, suficiente para sua suspensão, enquanto que sólidos finos têm baixa eficiência de detachment, uma vez que podem ser arrastadas pelos fluxos de água que são drenados da coluna de espuma.

x. O aumento do diâmetro de partícula ocasiona aumento na ordem de flotação, por conseguinte, diminuição da constante cinética do processo. Em virtude de fatores hidrodinâmicos. 


\section{REFERÊNCIAS BIBLIOGRÁFICAS}

AHMED, N.; JAMESON, G. J. Flotation kinetics. Mineral Processing and Extractive Metallurgy Review, v. 5, p. 77-99, 1989.

ALEXANDER, D. J.; MORRISON, R. D. Rapid estimation of floatability components in industrial flotation plants. Minerals Engineering, v. 11, n. 2, p. 133-43, 1998.

ARBITER, N. Hydrodynamics of flotation cells. Transactions of the American Institute of Mining and Metallurgical Engineers, v. 244, p. 134 - 48, 1969.

ARBITER, N. Development and scale - up of large flotation cells, in Advances in Flotation Technology. Littleton, CO: SME, ed. B. K. Parekh and J. D. Miller, p. 345-53, 1999.

BALDI, G.; CONTI, R.; ALARIA, E.. Complete suspension of particles in mechanically agitated vessels. Chemical Engineering Science, v. 33, n. 1, p. 21-5, 1978.

BARNES, H.A.; HUTTON, J.F.; WALTERS, K. An introduction to rheology, New York, Elsevier, 1989, 199 p. (Rheology series, v.3).

BAO, Y.; et al. Suspension of buoyant particles in a three phase stirred tank. Chemical Engineering Science. v. 60, n. 8-9, p. 2283-92, 2005.

BIRD, R. B. et al. Transport Phenomena. New York, John Wiley \& Sons, 1960, 611 p.

BRODKEY, R. S.; HERSHEY, H. C. Transport phenomena: a unified approach. New York. McGraw Hill, 1988, 847 p.

BROWN, G. M. et al. Unit operations, New York, John Wiley \& Sons, 1950, 611 p.

CALDERBANK, P. H. Physical rate processes in industrial fermentation. Part I: The interfacial area in gas - liquid contacting with mechanical agitation, Transaction of the institution of chemicalengineers, v. 36, n. 6, p. $443-463,1958$.

CHAPMAN, C. M.; NIENOW, A. W.; et al.. Particle-gas-liquid mixing in stirred vessels. Part I: Particle-liquid mixing. Chemical Engineering Research \& Design, v. 61, p. 71-81, 1983a.

CHAPMAN, C. M.; NIENOW, A. W.; et al.. Particle-gas-liquid mixing in stirred vessels. Part II: Gas-liquid mixing. Chemical Engineering Research \& Design, v. 61, p. 82-95, 1983b.

CHAPMAN, C. M.; NIENOW, A. W.; et al.. Particle-gas-liquid mixing in stirred vessels. Part III: Three phase mixing. Chemical Engineering Research \& Design, v. 61, p. 167-81, 1983 c. 
CHAVES, A. P.; LEAL FILHO, L. S. Flotação. Em: LUZ, A.B.; POSSA, M.V.; ALMEIDA, S. L., ed. Tratamento de Minérios, 2. ed, Rio de Janeiro, CETEM, 1998, 676 p.

CONNORS, K. A. Chemical kinetics the study of reaction rates in solution, S. L., VCH Publishers, 469 p. 1990.

DAI, Z.; FORNASIERO, D.; RALSTON, J. Particle-bubble collision models - a review. Advance in colloid and Interface Science, v. 85, n. 1, p. 231-56, 2000.

DEGLON, D. A.; EGYA-MENSAH, D.; FRANZIDIS, J. P. Rewie of hydrodynamics and gas dispersion in flotation cell on South African Platinum Concentrators, Minerals Engineering, v. 13, n. 3, p. 235 - 44, 2000.

DENVER SALA, Selection guide for process equipament, S. L., 1995, (Catálogo).

DERJAGUIN, B. V.; DUKHIN, S. S. Theory of flotation of small and medium size particles. Transactions of the American Institute of Mining and Metallurgical Engineers, v. 70, p. $221,1960$.

DICKEY, D.S.; FENIC, J.C. Dimensional analisys for fluid agitation systems. Chemical Engineering, v 83, n. 1, p. 139-45, 1976.

DOBBY, G. S.; FINCH, J.A. Particle size dependence in flotation derived from a fundamental model of the capture process. International Journal of Mineral Processing, v. 21, n. $1 / 2$, p. $241-60,1987$.

DOBBY, G. S.; YANATOS J. B.; FINCH, J.A. Estimation of bubble diameter in flotation columns from drift flux analysis. Canadian Metallurgical Quarterly. v. 27, n. 2, p. 85 - 90, 1988 .

DRZYMALA, J. Characterization of materials by Hallimond Tube Flotation. Part 1: maximum size of entrained particles. International Journal of Mineral Processing, v. 42, n. 3 - 4, p. $139-52,1994$.

DUTTA, N. N.; PANGARKAR, V. G. Critical impeller speed for solid suspension in multi impeller three phase agitated contactors. The Canadian Journal of Chemical Engineering, v. 73, n. 3, p. $273-283,1995$.

EDZWALD, J.K. Principles and applications of dissolved air flotation. Water Science and Technology, v. 31, n 3 - 4, p. 1 - 23, 1995.

FALLENIUS, K. Turbulence in flotation cells. International Journal of Mineral Processing, v. 21, n. 1/2, p. 1 - 23, 1987.

FINCH, J.A.; SMITH, G. W. Bubble - solid attachment as a function of bubble surface tension. Canadian Metallurgical Quarterly. v. 14, n. 1, p. 47 - 51, 1975.

FINCH, J.A.; DOBBY, G.S. Column flotation, Oxford, Pergamon Press, 1990, 180 p. 
FOGLER, H. S. Elements of chemical reaction engineering, 3. ed., Upper Saddle River, 3. ed, Prentice - Hall, 967 p. 1999.

FOUST, A. S. et al. Princípios das operações unitárias. Trad. de Horacio Macedo, 2. ed. Rio de Janeiro, Editora Guanabara Dois, 1982, 670 p.

FUERSTENAU, M. C. Flotation of fine particles. In: King, R. P., ed. Principles of Flotation, Johannesburg, South African Institute of Mining and Metallurgy, 1982, 268 p.

GAUDIN, A. M. Flotation. New York, McGraw - Hill, 1932, p. 358 - 85.

GAUDIN, A. M.; FUERSTENAU, D. W. Hemi - Micelle formation and flotation response. Transactions of the American Institute of Mining and Metallurgical Engineers, v. 202, p. 958, 1955.

GAUDIN, A.M. Principles of mineral dressing, New Delhi, Tata McGraw-Hill Publishing Company. 1975, $554 \mathrm{p}$.

GILES, R. V. Mecânica dos fluidos e hidráulica. Trad. de Sérgio dos Santos Borde, São Paulo, Editora McGraw-Hill do Brasil. 1977, 401 p. (Coleção Schaum).

GONTIJO, C. F.; FORNASIERO, D.; RALSTON, J. The limits of fine and coarse particle flotation. The Canadian Journal of Chemical Engineering, v. 85, n. 5, p. 739 - 47, 2007.

GORAIN, B. K; FRANZIDIS, J. P.; MANLAPIG, E. V. Flotation cell design: Aplication of Fundamental Principles. In Encyclopedia of Separation Science. San Diego, AC, ed. I. D. Wilson, p. 1502-12, 2007.

GUILLARD, F.; TRAGARDH, C. Mixing in industrial Rushton turbine-agitated reactors under aerated conditions. Chemical Engineering and Processing. v. 42, n. 5, p. 373-86, 2003.

GUIMARÃES, R.C. Separação de barita em minério fosfático através de flotação em coluna, Araxá, 1995. 271p. Dissertação (Mestrado) - Escola Politécnica, Universidade de São Paulo.

GÜVEN, N.; POLLASTRO, R. M., eds. Clay - water interface and its rheological implications. Boulder, The Clay Minerals Society, 1992, p. 82 - 120: Rheological aspect of aqueous smectite suspensions. (Cms Workshop Lectures, v.4).

HARRIS, C. C. Flotation machines. In: FUERSTENAU, M. C., ed. Flotation: A. M. Gaudin Memorial Volume, New York, AIME, 1976, v. 2.

HARRIS, C. C. Flotation machine design, scale up and performance: Data Base. Advances in Mineral Processing, Nato Series, Cap. 37, 1987.

HUH, C.; SCRIVEN, L. E. Shapes of axisymmetric fluid interfaces of unbounded extent. Journal of Colloid and Interface Science, v. 30, p. 323, 1969. 
ITYOKUMBUL, M. T.; SALAMA, A. I. A.; TAWEEL, A. M. A. Estimation of bubble size in flotation columns. Minerals Engineering, v. 8, n. 1 - 2, p. 77 - 89, 1995.

JONAITIS, A. J. Design, Development, Application, and operating benefits of $100-\mathrm{m}^{3}+$ Outokumpu TankCell flotation cells, in Advances in Flotation Technology. Littleton, CO: SME, ed. B. K. Parekh and J. D. Miller, p. 371-80, 1999.

JORDAN, C. E.; SPEARS, D. R. Evaluation of a turbulent flow model for fine bubble and fine particle flotation. In: SME ANNUAL MEETING, Las Vegas, 1989. Proceedings. New York, SME, 1989, p. $89-172$.

JOSHI, J. B.; PANDIT, A. B.; SHARMA, M. M. Mechanically agitated gas-liquid reactors. Chemical Engineering Science, v. 37, n. 6, p. 813-44, 1982.

JOWETT, A. Formation and disruption of particle-bubble aggregates in flotation. In: INTERNATIONAL SYMPOSIUM ON FINE PARTICLES, Las Vegas, 1980. Fine particles processing: proceedings New York, AIME, 1980, p 720 - 54.

KAWASE, Y.; et al. Hydrodynamics in three - phase stirred tank reactors with non newtonian fluids. Industral \& engineering chemistry research, , v. 36, n. 1, p. $270-276$, 1997.

KELLY, E.G.; SPOTTISWOOD, D.J. Introduction to mineral processing. New York, John Wiley \& Sons, 1982, 491 p.

KHOPKAR, A. R.; et al.. Gas-liquid flow generated by a Rushton turbine in stirred vessel: CARPT/CT measurements and CFD simulations. Chemical Engineering Science, v. 60, p. 2215-29, 2005.

KNUDSEN, J. G.; KATZ, D. L. Fluid dynamics and heat transfer, New York, McGraw Hill, p. 246-322. 1958.

KUSHALKAR, K. B.; PANGARKAR, V. G. Particle-liquid mass transfer in three-phase mechanically agitated contactors. Industral \& engineering chemistry research, , v. 33, n. 7, p. 1817-20, 1994.

LANDO, J. L.; OAKLEY, H. T. Tabulated correction factors for the drop - weight - volume determination of surface and interfacial tensions. Journal of Colloid and Interface Science, v. 25, n. 4, p. 526-30, 1967.

LANE, G. L.; SCHWARZ, M. P.; EVANS, V. M.. Numerical modelling of gas-liquid flow in stirred tanks. Chemical Engineering Science, v. 60, p. 2203-15, 2005.

LEAL FILHO, L. S.; RODRIGUES, W. J.; LIMA, O. A.; BARROS, L. A. F. The role of hydrodynamics in coarse apatite flotation . In: BENEFICIATION OF PHOSPHATES: TECHNOLOGY AND SUSTAINABILITY. Littleton-Colorado.: Society of Mining, Metallurgy and Exploration, Inc (SME), 2006, p. 25-36.

LEJA, J. Surface chemistry of froth flotation, New York, Plenum Press, 1982, 758 p. 
LEVENSPIEL, O. Engenharia das reações químicas, Trad. de Sérgio Fuchs Calil. São Paulo, Edgard Blücher, v. 1, 1974.

LIMA, O. A.; MARQUES, C. V. P.; LEAL FILHO, L. S. Suspension of apatite particles in a self-aerated Denver laboratory flotation cell. Minerals \& Metallurgical Processing, v. 26, n. 2, p. $74-8,2009$.

LINS, F. F.; ADAMIAN, R. Influência da aeração e agitação na flotação partículas de ouro e considerações sobre o tamanho máximo de flotação. Metalurgia - ABM, v. 45, n. 382, p 898 $-906,1989$.

MAVROS, P. Mixing and hydrodynamics in flotation cells. In: Mavros, P.; Matis, K. A. ed. Innovations in flotation technology, London, Kluwer Academic Publishers, pp. 211-34, 1992.

McCABE, W. L.; SMITH, J. C. Unit operations of chemical engineeing, New York. McGraw Hill Editors. 1956, 945 p.

MIKA, T. S.; FUERSTENAU D. W. A microscopic model of the flotation process. In: International Mineral Processing Congress, 8., Mekhanbor, 1968. Proceeding. S. L., s. ed, 1968, v. 2.

MOLERUS, O. Principles of flow in disperse systems, London, Chapman \& Hall, 1993, $299 \mathrm{p}$.

MORRIS, T. M. Measurement and evaluation of the rate of flotation as a function of particle size. Transactions of the American Institute of Mining and Metallurgical Engineers, v. 193, n. 8, p. $794-98,1952$.

NAGATA, S. Mixing: principles and applications. New York. John Wiley \& Sons. 1975, $458 \mathrm{p}$.

NEALE, J. W.; PINCHES, A. Determination of gas-liquid mass-transfer and solidssuspension parameters in mechanically-agitated three-phase slurry reactors. Minerals Engineering. v. 7, n. 2-3, p. 389-403, 1994.

NELSON, M. G.; LELINSKI, D. Hydrodynamics design of self-aerating flotation machines, Minerals Engineering, v. 13, n. 10 - 11, p. $91-8,2000$.

NEWELL, R.; GRANO, S. Hydrodynamics and scale up in Rushton turbine flotation cells: Part 2 - Flotation scale-up for laboratory and pilot cells. International Journal Mineral Processing. v. 81, n. 2, p. 65-78, 2006.

NEWELL, R.; GRANO, S. Hydrodynamics and scale up in Rushton turbine flotation cells: Part 1 - Cell hydrodynamics. International Journal Mineral Processing. v. 81, n. 4, p. 22436, 2007.

NGUYEN, A. V. New method and equations for determining attachment tenacity and particle size limit in flotation. International Journal of Mineral Processing, v. 68, n. 1, p. $167-82,2003$. 
NIENOW, A. W.; HARNBY, N.; EDWARDS, M. F. Mixing in the process industries. London. Butterworths, 1985, 375 p.

NIENOW, A. W.; KONNO, M.; BUJALSKI, W. Studies on three-phase mixing: a review and recent results. Chemical Engineering Research \& Design, v. 64, n. 1, p. 35-42, 1986.

OLDSHUE, J. Y. Fluid mixing technology. New York. McGraw Hill. 1983, 574 p.

ORWE, D.; GRANO, S. R.; LAUDER, D. W. Increasing fine copper recovery at the Ok Tedi concentrator, Papua New Guinea. Minerals Engineering, v. 11, n. 2, p. 171-87, 1998.

PADDAY, J. F. Surface tension. Part II. the measurement of surface tension. Surface and Colloid Science, v. 1, p. 101-49, 1969.

PERRY, R. H.; GREEN, D. W. Perry's chemical engineers'handbook, Sidney. McGraw Hill Editors. 7. ed. 1997, (várias paginações) p.

PIKE, B.; FORNASIERO, D.; RALSTON, J. Bubble particle heterocoagulation under turbulent conditions. Journal of Colloid and Interface Science, v. 265, n. 1, p. 141-51, 2003.

POLING, G. W. Selection and sizing of flotation machines. In: Mineral processing plant design, 2. ed. New York, SME, 1980, 946 p.

RALSTON, J.; CRAWFORD, R. The influence of particle size and contact angle in mineral flotation. International Journal of Mineral Processing, v. 23, n. 1/2, p. 1 - 24, 1988.

RALSTON, J.; FORNASIERO, D.; HAYES, R. Bubble-particle attachment and detachment in flotation. International Journal of Mineral Processing, v.56, n.1 - 4, p. 133 - 64, 1999a.

RALSTON, J.; DUKHIN, S. S.; MISHCHUK, N. A. Inertial hydrodynamic particle - bubble interaction in flotation. International Journal of Mineral Processing, v. 56, n. 1 - 4, p. 207 $-56,1999 b$.

REWATKAR, V. B.; JOSHI, J. B. Critical impeller speed for solid suspension in mechanically agitated three - phase reactors 1: experimental part. Industral \& engineering chemistry research, , v. 30, n. 8, p. $1770-84$, 1991a.

REWATKAR, V. B.; JOSHI, J. B. Critical impeller speed for solid suspension in mechanically agitated three - phase reactors 2: mathematical model. Industral \& engineering chemistry research, , v. 30, n. 8, p. $1784-91,1991 b$.

RODRIGUES, W. J. Aspectos hidrodinâmicos na flotação de partículas grossas, São Paulo, 2001a. 150p. Dissertação (Mestrado) - Escola Politécnica, Universidade de São Paulo.

RODRIGUES, W. J.; LEAL FILHO, L. S.; MASINI, E. A. Dimensionless hydrodynamic parameters and their influence on flotation behavior of coarse glass spheres. Minerals Engineering, v. 14, n. 9, p. 1047-54. 2001b. 
ROMAN, R. V.; TUDOSE, R. Z. Studies on transfer process in mixing vessels: suspending of solid particles in liquid by modified Rushto turbine agitors. Bioprocess engineering, $\mathrm{V}$. 15 , n. 4 , p. $221-29,1996$.

ROSCOE, R. The viscosity of suspensions of rigid spheres. British Journal of Applied Physics n. 3, p.267 - 69, 1952.

RUSHTON, J. H.; COSTICH, E. W.; EVERETT, H. J. Power characteristics of mixing impellers. Part I. Chemical Engineering Progress, v. 46, n. 8, p. 395 - 404, 1950a.

RUSHTON, J. H.; COSTICH, E. W.; EVERETT, H. J. Power characteristics of mixing impellers. Part II. Chemical Engineering Progress, v. 46, n. 9, p. 467 - 76, 1950 b.

SCHUBERT, H.; BISCHOFBERGER, C. On The Hydrodynamics of Flotation Machines. International Journal of Mineral Processing, v. 5, n. 2, p. 131-42, 1978.

SCHUBERT, H. On some aspects of the hydrodynamics of flotation process. In: Forssberg, K. S., ed. Flotation of sulphide minerals, Amsterdam, Elsevier, p. 337-55, 1985.

SCHUBERT, H. On the turbulence - controlled microprocesses in flotation machines. International Journal of Mineral Processing, v. 56, n. 1 - 4, p. 257 - 76, 1999.

SCHULZE, H. J. New theoretical and experimental investigations on stability of bubble/particle aggregates in flotation: a theory on the upper particle size of floatability. International Journal of Mineral Processing, v. 4, n. 3, p. 241 - 59, 1977.

SCHULZE, H. J. Dimensionless number and approximate calculation of the upper particle size of flotability in flotation machines. International Journal of Mineral Processing, v. 9, n. 4 , p. $321-28,1982$.

SCHULZE, H.J. Physico-chemical Elementary Processes in Flotation: An Analysis from the Point of View of Colloid Science including Process Engineering Considerations, Amsterdam, Elsevier, 1984, 348 p.

SCHULZE, H. J. Hydrodynamics of bubble - mineral particle collisions. Mineral Processing and Extractive Metallurgy Review, v. 5, p. 43 - 76, 1989.

SISSOM, L. E.; PITTS, D. R. Fenômenos de transporte. Trad. de Adir M. Luiz, Rio de Janeiro, Editora Guanabara. 1988, 765 p.

SOMASUNDARAN, P. The role of ionomolecular surfactant complexes in flotation. International Journal of Mineral Processing, v. 3, n. 1, p. 35 - 40, 1976.

SOMASUNDARAN, P. et al. Flotation mechanism based on ionomolecular complexes. XII International Mineral Processing Congress, preprint Iron. Volume II, São Paulo, 1977

SOUZA PINTO, T. C.; LIMA, O. A.; LEAL FILHO, L. S. Sphericity of apatite particles determined by gas permeability through packed beds. Minerals \& Metallurgical Processing, v. 26, n. 2, p. $105-08,2009$. 
SUBRAHMANYAM, T. M.; PRESTIDGE, C. A.; RALSTON, J. Contact angle and surface analysis studies of sphalerite particles. Minerals Engineering, v. 9, n. 7, p. 727 - 41, 1996.

SUBRAHMANYAM, T. M.; et al. Contact angles of quartz by capillary penetration of liquids and captive bubble techniques. Minerals Engineering, v. 12, n. 11, p. 1347 - 57, 1999.

SUN, H.; MAO, Z. S.; YU, G. Experimental and numerical study of gas hold-up in surface aerated stirred tanks. Chemical Engineering Science. v. 61, n. 12, p. 4098-110, 2006.

SUTHERLAND, K. L. Physical chemistry of flotation. 11. Kinetics of the flotation process. Journal Physical and Colloid Chemistry, v. 52, n. 2, p. $394-425,1948$.

TAGGART, A. F.; DEL GIUDICE, G. R. M.; ZIEHL, O. A. The case for the chemical theory of flotation. Transactions of the American Institute of Mining and Metallurgical Engineers, v. 112, p. 348 - 81, 1935.

TATTERSON, G. B. Fluid mixing and gas dispersion in agitated tanks. New York. McGraw Hill, 1991, 548 p.

THOMAS, D.G. Transport characteristics of suspensions: VIII. A note on the viscosity newtonian suspensions of uniform spherical particles. Journal of Colloid Science. n. 20, p.267 - 77, 1965 .

TRAHAR. W.J. A rational interpretation of the role of particle size in flotation. International Journal of Mineral Processing, v. 8, n. 4, p. 289 - 324, 1981.

UHL, V. W.; GRAY, J. B. Mixing theory and practice. New York. Academic Press Inc.. 1966, v.1.

UHL, V. W.; GRAY, J. B. Mixing theory and practice. New York. Academic Press Inc.. 1967, v.2.

VAN der WESTHUIZEN, A., P.; DEGLON, D., A. Evaluation of solids suspension in a pilot-scale mechanical flotation cell: The critical impeller speed. Minerals Engineering, v. 20, p. $233-40,2007$.

VATCHA, S.R., Directly determine reaction order. Chemical Engineering, v. 4, n. 2, p. 1956, 1987.

WEISS, N. L. SME mineral processing handbook, New York, Society of Mining Engineers, 1985. v. 1 (várias paginações).

WHITEN, W.; STEFFENS, P.; HITCHINS, J. An examination of pulp viscosity in tubes at higher shear rates. Minerals Engineering, v. 6, n. 4, p-397-404, 1993.

WILLIAMS, J.K.; DAWE R. A. Gravity effects in near - critical fluids in porous media. Journal of Colloid and Interface Science, v. 124, n. 2, p. 639 - 45, 1988. 
WOODBURN, E. T.; KING, R. P.; COLBORN, R. P. The effect of particle size distribution and the performance of the a phosphate flotation process. Mettalurgical Transactions, v. 2, n. 11, p. $3163-74,1971$.

XU, M.; FINCH, J. A. Bubble diameter estimation in a mechanically agitated flotation cell. Minerals and Metallurgical Processing, v. 5, n. 1, p. 43 - 4, 1988.

YOON, R.H.; LUTTRELL, G. H. The effect of bubble size on fine particle flotation. Mineral Processing and Extractive Metallurgy Review, v. 5, p. 101 - 22, 1989.

YOON, R.H. The role of hydrodynamic and surface forces in buble-particle interaction. International Journal of Mineral Processing, v. 58, n. 1, p. 129-43, 2000.

ZWIETERING, T. N. Suspending of solid particles in liquid by agitators. Chemical Engineering Science, v. 8, n. 3 - 4, p. 244 - 253, 1958. 


\section{ANEXO}

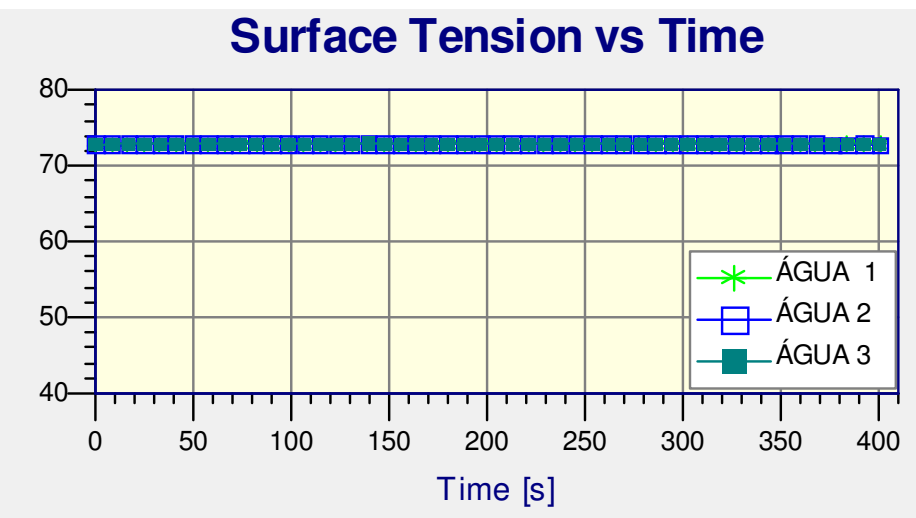

Figura 1. Tensão superficial versus t da água desionizada.

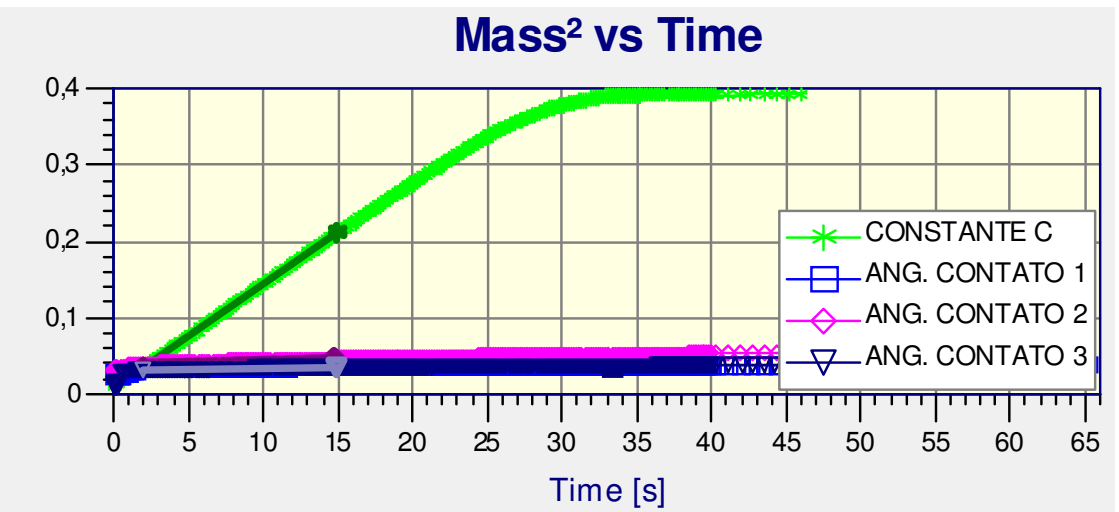

Figura 2. Curva de $\mathrm{M}^{2}$ versus t para determinação do ângulo de contato. 